The Free Internet Journal

for Organic Chemistry
Review

Arkivoc 2017, part i, 257-355

Organic Chemistry

\title{
Synthesis and properties of heteroaromatic carbenes of the imidazole and triazole series and their fused analogues
}

\author{
Nikolai I. Korotkikh, ${ }^{a *}$ Alan H. Cowley, ${ }^{b}$ Jason A.C. Clyburne, ${ }^{c}$ Katherine N. Robertson, ${ }^{c}$ \\ Vagiz Sh. Saberov, ${ }^{a}$ Nataliya V. Glinyanaya, ${ }^{d}$ Gennady F. Rayenko, ${ }^{d}$ and Oles P. Shvaika ${ }^{d}$ \\ a The Institute of Organic Chemistry, Ukrainian Academy of Sciences, 5, Murmanskaya Str., \\ Kiev-94 02660, Ukraine \\ ${ }^{b}$ Department of Chemistry, The University of Texas at Austin, 1 University Station A5300, \\ Austin, Texas 78712-0165, USA \\ 'The Atlantic Centre for Green Chemistry, Department of Chemistry, Saint Mary's University, \\ Halifax, Nova Scotia B3H 3C3, Canada \\ ${ }^{d}$ The L.M. Litvinenko Institute of Physical Organic and Coal Chemistry, Ukrainian Academy of Sciences, \\ 50 Kharkiv road, Kiev 02160, Ukraine \\ E-mail: nkorotkikh@ua.fm
}

Received 03-24-2017

Accepted 06-05-2017

Published on line $\quad 07-26-2017$

\section{Abstract}

The present review deals with the syntheses and properties of individual heteroaromatic carbenes of the imidazole, 1,2,4- and 1,2,3-triazole series, their fused analogs and mesoionic carbenes including unprecedented structures such as hyperbasic and hypernucleophilic carbenes. Particular emphasis is placed on their physical properties, novel chemical transformations, and catalytic properties.

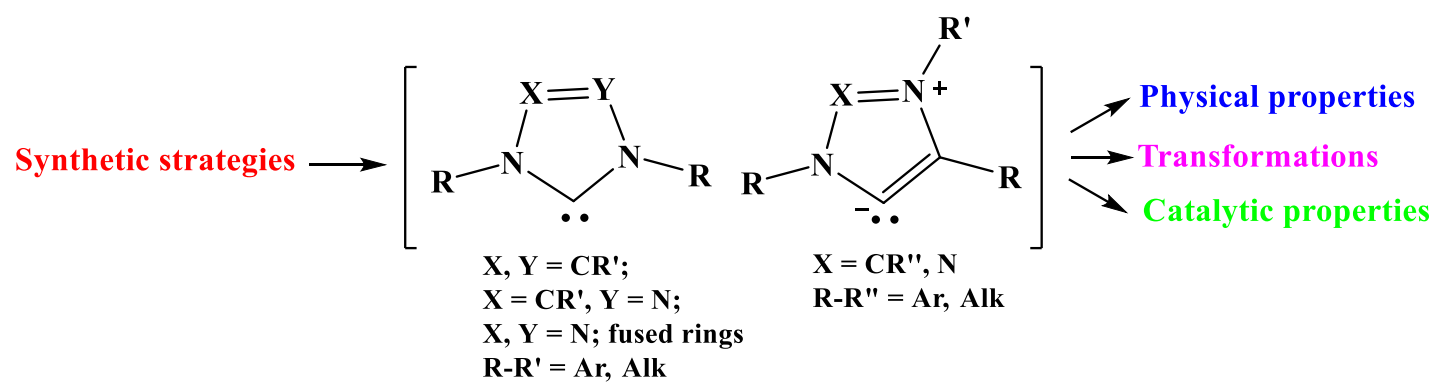

Keywords. Heteroaromatic carbenes, imidazoles, 1,2,3-triazoles, 1,2,4-triazoles. 


\section{Table of Contents}

1. Introduction

2. Synthesis of Carbenes of the Imidazole and Triazole Series and their Fused Analogues

2.1 Imidazol-2-ylidenes

2.1.1 Monoimidazol-2-ylidenes

2.1.2 Bis- and tris-imidazol-2-ylidenes

2.2 Fused aromatic analogues of imidazol-2-ylidenes

2.2.1 Fused monoimidazol-2-ylidenes

2.2.2 Bis-, tris- and poly-benzimidazol-2-ylidenes

\subsection{1,2,4-Triazol-5-ylidenes}

2.4 Hyperbasic and hypernucleophilic anionic carbenes

2.5 Mesoionic carbenes

2.5.1 Imidazolium-4(5)-ides

2.5.2 1,2,3-Triazolium-5-ides

3. Physical Properties of Stable Carbenes

$3.1{ }^{1} \mathrm{H}$ and ${ }^{13} \mathrm{C}$ NMR spectra

3.2 Structures

3.3 Basicities and electron donating properties

3.4 Hyperbasic and hypernucleophilic carbenes (HBNC)

3.5 Steric properties

4. Transformations of Individual Carbenes

4.1 Rearrangements and autotransformations

4.1.1 Migrations of atoms and groups in stable carbenes

4.1.2 Other autotransformations

4.1.3 Ring expansions of heterocyclic carbenes

4.1.4 Dimerization reactions and cross-couplings

$4.2 \mathrm{X}-\mathrm{H}$ Insertion Reactions

4.2.1 Insertions into polar X-H bonds

4.2.2 Hydrogen bonds of carbenes

4.2.3 Insertions into $\mathrm{C}-\mathrm{H}$ bonds

4.2.4 Carbenoid properties of carbene insertion products

4.3 Alkylation and Arylation of Carbenes

4.4 Reactions with Activated Multiple Bonds

4.4.1 Reactions with olefins

4.4.2 Reactions with acetylenes

4.4.3 Reactions with allenes and fullerenes

4.4.4 Reactions with $\mathrm{CX}_{2}(\mathrm{X}=\mathrm{O}, \mathrm{S})$

4.4.5 Reactions with azides

4.4.6 Reactions with diazoalkanes

4.4.7 Reactions with $\mathrm{N}_{2} \mathrm{O}$ and $\mathrm{NO}$

4.4.8 Reactions with carbodiimides

4.5 Carbenes in the Synthesis of Zwitterionic and Ionic compounds

4.5.1 Reactions with esters 
4.5.2 Formation of zwitterionic compounds in reactions with multiple bonds and cyclic sulfoesters

4.6 Reactions with Non-metals and some Nucleophiles

5. Catalytic Properties of Carbenes and their Complexes with Transition Metals

5.1 Catalysis by carbenes

5.1.1 Transesterification reaction

5.1.2 Benzoin condensation

5.2 Catalysis by carbene complexes of transition metals

5.2.1 Reduction of multiple bonds with alcohols (hydrogen transfer)

5.2.2 Hydrodehalogenation reactions of haloarenes

6. Biological Activity of Carbene Derivatives

7. Conclusions

References

\section{Introduction}

A quarter of a century has elapsed since Bertrand and Arduengo discovered and then synthesized the first disubstituted derivatives of stable carbenes. ${ }^{1-5}$ In turn, this provided a strong impetus for increased research activity in the field. Particular emphasis was placed on the synthesis of carbenes and their derivatives, and studies of their structures, transformations, biological and catalytic properties proliferated. Prior to these results only inorganic and monosubstituted organic analogues of carbenes were known (carbon(II) monoxide CO, carbon(II) thioxide CS and isocyanides, RNC). Although not normally identified as carbenes, these compounds had long been used as ligands and reagents for organic synthesis. The preparation of other types of individual carbenes took longer to materialise. ${ }^{6,7}$ However, today a large number of compounds have been isolated; these are predominantly heterocyclic species and include heteroaromatic carbenes, phosphanylsilylcarbenes, aminoalkyl- and diamino-carbenes of cyclic and acyclic series, borazino- and borazolo-carbenes, etc. $^{8-20}$

One of the major focuses of carbene applications has been the catalysis of organic reactions. ${ }^{21-30}$ The connection between individual carbene structure and function has been reported in many publications. However, there remains a considerable problem in that the leading structures in any particular area have not yet been well identified. Overall, heteroaromatic carbenes of the imidazole, triazole (the 1,2,4- and more recently the 1,2,3-type) and benzimidazole series are the best known in this field.

It is worth noting that in the literature the synthesis of carbene derivatives is often described (e.g., the number of metal carbene complexes is growing very rapidly) without the actual isolation of the individual precursor carbenes (their number is much less). The differences in properties between the two can be very significant. Although in situ transformations are sometimes able to do surprising things (see, for example, the recently described ${ }^{31}$ formation of carbene complexes of copper(I) from azolium salts and metallic copper), individual carbenes not only catalyse organic reactions but also open up new possibilities for organic synthesis. ${ }^{32,33}$

The present article is concerned with the syntheses, structural studies and transformations of individual heterocyclic carbenes of the imidazole and triazole series, as well as their fused analogues. The catalytic activities of these carbenes, and their derivatives, in some typical organic reactions (transesterification and benzoin condensation) will be discussed, as will carbene complexes of transition metals (haloarene hydrodehalogenation and reduction of multiple bonds). These reactions can be used to study the influence of 
catalyst structure on catalytic efficiency. During the discussion of such transformations, attention will be concentrated on structural rearrangements, and reactions with carbon and nitrogen electrophiles, particularly those with multiple bonds or nonmetals. The formation of complex compounds with metals and elementoelectrophiles of the main groups of the periodic table constitutes a very broad area, one that has been described in many reviews (see, for example, the most general of them ${ }^{34-37}$ ). Therefore, except in those cases where elementoderivatives are used for the synthesis of new types of carbenes or reactions of their ring expansions, the results of these studies are not considered in the present work. Attention has been paid to appropriate methods for the synthesis of carbene precursors (precarbenes), the carbenoid structures of which sometimes allow the achievement of in situ reactions. The results of such reactions are often comparable to those of free carbenes. ${ }^{7}$

Structures are numbered in this review according to the Scheme in which they first appear, in order to avoid a cumbersome sequence running into the 500s. We hope that this will be found convenient.

\section{Synthesis of Carbenes of the Imidazole and Triazole Series and their Fused Analogues}

\subsection{Imidazol-2-ylidenes}

2.1.1. Monoimidazol-2-ylidenes. Current methods for the preparation of imidazol-2-ylidenes involve the deprotonation of meso-unsubstituted imidazolium salts under the action of anhydrous and unprotic bases (metal hydrides, alkoxides, hexamethyldisilazanides, diisopropylamides, etc.). Using this approach Wanzlick et al. ${ }^{7}$ generated carbenes of the heterocyclic series in situ. However, Arduengo et al. provided the first example of a stable crystalline carbene 1,3-di-(1-adamantyl)imidazol-2-ylidene 1D2 ( $\mathrm{R}=1$-Ad) (Scheme 1). ${ }^{4}$ They demonstrated that the method is suitable for the isolation of individual substances and confirmed the lability of carbenes under environmental conditions (to water, oxygen and carbon dioxide). Subsequently, 1,3disubstituted imidazol-2-ylidenes, ${ }^{5,38-40}$ 4,5-dihydroimidazol-2-ylidenes ${ }^{41}$ and acyclic diaminocarbenes ${ }^{42}$ were $^{2}$ prepared and shown to behave in a similar fashion to the first Arduengo compound. In the latter case, there is a significant complexation of alkali metal cations, especially lithium, by the carbene.

The precursors of imidazol-2-ylidenes are 1,3-disubstituted imidazolium salts that are obtained by the alkylation of relevant imidazoles. However, this approach is not suitable for the preparation of sterically shielded 1,3-dialkylimidazolium salts such as 1C. As a consequence, a process that combines amines with formaldehyde (or paraformaldehyde), followed by the reaction of glyoxal with the condensation product 1B in the presence of acids, was devised (Scheme 1). ${ }^{43,44}$ Tetraphenylimidazolium salt 1 E1 and 1,3-di(1-adamantyl)4,5-diphenylimidazolium salt 1 E2 were obtained in other pathways: via the oxidation of the corresponding thione with nitric $\operatorname{acid}^{40}$ and via the quaternization of 4,5-diphenylimidazole with 1-bromoadamantane in the presence of sodium acetate in acetic acid, ${ }^{45}$ respectively.

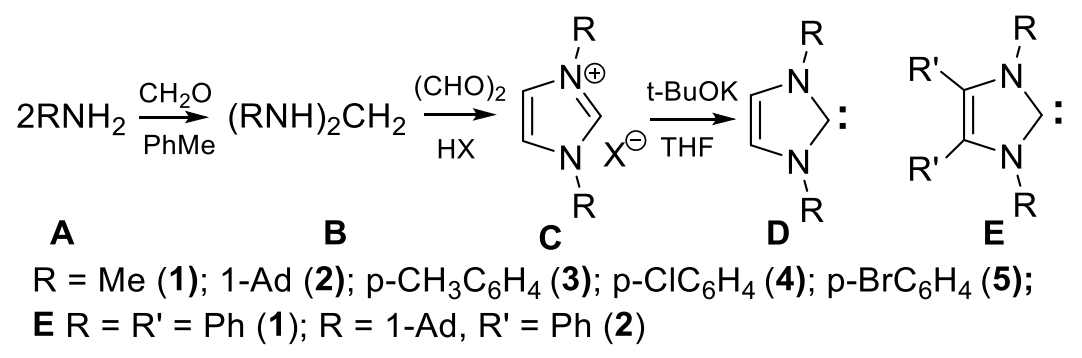

Scheme 1. Arduengo's method for the preparation of imidazol-2-ylidenes via diaminomethanes. 
Subsequently, in some cases this reaction was carried out in a different order. The first step produced the glyoxaldiimines $\mathbf{2 B}$ through the reaction of amines with glyoxal. The resulting diimines were cyclized to the imidazolium salts $\mathbf{2 C}$ by treatment with alkoxymethyl chlorides or paraformaldehyde in the presence of protonating, alkylating or silylating agents (Scheme 2). ${ }^{44,46}$ Similarly, the reaction of substituted glyoxals was used to produce alkyl-substituted imidazolium salts. ${ }^{5}$

The cyclization of diimines was effective for the preparation of sterically complicated imidazolium salts such as the mesityl- and Dipp-substituted compounds. ${ }^{46}$ The 1,3-diaryl substituted imidazolium salts and their respective carbenes with sterically branched aromatic substituents such as 2E (2,4-dibenzhydryl-4methylphenyl- and its analogues) have also been prepared by this method. ${ }^{47-53}$
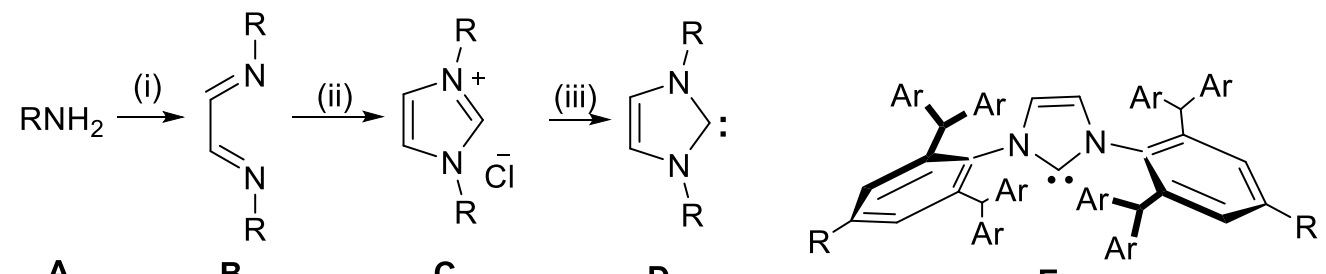

(i) $(\mathrm{CHO})_{2}$, i-PrOH; (ii) $\mathrm{ClCH}_{2} \mathrm{OEt}$, THF; (ii) $\mathrm{NaH}$ or t-BuOK, THF D Mes (1); Dipp (2); Me, 4,5-Me 2

(3); $\mathrm{CD}_{3}, 4,5-\left(\mathrm{CD}_{3}\right)_{2}$ (4). E R = Me, $\mathrm{Ar}=\mathrm{Ph}(1)$, Et, $\mathrm{Ph}(2) ; \mathrm{MeO}, \mathrm{Ph}(3) ; \mathrm{Me}, 1-\mathrm{C}_{10} \mathrm{H}_{7}$ (4).

Scheme 2. Arduengo's method for the preparation of imidazol-2-ylidenes via diimines.

For the syntheses of the imidazol-2-ylidenes 3B, Kuhn and Kratz used the reaction of potassium or a sodium-potassium alloy with the accessible $\mathrm{N}$-substituted imidazol-2-thiones by heating them in tetrahydrofuran (Scheme 3). ${ }^{54}$ The requisite thiones were prepared via the reaction of hydroxyketones with thioureas or via the reaction of sulfur with imidazolium salts in the presence of bases.

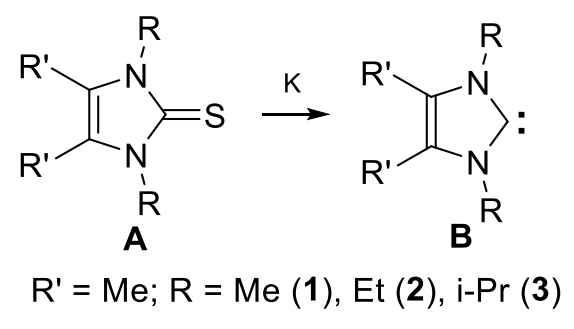

Scheme 3. Synthesis of imidazol-2-ylidenes by reduction of imidazol-2-thiones.

An unusual sterically shielded carbene featuring two imino groups has been synthesized using a sterically hindered acetanilide. ${ }^{55}$ Treatment of the latter with $\mathrm{PCl}_{5}$ readily generated the chloro-imine $4 \mathrm{~A}$. In turn, two equivalents of $4 \mathrm{~A}$ reacted with the imidazole, at the $\mathrm{NH}$ group and the tertiary nitrogen atom, thereby forming the salt $\mathbf{4 C}$ (Scheme 4). The carbene $\mathbf{4 D}$ was obtained by reaction of $\mathbf{4 C}$ with potassium hexamethyldisilazanide (KHMDS). During crystal growth 4D was partially converted back into 4B, followed by further insertion of a second equivalent of $4 \mathrm{D}$ into the $\mathrm{C}-\mathrm{H}$ bond of the $\mathrm{N}=\mathrm{C}(\mathrm{H}) \mathrm{N}$ moiety in the latter. 


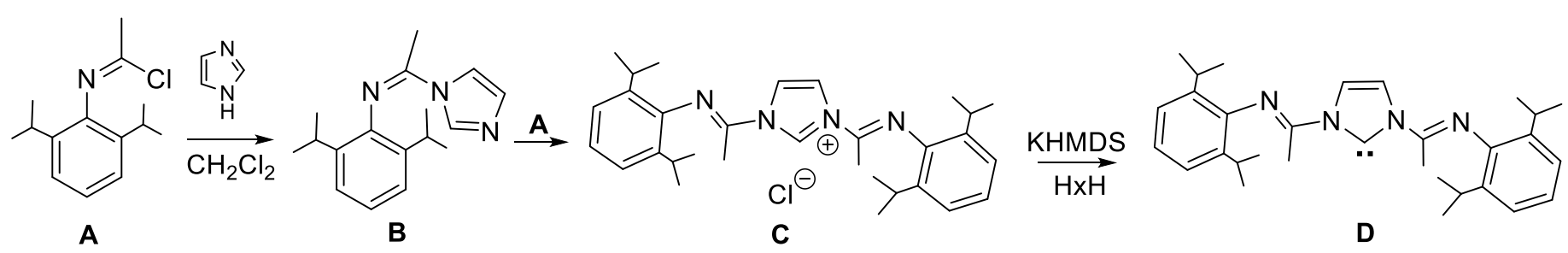

Scheme 4. Synthesis of diiminoimidazol-2-ylidenes.

This new breed of imidazol-2-ylidene carbenes permits significant steric protection of the reaction centers. Moreover, the structures of these compounds are unusual; studies of their catalytic properties could prove to be of significant interest.

Two sterically shielded, bifunctional imidazol-2-ylidenes with 6-trimethylsilylpyridine $\mathbf{5 A}$ and substituted phosphine 5B fragments have been synthesized using 1-Dipp-substituted imidazolium salts (Scheme 5). ${ }^{56}$

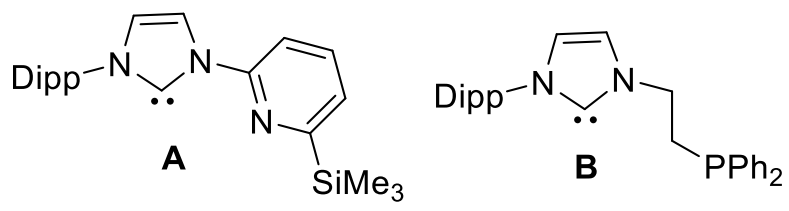

Scheme 5. Stable functionalised imidazol-2-ylidenes.

The functionalized 4,5-dichloro-substituted 1,3-dimesitylimidazol-2-ylidene $\mathbf{6 G}$ was obtained via the reaction of $\mathrm{CCl}_{4}$ with its 4,5 -unsubstituted analogue $6 \mathrm{~A}$ (Scheme 6 ). ${ }^{57}$ The reaction proceeds by the sequential chlorination of carbene $6 \mathrm{~A}$ with $\mathrm{CCl}_{4}$, deprotonation of the 4 and 5 positions of the intermediate salt $\mathbf{6 B}$ by the $\left[\mathrm{Cl}_{3} \mathrm{C}\right]^{-}$anion (generated during the reaction with $\mathrm{CCl}_{4}$ ) followed by chlorination of the anions $6 \mathrm{C}$, $\mathbf{E}$ with $\mathrm{CCl}_{4}$ in these positions. This transformation provides a useful pathway for the introduction of substituents at the 4and 5-positions of the imidazol-2-ylidene ring. The sterically complicated 4,5-dibromo-substituted imidazol-2ylidenes (IPrHBr, IMesHBr) were synthesized in a similar fashion using $\mathrm{CBr}_{4} \cdot{ }^{58}$ Along with the dichloro derivatives, these are all relatively stable on air.

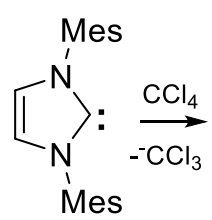

A

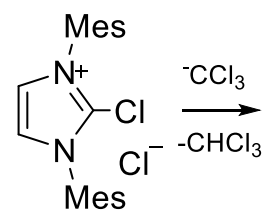

B

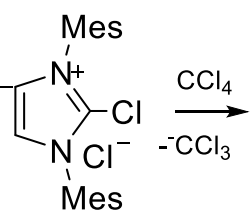

C<smiles>[Mg][n+]1c(Cl)cc(Cl)n1[Si]</smiles>

D

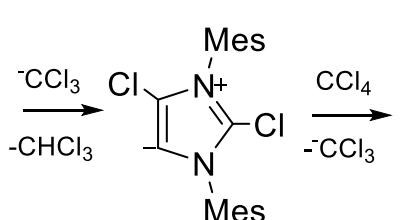

E

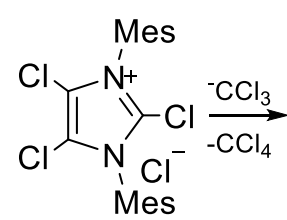

$\mathbf{F}$<smiles>CN1C=CN(C)C1Cl</smiles>

G

Scheme 6. Synthesis of 4,5-dichloroimidazol-2-ylidenes by chlorination of 4,5-unsubstituted imidazol-2ylidenes with $\mathrm{CCl}_{4}$.

Gates et al. have developed a method for the phosphaalkylation of the imidazol-2-ylidene 7A by reacting phosphaalkenes at the 4-position of the ring (Scheme 7). ${ }^{59}$ The reaction proceeds via a mesoionic state (carbene 7B), with addition of the phosphaalkene forming the phosphanylcarbene 7D. 


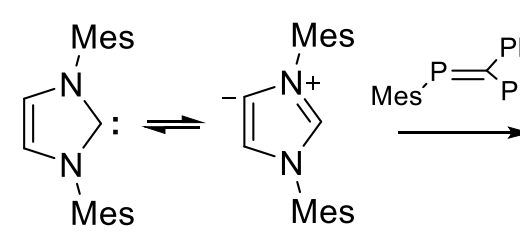

A

B<smiles>CCCn1cc(P(C)(C)(C)c2ccccc2)[n+](C)c1</smiles>

C<smiles>Cn1cc(-c2ccccc2)c(P(C)(C)(C)C)c1</smiles>

D

Scheme 7. Phosphanylation of imidazol-2-ylidenes with phosphaalkenes.

In order to obtain similar phosphanyl, as well as 4-aryl-, acyl-, alkylsulfonyl-, silyl-, and halogensubstituted imidazol-2-ylidenes (8C, Scheme 8), Bertrand et al. used a carbene rearrangement of the deprotonated products of the appropriate 2-substituted imidazolium salts $\mathbf{8 B} .{ }^{60,61}$ Silyl derivatives of the imidazol-2-ylidene have also been used for carbene functionalization, without changes at the carbene center, using 1-adamantylamine (structure 8D). ${ }^{62}$

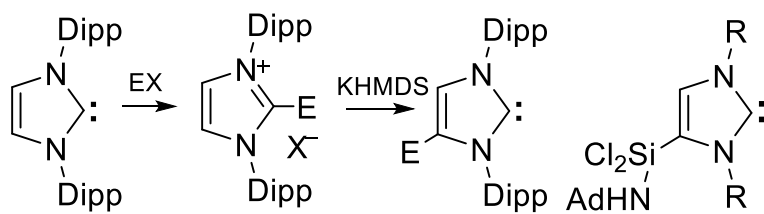

A

B

C

D

$\mathrm{E}=\mathrm{Ph}_{2} \mathrm{P}, \mathrm{Me}_{3} \mathrm{Si}, \mathrm{RCO}, \mathrm{CF}_{3} \mathrm{SO}_{2}, \mathrm{Cl}, \mathrm{Br}$

Scheme 8. Synthesis of 4-substituted imidazol-2-ylidenes by rearrangement of carbene adducts with electrophiles.

The difunctionalized derivative, 1,4-dimethyl-4,5-diphosphanylimidazol-2-ylidene $\mathbf{9 F}$, was synthesized in a similar fashion, namely by deprotonation of the corresponding imidazolium salt with LiHMDS (Scheme 9). ${ }^{63}$<smiles>[Y]n1c[n+](C)c(P)c1P([Y])c1ccccc1</smiles>

(i) LiHMDS; (ii) $\mathrm{Ph}_{2} \mathrm{PCl}$; (iii) $\mathrm{HX}$

Scheme 9. 4,5-Diphosphanylation of imidazol-2-ylidenes.

A precursor for the synthesis of carbenes was obtained using a method similar to that employed by Arduengo et al. This involved sequential phosphanylation of the 1,3-dimethyl-2-phosphanylimidazolium salts $9 \mathrm{~B}, \mathrm{E}$ with diphenylphosphanyl chloride in the presence of LiHMDS. ${ }^{63} \mathrm{All}$ attempts to isolate the 4-phosphorylated carbenes of similar type were unsuccessful. However, it was possible to obtain a number of carbene complexes of rhodium and iridium. ${ }^{64}$

The $\mathrm{N}$-phosphorus containing carbenes $10 \mathrm{C}$ were synthesized by the direct phosphanylation of the azole lithium derivatives 10B, to which a carbene structure was assigned (Scheme 10). ${ }^{65}$ The syntheses of phosphanyl substituted carbenes have been described in the review by Gaillard et al. ${ }^{66}$ 
Polymeric derivatives of 4-lithiumimidazol-2-ylidenes of the type 11B were prepared via the reaction of butyllithum with the imidazol-2-ylidene 11A. These were used for the synthesis of the chiral silyl substituted mono- (11E) and bis-imidazol-2-ylidenes, ${ }^{67}$ and also via the reaction with dimesitylborofluoride for the synthesis of the boryl substituted carbene 11C (Scheme 11 ). ${ }^{68}$ The latter product could also be obtained via the reaction of dimesitylborofluoride with carbene 11A, followed by the deprotonation of the zwitterion 11D using potassium hexamethyldisilazanide.

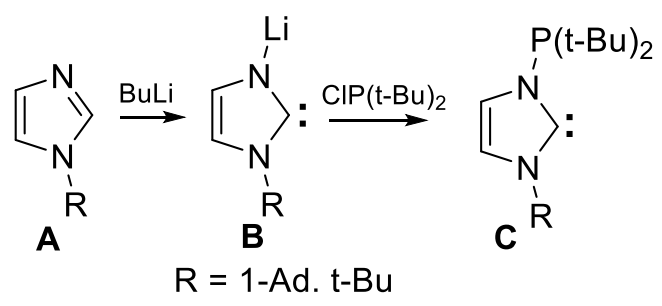

Scheme 10. Synthesis of 3-phosphanylimidazol-2-ylidenes via phosphanylation of Li-azoles.

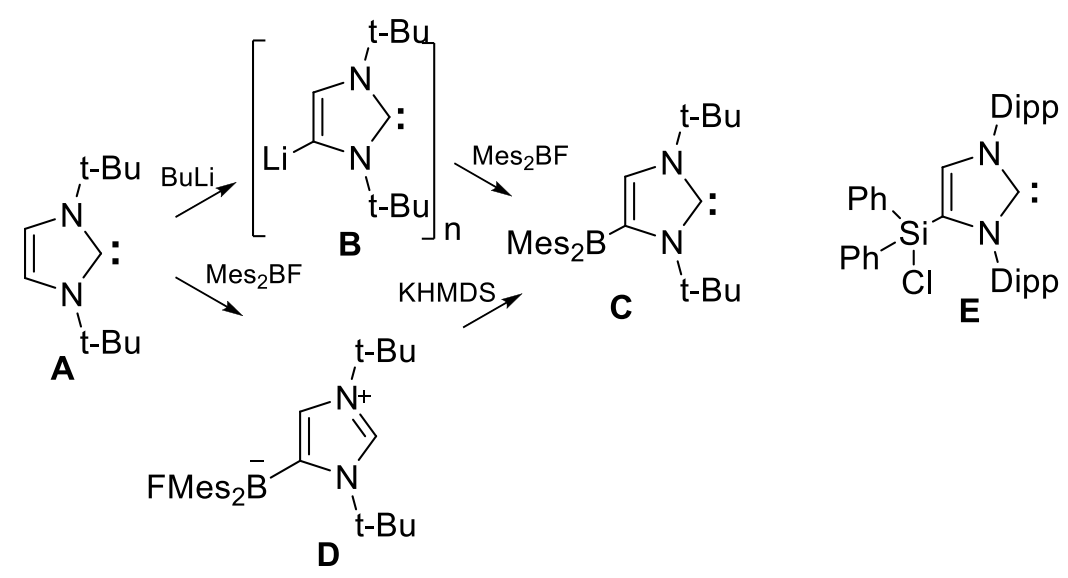

Scheme 11. Borylation and silylation of imidazol-2-ylidenes.

The 4,5-bisdimethylaminoimidazolium and tetrasubstituted bisdimethylaminoimidazolium derivatives 12C were prepared by the interaction of lithium amidines with the diphosphonium salts 12B (Scheme 12). ${ }^{69}$ The reaction of potassium hydride with the salts $12 \mathrm{C}$ in THF resulted in the formation of the carbenes 12D. The strongly polarized carbenes 12D are good representatives for Umpolung reactivity. The corresponding reaction of butyllithium with $\mathbf{1 2 C}$ resulted in the formation of the lithium salt complexes $\mathbf{1 2 E}$ that were characterized by chemical transformations.

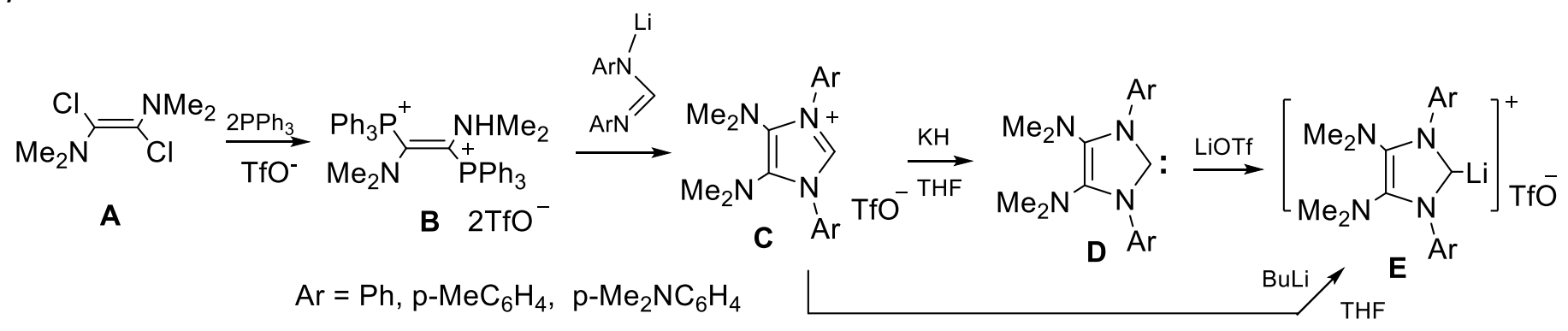

Scheme 12. Synthesis of 4,5-diaminoimidazol-2-ylidenes. 
4,5-Dicyano-substituted imidazol-2-ylidenes have been used for the preparation of palladium complexes. However, the free carbenes were not isolated. ${ }^{70,71}$

Cyclosilanyl derivatives of the imidazol-2-ylidenes were obtained from the reaction of carbenes with stable silylenes 13A. ${ }^{72}$ These, in turn, gave rise to the stable carbenes $13 \mathrm{C}$ due to ylide formation at the methyl group (13B) (Scheme 13). The resulting compounds were then used for carbene-silylene complexation of transition metals. $^{73}$

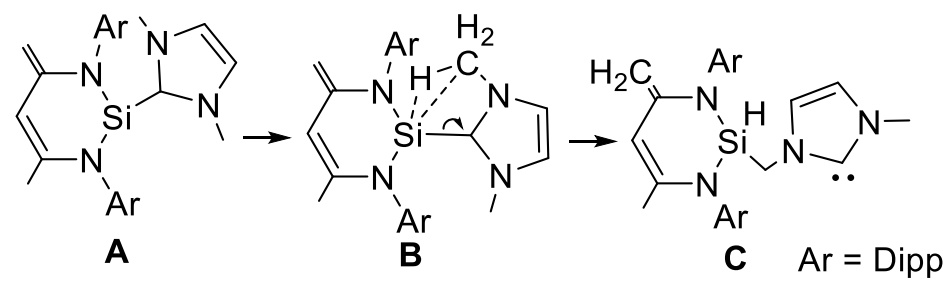

Scheme 13. Synthesis of silanyl derivatives of imidazol-2-ylidenes.

Hydrocarbon derivatives that had been introduced on the nitrogen atoms of imidazolium salts have been converted to the respective carbene complexes by known methods. However, the free carbenes were not isolated. ${ }^{74}$ Instead, complexation afforded a series of neutral $\mathrm{Rh}(\mathrm{I})$ compounds that showed promising activity for enantioselective ketone hydrosilylation.

Carboranyl substituted compounds have been synthesized using a method similar to that described by Arduengo et $a .^{75}$ A cesium (anionic) derivative of a carboranylamine was synthesized via the appropriate dicesium-diimine followed by further cyclization of the latter with paraformaldehyde in the presence of hydrogen chloride (Scheme 14). The resulting salt 14A could be deprotonated under a variety of conditions to give a mixture of products. After optimization of the syntheses it became clear that the normal carbene complex with lithium at the 2 position 14B is formed by treatment with LiHMDS (2 eq.) at $-78^{\circ} \mathrm{C}\left(\mathrm{C}^{2}\right.$ signal in the ${ }^{13} \mathrm{C}$ NMR spectrum, $\left.\delta 196.9 \mathrm{ppm}\right)$. The reaction with LDA leads to the product under thermodynamic control, namely the mesoionic complex $14 \mathrm{C}\left(\delta C^{4} 174.7 \mathrm{ppm}\right)$. In solution compound 14B was converted (50\%) to complex $14 \mathrm{C}$ after 2 weeks, while at $50^{\circ} \mathrm{C}$ the reaction was complete in 24 hours. The biscarbene complex 14D was formed ( $\delta C^{2,4} 195.6,169.5 \mathrm{ppm}$ ) by the addition of three equivalents of butyllithium to $14 \mathrm{~A}$.

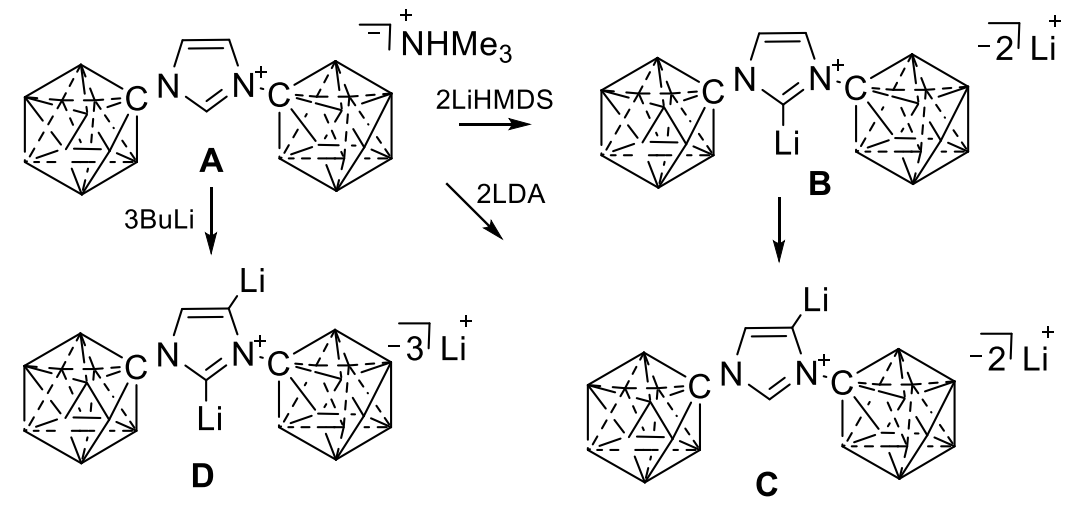

Scheme 14. Synthesis of lithium complexes of carboranylimidazol-2-ylidenes.

Non-aromatic fused derivatives of the imidazol-2-ylidenes 15C,D were obtained by Glorius et al. starting from the appropriate oxazolines and bisoxazolines $15 A^{76-78}$ (Scheme 15). The carbenes were characterized in 
solution on the basis of their spectral data. Compounds of type 15D exhibit high steric shielding of the carbene center. In fact, the steric shielding exceeds those reported for the tert-butyl and adamantyl substituted imidazol-2-ylidenes. ${ }^{79}$

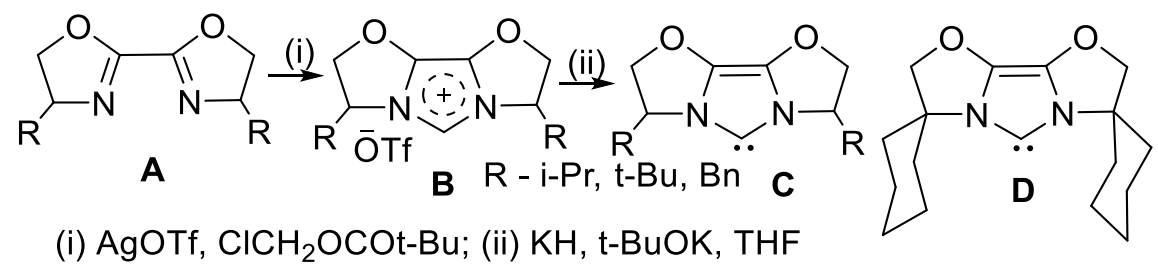

(i) AgOTf, $\mathrm{ClCH}_{2} \mathrm{OCOt-Bu}$; (ii) $\mathrm{KH}$, t-BuOK, THF

Scheme 15. Synthesis of sterically hindered dioxazolinoimidazol-2-ylidenes.

Bildstein et al. proposed the use of ferrocene containing imidazol-2-ylidenes ${ }^{80}$ for the synthesis of transition metal complexes, thus taking into account the useful electrochemical properties of metallocene derivatives such as their high chemical stability and reversible redox behaviour. However, only salt precursors were obtained using the classical method of Arduengo for ferroceneimines. The cyclization of diimines was carried out via the reaction of paraformaldehyde with zinc triflate. After treatment with bases, the isolation of stable carbenes was unsuccessful.

The precursors and complexes of chiral ferrocenes containing imidazol-2-ylidenes were also synthesized via the reaction of chiral alcohols with imidazoles in acetic acid. ${ }^{81}$ Chiral phosphine and sulfide containing ferroceneimidazol-2-ylidenes were obtained starting from the reaction of the corresponding amines with triethylorthoformate to form formamidines 16A. This was followed by the alkylation of the latter with bromoacetal and cyclization of the substituted formamidine 16B with boron trifluoride to form the salts 16C (Scheme 16). ${ }^{82-84}$

The synthesis of the 1,3-diferrocene containing imidazol-2-ylidene 16D was reported initially by Broggini and Togni. ${ }^{85}$ The carbene was identified as a monomer and the structure was determined by means of X-ray diffraction. Compound 16E was isolated and analyzed by NMR spectroscopy. ${ }^{86}$ 1-Methyl-3-(2-dimethylaminomethylferrocenyl)imidazol-2-ylidene $\mathbf{1 6 F}$ was synthesized by reaction with the corresponding amino- (via diimino formation) or halogeno-ferrocenes (via alkylation of imidazoles). ${ }^{87}$
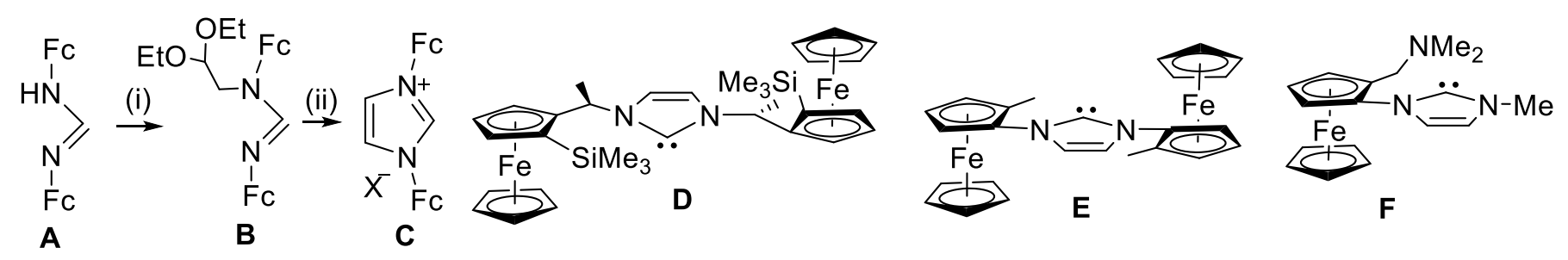

(i) $\mathrm{BrCH}_{2} \mathrm{CH}(\mathrm{OEt})_{2}, \mathrm{NaH}, \mathrm{DMF}$

(ii) $\mathrm{BF}_{3}, \mathrm{Nal}, \mathrm{CH}_{3} \mathrm{CN}$

Scheme 16. Synthesis of ferrocenyl substituted imidazol-2-ylidenes.

Carbenes of the imidazol-2-ylidene series have also been obtained from the corresponding azolium salts using electrochemical synthesis. ${ }^{88}$ The ability of carbenes to be electrochemically reduced to anion radicals ${ }^{89}$ had already been demonstrated on the compound 1,3,4-triphenyl-1,2,4-triazol-5-ylidene. 
2.1.2. Bis- and tris-imidazol-2-ylidenes. Herrmann et al. first isolated bisimidazol-2-ylidene $17 A 1(R=M e, X=$ $\left.\left(\mathrm{CH}_{2}\right)_{2}\right)$ by deprotonation of a bisimidazolium salt with sodium hydride in liquid ammonia (Scheme 17). ${ }^{90}$ However, the crystal structure has not yet been determined. The most stable carbenes $17 A 2(R=M e s, D i p p, X$ $=\mathrm{CH}_{2}$ ) were synthesized much later via the reaction of 3,3'-diarylbisimidazoliummethanes with potassium tertbutoxide in THF. ${ }^{91}$ The triscarbene 17B was isolated in a crystalline state by Dias et al. as a result of deprotonation of the corresponding trisimidazolium salt with potassium tert-butoxide in THF. ${ }^{92}$ However, in this case an X-ray diffraction study was not carried out. The first bisimidazol-2-ylidenes $17 A 3$ (X = pyridine-2,6diyl) with precisely defined structures were synthesized by Danopoulos et al. ${ }^{93}$ using pyridine-2,6diimidazolium salts (the condensation products of 2,6-dibromopyridine with the corresponding 1-substituted imidazoles). These biscarbenes are stable at room temperature for several hours and indefinitely stable when cooled $\left(-30^{\circ} \mathrm{C}\right)$. The triscarbene $17 \mathrm{C}$ was synthesized via the reaction of the appropriate trisimidazolium salt with potassium tert-butoxide in THF solution. ${ }^{94}$
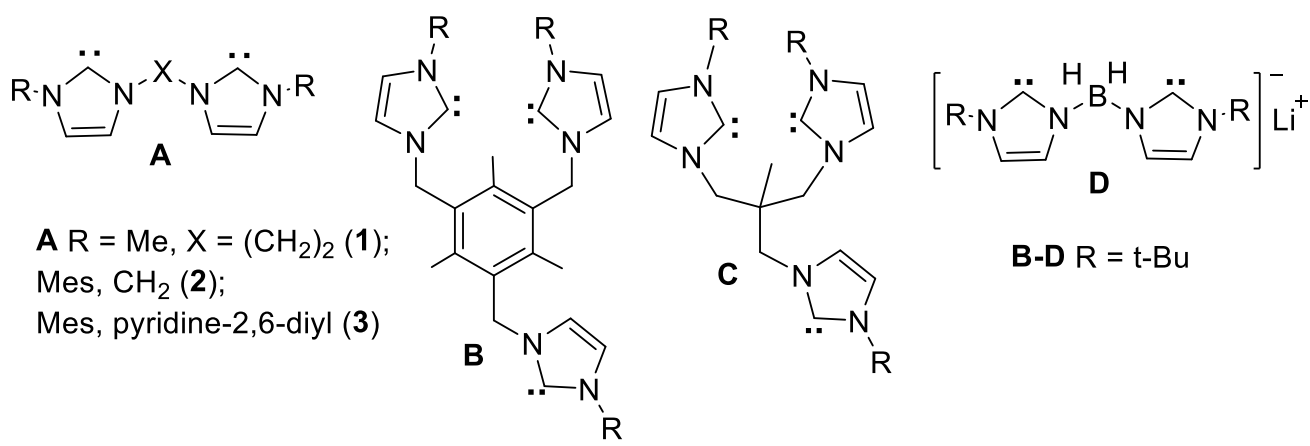

$B-D R=t-B u$

Scheme 17. Stable bis- and trisimidazol-2-ylidenes.

The precursors to the bis- and triscarbenes 17A-C were synthesized by quaternization of the corresponding $\mathrm{N}$-substituted imidazoles with the respective haloalkanes. ${ }^{90-94}$

The borane derivatives of the bisimidazol-2-ylidenes 17D were generated from the corresponding salts in order to obtain their transition metal complexes. ${ }^{95-98}$ Synthesis of the precursors takes place easily via the reaction of haloboranes with $\mathrm{N}$-substituted imidazoles (or alternatively with tert-amine complexes of haloboranes) or via the reaction of metal borohydrides with imidazoles followed by subsequent quaternization. Lithium complexes of boranbisimidazol-2-ylidenes have also been prepared. ${ }^{98}$ Furthermore, the corresponding potassium complexes can be used for the synthesis of stabilized germylenes. ${ }^{99,100}$

The lithiated carbene 18A was used for the preparation of the silylene-containing biscarbene 18B (Scheme 18). ${ }^{67}$ An alternative route to similar structures (19D) was proposed by Schneider et al. (Scheme 19), ${ }^{101}$ involving the direct silylation of carbene 19A. The adduct 19B is further transformed by heating to form the bridged silylene imidazolium salt $19 \mathrm{C}$ (obtained from $\mathrm{Ph}_{2} \mathrm{SiCl}_{2}$ with two equivalents of the carbene) followed by deprotonation of $19 \mathrm{C}$ with sodium hydride in the presence of potassium tert-butoxide in THF solution.

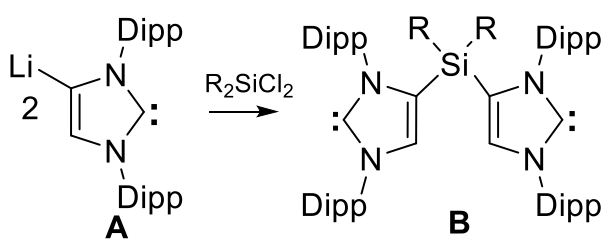

Scheme 18. Synthesis of bis-imidazol-2-ylidenes by silylation of Li-imidazol-2-ylidenes. 
<smiles></smiles>

A

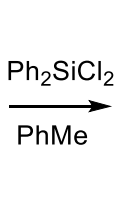

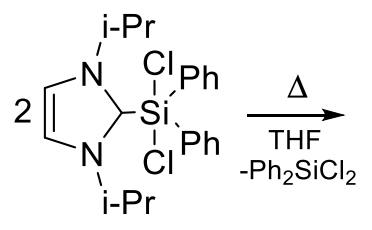

B

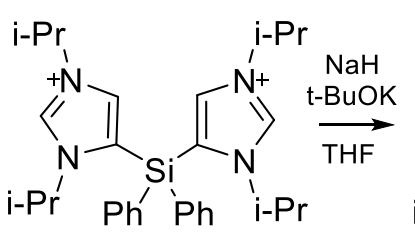

C $2 \mathrm{Cl}$

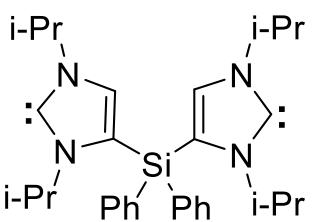

D

Scheme 19. Synthesis of bis-imidazol-2-ylidenes by silylation of imidazol-2-ylidenes.

\subsection{Fused aromatic analogues of imidazol-2-ylidenes}

2.2.1. Fused monoimidazol-2-ylidenes. The following alkylation methods were used to obtain precursors for the simplest 1,3-disubstituted, 10-n, $\pi$-electron benzimidazol-2-ylidenes. The benzimidazolium salt 20C was synthesized in high yield by alkylation of 1-(1-adamantyl)benzimidazole 20B with 1-bromoadamantane. ${ }^{102}$ The reaction of sodium hydride with salt $20 \mathrm{C}$ in acetonitrile resulted in formation of the carbenoid 2-cyanomethyl derivative of the corresponding $2 \mathrm{H}$-benzimidazoline 20D, which then decomposes to form the pure 1,3-di-(1adamantyl)-benzimidazol-2-ylidene $20 \mathrm{E}$ (Scheme 20). ${ }^{103,104}$

Subsequently, adamantyl substituted salts of the type 20C were obtained starting from 1-adamantylamine and substituted $o$-dibromobenzenes in the presence of sodium tert-butoxide, palladium acetate and racemic BINAP followed by cyclization of the resulting diamines with triethylorthoformate in the presence of concentrated hydrochloric acid. ${ }^{105}$

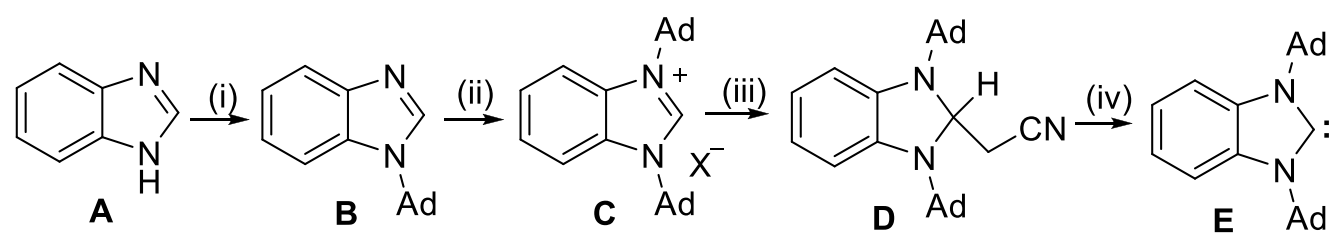

(i) $\mathrm{AdBr}, \mathrm{K}_{2} \mathrm{CO}_{3}, \mathrm{o}-\mathrm{DCB}$; (ii) $\mathrm{AdBr}$, o-DCB; (iii) $\mathrm{NaH}, \mathrm{CH}_{3} \mathrm{CN}$; (iv) $180^{\circ} \mathrm{C},-\mathrm{CH}_{3} \mathrm{CN}$

Scheme 20. Synthesis of 1,3-diadamantylbenzimidazol-2-ylidene via decomposition of 2-cyanomethyl-2Hbenzimidazoline.

A modification of the method of Kuhn and Kratz that uses a potassium-sodium alloy and azolethiones in toluene solution ${ }^{106}$ was utilized for the synthesis of 1,3-dineopentylbenzimidazol-2-ylidene 21D ( $R=N p$, as a mixture of stereoisomers). Its formation takes place at room temperature over a period of 20 days (Scheme 21 ) in a $60 \%$ yield. It is interesting that if the reaction is carried out in THF under the same conditions, the carbene is reduced to the $2 \mathrm{H}$-azoline. However, this outcome may have been due to insufficient drying of the solvent.

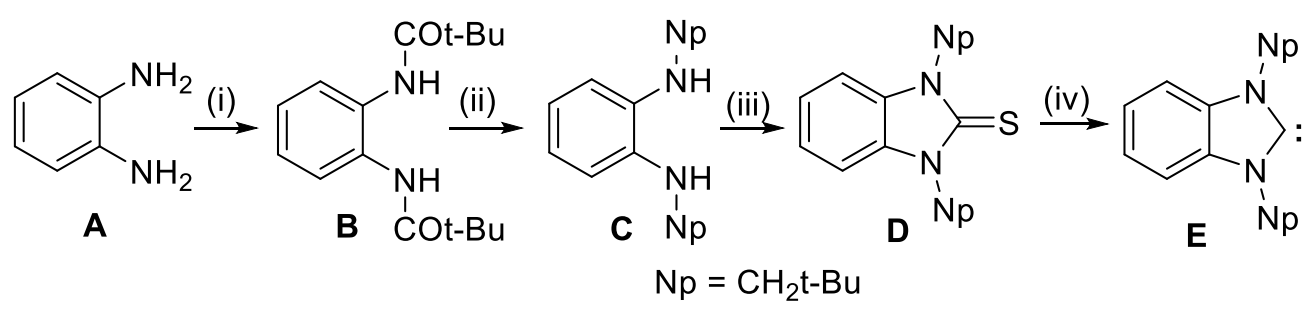

(i) ClCOt-Bu; (ii) $\mathrm{LiAlH}_{4}$, THF; (iii) $\mathrm{CSCl}_{2}$; (iv) $\mathrm{K} / \mathrm{Na}, \mathrm{PhMe}$

Scheme 21. Hahn's synthesis of 1,3-dineopentylbenzimidazol-2-ylidene. 
The precursor 21D was obtained from the diamide 21B, which was then reduced by lithium aluminium hydride followed by treatment of the resulting diamine $21 \mathrm{C}$ with thiophosgene.

Decreasing the steric hindrances in $\mathbf{2 1 E}$ results in dimerization of the carbene. A good example of relatively slow dimerization is provided by 1,3 -diisobutylbenzimidazol-2-ylidene. ${ }^{107}$

The $o$-phenylenediamine required for the synthesis of 1,3-dimesitylbenzimidazol-2-ylidene was prepared by catalytic routes according to the Buchwald and Hartwig method, namely: (1) the arylation of $o$-phenylenediamine with mesitylbromide (and related haloarenes) in the presence of $\mathrm{Pd}_{2} \mathrm{dba}_{3}$, BINAP and sodium tertbutoxide; 108 or (2) the amination of 0 -dibromobenzene with mesitylamine in the presence of palladium acetate, BINAP and sodium tert-butoxide. ${ }^{104}$ The actual syntheses of these carbenes have not yet been described. ${ }^{109}$

The salt precursors for the benzimidazol-2-ylidenes 22A were synthesized by quaternization of N-methylbenzimidazole with di-tert-butylphosphanyl bromide (Scheme 22). Similar compounds were isolated by direct phosphanylation of lithium benzimidazoles with di-tert-butylphosphanyl chloride according to Scheme 10 or by deprotonation of the appropriate N-phosphanylbenzimidazolium salts with NaHMDS, Me ${ }_{2} \mathrm{NLi}$ or MeLi. ${ }^{65,110}$<smiles>[R20]n1[Y]nc2ccccc21</smiles>

A ' $\mathrm{R}^{\prime}$<smiles>CNc1ccccc1NC(F)(F)F</smiles>

B $\stackrel{\prime}{\mathrm{Me}}$<smiles>FN1CNc2ccccc21</smiles>

C Me<smiles>[X]n1c[n+](C=[N+])c2ccc(C)cc21</smiles>

D ${ }_{\mathrm{M}}^{1} \mathrm{X}$
$A \mathrm{R}=\mathrm{t}-\mathrm{Bu}, \mathrm{i}-\mathrm{Pr}_{2} \mathrm{~N} ; \mathrm{R}^{\prime}=\mathrm{Me}, \mathrm{i}-\mathrm{Pr}$;
(i) $\mathrm{CH}_{2} \mathrm{O}, \mathrm{H}_{2} \mathrm{O}$;
(ii) $\mathrm{Ph}_{3} \mathrm{C} \mathrm{BF} 4$

Scheme 22. $N$-phosphanylbenzimidazol-2-ylidenes and synthesis of $N$-ferrocenylbenzimidazolium salts.

The ferrocene-containing benzimidazolium salts 22D were first synthesized by Bildstein et al. and used for the preparation of metal complexes. ${ }^{111}$ The key stage of the reaction involves the cyclization of the ferrocenediamines to azolines $\mathbf{2 2 C}$ and the elimination of a hydride ion from each of them. Isolation of the individual carbenes was impossible in this case due to their tendency to dimerize (note, however, that the coupled product that was formed by deprotonation of the salts 22D was isolated in high yields).

Bielawski et al. added two benzimidazolium fragments to ferrocene according to Scheme $23 .{ }^{112}$

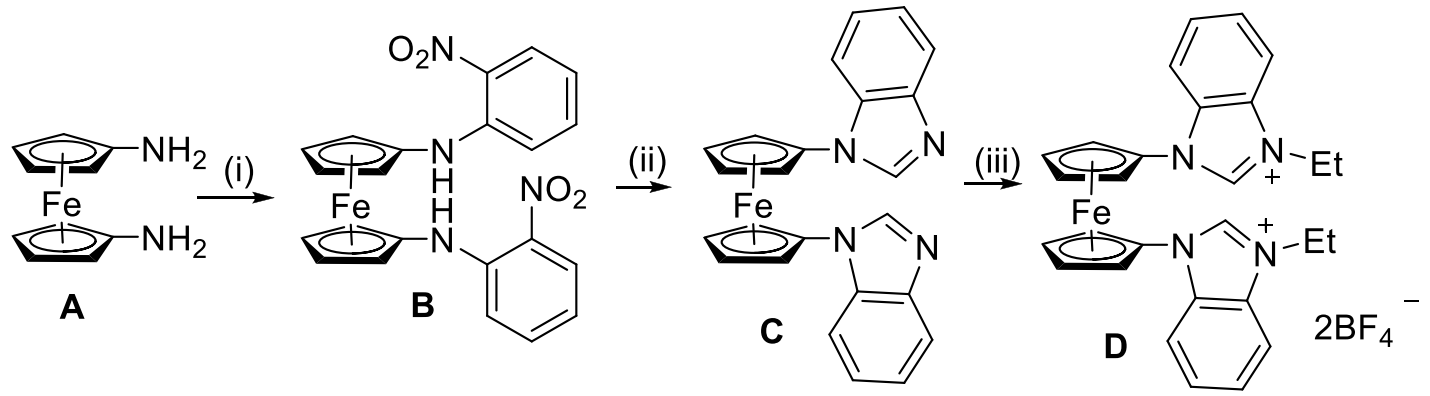

(i) o- $\mathrm{O}_{2} \mathrm{NCIC}_{6} \mathrm{H}_{4}$, DMSO, $\mathrm{NaHCO}_{3}$; (ii) $\mathrm{Pd} / \mathrm{C}, \mathrm{HCOOH} / \mathrm{HCOONa}$; (iii) $\mathrm{Et}_{3} \mathrm{O} \mathrm{BF}$, DCM

Scheme 23. Synthesis of ferrocene-bridged benzimidazolium precarbenes.

The 2-aza-analogues of the benzimidazol-2-ylidenes 24A1,2, with sterically shielding neopentyl substituents, were synthesized from the corresponding diamines by cyclization with triethyl orthoformate in 
the presence of ammonium salts. This was followed by deprotonation of the quaternary salts with potassium hydride in THF (Scheme 24). ${ }^{113}$ The authors evaluated carbenes $\mathbf{2 4 A 1 , 2}$ and found them to be less stable with respect to their analogs: silylenes, germylenes and stannylenes, the observed order of stability being: Sn > Ge $>\mathrm{Si}>\mathrm{C}$.

The fused carbene 24B ( $80 \%$ purity in an admixture with the corresponding $2 \mathrm{H}$-azoline) was obtained by deprotonation of the appropriate naphthoimidazolium salts with potassium-graphite $\mathrm{KC}_{8}$ in $\mathrm{THF}^{114} \mathrm{~A}$ purer carbene $(90 \%$ content) was obtained in this work by Kuhn's method using a mixture of the corresponding thione and potassium in THF.

A new carbenoid system based on 2,3-dichloroquinoxaline (precursor to carbene $24 \mathrm{C}$ ) was successfully prepared by its reaction with isopropylamine or neopentylamine, followed by further cyclization of the intermediate diamine with triethyl orthoformate. Deprotonation of the intermediate salt with potassium hydride in THF was used in situ for the syntheses of the carbene complexes of rhodium and silver. ${ }^{115}$ However, the preparation and isolation of free carbenes $\mathbf{2 4 C}$ has not yet been reported.

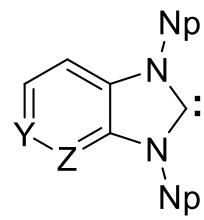

A1,2<smiles>[R]N1[Y]N([R])c2cc3ccccc3cc21</smiles>

B<smiles>[R]N1Nc2nc3ccccc3nc2N1[R]</smiles>

C<smiles></smiles>

D<smiles></smiles>

E1-4

A1,2: $Y=C H, Z=N(1) ; Y=N, Z=C H(2) ; B, C R=i-P r, N p ; E 1,2 R=C^{*} H(M e)(P h), R^{\prime}=B u(1)$; $\mathrm{R}^{\prime}=\mathrm{Bn}(2) ; \mathrm{R}=\mathrm{R}^{\prime}=\mathrm{Bu}(3) ; \mathrm{R}=\mathrm{R}^{\prime}=0-\mathrm{Tol}(4)$.

Scheme 24. Fused analogues of imidazol-2-ylidenes.

The Dipp-protected, fused 16-n, $\pi$-electron acenaphthyleneimidazol-2-ylidene 24D was synthesized using acenaphthylenediimine and methoxymethyl chloride ${ }^{116}$ according to the classical Arduengo scheme. The carbene that is formed via the reaction of potassium tert-butoxide with the fused imidazolium precursor in THF has a very high melting point (approximately $300{ }^{\circ} \mathrm{C}$ ). It readily forms complexes with transition metal salts, ${ }^{116-118}$ including palladium complexes that are efficient as catalysts for the Suzuki-Miyaura reaction. ${ }^{119}$

The phenanthrene-fused, aromatic 18-n, $\pi$-electronic imidazol-2-ylidenes 24E1-4 were generated as described in the referenced works. ${ }^{120-123}$ However, these compounds were not isolated in a crystalline state. The authors ${ }^{121}$ believe that the butyl and benzyl derivatives are stable for some time, and that the latter does not form ylides. The oily di-o-tolyl-substituted compound 24E4 is considered to be the most stable of these compounds. ${ }^{122}$

Butyl-substituted pyreneimidazol-2-ylidenes ${ }^{124,125}$ and Dipp-substituted pyranocenes ${ }^{126,127}$ were generated from the corresponding salts 25A,B with a view to obtaining carbene complexes (Scheme 25). However, the isolation of these carbenes has not been carried out (the carbenes derived from the 25A precursors probably exist as dimers). Polymeric complexes of these compounds were studied for their catalytic behavior. ${ }^{128}$ 
<smiles>[R]c1cc2ccc3cc([R])cc4c3c2c(c1)c1c2c3cc([R])c[n+]([R])c3c3cc([R])c[n+]([R])c4c2c31</smiles>

A

$\mathrm{R}=\mathrm{Bu} ; \mathrm{R}^{\prime}=\mathrm{H}, \mathrm{t}-\mathrm{Bu}$

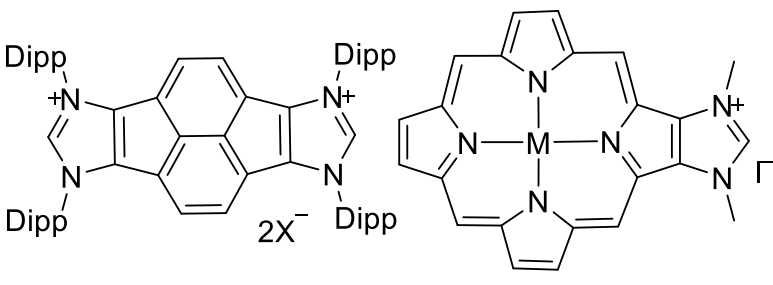

B

C

Scheme 25. Pyrene, pyranocene and porphyrine precarbenes.

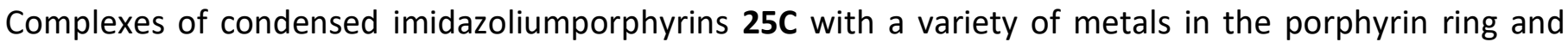
rhodium in the carbenoid have been obtained ${ }^{129}$. However, individual carbenes of these types have not yet been isolated. The desired imidazoporphyrins were synthesized by nitration of the related porphyrin complex with $\mathrm{LiNO}_{3}$ in the presence of $\mathrm{AcOH}$ and $\mathrm{Ac}_{2} \mathrm{O}$. This is followed by amination of the 1-nitroporphyrins with 4amino-1,2,4-triazole in a basic medium, reduction of the 2-amino-1-nitroporphyrins with sodium borohydride and cyclization of the 1,2-diaminoporphyrins with triethyl orthoformate or by other methods. ${ }^{130}$ The precarbene quaternary salts are easily prepared by quaternization of imidazoporphyrins with alkylating agents. The carbenoid analogue salts $\mathbf{2 6 C}$ were synthesized by derivatizing the aldehyde function of azaquinolines (Scheme 26). ${ }^{131}$

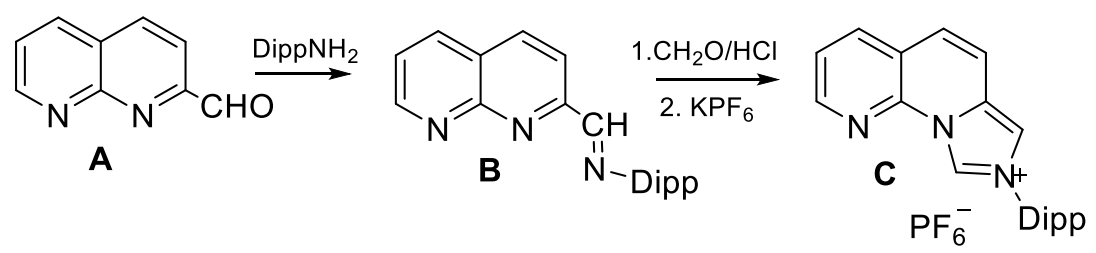

Scheme 26. Synthesis of precarbene phenanthroline analogues.

The analogues of benzimidazol-2-ylidenes are the $N$-annulated carbenes (pyridoimidazol-2-ylidenes) 27C (Scheme 27). Typically they are synthesized by cyclization of the formylaminomethylpyridines $27 \mathrm{~A}$ in $\mathrm{POCl}_{3}$ in the presence of $\mathrm{KPF}_{6}$, followed by deprotonation of the salts 27B with sodium hydride in the presence of catalytic amounts of potassium tert-butoxide. ${ }^{132}$ The resulting compounds are either oils or amorphous solids. They have been characterized on the basis of their ${ }^{1} \mathrm{H}$ and ${ }^{13} \mathrm{C}$ NMR spectra and remain stable for long periods of time at room temperature. The structure of the methyl substituted compound ( $\left.R=M e, R^{\prime}, R^{\prime \prime}, R^{\prime \prime \prime}=H\right)$ was established on the basis of a single crystal X-ray diffraction study. ${ }^{133}$ Transition metal complexes from the salt precursors 27B can also be prepared from the corresponding pyridinealdehydes 27D via the imines 27E according to a published method. ${ }^{134}$ 
<smiles>[R]c1cc(/C=N/[Na])nc([R])c1[R]</smiles>

ل(iv)<smiles>[R]c1cc(C=O)nc([R])c1[R]</smiles><smiles>[R]c1cc(CN([R])CO)nc([R])c1[R]</smiles>

(i) $\mathrm{POCl}_{3}, \mathrm{KPF}_{6}$; (ii) $\mathrm{NaH}, \mathrm{THF}$; (iii) $\mathrm{MesNH}_{2}, \mathrm{PhMe}$;

(iv) AgOTf, $\mathrm{ClCH}_{2} \mathrm{OCOt}-\mathrm{Bu}, \mathrm{DCM}$

$\mathrm{R}=\mathrm{Me}$, Mes; R' = R" = R'"' = H; R', R" or R", R'" = $(\mathrm{CH})_{4}$

Scheme 27. Synthesis of $\mathrm{N}$-annulated pyridoimidazol-2-ylidenes.

A similar reaction sequence was used to prepare an annulated carbenoid derivative $\mathbf{2 8 C}$ from quinoline-2aldehyde (Scheme 28). ${ }^{135}$ The sulfur containing analogues of $\mathbf{2 7 B}, \mathbf{2 8 C}$ and their related complexes are also known. ${ }^{136}$

Cyclophane derivatives of the imidazolium salts 28D, including those that are chiral, have been described. ${ }^{137,138}$ The cyclophane carbene ligands $(R=H, O M e)$ in complexes of the type described therein possess notedly higher donor abilities than their non-cyclophane analogues. But fluoro-containing carbene $(R=F)$ exhibits lower electron donating ability (at the level of non-cyclophanes). Chiral compounds 28E have been synthesized for asymmetrical catalysis of the Miyaura reaction of arylboronic acids with aromatic aldehydes to form chiral diarylcarbinols. However, individual carbenes of both types (28D,E) have not yet been synthesized.

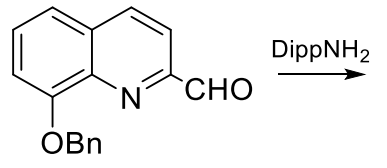

A

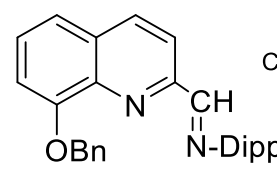

B

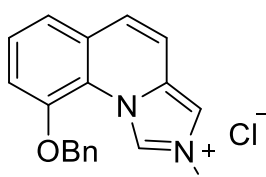

C

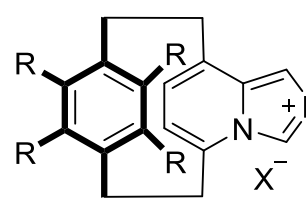

D $\mathrm{R}=\mathrm{H}, \mathrm{F}, \mathrm{OMe}$

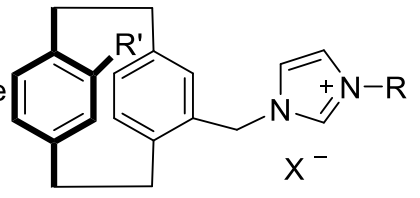

E

$\mathrm{R}=\mathrm{Me}, \mathrm{R}-\mathrm{CHMePh}$, $\mathrm{S}-\mathrm{CHMePh}, \mathrm{Mes}$ $\mathrm{R}^{\prime}=\mathrm{OMe}, \mathrm{Ph}_{2} \mathrm{PO}$

Scheme 28. Synthesis of precarbenes of N-annulated quinolinoimidazol-2-ylidenes.

The development of a method for the preparation of 1,10-diazafluorenylium bistriflate $29 \mathrm{C}$, via the reaction of trifluoromethanesulfonic acid with a diazoarsonium derivative 29A, preceded the synthesis of the $14 \mathrm{n}, \pi$-electronic 1,10-diazafluoren-11-ylidene 29D $(\mathrm{R}=\mathrm{H})$ (Scheme 29). ${ }^{139} \mathrm{It}$ can be considered as an aromatic biPy complex of carbon(0). The reaction proceeds via the intermediate arsonium methyltriflate 29B which effectively generates methylene to connect with 2,2'-bipyridyl and thereby form the bisalt 29C. The triflate anion was easily exchanged for bromide via reaction with tetrabutylammonium bromide, allowing isolation and characterization of a solid bromide derivative of $\mathbf{2 9 C}$. Deprotonation of the former with potassium tert- 
butoxide in THF solution produced the carbene 29D, which, however, failed to form in a crystalline state. ${ }^{139-141}$ A more stable version of the carbene (di-tert-butyl-substituted, $\mathrm{R}=t$-Bu) was also prepared. ${ }^{133}$

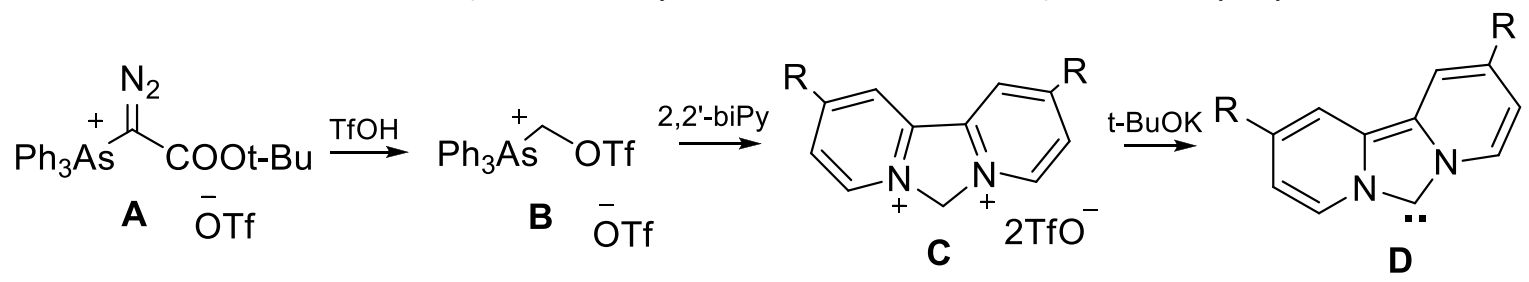

Scheme 29. Synthesis of stable 1,10-diazafluoren-11-ylidenes.

Attempts have been made to prepare related carbene complexes using 2,8-dichloro- and sulfurcontaining precursors. However, the isolation of carbenes was unsuccessful ${ }^{142}$ due to decomposition of the carbene during deprotonation of the precursor salt.

The syntheses of carbenoid imidazolium salts 30D, for the preparation of anion-fused imidazol-2-ylidenes of the Arduengo type (pentalene analogues), were implemented using a substitution reaction on imidazole rings (Scheme 30). However, after the addition of potassium tert-butoxide to the salt in THF solution only the pentalene $30 \mathrm{E}$ was formed, and further attempts at deprotonation were unsuccessful. ${ }^{143}$ Nevertheless, desired compounds of ferrocene containing the imidazol-2-thione $30 \mathrm{~F}^{144}$ and related transition metal complexes $^{145}$ have been obtained. Using the chloro-substituted derivative $30 \mathrm{C}$ and an appropriate salt the ruthenium complex 30G was synthesized, it being nearest to the target pentalene-carbene in terms of its structure. ${ }^{146}$

The syntheses of salts and complexes of the fused derivatives of imidazol-2-ylidene and analogues of the type 31A,B have been carried out in studies by Metallinos, ${ }^{147-149}$ and Grubbs et al. ${ }^{150}$ (Scheme 31).

Following the publication of a paper ${ }^{151}$ in which 5-substituted palladium complexes of benzimidazolium-5ide have been described, the syntheses of mesoionic carbenes of the annulated type 31C can be anticipated.

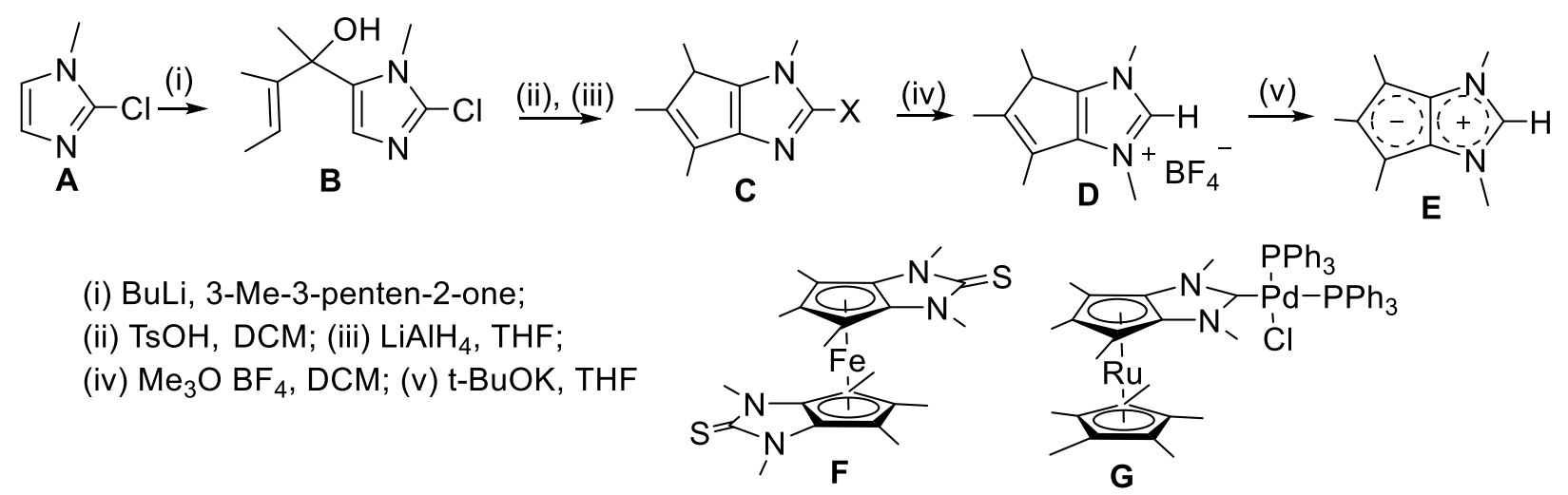

Scheme 30. Synthesis of a precarbene imidazolium annulene.

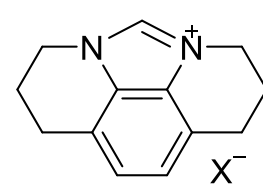

A

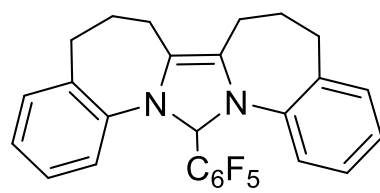

B<smiles></smiles>

C $\mathrm{Bn}$ 
Scheme 31. Aliphatic and aromatic fused carbenoids of the imidazole series.

2.2.2. Bis- tris- and polybenzimidazol-2-ylidenes. The syntheses of aromatic derivatives of the sterically shielded benzimidazol-2-ylidenes were carried out on selected annulated bisimidazol-2-ylidenebenzenes. Initially, the tetramines 32B were obtained by means of treatment of tetrabromobenzene 32A or its chloroanalogue with the respective amines, in the presence of an alkoxide and a catalytic complex of the carbene IPr with palladium acetate (Scheme 32). ${ }^{152}$ The desired bisimidazolium salts $32 \mathrm{C}$ were then synthesized by treatment of 32B with triethyl orthoformate in the presence of an acid capable of undergoing deprotonation by strong bases (potassium tert-butoxide, sodium hydride or KHMDS), ${ }^{153,154}$ thereby forming the stable carbenes 32D. Deprotonation of the asymmetric derivative 32D4 resulted in the formation of a dimer in which there are two sterically shielded carbene centers 32E.

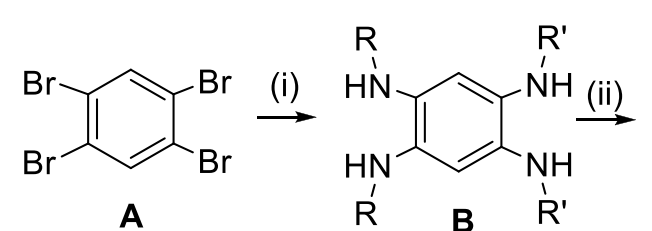<smiles>[R]n1c[n+]([R])c2cc3c(cc21)n([R])c[n+]3[R]</smiles><smiles>[CH]</smiles><smiles>[R]N1CN([Y])c2cc3c(cc21)N([R])C([O])N3[R]</smiles>

(iv) $\downarrow$ C

$B-D R=R^{\prime}=1-A d(1)$ t-Bu (2), t-Am (3); B-D (4), $E R=t-B u, R^{\prime}=M e$<smiles>[R][Y]1N([R])c2cc3c(cc2N1[R])N([R])C(=C1N([R])c2cc4c(cc2N1[R])N([R])C=[Y]N4[R])N3[R]</smiles>

(i) $\mathrm{RNH}_{2}$ or $\mathrm{R}^{\prime} \mathrm{NH}_{2}$, t-BuONa, $\mathrm{Pd}(\mathrm{OAc})_{2}$, IPr $\cdot \mathrm{HCl}$; (ii) $\mathrm{CH}(\mathrm{OEt})_{3}$, HX; (iii) LDA, PhMe; (iv) $\mathrm{NaH}, \mathrm{t}-\mathrm{BuOK}, \mathrm{PhMe}$

Scheme 32. Synthesis of bisbenzimidazol-2-ylidenes.

The building blocks of bisbenzimidazolylidene borate and bisbenzimidazol-2-ylidene phthalimide were created by reaction of the 5,6-dihydroxybenzimidazolium salt with benzene diboronic acid or from imidazo[5,6-d]phthalic anhydride with aromatic polyamines (e.g., tris-(4-aminophenyl)methane or its tetrakisanalogue. ${ }^{155,156}$ Only one individual carbene was isolated (compound 33E, Scheme 33). Unfortunately, it was not possible to characterize this compound by means of $X$-ray diffraction.

Trisbenzimidazol-2-ylidenes of the triptycene series 34D were obtained from the 9,10-dibutylhexabromotripticenes 34A by heating with tert-BuNH 2 in toluene solution in the presence of carbene complex $\mathrm{Pd}(\mathrm{OAc})_{2}$. This was followed by cyclization of the resulting diamines 34B with triethyl orthoformate in the presence of $\mathrm{HBF}_{4} \cdot \mathrm{OEt}_{2}$ and subsequent deprotonation of the salts $\mathbf{3 4 C}$ with sodium hydride in the presence of potassium tert-butoxide (Scheme 34). ${ }^{157}$ 


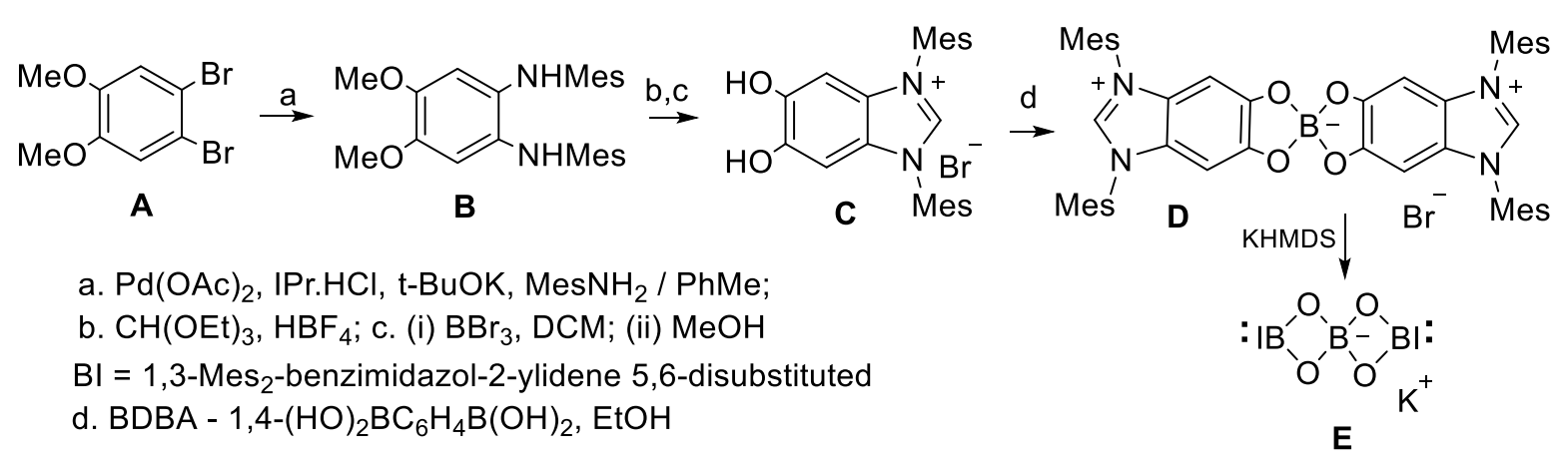

Scheme 33. Synthesis of boron containing bisbenzimidazol-2-ylidene and its precarbene.

Complexes of the conjugated 30-n, $\pi$-electron trisbenzimidazol-2-ylidenes 34E were obtained in a similar fashion starting from hexabromotriphenylene. ${ }^{158,159}$ The isolation of the triscarbenes 34E was effected by treatment of the appropriate tetrafluoroborate salts with potassium hydride in tetrahydrofuran. ${ }^{160}$

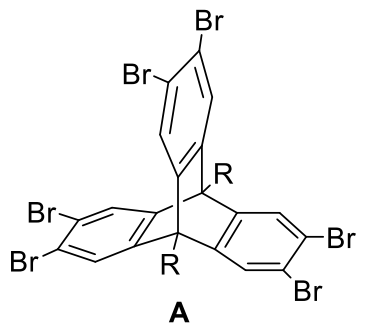

$\mathrm{R}=\mathrm{Bu}(\mathbf{1}), \mathrm{Hx}(\mathbf{2})$

(i) $\mathrm{t}-\mathrm{BuNH} \mathrm{N}_{2} / \mathrm{Pd}(\mathrm{OAC})_{2}-\mathrm{IPr} \mathrm{HCl}-$ t-BuONa / PhMe; (ii) $\mathrm{CH}(\mathrm{OEt})_{3}$ / $\mathrm{HBF}_{4} \cdot \mathrm{OEt}_{2} ;$ iii NaH, t-BuOK / THF

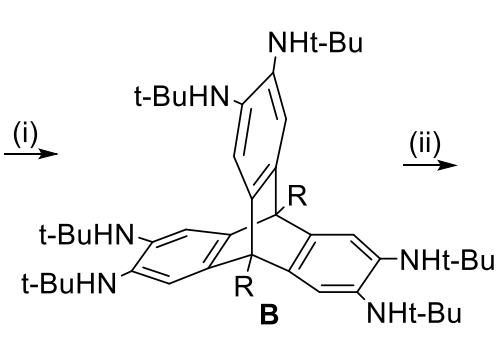

B

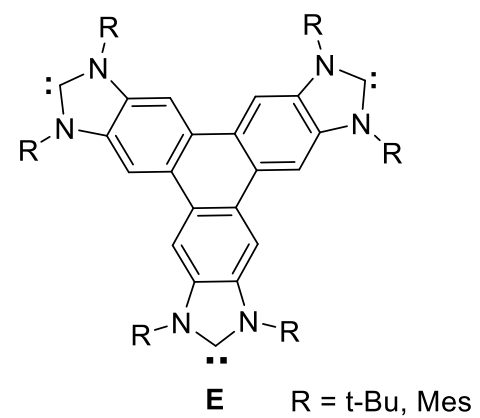

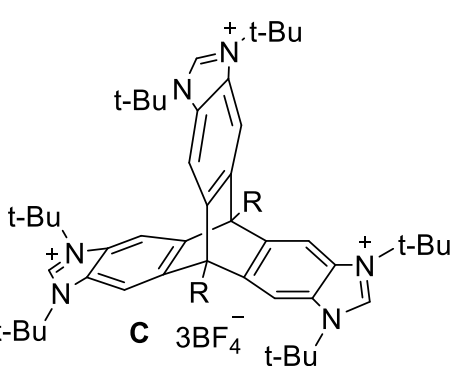

(iii)

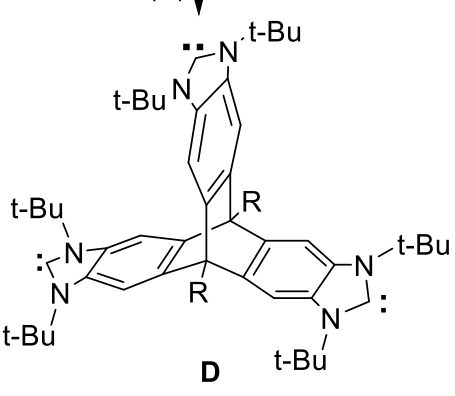

Scheme 34. Synthesis of fused trisbenzimidazol-2-ylidenes.

The polymeric carbenes 35A can be synthesized from Bielawski biscarbenes using $\mathrm{B}_{2} \mathrm{Br}_{4}$ followed by reaction of the carbene adducts with sodium naphthalenide (Scheme 35 ). ${ }^{161}$ Other polymeric structures have also been prepared. ${ }^{162}$ However, their structures are different due to the absence of terminal carbene fragments.

Promising precursors for benzimidazol-2-ylidene derivatives can be prepared from ionic benzimidazolium and imidazolium crown derivatives. These can be synthesized using benzimidazole and 1,5-dichloro-3oxapentane or 1,8-dichloro-3,6-dioxaoctane in an alkaline medium under the conditions required for phase transfer catalysis by quaternary ammonium salts, followed by quaternization of the intermediate alkylenebisbenzimidazoles with same reagents in o-dichlorobenzene. ${ }^{163,164}$ However, it was found that the deprotonation of the benzimidazolium compounds $35 \mathrm{~B}$ resulted in the formation of carbene polymers $35 \mathrm{C} .{ }^{165}$

Recent reviews of the syntheses and properties of annulated imidazolylidenes are available in the cited papers. ${ }^{166,167}$ 
<smiles>[R][Y]1N([R])c2cc3c(cc2N1[R])N([R])C(C(C)C)N3[R]</smiles>

$R=1-A d, t-B u, t-A m$

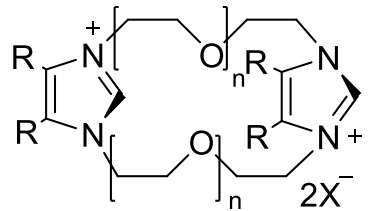

B

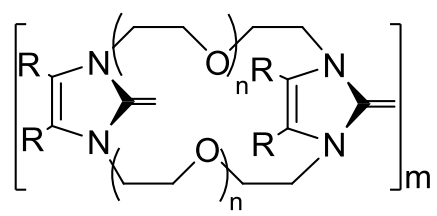

C

B: $\mathrm{R}, \mathrm{R}=(\mathrm{CH})_{4}, \mathrm{n}=1(1) ; \mathrm{R}, \mathrm{R}=(\mathrm{CH})_{4}, \mathrm{n}=2(2) ; \mathrm{R}=\mathrm{H}, \mathrm{n}=1(3) ; \mathrm{R}=\mathrm{H}, \mathrm{n}=2(4) ; \mathrm{X}=\mathrm{Cl}, \mathrm{ClO}_{4}$;

C: $\mathrm{R}, \mathrm{R}=(\mathrm{CH})_{4}, \mathrm{n}=1$

Scheme 35. Boron containing carbene polymers and new carbenoids of crown type.

\subsection{1,2,4-Triazol-5-ylidenes}

The first 1,2,4-triazol-5-ylidene $\mathbf{3 6 C}$ was synthesized by Enders et al. via deprotonation of the 1,3,4-triphenyl1,2,4-triazolium salt 36A with sodium methoxide. Further decomposition of 5-methoxytriazoline 36B occurred upon heating under vacuum at $80^{\circ} \mathrm{C}$ for $24 \mathrm{~h}$ (Scheme 36). ${ }^{168}$

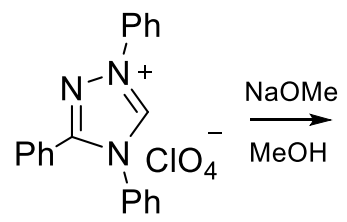

A

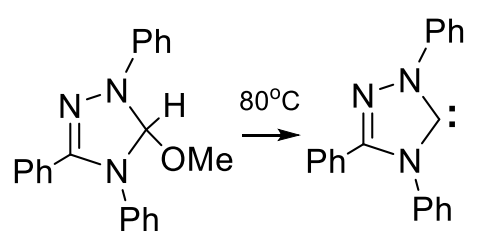

B

C

Scheme 36. Enders' synthesis of 1,3,4-triphenyl-1,2,4-triazol-5-ylidene.

For the synthesis of the precarbene 1,3,4-triphenyl-1,2,4-triazolium salt 37D, a route was developed starting from aniline and benzoyl chloride (Scheme 37). ${ }^{169}$ The overall yield of salt from aniline is $45 \%$. However, the carbenes of other derivatives of meso-unsubstituted triaryltriazolium salts have not yet been prepared and if used are generated in situ.

Recently the authors of this review have developed an alternative method for preparing the 1,3,4-triaryl1,2,4-triazolium salts $\mathbf{3 8 C}$, which is based on the reaction of phenylhydrazine with benzoyl chloride and the subsequent acylation of the product with formic acid. Vilsmeier reaction of the intermediate 38B sequentially with $\mathrm{POCl}_{3}$ and aniline (Bredereck amino-version) generates 38C (Scheme 38). ${ }^{170}$ This method permits the introduction of sterically shielding aryl groups (Mes, Dipp) to the four position of the cycle and results in a yield of salts from phenylhydrazine of $62-70 \%$. Deprotonation of these salts results in the formation of the carbenes 38D.

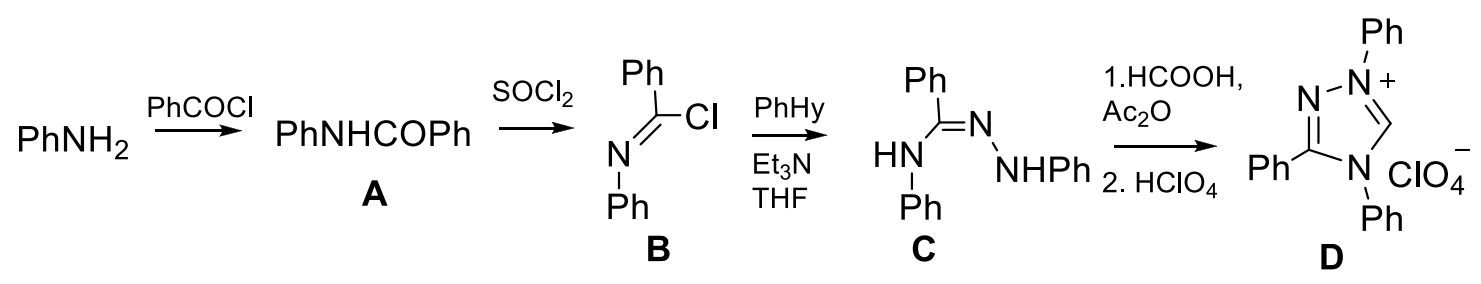

Scheme 37. Enders' synthesis of the 1,3,4-triphenyl-1,2,4-triazolium precarbene. 


$$
\underset{\mathrm{PhNHNH}}{2} \underset{\mathrm{Py}}{\mathrm{PhCOCl}} \mathrm{PhCONHNHPh} \stackrel{\mathrm{HCOOH}}{\longrightarrow} \mathrm{PhCONHNPh} \stackrel{\mathrm{Ar}=\mathrm{Ph}, \mathrm{Mes}, \mathrm{Dipp}}{\longrightarrow}
$$

Scheme 38. Synthesis of 1,2,4-triazol-5-ylidenes from phenylhydrazine.

A related approach (to pathway 37) had been used previously for the synthesis of 1-alkyl-3,4-diaryl-, 1,4dialkyl-3-aryl- and 1,3,4-trialkyl substituted 1,2,4-triazolium salts 39D, which were obtained in 41-84 \% yields. The 1-methyl-3-phenyl-4-(1,6-hexylene) substituted bis-salt was also isolated in $11 \%$ yield. In this case the reaction of chloroimidoyl chloride 39B was carried out with 1-formyl-1-alkylhydrazines 39C (Scheme 39). ${ }^{171}$

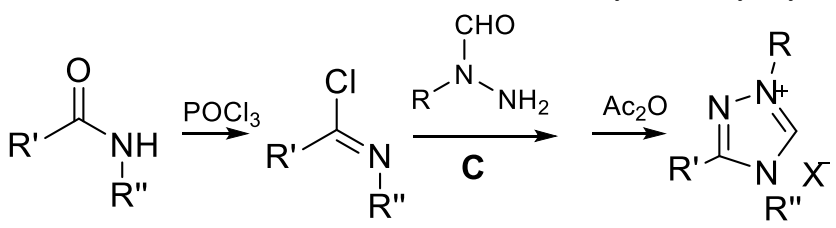

A

B

D

$\mathrm{R}=\mathrm{Me} ; \mathrm{R}^{\prime}=\mathrm{Me}, \mathrm{Ph} ; \mathrm{R}^{\prime \prime}=\mathrm{Me}$, chiral Alk

Scheme 39. Synthesis of 1,2,4-triazolium precarbenes from amides.

Similar transformations (to pathways 37 and 39) were carried out to obtain fused analogues of triazolium salts of the type 40A-E (Scheme 40). ${ }^{172-181}$ For example, salt 40D was prepared by the methylation of amides with trimethyloxonium tetrafluoroborate. This was followed by further hydrazination of the resulting methoxyazine 41B and finally cyclization of the hydrazino derivative 41C with triethyl orthoformate (Scheme 41). ${ }^{172}$ Similarly, compound $40 \mathrm{~A}$ was prepared from the corresponding azolidone. ${ }^{172}$ Carbenes from compounds 40A-D and their analogues have not yet been isolated.

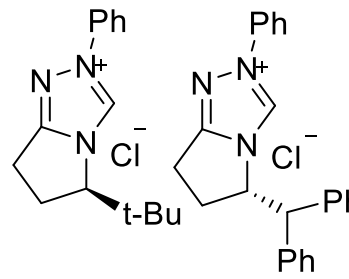

A
B

$$
\text { C R }=\mathrm{Ph}, \mathrm{Me} ; \mathrm{R}^{\prime}=\mathrm{TMS}, \mathrm{TBS}
$$

D<smiles></smiles><smiles></smiles>

E

Scheme 40. Fused 1,2,4-triazolium precarbenes.

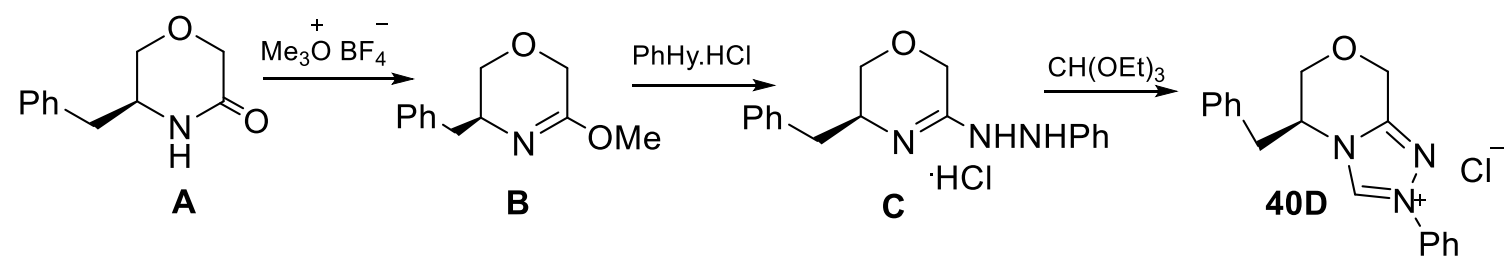


Scheme 41. Synthesis of one of the fused 1,2,4-triazolium precarbenes.

The fused systems just described have been used for carbene catalysis of organic reactions. Stable carbenes were generated in the reaction mixture in the presence of bases (alkoxides, hexamethyldisilazanides of metals, etc. $)^{24,177,82-194}$

Syntheses of the 1-alkyl-3,4-diaryl-1,2,4-triazol-5-ylidenes 42D have now been developed in more detail. Substituents in the 1-, 3- and 4-positions have all been varied, including the formation of fluoroaryl substituted compounds (Scheme 42). ${ }^{32,51,85,104,195-198}$

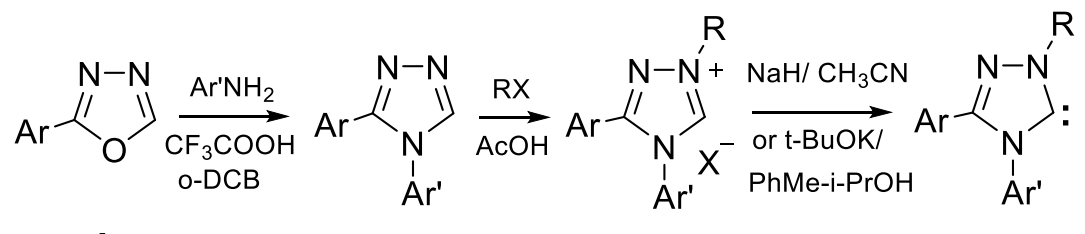

A

B C1-22

D1-22

C,D: $\mathrm{R}=1-\mathrm{Ad}, \mathrm{Ar}=\mathrm{Ar} \mathrm{r}^{\prime}=\mathrm{Ph}(1) ; \mathrm{R}=1-\mathrm{Ad}, \mathrm{Ar}=\mathrm{Ph}, \mathrm{Ar} \mathrm{r}^{\prime}=\mathrm{p}-\mathrm{Br}_{-}-\mathrm{C}_{6} \mathrm{H}_{4}(2) ; \mathrm{R}=1-\mathrm{Ad}, \mathrm{Ar}=\mathrm{Ar}=\mathrm{p}-\mathrm{Br}-\mathrm{C}_{6} \mathrm{H}_{4}(3)$;

$\mathrm{R}=1-\mathrm{Ad}, \mathrm{Ar}=\mathrm{Ph}, \mathrm{Ar}^{\prime}=\mathrm{C}_{10} \mathrm{H}_{7}(4) ; \mathrm{R}=\mathrm{t}-\mathrm{Bu}, \mathrm{Ar}=\mathrm{Ar}{ }^{\prime}=\mathrm{Ph}(5) ; \mathrm{R}=\mathrm{t}-\mathrm{Bu}, \mathrm{Ar}=\mathrm{Ph}, \mathrm{Ar}{ }^{\prime}=\mathrm{p}-\mathrm{Br}-\mathrm{C}_{6} \mathrm{H}_{4}(6) ; \mathrm{R}=\mathrm{t}-\mathrm{Bu}$,

$\mathrm{Ar}=\mathrm{Ar}{ }^{\prime}=\mathrm{p}-\mathrm{Br}-\mathrm{C}_{6} \mathrm{H}_{4}(7) ; \mathrm{R}=\mathrm{t}-\mathrm{Bu}, \mathrm{Ar}=0-\mathrm{Cl}_{-} \mathrm{C}_{6} \mathrm{H}_{4}, \mathrm{Ar} \mathrm{r}^{\prime}=\mathrm{Ph}(8) ; \mathrm{R}=\mathrm{t}-\mathrm{Bu}, \mathrm{Ar}=\mathrm{Ph}, \mathrm{Ar} r^{\prime}=\mathrm{p}-\mathrm{F}-\mathrm{C}_{6} \mathrm{H}_{4}(9) ; \mathrm{R}=\mathrm{t}-\mathrm{Bu}$,

$\mathrm{Ar}=\mathrm{o}-\mathrm{Cl}-\mathrm{C}_{6} \mathrm{H}_{4}, \mathrm{Ar} \mathrm{r}^{\prime}=\mathrm{p}-\mathrm{F}-\mathrm{C}_{6} \mathrm{H}_{4}(\mathbf{1 0}) ; \mathrm{R}=\mathrm{t}-\mathrm{Bu}, \mathrm{Ar}=\mathrm{Ph}, \mathrm{Ar} \mathrm{r}^{\prime}=\mathrm{m}-\mathrm{F}-\mathrm{C}_{6} \mathrm{H}_{4}(\mathbf{1 1}) ; \mathrm{R}=\mathrm{t}-\mathrm{Bu}, \mathrm{Ar}=\mathrm{o}-\mathrm{Cl}-\mathrm{C}_{6} \mathrm{H}_{4}, \mathrm{Ar} r^{\prime}=\mathrm{m}-\mathrm{F}-\mathrm{C}_{6} \mathrm{H}_{4}$ (12); $\mathrm{R}=\mathrm{t}-\mathrm{Bu}, \mathrm{Ar}=\mathrm{Ph}, \mathrm{Ar}=2,4-\mathrm{F}_{2}-\mathrm{C}_{6} \mathrm{H}_{3}(13) ; \mathrm{R}=\mathrm{t}-\mathrm{Bu}, \mathrm{Ar}=\mathrm{Ph}, \mathrm{Ar}^{\prime}=2,3,4-\mathrm{F}_{3}-\mathrm{C}_{6} \mathrm{H}_{2}(14) ; \mathrm{R}=1-\mathrm{Ad}, \mathrm{Ar}=\mathrm{Ph}, \mathrm{Ar}=$ $\operatorname{Mes}(15) ; R=t-B u, A r=P h, A r^{\prime}=\operatorname{Mes}(16) ; R=t-B u, A r=P h, A r^{\prime}=\operatorname{Dipp}(17) ; R=1-A d, A r=P h, A r^{\prime}=\operatorname{Dipp}(18) ; R$ $=1-\mathrm{Ad}, \mathrm{Ar}=\mathrm{Ph}, \mathrm{Ar}^{\prime}=\mathrm{Dbmp}(19) ; \mathrm{R}=\mathrm{Ar}=\mathrm{Ar} r^{\prime}=\mathrm{Ph}(20) ; \mathrm{R}=\mathrm{Ar}=\mathrm{Ph}, \mathrm{Ar} r^{\prime}=\mathrm{Mes}(21) ; \mathrm{R}=\mathrm{Ar}=\mathrm{Ph}, \operatorname{Ar}=\operatorname{Dipp}(22)$.

Scheme 42. Synthesis of 1-alkyl-3,4-diaryl-1,2,4-triazol-5-ylidenes from 1,3,4-oxadiazoles.

These syntheses require the deprotonation of the salts $\mathbf{4 2 C}$, using either sodium hydride in acetonitrile (the acetonitrile method) or metal alkoxides in a mixture of alcohol and an aromatic solvent (the toluenealcohol method). The first method results in the formation of the pure carbenes 42D, which precipitate from the acetonitrile solutions in the form of weak solvates. However, when sufficiently soluble, the triazolylidenes react relatively rapidly to form new products after insertion into the $\mathrm{C}-\mathrm{H}$ bond of the acetonitrile. ${ }^{104}$

The second (toluene-alcohol) method is universal and proceeds well in pure aromatic solvents. The carbene center is protected in the presence of alcohol due to the formation of 5-alkoxyazolines. As a consequence, it becomes less sensitive to environmental factors (traces of moisture, oxygen, etc.) thus permitting the isolation of pure samples of the carbenes.

The precarbenes $\mathbf{4 2 C}$ were obtained after ring transformations of the 2-aryl-1,3,4-oxadiazoles 42A with anilines, ${ }^{199}$ followed by quaternization of the intermediate triazoles with 1-adamantyl bromide $42 \mathrm{~B}$ or tertbutyl iodide in acetic acid. The quaternization reaction under these conditions is directed solely at position 1 , whereas methylation results in a $25 \%$ yield of the 2 -substituted isomer. Several carbenes, sterically shielded at positions 1 (tert-butyl, 1-adamantyl) and 4 (Mes, Dipp and lately Dbmp) 42D9-13, have been produced using this method, which confirms a wide range of possible uses for this synthetic scheme. ${ }^{51,169}$

New phosphanylated 1,2,4-triazol-5-ylidenes 43A were synthesized by deprotonation of the respective triazolium sats, which, in turn, were obtained by quaternization of the corresponding triazoles with phosphanyl bromides or phosphanyltriazoles with alkyltriflates ${ }^{200,201}$.

The above methods can be used to prepare a number of individual conjugated biscarbenes of the 1,2,4triazole type $\left(\mathrm{X}=p-\mathrm{C}_{6} \mathrm{H}_{4}, m-\mathrm{C}_{6} \mathrm{H}_{4}\right)$, as well as for the aliphatic bridged structures (compounds 43B, 43C) (Scheme 43). ${ }^{202-204}$ The acetonitrile method is best for the synthesis of compounds 43B. On the other hand, a 
mixture of alcohol and toluene is preferred for the synthesis of 43C. The predominant isomers of the biscarbenes adopt trans-configurations. Similar to Arduengo's 1,3-dimesityl-4,5-dichloroimidazol-2-ylidene, ${ }^{57}$ these compounds are among the most stable carbenes known, both thermally and chemically (they can be saved, without significant changes, open to the air for several days). Recently, this method has also been used for the generation of carbenes with 4-[2-(dimethylaminomethyl)phenyl] substituted 1,2,4-triazolylidenes. These were then utilized for the preparation of palladium complexes. ${ }^{205,206}$<smiles></smiles>

A1-3<smiles></smiles>

B1-4<smiles></smiles>

C1,2<smiles>[R][n+]1cn(-n2cn[n+]([R])c2)cn1</smiles>

D

$A: \mathrm{R}=\mathrm{t}-\mathrm{Bu}, \mathrm{R}^{\prime}=\mathrm{Me}(1)$, Et (2), i-Pr (3); $\mathrm{B}: \mathrm{R}=1-\mathrm{Ad}, \mathrm{Ar}=\mathrm{Ph}, \mathrm{X}=p-\mathrm{C}_{6} \mathrm{H}_{4}(1) ; \mathrm{R}=1-\mathrm{Ad}, \mathrm{Ar}=\mathrm{Ph}$

$\mathrm{X}=m-\mathrm{C}_{6} \mathrm{H}_{4}(2) ; \mathrm{R}=1-\mathrm{Ad}, \mathrm{Ar}=\mathrm{Ph}, \mathrm{X}=\left(\mathrm{CH}_{2}\right)_{4}(3) ; \mathrm{R}=\mathrm{t}-\mathrm{Bu}, \mathrm{Ar}=\mathrm{Ph}, \mathrm{X}=p-\mathrm{C}_{6} \mathrm{H}_{4}(4)$;

C: $\mathrm{R}=1-\mathrm{Ad}, \mathrm{X}=p-\mathrm{C}_{6} \mathrm{H}_{4}(1) ; \mathrm{R}=1-\mathrm{Ad}, \mathrm{X}=m-\mathrm{C}_{6} \mathrm{H}_{4}(2)$;

Scheme 43. Stable phosphanyl substituted 1,2,4-triazol-5-ylidenes A, conjugated bis-1,2,4-triazol-5-ylidenes

B,C and precarbene $\mathbf{D}$.

Peris et al. 207,208 proposed using bistriazolylidene ligands for the synthesis of precursors to $43 \mathrm{C}$, prior to the generation of metal complexes. However, carbenes of this type have not yet been prepared. Furthermore, the compounds $\mathbf{4 3 C}$ are the bis-heterocyclic analogues of 3,5-unsubstituted mono-1,2,4-triazolium salts. These undergo deprotonation with strong bases even in aprotic media, thereby resulting in ring closure to 1-cyanoamidines. ${ }^{209}$

1,2,4-Triazolium salts with electron withdrawing groups (3-nitro and 4-(2,4-dinitrophenyl)) have been used for the preparation of rhodium complexes (structures $42 \mathrm{C}$ ). ${ }^{210}$ Compounds of this type could be some of the least electron donating carbenes known. However, none have yet been isolated.

The only condensed derivatives of 1,2,4-triazol-5-ylidenes were synthesized in the work described in Scheme 44. ${ }^{211}$ Synthesis of the salt 44C was carried out starting from 2-pyridylhydrazine 44A and trialkyloxonium tetrafluoroborate and triethylorthoformate, enabled the formation of 44B. Subsequent deprotonation with sodium hydride in THF produced the pure carbenes $\mathbf{4 4 C}$ that can be stored indefinitely in the solid state. However, if the deprotonation in THF is carried out in the presence of potassium carbonate, irreversible formation of the carbene dimers, as mixtures of the cis- and trans-isomers, occurs. This data supports the hypothesis concerning the catalytic character of carbene dimerization in a heterocyclic series; protic compounds (water, alcohols, acids, meso-unsubstituted azolium salts, etc.) accelerate the process. The cyclization of the related arylsubstituted hydrazines proceeds similarly (in the presence of $\mathrm{NH}_{4} \mathrm{PF}_{6}$ ) to the salts 44B $\left(R^{\prime}=A r\right) .{ }^{211}$

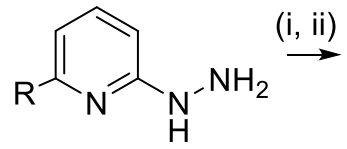

A

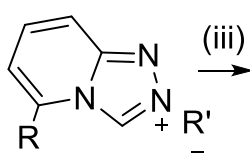

B $\mathrm{BF}_{4}^{-}$

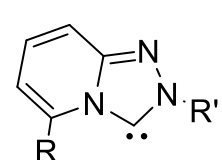

C

$$
\mathrm{R}=\mathrm{H}, \mathrm{Me} \quad \text { (i) } \mathrm{R}_{3}^{\prime} \mathrm{OBF}_{4} \text {; (ii) } \mathrm{CH}(\mathrm{OEt})_{3} \text {; (iii) } \mathrm{NaH}, \mathrm{THF}
$$

Scheme 44. Synthesis of N-annulated 1,2,4-triazol-5-ylidenes. 


\subsection{Hyperbasic and hypernucleophilic anionic carbenes}

The terms "hyperbasic and hypernucleophilic (HBN) carbenes" were proposed to designate structures in which the introduction of anionic centers to the carbene molecule leads to fundamental changes in the carbene's properties. Included are significant increases of their basicities and nucleophilicities by charge transfer to the carbene center via the conjugation chain. ${ }^{21,212}$ This outcome is particularly clear in the cases of oxido-, sulfido-, imido-, phosphido- and other related structures of the type 45A, all of which exert their influence via an aromatic ring (Scheme 45). The phenoxides and phenothioxides themselves do not possess high basicities and proton affinities (PAs). However, the PA of the carbene center under their influence increases very significantly (PA from 230-285 for neutral carbenes to 330-460 Kcal/mol for hyperbasic systems). In structures with basic nitrogen or carbon-containing anionic centers these centers can be competitive with the carbenic carbon. However, the significant impact of the anionic center on the basicity and nucleophilicity of the carbene is also preserved in these cases.

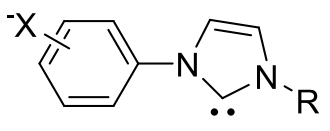

A $X=O, S, N R, P R$

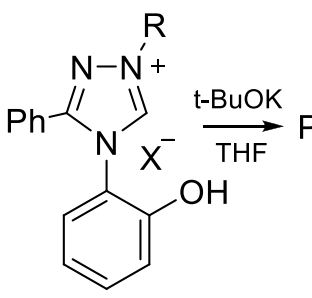

B

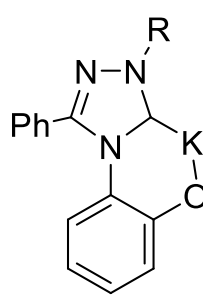

C

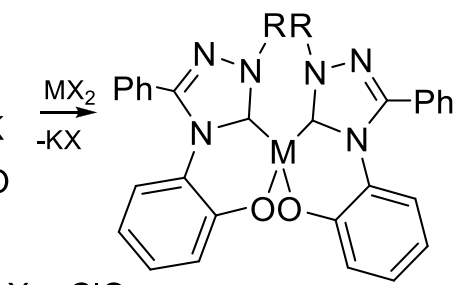

$\mathrm{X}=\mathrm{ClO}_{4}$
$\mathrm{M}=\mathrm{Ni}, \mathrm{Pd}$
D

Scheme 45. Synthesis of HBN 1,2,4-triazol-5-ylidene complexes.

Transition metal complexes of such HBN-carbenes on the non-aromatic objects, e.g. 4,5-dihydroimidazol2-ylidenes were synthesized by Grubbs and Hoveyda, ${ }^{213,214}$ and heteroaromatic complexes of HBN-carbenes with alkali metals such as 45C have been described in the following papers (Scheme 45). ${ }^{198,215,216}$ These compounds can be considered to be chelated complexes of anionic carbenes. The heteroaromatic complexes 45D were obtained by replacing the potassium in the precursor with nickel or palladium.

Bielawski et al. developed a synthesis for similar chelated palladium complexes of the benzimidazole series using the reaction of $N$-(hydroxyphenyl)benzimidazolium salts with palladium acetate in THF. This was followed by the addition of sodium carbonate to the intermediate carbene complexes, and finally by their cyclization in a mixture of THF and methanol. ${ }^{217}$ Alternatively, bisbenzimidazolium salts in DMSO could be used to form chelated organometallic polymers. Alkali metal complexes of this type have not yet been synthesized.

Attempts to synthesize the HBN-carbene $46 \mathrm{~B}$ were made later, ${ }^{21,218,219}$ by deprotonation of 1,4 -diphenyl1,2,4-triazolium-3-phenylimide 46A ("nitron") with potassium tert-butoxide in THF (Scheme 46). However, in the presence of small amounts of oxygen the oxidation of carbene 46B resulted in the formation of the azoamidine 46C.

It was found that the mesoion 46A is a generator of the carbene 46D. The difference in their energies was found to be only $6.2 \mathrm{Kcal} / \mathrm{mol}$. However, this also allowed the generation of carbene complexes of copper(I) 47C,D upon boiling of 47A and copper(I) salts in acetonitrile solutions (Scheme 47).

Later, Siemeling et al. produced similar rhodium carbene complexes, $\mathrm{LRh}(\mathrm{CO}){ }_{2} \mathrm{Cl},{ }^{220}$ and phosphinocarbene ruthenium complexes, in which there is bonding participation at the ortho-position of the aromatic carbene ring. 221 
Interestingly, intra- and intermolecular anionic carbene generated systems (carbenoids) have been described recently for the imidazolium $N$-uracylides ${ }^{222}$ and for the zwitterionic azolium indolides ${ }^{223,224}$ (anionic center at the nitrogen atom), the imidazolium- $N$-fluorenides ${ }^{225}$ (anionic center at the carbon atom), and the imidazolium carboxylates 224 (and references therein). However, these systems are not related to the HBN anionic carbenes.

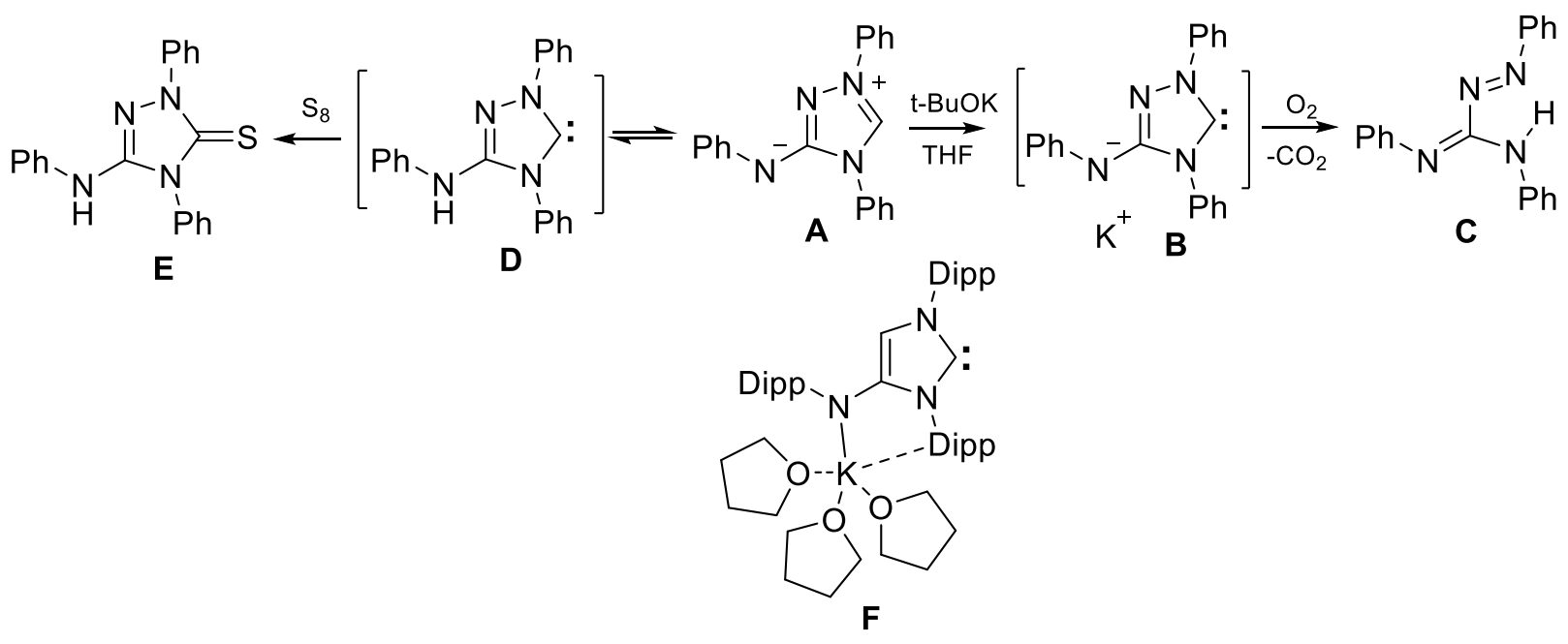

Scheme 46. Reactions of an HBN-carbene with oxygen and its precarbene with sulfur.

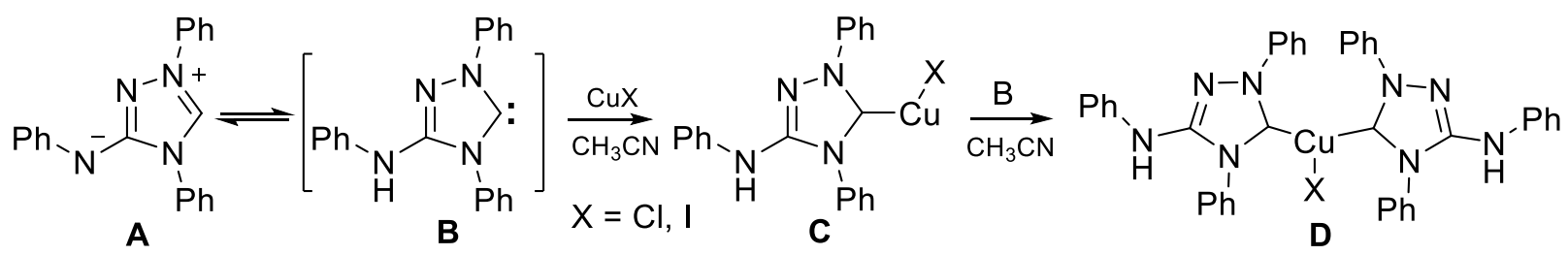

Scheme 47. Carbenoid reactions of 1,4-diphenyl-1,2,4-triazolium-3-phenylimide with copper(I) salts.

An important development in the chemistry of HBN carbenes of the type 46B was made by Danopoulos et al., ${ }^{226}$ who succeeded in synthesizing a similar, but more sterically shielded, structure of the imidazol-2-ylidene series, namely the THF complex 46F. In this case the precursor zwitterion was treated with benzylpotassium $(\mathrm{KBn})$ in THF solution. If the ratio of the mesoion to KBn was changed, polymer associated structures were formed. The interaction of the potassium cation with the nitrogen atom, rather than the carbene center, is probably due to the hardness of the potassium atom relative to transition metals such as copper, rhodium, etc. Nickel ions (in $\mathrm{NiCl}_{2}$ ) are also harder and react with the nitrogen atoms of the mesoion. ${ }^{218}$ Thus, in the presence of anionic centers on the nitrogen atoms of a hyperbasic carbene, there is a competition between the carbene and the anionic center, the outcome of which depends on the basicity and hardness of the anionic center.

The $C$-anionic carbenes are also related to HBNs in that they are formed by the additional deprotonation of heterocyclic azolylidene nuclei. Such carbenes have been used by Liddle and Arnold for in situ experiments involving the synthesis of transition metal carbene complexes. ${ }^{227}$ Subsequently, Robinson et al. succeeded in preparing stable complexes of both anionic carbenes and alkali metals. ${ }^{228}$ Initially, the reaction of butyllithium 
with the imidazol-2-ylidenes $48 \mathrm{~A}$ in THF solution, and in the presence of TMEDA or lithium in the same solvent, produced the oligomeric lithium complexes 48B,C (Scheme 48).

(iv)

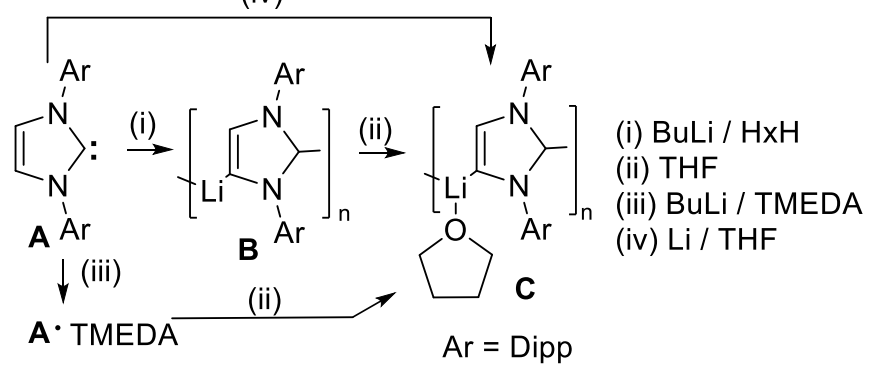

Scheme 48. Synthesis of HBN-carbenes from imidazol-2-ylidenes.

The reaction of the latter with Lewis acids resulted in boron, silicon and aluminum derivatives, etc. Treatment with potassium tert-butoxide produced the complexes 48B,C. The potassium analogues were also synthesized, ${ }^{229}$ and it was discovered that potassium can be exchanged for other metals (for example, with their hexamethyldisilazanides).

A new phosphanide containing an HBNC of the imidazol-2-ylidene series was synthesized as a complex with alkali metal cations and 12 -crown-4 (Scheme 49). ${ }^{230}$ For this purpose the reactions of the phosphanylimidazole-2-thione 49A or its bis-analogue 49C with potassium were carried out in THF solution thereby producing the mesoion 49B. Treatment of the latter with butyllithium or KHMDS resulted in the formation of the HBN-carbene complex 49D.

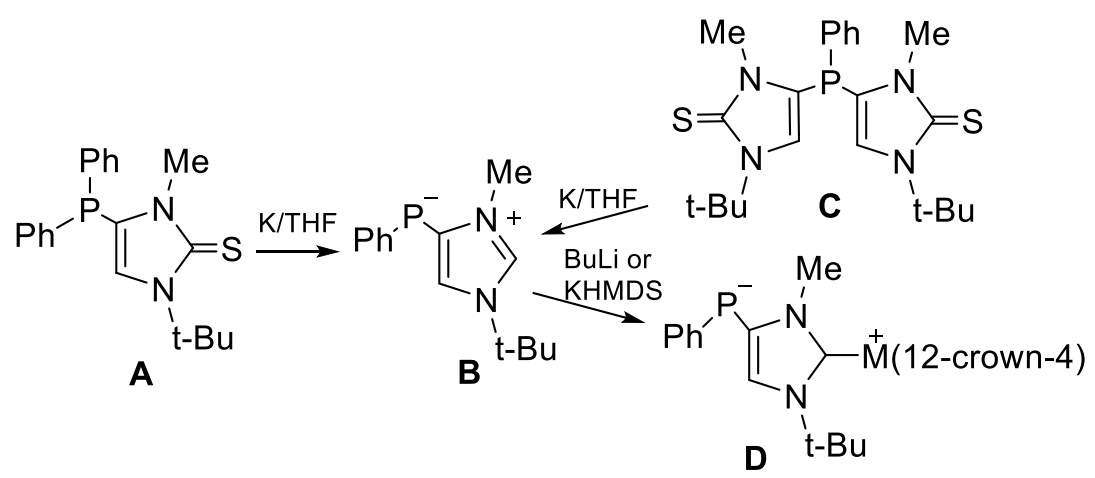

Scheme 49. Synthesis of phosphanide substituted HBN imidazol-2-ylidenes.

Anionic carbenes which have no conjugation between the heterocyclic nucleus and the anionic center are not of the HBN-type. However, a stable structure 50D that features two potassium cations has been synthesized recently by Arduengo et al. (Scheme 50). ${ }^{231}$ The basicities of the anions are significantly reduced due to the influence of the trifluoromethyl groups. The aim of the study was to create tridentate carbene ligands. The replacement of the potassium atoms by a nickel cation resulted in the formation of a chelated carbene-alkoxide complex of nickel(II). However, the paper does not include any data regarding the interaction between the potassium atoms and the carbene center in compound 50D. The syntheses of the precursors for these carbenes were carried out using 1,1-bis(trifluoromethyl)oxirane and imidazole according to Scheme 50. 


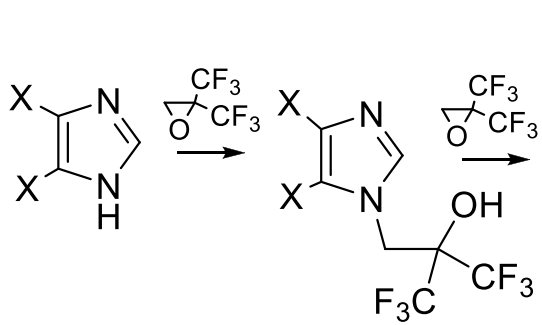

A

B<smiles></smiles>

C

$$
\mathrm{X}=\mathrm{H}, \mathrm{Cl}, \mathrm{Ph}
$$

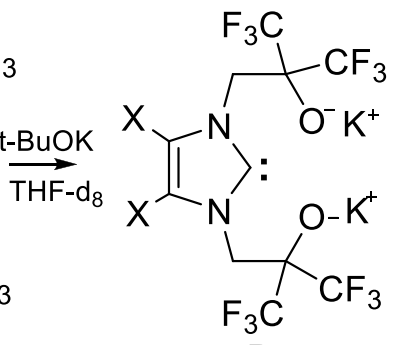

D

Scheme 50. Synthesis of imidazol-2-ylidene alkoxides.

\subsection{Mesoionic carbenes}

2.5.1. Imidazolium-4-ides. The so-called mesoionic (abnormal) carbenes (or more precisely intracyclic mesoions) in which the negative charge is localized on a ring carbon atom, were synthesized for the first time by Bertrand ${ }^{232-235}$ (for their carbene complexes see refs 236, 237 and reviews ${ }^{238-242}$ ). Strong bases, such as potassium hexamethyldisilazanide, were used to obtain the imidazolium-4-ides. Weaker bases, such as potassium tert-butoxide, were employed to obtain the 1,2,3-triazolium-5-ides. As an example, Scheme 51 illustrates the preparation of the Dipp-substituted imidazolium-4-ides 51D. ${ }^{233}$ Precursors for the imidazolium4-ides of the type 51D were synthesized from the corresponding sterically shielded benzamidines 51A and haloketones, followed by cyclization of the intermediates 51B under acidic dehydration conditions. ${ }^{232,233}$

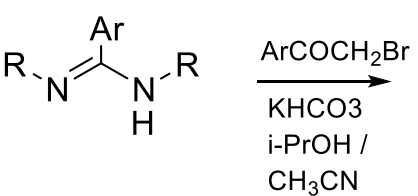

A

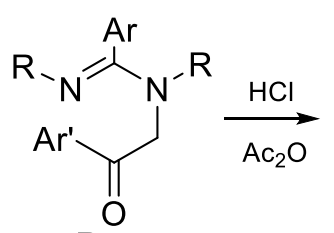

B

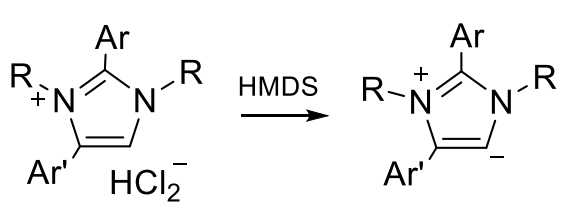

C

$\mathrm{R}=$ Dipp; $\mathrm{Ar}=\mathrm{Ph}, 3,5-\left(\mathrm{CF}_{3}\right)_{2} \mathrm{C}_{6} \mathrm{H}_{3} ; \mathrm{Ar}=\mathrm{Ph}, \mathrm{p}-\mathrm{FC}_{6} \mathrm{H}_{4}, \mathrm{p}-\mathrm{ClC}_{6} \mathrm{H}_{4}, \mathrm{p}-\mathrm{BrC}_{6} \mathrm{H}_{4}, \mathrm{p}-\mathrm{CF}_{3} \mathrm{C}_{6} \mathrm{H}_{4}$, Tol, p- $\mathrm{MeOC}_{6} \mathrm{H}_{4}, 3,5-\left(\mathrm{CF}_{3}\right)_{2} \mathrm{C}_{6} \mathrm{H}_{3}$;

Scheme 51. Synthesis of stable mesoionic carbenes imidazolium-4-ides.

2.5.2. 1,2,3-Triazolium-5-ides. The starting 1,2,3-triazolium salts were obtained by cycloaddition of $1,3-$ diaryltriazenium salts to acetylenes ${ }^{235}$ or by quaternization of the corresponding 1,2,3-triazoles, which in turn were synthesized by click-cycloaddition of azides to acetylenes in the presence of copper(II) compounds. ${ }^{243}$ The individual 1,2,3-triazolium-5-ides $\mathbf{5 2 C}$ were synthesized by deprotonation of the appropriate 1,2,3triazolium salts 52B with potassium tert-butoxide or KHMDS in THF or ether solutions (Scheme 52). ${ }^{234}$ Similarly, the pyrazolium-4-ide 52D was synthesized from a 3,5-diphenoxypyrazolium salt in which the distribution of electron density is more like that of a conjugated cyclic allene. ${ }^{232}$

Stable potassium carbazolide complexes of 1,2,3-triazolium-5-ides 53 C have been synthesized in a similar fashion (Scheme 53). ${ }^{244}$ The replacement of potassium by copper or nickel results in the respective transition metal complexes. 


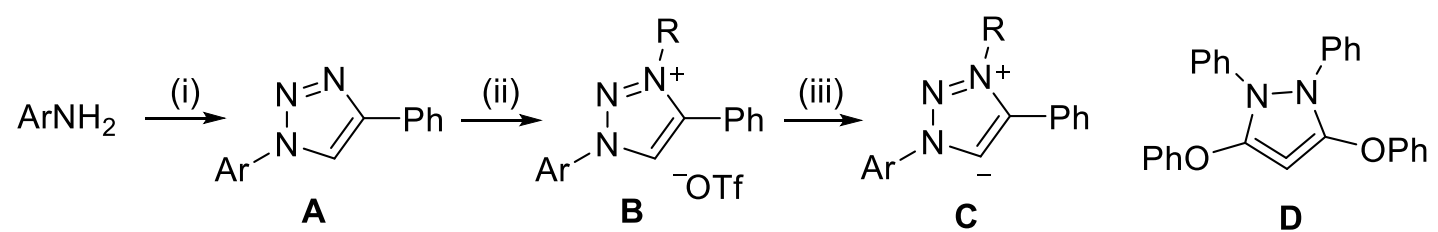

(i) 1. t-BuONO, $\mathrm{Me}_{3} \mathrm{SiN}_{3} / \mathrm{CH}_{3} \mathrm{CN}$; 2. $\mathrm{PhCCH} / \mathrm{CuSO}_{4}, \mathrm{Na}$ ascorbate; (ii) ROTf / DCM;

(iii) $\mathrm{KHMDS} / \mathrm{Et}_{2} \mathrm{O}$. $\mathrm{R}=\mathrm{Me}$, i-Pr.

Scheme 52. Synthesis of stable 1,2,3-triazolium-5-ides $\mathbf{C}$ and structure of a cyclic allene $\mathbf{D}$.

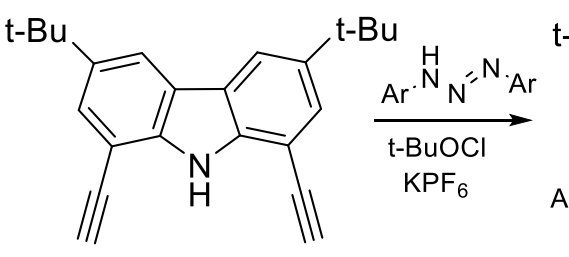

A $\quad \operatorname{Ar}=\operatorname{Dipp}$

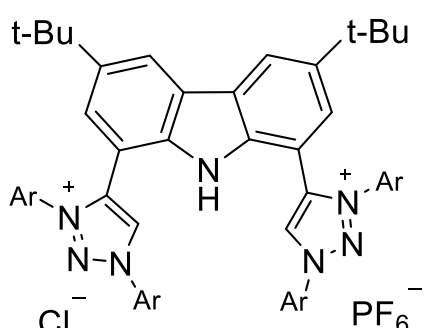

B

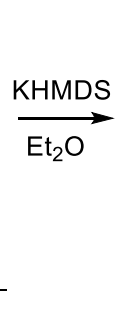

$\underset{\mathrm{E}}{2} \mathrm{O}$

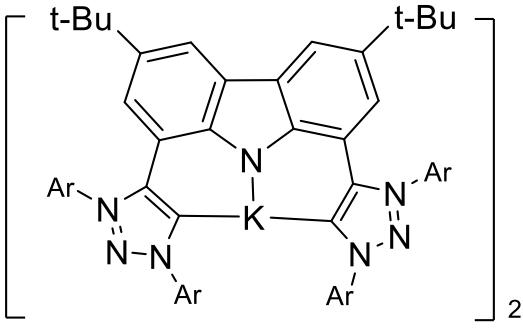

C

Scheme 53. Synthesis of potassium bis-1,2,3-triazolium-5-ide carbazolide complexes.

\section{Physical Properties of Stable Carbenes}

\section{1. ${ }^{1} \mathrm{H}$ and ${ }^{13} \mathrm{C}$ NMR spectra}

In the ${ }^{1} \mathrm{H}$ NMR spectra, the proton signals of virtually all the ring carbene atoms are shifted upfield with respect to those in the spectra of their corresponding salts. Also noteworthy is the unusual deshielding of the nitrogen connected to adamantyl $\mathrm{CH}_{2}$ protons in the spectra of carbenes $20 \mathrm{E}$ and 42D1-4, which causes a downfield shift, by $0.2-0.3 \mathrm{ppm}$, with respect to the signals for their salt analogues. ${ }^{104}$

In the ${ }^{13} \mathrm{C}$ NMR spectra (Table 1) the most important signals are those for the carbenic carbon atoms. In carbenes these are known to cover a wide range, $\delta 184-381$ ppm $^{245}$ (for the respective precarbenes 114-193 ppm). However, for the specific group of compounds of the azole series, this range is narrowed significantly, $\delta$ 190-235 ppm (for their precarbenes 114-150 ppm).

The $N$-aryl derivatives of the imidazol-2-ylidenes (e.g., 1D4,2D1,2, 2E2) are typically deshielded by a larger amount than are their aliphatic analogues (1D2,3,2D4). The effect of the $N$-substituents on the chemical shift is larger than that for $C$-substituents (cf. 1D2, 1E2; 2D1, 6G). In the NMR spectrum of the imidazol-2-ylidene 2E2 steric shielding should result from the branched aromatic substituents (2,6-dibenzhydryl-4-ethylphenyl, dbep). However, the $\delta$ value for $\mathrm{C} 2$ is almost the same (218.5 ppm) as that observed for 1,3-dimesitylimidazol2-ylidene 2D1 (219.7 ppm), implying that there is no significant anisotropic effect of the aromatic nuclei at the carbenic center. The chemical shift of the carbenic carbon atom in the compound 4D (222.9 ppm) is reminiscent of that for compound 2E2. The introduction of electron withdrawing groups into a structure (benzoyl, trifluoromethylsulfonyl, diphenylchlorosilyl, dimesitylboryl) causes downfield shifts (8C1,6, and $11 \mathrm{C}, \mathrm{E})$. However, the simultaneous presence of electron donors reduces the change in $\delta(\mathbf{8 C 2})$. The electron donating influence naturally causes an upfield chemical shift of the C2 signal ( $\delta 190$ ppm for 12D, 195.8 ppm 
Table 1. Typical ${ }^{13} \mathrm{C}$ NMR chemical shifts of the carbenic carbon atoms, bond lengths and angles at the carbenic carbon atoms for individual compounds of the imidazole, 1,2,4- and 1,2,3-triazole, and fused series (carbene numbering and references are as indicated in the text). For notes see end of table

\begin{tabular}{|c|c|c|c|c|c|c|}
\hline Carbene & $\mathrm{R}$ & $R^{\prime}, R^{\prime \prime}$ or $X$ & $\delta \mathrm{C}_{\text {carbene }}$ & $\mathrm{N}-\mathrm{C}$ or $\mathrm{C}-\mathrm{C}$ & Bond order* & Ref. \\
\hline \multirow{2}{*}{ 1D2 } & \multirow{2}{*}{$\mathrm{Ad}$} & \multirow{2}{*}{$\mathrm{H}$} & \multirow{2}{*}{211.4} & 1.367 & 1.615 & \multirow{2}{*}{4} \\
\hline & & & & 1.373 & 1.580 & \\
\hline 1D3 & $t$-Bu & $\mathrm{H}$ & 213.2 & 1.362 & 1.644 & 38 \\
\hline \multirow{2}{*}{ 1D4 } & \multirow{2}{*}{$p-\mathrm{MeC}_{6} \mathrm{H}_{4}$} & \multirow{2}{*}{$\mathrm{H}$} & \multirow{2}{*}{215.8} & 1.371 & 1.592 & \multirow{2}{*}{5} \\
\hline & & & & 1.375 & 1.569 & \\
\hline \multirow{2}{*}{ 2D1 } & \multirow{2}{*}{ Mes } & \multirow{2}{*}{$\mathrm{H}$} & \multirow{2}{*}{219.7} & 1.365 & 1.626 & \multirow{2}{*}{5} \\
\hline & & & & 1.371 & 1.592 & \\
\hline 2D2 & Dipp & $\mathrm{H}$ & 220.6 & 1.367 & 1.615 & 46 \\
\hline 2D4 & $\mathrm{CD}_{3}$ & $\mathrm{CD}_{3}$ & 212.5 & 1.364 & 1.632 & 39 \\
\hline \multirow{2}{*}{$2 \mathrm{E} 2$} & \multirow{2}{*}{ Dbep } & \multirow{2}{*}{$\mathrm{H}$} & \multirow{2}{*}{218.5} & 1.364 & 1.632 & \multirow{2}{*}{52} \\
\hline & & & & 1.368 & 1.639 & \\
\hline 1E1 & $\mathrm{Ph}$ & $\mathrm{Ph}$ & 219.6 & 1.369 & 1.603 & 40 \\
\hline $1 E 2$ & $\mathrm{Ad}$ & $\mathrm{Ph}$ & 211.4 & - & - & 45 \\
\hline 6G & Mes & $\mathrm{Cl}$ & 219.9 & 1.364 & 1.632 & 57 \\
\hline 4D & $* 1$ & $\mathrm{H}$ & 222.9 & - & - & 55 \\
\hline \multirow{2}{*}{$5 A$} & Dipp. & \multirow{2}{*}{$\mathrm{H}$} & \multirow{2}{*}{-} & 1.366 & 1.621 & \multirow{2}{*}{56} \\
\hline & 6- $\mathrm{Me}_{3} \mathrm{SiPy}$ & & & 1.360 & 1.655 & \\
\hline \multirow[t]{2}{*}{ 5B } & Dipp. & \multirow[t]{2}{*}{$\mathrm{H}$} & \multirow[t]{2}{*}{-} & 1.367 & 1.615 & 56 \\
\hline & $\mathrm{Ph}_{2} \mathrm{P}$-ethyl & & & 1.378 & 1.552 & \\
\hline 7D & Mes & $* 2 . \mathrm{H}$ & 220.3 & 1.363 & 1.638 & 57 \\
\hline & & & & 1.366 & 1.621 & \\
\hline $8 \mathrm{C} 1$ & Dipp & $\mathrm{PhCO}, \mathrm{H}$ & 227.2 & 1.372 & 1.586 & 60 \\
\hline & & & & 1.351 & 1.707 & \\
\hline $8 C 2$ & Dipp & $\mathrm{Ph}_{2} \mathrm{P}, \mathrm{PhCO}$ & 217.7 & - & - & 60 \\
\hline $8 C 3$ & Dipp & $\mathrm{Cl}, \mathrm{H}$ & 222.5 & - & - & 60 \\
\hline $8 C 4$ & Dipp & $\mathrm{Br}, \mathrm{H}$ & 223.3 & - & - & 60 \\
\hline $8 C 5$ & Dipp & $\mathrm{Ph}_{2} \mathrm{P}, \mathrm{H}$ & 223.5 & - & - & 60 \\
\hline $8 C 6$ & Dipp & $\mathrm{CF}_{3} \mathrm{SO}, \mathrm{H}$ & 231.6 & - & - & 60 \\
\hline $8 C 7$ & Dipp & $\mathrm{Me}_{3} \mathrm{Si}, \mathrm{H}$ & 223.7 & - & - & 60 \\
\hline 9F & $\mathrm{C}_{6} \mathrm{H}_{4} \mathrm{NMe}_{2}$ & $\mathrm{NMe}_{2}$ & 208.4 & - & - & 63 \\
\hline $10 C 1$ & $\mathrm{P}(t-\mathrm{Bu})_{2}$ & $\mathrm{Ad}$ & 222.0 & - & - & 65 \\
\hline $10 C 2$ & $\mathrm{P}(t-\mathrm{Bu})_{2}$ & $\mathrm{t}-\mathrm{Bu}$ & 222.7 & - & - & 65 \\
\hline $11 E$ & Dipp & $\mathrm{Ph}_{2} \mathrm{SiCl}$ & 225.88 & 1.373 & 1.580 & 67 \\
\hline & & & & 1.380 & 1.540 & \\
\hline $11 C$ & $t-B u$ & $\mathrm{Mes}_{2} \mathrm{~B}$ & 224.6 & 1.364 & 1.632 & 68 \\
\hline & & & & 1.373 & 1.580 & \\
\hline 12D & $p$-Tol & $\mathrm{NMe}_{2}$ & 190.0 & - & - & 69 \\
\hline
\end{tabular}




\begin{tabular}{lllllll}
\hline $13 C$ & $* 3$ & $\mathrm{H}$ & 208.7 & - & - & 72 \\
$15 \mathrm{C}$ & $i-\mathrm{Pr}$ & $\mathrm{H}$ & 195.8 & - & - & 78 \\
\hline
\end{tabular}

Table 1. Continued

\begin{tabular}{|c|c|c|c|c|c|c|}
\hline Carbene & $\mathbf{R}$ & $\mathbf{R}^{\prime}, \mathbf{R}^{\prime \prime}$ or $\mathrm{X}$ & $\delta C_{\text {carb }}$ & $\mathrm{N}-\mathrm{C}$ or $\mathrm{C}-\mathrm{C}$ & Bond order* & Ref. \\
\hline \multirow{2}{*}{ 16D } & \multirow{2}{*}{$* 3$} & \multirow{2}{*}{$\mathrm{H}$} & \multirow{2}{*}{212.6} & 1.364 & 1.632 & \multirow{2}{*}{85} \\
\hline & & & & 1.357 & 1.672 & \\
\hline $17 \mathrm{~A} 1$ & $\mathrm{Me}$ & $\left(\mathrm{CH}_{2}\right)_{2}$ & 215.9 & - & - & 90 \\
\hline \multirow{2}{*}{ 17A2 } & \multirow{2}{*}{ Mes } & \multirow{2}{*}{$\mathrm{CH}_{2}$} & \multirow{2}{*}{218.0} & 1.370 & 1.644 & \multirow{2}{*}{91} \\
\hline & & & & 1.362 & 1.598 & \\
\hline \multirow{2}{*}{$17 A 3$} & \multirow{2}{*}{ Dipp } & Pyridin- & \multirow{2}{*}{217.4} & 1.359 & 1.661 & \multirow{2}{*}{93} \\
\hline & & 2,6-diyl & & 1.372 & 1.586 & \\
\hline 17B & $t-B u$ & $\mathrm{H}$ & 215.3 & - & - & 92 \\
\hline \multirow{2}{*}{$18 \mathrm{~B}$} & \multirow{2}{*}{ Dipp } & \multirow{2}{*}{$\mathrm{Ph}_{2} \mathrm{Si}$} & \multirow{2}{*}{226.3} & 1.367 & \multirow{2}{*}{1.615} & \multirow{2}{*}{67} \\
\hline & & & & 1.367 & & \\
\hline 19D & $t-\mathrm{Bu}$ & $\mathrm{Ph}_{2} \mathrm{Si}$ & 212.01 & - & - & 101 \\
\hline \multirow{2}{*}{$20 \mathrm{E}$} & \multirow{2}{*}{$\mathrm{Ad}$} & \multirow{2}{*}{$(\mathrm{CH})_{4}$} & \multirow{2}{*}{229.0} & \multirow{2}{*}{1.374} & 1.575 & \multirow{2}{*}{104} \\
\hline & & & & & 1.586 & \\
\hline 21D & $\mathrm{Np}$ & $(\mathrm{CH})_{4}$ & 231.5 & 1.361 & 1.649 & 106 \\
\hline & & & & 1.387 & 1.500 & \\
\hline $22 \mathrm{~A}$ & $P(t-B u)_{2}$ & Me & 235.4 & 1.355 & 1.684 & 110 \\
\hline $22 \mathrm{~A}$ & $\mathrm{P}(t-\mathrm{Bu})_{2}$ & $\mathrm{Ad}$ & 233.8 & - & - & 65 \\
\hline $22 A$ & $\mathrm{P}(t-\mathrm{Bu})_{2}$ & $\mathrm{t}-\mathrm{Bu}$ & 234.1 & - & - & 65 \\
\hline 24A1 & $\mathrm{Np}$ & - & 235.2 & - & - & 113 \\
\hline $24 A 2$ & $\mathrm{~Np}$ & - & 235.8 & - & - & 113 \\
\hline & & & & 1.379 & 1.546 & \\
\hline 24D & Dipp & - & - & 1.377 & 1.557 & 116 \\
\hline 24E1 & $\mathrm{Bu}$ & $\mathrm{MeC} * \mathrm{HPh}$ & 223.3 & - & - & 121 \\
\hline 24E2 & $\mathrm{Bn}$ & $\mathrm{MeC}^{*} \mathrm{HPh}$ & 225.1 & - & - & 121 \\
\hline 24E3 & $\mathrm{Bu}$ & $\mathrm{Bu}$ & 225.1 & - & - & 120 \\
\hline 24E4 & o-Tol & o-Tol & $\begin{array}{c}224.5 \\
224,9\end{array}$ & - & - & 122 \\
\hline & & & & 1.389 & 1.489 & \\
\hline 27C1 & Me & $\mathrm{H}, \mathrm{H}, \mathrm{H}$ & 209.7 & 1.355 & 1.684 & 132 \\
\hline $27 C 1$ & Mes & $\mathrm{H}, \mathrm{H}, \mathrm{Me}$ & 206.9 & - & - & 133 \\
\hline 29D1 & - & $\mathrm{H}$ & 197.8 & - & - & 139 \\
\hline 29D2 & _- & $t-B u$ & 1963 & 1,374 & 1,575 & 133 \\
\hline 2902 & - & $t-B u$ & 196.3 & 1,380 & 1,540 & 133 \\
\hline 32D1 & $1-\mathrm{Ad}$ & _ & 2276 & 1,369 & 1,603 & 153 \\
\hline 3201 & I-Ad & - & 221.6 & 1,368 & 1,609 & 153 \\
\hline 32D2 & $t-\mathrm{Bu}$ & - & 228.3 & - & - & 153 \\
\hline 32D3 & $t-A m$ & - & 230.2 & - & - & 153 \\
\hline 34D & $t-\mathrm{Bu}$ & $\mathrm{Hx}$ & 225.8 & 1.379 & 1.546 & 157 \\
\hline $34 \mathrm{E}$ & $t-\mathrm{Bu}$ & - & 230.4 & 1.370 & 1.598 & 160 \\
\hline
\end{tabular}


1.374

1.575

34E

Mes

231.4

160

Table 1. Continued

\begin{tabular}{|c|c|c|c|c|c|c|}
\hline Carbene & $\mathbf{R}$ & $R^{\prime}, R^{\prime \prime}$ or X & $\delta C_{\text {carb }}$ & $\mathrm{N}-\mathrm{C}$ or C-C & Bond order* & Ref. \\
\hline \multirow{2}{*}{$36 C$} & \multirow{2}{*}{$\mathrm{Ph}$} & \multirow{2}{*}{$\mathrm{Ph}$} & \multirow{2}{*}{214.6} & 1.351 & 1.707 & \multirow{2}{*}{168} \\
\hline & & & & 1.373 & 1.580 & \\
\hline \multirow{2}{*}{ 42D2 } & \multirow{2}{*}{$\mathrm{Ad}$} & Ph, & \multirow{2}{*}{210.6} & 1.346 & 1.736 & \multirow{2}{*}{195} \\
\hline & & $\mathrm{C}_{6} \mathrm{H}_{4} \mathrm{Br}-p$ & & 1.384 & 1.517 & \\
\hline \multirow{2}{*}{ 42D2 } & \multirow{2}{*}{$\mathrm{Ad}$} & $\mathrm{Ph}$ & \multirow{2}{*}{210.6} & 1.346 & 1.736 & \multirow{2}{*}{195} \\
\hline & & $\mathrm{C}_{6} \mathrm{H}_{4} \mathrm{Br}-p$ & & 1.384 & 1.517 & \\
\hline \multirow{2}{*}{ 42D6 } & \multirow{2}{*}{$t-\mathrm{Bu}$} & $\mathrm{Ph}$ & \multirow{2}{*}{207.8} & 1.335 & 1.799 & \multirow{2}{*}{196} \\
\hline & & $\mathrm{C}_{6} \mathrm{H}_{4} \mathrm{Br}-p$ & & 1.388 & 1.494 & \\
\hline \multirow{2}{*}{ 42D17 } & \multirow{2}{*}{$t-B u$} & \multirow{2}{*}{ Ph, Dipp } & \multirow{2}{*}{213.0} & 1.349 & 1.718 & \multirow{2}{*}{51} \\
\hline & & & & 1.384 & 1.517 & \\
\hline \multirow{2}{*}{ 43A4 } & \multirow{2}{*}{$t-B u$} & \multirow{2}{*}{$\mathrm{C}_{6} \mathrm{H}_{4}-p$} & \multirow{2}{*}{202.9} & 1.343 & 1.753 & \multirow{2}{*}{202} \\
\hline & & & & 1.385 & 1.511 & \\
\hline \multirow{2}{*}{ 43B1 } & \multirow{2}{*}{$\mathrm{Ad}$} & \multirow{2}{*}{$\mathrm{C}_{6} \mathrm{H}_{4}-p$} & \multirow{2}{*}{206.2} & 1.338 & 1.782 & 201 \\
\hline & & & & 1.390 & 1.483 & 204 \\
\hline 44D & $\mathrm{H}$ & Me & 203.8 & - & - & 211 \\
\hline $46 \mathrm{~F}$ & Dipn & Dipn & 205.99 & 1.347 & 1.730 & 226 \\
\hline & & & & 1.389 & 1.489 & \\
\hline A8R & Dinn & $\mathrm{H}$ & & 1.375 & 1.569 & 228 \\
\hline 400 & 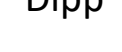 & $\Pi$ & - & 1.361 & 1.649 & $2<0$ \\
\hline 49D & $M=L i$ & - & 212.8 & - & - & 230 \\
\hline 49D & $M=k$ & - & 2125 & 1.385 & 1.511 & 230 \\
\hline & & & & 1.354 & 1.690 & \\
\hline 50D & - & $X=H$ & 218.34 & - & - & 231 \\
\hline 51D & Dipp & $\mathrm{Ph}$ & $* 4$ & 1.417 & 1.328 & 232 \\
\hline & & & & 1.383 & 1.766 & \\
\hline $52 \mathrm{C}$ & Dipp & $\mathrm{Ph}, \mathrm{Me}$ & 202.1 & 1.366 & 1.620 & 243 \\
\hline & & & & 1.405 & 1.653 & \\
\hline $53 C$ & Dipp & $t-B_{u}$ & 1948 & 1.374 & 1.575 & 244 \\
\hline & & & & 1.408 & 1.640 & 244 \\
\hline
\end{tabular}

Notes to Table 1. ${ }^{*}$ The bond orders were calculated according to their linear dependence from the bond lengths of the simplest comparable compounds. ${ }^{246}{ }^{* 1} \mathrm{R}=\mathrm{DippN}=\mathrm{C}(\mathrm{Me}) ;{ }^{* 2} \mathrm{R}=\mathrm{Ph}_{2} \mathrm{PCH}$ (Mes); ${ }^{* 3}$ According to the structure; ${ }^{* 4}$ For tetraphenyl derivative $\delta 201.9$ ppm. ${ }^{232}$

least $208.7 \mathrm{ppm}$ for $13 \mathrm{C}$ ). The same can be said about the signal of the diphosphanyl substituted carbene $9 \mathrm{~F}$ ( $\delta$ $208.4 \mathrm{ppm})$. The influence of the di-tert-butylphosphanyl group is close to that of the aromatic analogues $(10 C 1,2)$. In the spectra of the biscarbenes 17A1-3, 17B the chemical shift of C2 is a function of the substituents, and there is little mutual influence of the nuclei. The influence of the diphenylsilylene bridge in 18B is larger and $\delta$ rises markedly (226.3 ppm). 
The fused analogues of the imidazol-2-ylidenes 20E, 21B, 22A, 24A exhibit chemical shifts in the ${ }^{13} \mathrm{C} N M R$ spectra that are almost $18 \mathrm{ppm}$ deshielded (i.e. to lower field) than those of their unfused analogues (cf. 20E and 2D2); these fall in the range of $229-236 \mathrm{ppm}$. The chemical shifts of the carbenic carbon atoms for the phenanthrene fused compounds 24E1-4 are 223-225 ppm and therefore somewhat deshielded than those for the imidazol-2-ylidenes. In contrast, they are more shielded than those for the 2-benzimidazol-2-ylidenes (for the diadamantyl derivative $20 \mathrm{E}$ the value is $229 \mathrm{ppm}$, while for the neopentyl substituted analogue 21D the value is $231.5 \mathrm{ppm}$ ). This may imply an electron donating impact on the fused carbenic carbon atom. However, in the spectra of the aza-fused analogues $\mathbf{2 7 C}, \delta$ of C2 is significantly shielded (up to $209.7 \mathrm{ppm}$ ). Moreover, in the spectra of the diaza-fused compounds 29D1,2, $\delta$ of C2 passes the threshold of 200 ppm (196.3, 197.8 $\mathrm{ppm})$. It is likely that this outcome arises from the significant influence of the electron donating nitrogen atoms. The chemical shifts of C2 for the compounds 32D, 34D,E are comparable to those for their mononuclear fused analogues.

In the case of the 1,2,4-triazol-5-ylidenes, an even wider variation in the structure does not substantially change the $\delta$ (C5) value (203-215 ppm). For the sterically shielded carbenes of the 1,2,4-triazole series 42D (aryl, Mes, or Dipp in the 4-position) the signals for the C5 atoms are shifted somewhat downfield ( $\delta 211.5-213$ $\mathrm{ppm}){ }^{51}$ In the case of the biscarbenes that feature five aromatic rings, 43A,B, the C5 signals of the triazolylidene nuclei are shifted upfield (up to 203-206 ppm) versus $208 \mathrm{ppm}$ for the aliphatically connected 3,3'-bridged biscarbenes. This is probably due to conjugation between the nuclei. The increased thermal and chemical stabilities of these compounds also support this idea. In the aza-annulated triazolylidene 44D the carbenic carbon signal is strongly shifted upfield (203.8 ppm) in comparison with that of its imidazolylidene analogue 27C.

In the case of the HBN-carbene 46F the expected upfield shift of the signal for the C2 atom ( $\delta 206 \mathrm{ppm}$ ) was observed, in comparison with the same signal for its neutral analogues. The signal for the phosphanide carbene 49D, even in complexes with lithium and potassium cations, was found to be in the range of 212-213 ppm.

In the spectra of the imidazolium-4-ides 51D the $\mathrm{C} 4$ signals were found to be in the same range as those for C5 of 1,2,3-triazolium-5-ides 52C (201 - 202 ppm). ${ }^{232,243}$

\subsection{Structures}

The bond lengths at the carbenic carbon atoms of the imidazol-2-ylidenes (Table 1) do not differ significantly for open and sterically shielded aryl substituted structures (the bond orders at the carbene carbon atom $p$ are 1.55-1.64). With the introduction of the electron withdrawing benzoyl group (8C1), the order at one of the bonds increased to 1.71. In the case of the adamantyl- and aryl- substituted carbenes 1D2,3 and 1E1,2, the angle at the C2 atom increased by almost one degree with respect to those for other derivatives. For the 1,3di-(1-adamantyl)benzimidazol-2-ylidene 20E, the bond angle at the carbenic carbon atom increased by $1.6^{\circ}$ relative to that of the imidazol-2-ylidene 1D2. This increase occurs in concert with an increase in the chemical shift of the $\mathrm{C} 2$ atom in the ${ }^{13} \mathrm{C}$ NMR spectra. As in the Dipp-substituted imidazol-2-ylidenes, in the Dbepsubstituted carbenes the $\mathrm{N}$-aromatic nuclei are located in an almost perpendicular fashion with respect to the imidazole nucleus.

The structural characteristics of the 30-n, $\pi$ electron compound 34E are similar to those of the 1,3-di-(1adamantyl)benzimidazol-2-ylidene $20 \mathrm{E}$, despite the considerable chain conjugation in the planar aromatic system.

In the case of the 1,2,4-triazol-5-ylidenes and their conjugated analogues, the bond length N1-C5 is shorter and C5-N4 is longer for the N1-alkyl substituted carbenes relative to those for the more conjugated 
$\mathrm{N} 1$-aryl substituted analogues. This is indicative of an increased contribution of the ylidic resonance form (for compound 42D6 up to $80 \%$ ( $p$ to 1.80)).

In imidazolium-4-ides, the C-C5 bonds are substantially elongated (for the $\operatorname{Dipp}_{2} \mathrm{Ph}_{2}$ derivative $p$ is 1.77 ) and the C4-N3 bonds are shortened ( $p$ is 1.33) due to interaction with the aromatic ring. The bond angle at the anionic carbon atom is $101.0^{\circ}$.

In the case of the 1,2,3-triazolium-5-ides the nature of the bonds is similar to the above. For example, the C4-C5 bond for the Dipp 2 PhMe derivative is elongated relative to those for the imidazolium-4-ides ( $p$ is 1.65) and the C4-N3 bond is shortened ( $p$ is 1.65), thus implying a stronger interaction of these atoms than in the case of the imidazolium-4-ides. The bond angle at the anionic center is even smaller $\left(99.7^{\circ}\right)$ than those of the imidazolium-4-ides.

\subsection{Basicities and electron donating properties}

The basicities of the imidazol-2-ylidenes have been determined in several studies of individual carbenes, using indicator compounds with similar acidities (usually within two units of $\mathrm{p} K_{\mathrm{a}}$ ), NMR or spectroscopic methods (see, e.g., refs 247-249), and they fall in the range of $\mathrm{p} K_{\mathrm{a}}$ 19.6-24.0 (in THF). For 1,3-diisopropylimidazol-2ylidene, taking into account ionic pairs, a $\mathrm{pK}_{\mathrm{a}}$ value of 23.04 was obtained in DMSO.1,3-di-tert-butylimidazol-2ylidene gave values of 22.2 in DMSO and 20.0 in THF. ${ }^{248}$ Using the ${ }^{1} \mathrm{H}$ NMR method with comparison to fluorene, 1,3-di-(1-adamantyl)benzimidazol-2-ylidene 20E and 1-tert-butyl-3,4-diphenyl-1,2,4-triazol-5-ylidene 42D6 gave indices of 23.4 and 21.6 (in benzene- $\mathrm{d}_{6}$ ), respectively. ${ }^{21}$

For a series of imidazol-2-ylidenes, $\mathrm{p} K_{\mathrm{a}}$ evaluations were carried out in aqueous media by studying the deprotonation equilibria of their respective imidazolium salts. ${ }^{250,251}$ Specific values were obtained for the diaryl (Mes and Dipp) substituted carbenes (20.8, 21.1), along with those for the di-tert-butyl (25.2) and di(1adamantyl) (25.4) derivatives. ${ }^{250}$

For the bridged carbene 17A the $\mathrm{p} K_{\mathrm{a}}$ value in water was found to be 19.9. However, upon transition to the dimethylene bridged compound, the $\mathrm{p} K_{\mathrm{a}}$ value increased to 21.6, and for the trimethylene analogue the value was determined to be 22.3. For the 3,4-aliphatic annulated derivatives of 1,2,4-triazol-5-ylidenes the $\mathrm{p} K_{\mathrm{a}} \mathrm{S}$ were found to be in the range of $16.8-18.5$ (in $\mathrm{H}_{2} \mathrm{O}$ ). ${ }^{252}$

The basicities of a number of stable heterocyclic carbenes have been calculated ${ }^{253}$ on the basis of their free energies in an appropriate solvent, which for imidazol-2-ylidenes in DMSO fall in the range 16.1-24.5 (cf. for 1,3-dimethyl-5,6-dihydro-4H-pyrimidin-2-ylidene, 27.9, and 3-methylthiazol-2-ylidene, 14.6).

Detailed characteristics of the basicities have been presented in a review paper. ${ }^{254}$ Usually, basicities are changed automatically to proton affinities, although definite deviations have been observed (see, for example reference 253).

According to the calculations of the review authors, the proton affinities PA of the aromatic derivatives of imidazol-2-ylidenes differ only slightly from one another (Ph - 263.7, Mes - 274.6, Dipp - 272.5, Dbp - 274.2, Ttbp $269.8 \mathrm{Kcal} / \mathrm{mol}$, calculated at the level DFT/B3LYP5/3-21G/RHF). There is some reduction for the phenyl and tris-tert-butylphenyl derivatives as such systems have substantial differences in their steric buried volumes. The steric influence of the substituents in these cases has been transferred to the proton affinities of the system: the effects of the tert-butyl groups acting through the aromatic nucleus are conspicuous when they are located in ortho-positions. The reduction of the PA for the diphenyl derivative, with respect to the Mes and Dipp-substituted imidazol-2-ylidenes, is apparently due to electronic factors (the absence of donor alkyl groups).

The PA of 1,3-dimethylimidazol-2-ylidene is significantly less than that of its 1,3-di-(1-adamantyl) analogue ( 265.0 versus $277.2 \mathrm{Kcal} / \mathrm{mol})$, due to an increase of the electron donating effect of the alkyl group in the 
latter. Overall, for carbenes with a considerable steric effect (Dbp, Dbmp, Dbep, etc.) the proton accepting properties are probably close to those for the related Mes- and Dipp-substituted compounds.

Benzimidazol-2-ylidenes are slightly inferior to imidazol-2-ylidenes in terms of their PAs (for the 1,3dimethyl derivative the PA value is 264.2 , while that for the 1,3-di-(1-adamantyl) derivative is $274.9 \mathrm{Kcal} / \mathrm{mol}$ ). The 1,2,4-triazol-5-ylidenes are significantly more proton accepting (for the aromatic derivative of 1-tert-butyl3,4-diphenyl-1,2,4-triazol-5-ylidene the PA value is $265.3 \mathrm{Kcal} / \mathrm{mol}$, while that for 1,4-dimethyl-1,2,4-triazol-5ylidene is $250.3 \mathrm{Kcal} / \mathrm{mol}$ ).

The previously unknown 1,2,3,5-tetramesitylimidazolium-4-ide has a very high PA (300.3 Kcal/mol), which distinguishes it from all other carbene bases that have been studied. The 1,2,3-triazolium-5-ides have significantly smaller proton affinities, although they are still higher than those for normal carbenes of the imidazole and 1,2,4-triazole series (for 1-(1-adamantyl)-3-methyl-4-phenyl-1,2,3-triazolium-5-ides the PA is $276.4 \mathrm{Kcal} / \mathrm{mol})$.

$\sigma$-Electron donating carbene properties are usually evaluated with respect to metal atoms. It must be kept in mind that the interaction with metals is energetically different than that with a proton (Bronsted basicity). However, both properties (basicity and electron donation) are manifestations of Lewis basicity, i.e. the electron donating properties of an unshared electron pair. Although there is no fundamental difference between basicity and electron donating properties, the concrete expression of the latter depends on the specific object of the donation. Here, the nature of the metal and the structure of the compound have important implications. In early work, Tolman proposed a method to estimate electron donating properties according to the infrared frequencies of carbonyl absorption for complexes of donors with tricarbonylnickel $\mathrm{LNi}(\mathrm{CO})_{3}$ (Tolman's electronic parameter, TEP). ${ }^{255}$ Subsequently, this process was repeated with rhodium and iridium complexes of the type $\mathrm{LM}(\mathrm{CO})_{2} \mathrm{Cl}$, which can be related back to the TEP according to linear equations of the type, e.g., TEP $=0.722 v_{\text {av }}(\mathrm{CO})[\mathrm{Ir}]+593 \mathrm{~cm}^{-1},{ }^{254}$ where $\mathrm{vav}(\mathrm{CO})[\mathrm{Ir}]$ is a corresponding frequency for the related Ir complex. In this type of assessment, steric interactions of the carbene with the carbonyl groups can have a definite contribution which then reduces the electron donation. The TEP indices for a large group of carbenes have been discussed in some detail. ${ }^{254}$

The value of the TEP should harmonize with the interaction energy between the electron donor and $\mathrm{Ni}(\mathrm{CO})_{3}\left(E_{\mathrm{dn}}\right)$, both of which are easy to calculate theoretically. The $E_{\mathrm{dn}}$ indices for a selected group of carbenes were calculated by the authors of this article (at the DFT/B3LYP/3-21G/RHF level) and are given in Scheme 54. The results suggest a substantially greater electron donating effect for the heterocyclic imidazol-2-ylidenes with respect to phosphines, for the imidazol-2-ylidenes towards the 1,2,4-triazol-5-ylidenes, for the imidazolium-4-ides relative to the 1,2,4-triazolium-5-ides and for the imidazolium-4-ides compared with neutral carbenes. The strongest electron donating carbenes should be the HBN-carbenes with exocyclic anionic centers. However, despite the correspondence of $E_{d n}$ with the TEP in many cases, the moderate $E_{d n}$ value calculated for the structure $\mathbf{5 4 H}$ draws attention since its TEP index was the lowest found experimentally $\left(2029.2 \mathrm{~cm}^{-1}\right) .{ }^{256}$ The high value of $E_{\mathrm{dn}}$ calculated for the yet unknown mesoion $54 \mathrm{G}(80.0 \mathrm{Kcal} / \mathrm{mol})$ is also noteworthy (Scheme 54).

The theoretically estimated stabilities, nucleophilicities, electrophilicities and redox in dices of a number of heterocyclic carbenes have been reported 257,258 and show that mesoionic (abnormal) carbenes are generally less stable and more nucleophilic than conventional carbenes. Furthermore, the annulated and carbonylated carbenes are less nucleophilic and more electrophilic than the normal ones.

In addition to the $\sigma$-electron donating ability of carbenes, the ability to form double bonds with metals and other electrophiles is a characteristic that depends on the carbene's ability to accept $\pi$-electron density (its $\pi$-electron withdrawing properties). As a criterion of the $\pi$-electron accepting properties, the 
measurement of the chemical shifts of hetero groups bonded to the carbene ( ${ }^{31} \mathrm{P}$ and $\left.{ }^{77} \mathrm{Se}\right)$ have been proposed; ; $259-266$ these have been found to correlate, one with the other, moderately well $\left(R^{2}=0.9051\right)$. However, the correlation coefficient with the electron donating indices TEP is worse $\left(R^{2}=0.833\right) .{ }^{262} A n$ improved correlation of $\sigma$-electron donation with the NMR coupling constant ${ }^{1} \mathrm{~J}$ CSe has been reported. ${ }^{262}$ However, the data for this index are considerably scarcer than those for the chemical shifts of ${ }^{31} \mathrm{P}$ and ${ }^{77} \mathrm{Se}$. Obviously, the chemical shift of ${ }^{77} \mathrm{Se}$, as well as other NMR indices, are under the influence not only of electronic but also anisotropic shielding effects.

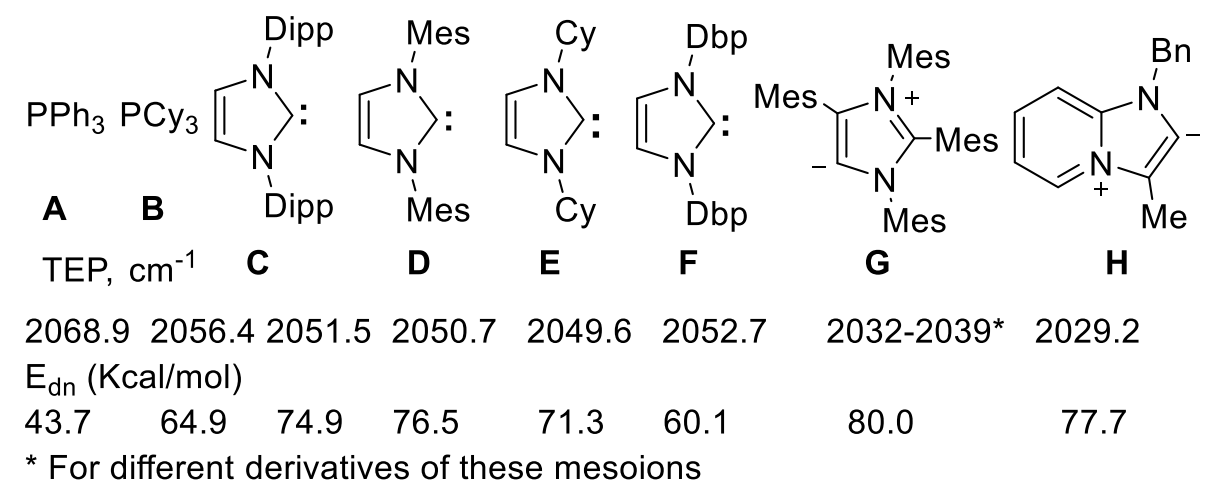

Scheme 54. Electron donating properties of stable carbenes and their analogues.

\subsection{Hyperbasic and hypernucleophilic carbenes (HBNC)}

As noted above, the introduction of anionic centers into the conjugated molecule results in fundamental changes in the properties of the carbene. A significant increase in their basicities and nucleophilicities is observed due to charge transfer along the chain of conjugation. These have been termed "hyperbasic and hypernucleophilic" carbenes (HBNC). ${ }^{21,212}$ The anionic centers can be either exocyclic or endocyclic.

According to DFT calculations (carried out at the B3LYP5/6-31G/RHF level), the proton affinities PA for carbene systems with exocyclic anionic centers range in value from 330 to $460 \mathrm{Kcal} / \mathrm{mol}$, and the affinities for copper (I) and potassium cations are 220-424 and 92-230 Kcal/mol, respectively (Scheme 55). These are significantly larger than the respective values for the neutral carbenes $(230-285,149-170$, and 26-34 $\mathrm{Kcal} / \mathrm{mol}) \cdot{ }^{21,212}$

Obviously, anionic compounds cannot exist without a cation (although they can be involved in zwitterionic complexes). Closest to the anionic carbene state are carbene complexes formed with alkali metal cations, those in which the interaction of the carbene center with the metal atom are smallest (e.g., potassium, cesium, etc.). It has been found, however, that the interaction with alkali metal cations is quite significant, although not so large as the interaction with transition metal atoms. As a consequence of the forgoing, the hydroxyl form of carbene $55 \mathrm{E} 1$ is less protonophilic (PA $258.3 \mathrm{Kcal} / \mathrm{mol}$ ) than even the primordial diphenyl substituted carbene of this series (PA $265.5 \mathrm{Kcal} / \mathrm{mol}$ ).

On the other hand, the potassium-oxide carbene 55E2 is more protonophilic than all of the known neutral nucleophilic carbenes (PA $286.3 \mathrm{Kcal} / \mathrm{mol}$ ). Furthermore, the oxide 55E3 is significantly more protonophilic than the former (PA $330.5 \mathrm{Kcal} / \mathrm{mol}$ ). The ortho-substituted compounds 55F, G are, again, even more protonophilic (PA 352 and $422 \mathrm{Kcal} / \mathrm{mol}$ ). Considering that proton affinities and basicities typically change symbatically, it can be assumed that the same conclusions can be reached about the basicities of these systems. 
The HBN-properties are particularly pronounced for the oxido-, sulfido-, and phosphido-containing aromatic derivatives of carbenes. However, they are also characteristic of nitrogen- and carbon-containing, and related, anionic conjugated carbene systems.

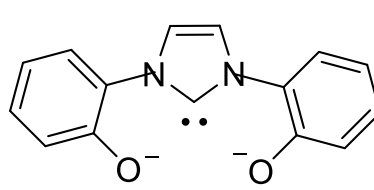

$462(399,230)$

A<smiles>[O-]c1ccccc1C1CCCN(c2ccccc2[O-])C=N1</smiles>

$432(346)$

B<smiles></smiles>

$409(287)$<smiles>CN(C1=NN(c2ccccc2)CN1Pc1ccccc1)c1ccccc1</smiles>

$337(221,77)$

D<smiles>CC(C)(C)N1CN(c2ccc(O)cc2)C(c2ccccc2)=N1</smiles>

258

E1<smiles>CC(C)(C)N1CN(c2ccc(O)cc2)C(c2ccccc2)=N1</smiles>

286<smiles></smiles>

$330(220)$

E3<smiles>CC(C)(C)N1CN(N=c2n(C(C)(C)C)cc(-c3ccccc3[O-])n2-c2ccccc2[O-])C(c2ccccc2[O-])=N1</smiles>

$352(276,92)$

$\mathbf{F}$
422

Scheme 55. Calculated $\mathrm{H}^{+}, \mathrm{Cu}^{+}$and $\mathrm{K}^{+}$affinities for oxide containing $\mathrm{HBN}$-carbenes.

In the case of the latter, a change of the most basic reaction center is possible. Typically, hyperbasic systems are formulated with alkali metal cations and anions of the type 56A-G, most of which are yet unknown (Scheme 56). ${ }^{212}$ In all of the structures the basicity of the carbene center is significantly increased with respect to that in the non-anionic (for anion protonated) carbenes (in brackets), due to the transfer of electron density from the anion center (by 75-120 Kcal/mol, calculated at the DFT/B3LYP5/3-21G/RHF level).<smiles>[W]=c1n(-c2ccccc2)nc([Nb]c2ccccc2)n1-c1ccccc1</smiles>

A $(260.2)$

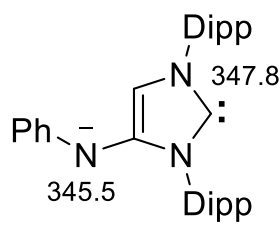

(272.5)

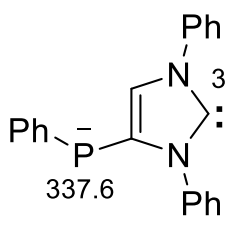

(270.6)

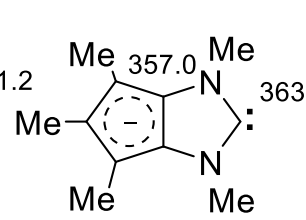

D
$(278.0)$

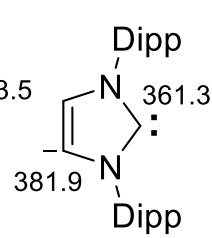

E

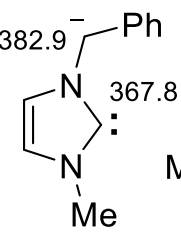

$\mathbf{F}$

(265.7)<smiles></smiles>

G (258.8)

Proton affinities of the related non-anionic carbenes are indicated in brackets

Scheme 56. Proton affinities of HBN-carbenes and their exocyclic centers.

In compound 56A the proton affinities of the basic centers are close to each other ( $N_{\text {an }}$ and C5 331.0 and $337.2 \mathrm{Kcal} / \mathrm{mol}$, respectively). In the case of the isolated imidazolylidene analogue 56B of Danopoulos (without the crystallization solvent THF), ${ }^{226}$ the PAs are even closer $(345.5$ and $347.8 \mathrm{Kcal} / \mathrm{mol}$, respectively), but the carbene centers are the more basic in both compounds. In such cases, the direction of the interaction with electrophiles depends on the hardnesses of the reaction centers and may vary for different partners.

In the phosphide anion 56C the difference between the carbenic and anionic centers becomes more substantial (13.6 vs. $6.2 \mathrm{Kcal} / \mathrm{mol})$, relative to that in 56A. In the hypothetical Arduengo bicyclic system 56D 
the basic centers are closer in their PAs (C2 363.5, $\left.\mathrm{C}_{\text {an }} 357.0 \mathrm{Kcal} / \mathrm{mol}\right)$ than those of the known complexes $56 \mathrm{E}$ ( $C_{\text {an }} 381.9$ and $C 2361.3 \mathrm{Kcal} / \mathrm{mol}$ ). In the case of the yet unknown anionic carbene $56 \mathrm{~F}$ the larger PA relates to the exocyclic carbon atoms ( $\left.C_{a n} 382.9, C 2367.8 \mathrm{Kcal} / \mathrm{mol}\right)$. In comparison, the anionic azine system $56 \mathbf{G}$ has a larger PA for the carbene atom C2 (PA 351,4 Kcal/mol) than that for the atom C5 $(323.4 \mathrm{Kcal} / \mathrm{mol})$. In the case of complexes with alkali metal cations, the PA values are reduced significantly. Nevertheless, these complexes remain the more basic in comparison with neutral carbenes. For example, in the case of the 4-Li derivative of the imidazol-2-ylidene $56 \mathrm{E}$ the value of the PA (at C2) is $284.9 \mathrm{Kcal} / \mathrm{mol}$ while that for the 4 - $\mathrm{K}$-derivative is $293.3 \mathrm{Kcal} / \mathrm{mol}$.

\subsection{Steric properties}

Steric factors can have a significant impact on the reactivities of carbenes and their indices, such as the TEP and $E_{d n}$. On the basis of the above data (Scheme 51 ) it is clear that the value of $E_{d n}$ is significantly reduced for compound 54F in comparison with that of 54D, and even that of 54C.

Recently the steric influence of carbenes has been estimated using the criterion of "percent buried volume" $\left(\% \mathrm{~V}_{\text {bur }}\right)$, ${ }^{267}$ which is defined as the percentage of the total volume of a sphere occupied by a ligand. It is generally considered to be a more reliable method than use of the Tolman cone angle (the cone angle is such that the metal is at the vertex and the atoms are at the perimeter of the cone).

For large structures such as $\mathbf{2 E}$, the values of the $\% \mathrm{~V}_{\text {bur }}$ for complexes of the type $\mathrm{LAuCl}$ are in the range of $50-53 \% .^{50}$ The values for complexes of Mes and Dipp-substituted imidazol-2-ylidenes are significantly lower (36.5 and $44.5 \%$, respectively). New types of sterically complicated carbenes, ones that contain 2,6-dialkyl-4methoxyphenyl substituents, are used frequently in catalytic studies, e.g., palladium complex catalysis of the Buchwald-Hartwig ${ }^{268,269}$ and Kumada reactions. ${ }^{53}$ However, the individual carbenes have not yet been isolated. Catalytic applications of these highly sterically shielded compounds are described. ${ }^{270,271}$

The electron donating and steric properties of some related carbenes with branched aromatic groups have been compared (IPr, IPrOMe, IPr*, IPr*OMe). ${ }^{264}$ It was found that the introduction of a $p$-methoxy-group to the 2,6-diisopropylphenyl system (IPrOMe, IPr*OMe) leads to a marked increase in the Tolman donating ability of the ligand. However, the buried volumes are somewhat smaller (by 2-3\%) with respect to those for the compounds IPr and IPr*. On the basis of ${ }^{77}$ Se chemical shifts in the NMR spectra of the respective selenones, it was found that the $\pi$-accepting properties of the carbenes with aromatic branched fragments (IPr*, IPr*OMe) are markedly increased in relation to those of the Dipp-substituted carbenes (IPr, IPrOMe). Furthermore, the methoxy-substituted carbenes were found to be slightly less electron accepting, than the related IPr and IPr* compounds. These properties are important from the standpoint of the catalysis of organic reactions such as Buchwald-Hartwig, arylthiol arylation, etc. ${ }^{272,273}$ In the case of the imidazolylidene, IPent with 2,6-di-(3amyl)phenyl substituents, synthesized by Nolan et al., ${ }^{274}$ the $\% \mathrm{~V}_{\text {bur }}$ is almost the same (about $49 \%$ ) as that for IPr*.

Another sterically shielded carbene, namely the 1,3-di-(2,6-dinaphthohydryl-4-methylphenyl) substituted imidazol-2-ylidene, has been used in situ for the preparation of silver, copper, rhodium and palladium complexes. ${ }^{275}$ The $\% \mathrm{~V}_{\text {bur }}$ values for the $\mathrm{AgCl}$ and $\mathrm{CuCl}$ complexes, which are normally close in value to those of the related $\mathrm{AuCl}$ complexes, reach 57.1 and $57.4 \%$, respectively.

\section{Transformations of Individual Carbenes}


It is clear from the previous section that structural features have a definite influence on the reactivities of carbenes. In the present paper, the focus of the work concerns those transformations that, according to the authors, have previously been inadequately represented in the literature. This comment includes rearrangements, autotransformations, ring expansions, insertions, the formation of organic complexes, reactions with multiple bonds, and complexes with non-metals, ${ }^{19,32,33}$ all of which are important from the standpoint of organic synthesis.

\subsection{Rearrangements and autotransformations}

Rearrangements that involve the migrations of groups and atoms in carbenes are related to the most important carbene properties. Autotransformations are cascade (tandem) transformations that take place, between heterocyclic carbenes and the products of their thermal decomposition, in situ without the participation of other reagents. Thermolysis reactions can be carried out by heating or under mild conditions (at room or low temperatures). In the simplest cases, these consist of proton migrations, which are particularly easy in the case of simple carbenes, and which occur even at low temperatures. Autotransformations of heterocyclic carbenes, and their aromatic derivatives, were only discovered in the 1990s. ${ }^{276-278}$ Several of the studies showed that some heterocyclic carbenes become unstable upon heating. ${ }^{103,168,279}$ Interestingly, reactions of this type have not been studied until recently.

4.1.1. Migrations of atoms and groups in stable carbenes. The simplest example of such a migration involving heterocyclic carbenes is the 1,2 $\mathrm{H}$-shift reaction to imidazol-2-ylidenes that has been known since the beginning of the 1990s. ${ }^{19,32,33,280-284}$ The unimolecular concerted mechanism for this reaction was found to take place only with carbenes of low stabilities. ${ }^{281,285,286}$ This prompted a search for an alternative intermolecular mechanism. The intermolecular proton transfer mechanism was found to be the best option for heteroaromatic carbenes, ${ }^{287-289}$ where the intramolecular reaction was found to be energetically unfavorable. The migration of protons results in the aromatization of heterocycles such as imidazoles (Scheme $57)$ or thiazoles. Theoretical calculations revealed that the activation energy of the reaction is quite large ( $E_{a}$ 40-47 Kcal/mol), despite the fact that the process is exothermic $(\Delta H-26$ to $-29 \mathrm{Kcal} / \mathrm{mol})$. Mayer et al. obtained similar values for thiazol-2-ylidene $\left(E_{a} 42\right.$ and $\left.\Delta H-34 \mathrm{Kcal} / \mathrm{mol}\right)$. However, quantum mechanical tunneling was found to reduce the enthalpy of the process significantly (for thiazol-2-ylidene by a factor of about $10^{5}$ at $\left.60 \mathrm{~K}\right) .^{290}$

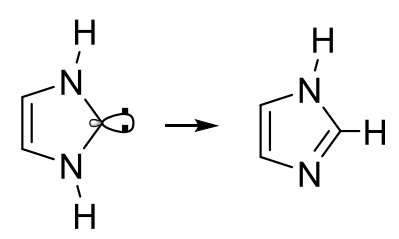

Scheme 57. Proton migration in imidazol-2-ylidenes.

The migration of trimethylsilyl groups in a number of stable carbenes was discovered by Bertrand et al. ${ }^{291}$ These authors showed that the deprotonation of trimethylsilyl substituted 1,2,4-triazolium salts 58A1-4 (Scheme 58) with different bases through the intermediate triazolylidenes 58B1-4 resulted in the formation of 3-trimethylsilyltriazoles $\mathbf{5 8 C 1 - 4}$ in yields of $42-81 \%$. 


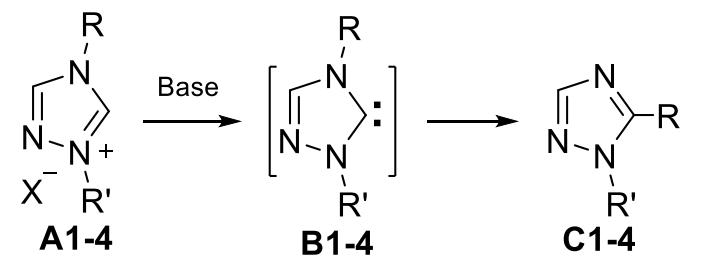

$$
\begin{aligned}
& \text { A1-4: } X=\mathrm{CF}_{3} \mathrm{SO}_{3} ; \\
& \text { A-C1-3: } 1 \mathrm{R}=\mathrm{SiMe}_{2}(i-\mathrm{Pr}), \mathrm{R}^{\prime}=\mathrm{Me} ; \\
& \text { 2 } \mathrm{R}=\mathrm{SiMe}_{2}(t-\mathrm{Bu}), \mathrm{R}^{\prime}=\mathrm{Me} ; \\
& \text { 3 } \mathrm{R}=\mathrm{SiMe}_{2}(i-\mathrm{Pr}), \mathrm{R}^{\prime}=\mathrm{Bn} ; \\
& \text { 4 } \mathrm{R}=\mathrm{SiMe}_{2}(t-\mathrm{Bu}), \mathrm{R}^{\prime}=\mathrm{Bn}
\end{aligned}
$$

Scheme 58. Silyl migrations in 1,2,4-triazol-5-ylidenes.

It was found that the addition of strong bases, in less than equimolar amounts, resulted in an interaction of the carbene with the unreacted salt. This was accompanied by the migration of a trimethylsilyl group onto the carbene carbon atom, thereby forming triazoles. A similar result was observed when Enders' carbene was reacted with the trimethylsilyl substituted salt. In an excess of 1-benzyltriazole, the $N$-methyl- $N^{\prime}$-trimethylsilyl substituted salt resulted in the formation of a 1-methyltrimethylsilyl substituted triazole and a triazolium salt, i.e. an exchange of alkyl and silyl substituents had taken place. Deprotonation of the mixture of triazolium salts (Me-, Bn-, R-, R'- substituted, where $\mathrm{R}=\mathrm{SiMe} \mathrm{e}_{2}-\mathrm{Pr} ; \mathrm{R}^{\prime}=\mathrm{SiMe} \mathrm{e}_{2}-\mathrm{Bu}$ ) with potassium hydride resulted in a mixture of triazoles with the same substituents. This confirmed the mechanism of the reaction as a rearrangement (autotransformation) of the intermediate carbene (Scheme 58).

The migration of a methyl group was also observed in the recently discovered mesoionic 1,2,3-triazolium5 -ide carbenes. In addition, the reaction of the Dipp-Ph-Me substituted 59B, that was obtained from the salt 59A, took place quite readily at $50{ }^{\circ} \mathrm{C}$ in benzene solution and resulted in the formation of the triazole 59C (Scheme 59). ${ }^{246}$ However, the methyl group could be replaced with an aromatic group thereby stabilizing the system. In fact, the transformation of the Mes $2 \mathrm{Ph}$ substituted carbene did not take place under these conditions even after 12 hours. Furthermore, dimerization was not observed under these conditions. ${ }^{246}$ In contrast to the 1,2,3-triazolium-5-ides, the imidazolium-4-ides are considerably more stable. However, only their aromatic derivatives have been studied.

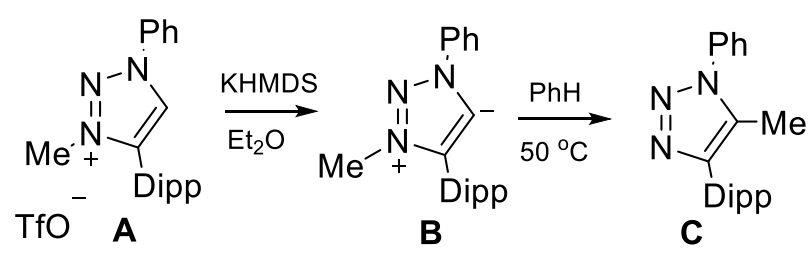

Scheme 59. Rearrangement (methyl migration) of 1,2,3-triazolium-5-ides.

Denk et al. ${ }^{292,293}$ discovered an intermolecular H-D exchange between 1,3-di-tert-butylimidazol-2-ylidene and DMSO- $d_{6}{ }^{294,295}$ The deoxygenating properties of these carbenes had been reported previously. For example, deoxygenation of DMSO by short lived carbenes had been described. ${ }^{294}$ Wishing to examine the deoxygenation of DMSO by stable carbenes at elevated temperatures, the authors found that the ${ }^{13} \mathrm{C}$ NMR signals of the C4 and 5 atoms gradually disappeared after dissolution in DMSO- $d_{6}$; 4,5-dideuterium-1,3-di-tertbutylimidazol-2-ylidene was isolated (Scheme 60).

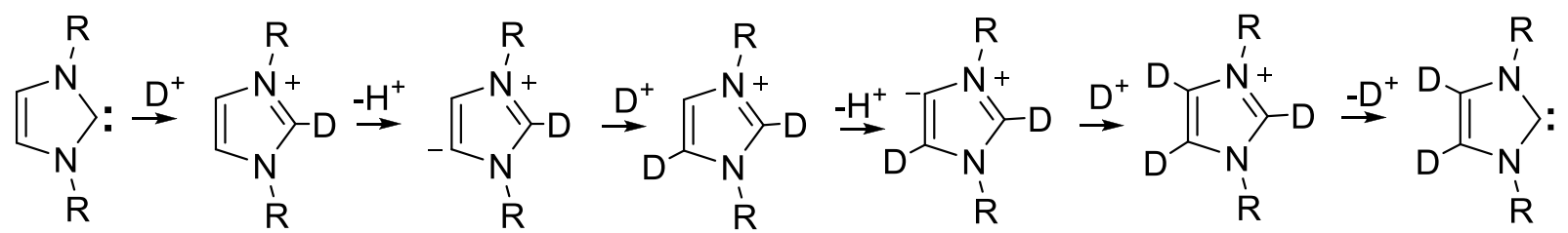


Scheme 60. Deuteration of imidazol-2-ylidenes in deuterated solvents (e.g., DMSO- $d_{6}$ ).

The proton/deuterium exchange that took place in the imidazol-2-ylidene at positions 4 and 5 could occur by a mechanism similar to that found for the related reactions of carbenes with $\mathrm{CCl}_{4}$ (in the latter case proton/ $\mathrm{Cl}^{+}$exchange). ${ }^{57}$ The method for the preparation of stable imidazol-2-ylidenes reported by Arduengo ${ }^{41}$ was used for the synthesis of the bisdibenzotropylidene substituted carbene 61B (Scheme 61) starting from the corresponding amine. ${ }^{296}$ However, the deprotonation of salt $61 \mathrm{~A}$ resulted in a rearrangement of the carbene 61B to the imidazole $61 \mathrm{C}$ in $44 \%$ yield. The reaction mechanism involves a 1,2-alkyl shift and isomerization of the tropylidene radical (from a 5- to a 10-substituted isomer). It is assumed that this rearrangement occurs because of the addition of the carbene to a double bond of the dibenzotropylidene ring. This results in the rearrangement of the cyclopropane adduct first formed to the imidazole $\mathbf{6 1 C}$. Unfortunately, the isolation of the pure carbene 61B failed in this case.

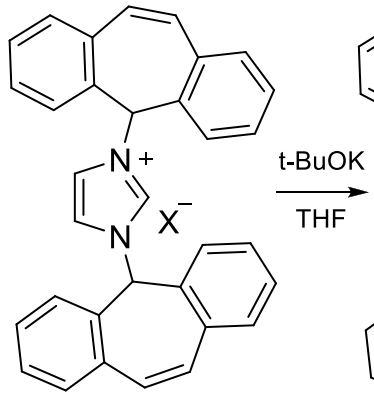

A

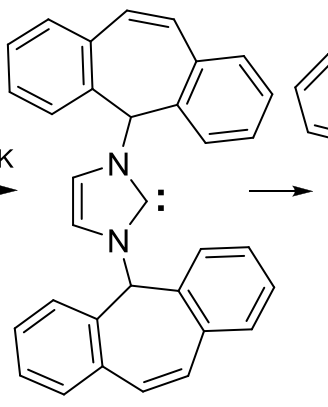

B

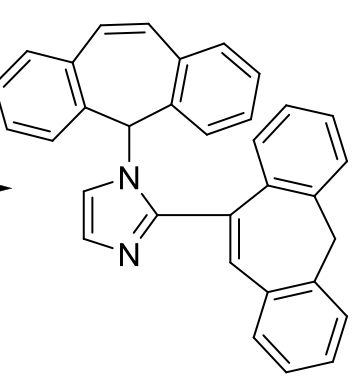

C

Scheme 61. Rearrangement of tropylidene derivatives of imidazol-2-ylidenes.

The sterically shielded 1-alkyl-3-phosphanylbenzimidazol-2-ylidenes 62A undergo rearrangement upon heating to form the corresponding 2-phosphanylbenzimidazoles 62B (Scheme 62). ${ }^{65,110}$ As a consequence, it was demonstrated that the intermediates in the electrophilic substitution reactions of azoles are carbenic in nature. Previously, cyclic ylide structures had been assigned to such intermediates on the basis of the resonance possible for these carbenes. ${ }^{297}$ The reaction of phosphanylated imidazoles and 1,2,4-triazol-5ylidenes 62C to phosphanylazoles 62D proceeds similarly. ${ }^{65,200,201}$ Thus, although in mainstream heterocyclic chemistry the $\mathrm{N}$-substituent migration involves a carbene carbon atom, shifts to the 4 and 5 positions of the imidazol-2-ylidene nucleus are also possible.
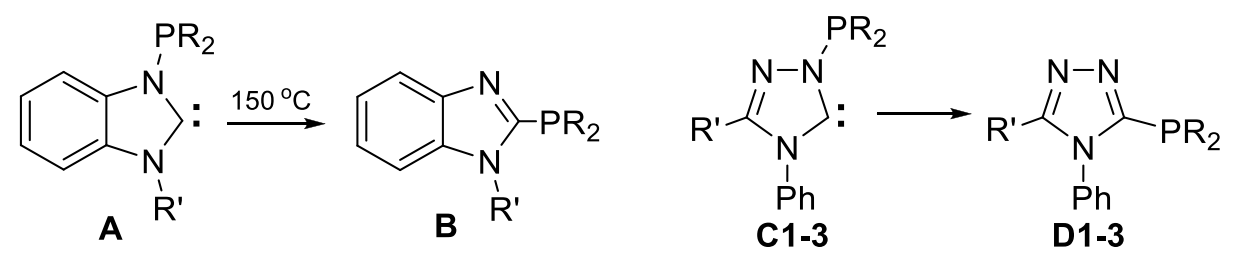

$A, B R=t-B u, i-P r_{2} N ; R^{\prime}=M e, i-P r ; C, D: R=t-B u, R^{\prime}=M e(1), E t(2), i-\operatorname{Pr}(3)$

Scheme 62. Rearrangement of $N$-phosphanylazolylidenes. 
4.1.2. Other autotransformations. In several early studies, instability was noted for the aryl substituted 1,2,4triazol-5-ylidenes upon heating. ${ }^{168}$ However, the processes that take place at elevated temperatures in the absence of other reactants have not been studied.

Subsequently, it was discovered that heating 1-alkyl-3,4-diaryl substituted 1,2,4-triazol-5-ylidenes 63A in organic solvents (decane or 1,3,5-triethylbenzene), at temperatures close to their melting points, resulted in autotransformation to give 5-amidino-1,2,4-triazoles 63D in yields of 41-81\% (Scheme 63). ${ }^{196,218}$ The reaction involves decomposition of the carbene 1,2,4-triazole ring to a nitrile and an alkylarylcarbodiimide 63B. This is followed by further reaction of the latter with the remaining carbene (the induced tandem reaction).

The intermediate products of the reaction are the zwitterionic compounds $63 \mathrm{C}$, which further eliminate isobutene to form the final products, the 5-amidino-1,2,4-triazoles 63D. The reaction was found to take place via a slow first step followed by a rapid second stage. As a consequence, there was no accumulation of carbodiimide.

The first example of a tandem reaction for stable carbenes was probably carried out by Arduengo et al..$^{57}$ The interaction of 1,3-dimesitylimidazol-2-ylidene with $\mathrm{CCl}_{4}$ in $\mathrm{THF}$ at room temperature (Scheme 6) was found to form 4,5-dichloro-1,3-dimesitylimidazol-2-ylidene 6G and chloroform. The subsequent conversion of 6G with carbon tetrachloride results in the formation of 2,4,5-trichloroimidazolium chloride and an adduct of carbene $\mathbf{6 G}$ with dichlorocarbene. However, this reaction is not an autotransformation because it occurs with the participation of $\mathrm{CCl}_{4}$.

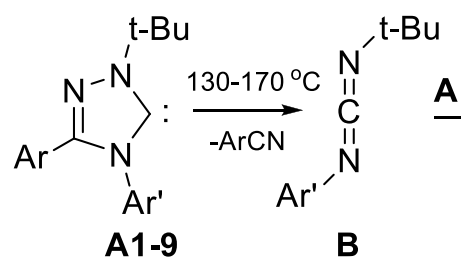

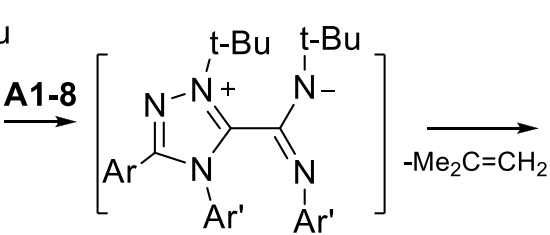

C

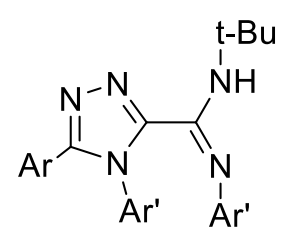

D1-9

A,D: $\mathrm{Ar}=\mathrm{Ar} \mathrm{r}^{\prime}=\mathrm{Ph}(\mathbf{1}) ; \mathrm{Ar}=\mathrm{C}_{6} \mathrm{H}_{5}, \mathrm{Ar}^{\prime}=4-\mathrm{CH}_{3} \mathrm{C}_{6} \mathrm{H}_{4}(2) ; \mathrm{Ar}=\mathrm{Ph}, \mathrm{Ar}=p-\mathrm{Br}^{\prime}-\mathrm{C}_{6} \mathrm{H}_{4}(3)$;

$\mathrm{Ar}=\mathrm{Ar} r^{\prime}=p-\mathrm{Br}_{-} \mathrm{C}_{6} \mathrm{H}_{4}(\mathbf{4}) ; \mathrm{Ar}=0-\mathrm{Cl}-\mathrm{C}_{6} \mathrm{H}_{4}, \mathrm{Ar}=\mathrm{Ph}(\mathbf{5}) ; \mathrm{Ar}=\mathrm{Ph}, \mathrm{Ar}^{\prime}=p-\mathrm{F}_{-}-\mathrm{C}_{6} \mathrm{H}_{4}(\mathbf{6}) ;$

$\mathrm{Ar}=0-\mathrm{Cl}-\mathrm{C}_{6} \mathrm{H}_{4}, \mathrm{Ar}=p-\mathrm{F}-\mathrm{C}_{6} \mathrm{H}_{4}(7) ; \mathrm{Ar}=\mathrm{Ph}, \mathrm{Ar}=m-\mathrm{F}-\mathrm{C}_{6} \mathrm{H}_{4}(8) ; \mathrm{Ar}=0-\mathrm{Cl}-\mathrm{C}_{6} \mathrm{H}_{4}$, $\mathrm{Ar}^{\prime}=m-\mathrm{F}-\mathrm{C}_{6} \mathrm{H}_{4}(\mathbf{9})$.

Scheme 63. Tandem induced autotransformation of 1-tert-butyl-3,4-diaryl-1,2,4-triazol-5-ylidene.

Similar conversions take place with the tetrazol-5-ylidenes, but proceed more rapidly than the reactions of the 1,2,4-triazol-5-ylidenes. Deprotonation of the 1,4-disubstituted tetrazolium salts 64A,D, using sodium hydride or hydroxide (Scheme 64), resulted in the formation of the unstable carbenes 64B,E. In the subsequent decomposition, the carbodiimides 64C,F were formed, thus proving the low stabilities of the intermediate 1,4-disubstituted tetrazol-5-ylidenes under these reaction conditions. ${ }^{298}$ Given that tetrazol-5ylidene is one of the most aromatic of this type of heterocyclic carbene, ${ }^{299}$ the instability of $64 \mathrm{~B}$ may be a consequence of the presence of intermediates that may be formed during the synthesis of tetrazol-5-ylidenes from the corresponding tetrazolium salts. 


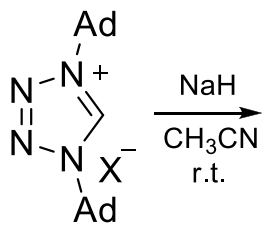

A

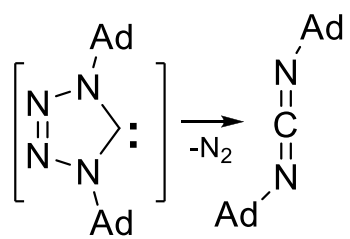

B
C

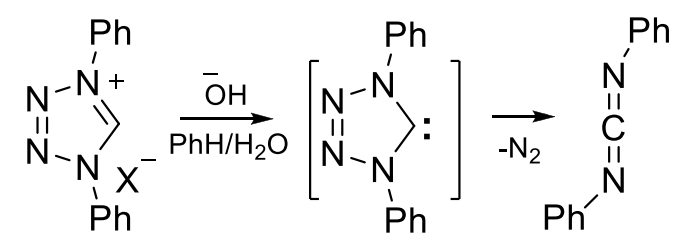

E

$\mathbf{F}$

Scheme 64. Formation and cleavage of tetrazol-5-ylidenes.

Scheme 65 shows the calculated bond energies that were obtained from DFT calculations (at the B3LYP5/RHF/6-311G (d, p) level) for a series of tetrazol-5-ylidene derivatives. In the case of the singlet carbene 65A, the cyclic bonds are strong enough to avoid the instability problem. In the case of the triplet carbene 65B, which could be formed during reactions, the cyclic bonds are weakened. However, the bond energy of N1-N2 in the anionic tetrazol-5-ylidene 65C, which is formed by the transfer of a hydride ion from the nucleophile (metal hydride) to the carbene, is significantly smaller. As a consequence, rapid decomposition of the intermediate was possible, thus converting the anion into the carbodiimide and nitrogen. In contrast, the tetrazolylidenes themselves are probably stable, and two types of isomeric compounds have been obtained in complexes, namely, normal 65D and mesoionic $65 \mathrm{E} .{ }^{300}$ To the best of our knowledge, comparable studies of carbenes of other azole series have not yet been undertaken.

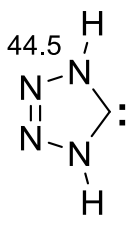

A

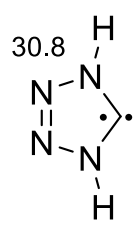

B

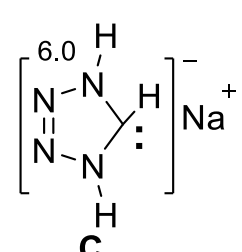

C

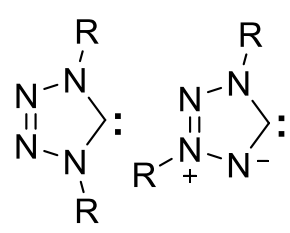

D $\quad$ E

Scheme 65. Calculated bond energies $(\mathrm{Kcal} / \mathrm{mol})$ for different types of tetrazol-5-ylidene derivatives.

Recently, a related decomposition was detected for a non-aromatic 1,3-p-tolyl-4,5-dihydroimidazol-2ylidene at $110{ }^{\circ} \mathrm{C}$ in toluene. This compound eliminated ethylene (from the ethylene moiety of the ring), and the resulting carbodiimide (di- $p$-tolyl substituted) added to a second equivalent of the unreacted carbene, forming the zwitterion $66 \mathrm{C}$ (Scheme 66). ${ }^{301}$ This reaction resembles the above-described autotransformation reaction (Scheme 63); the only difference is that here the stable tolyl groups in the adduct are not cleaved, and hence the zwitterion $66 \mathrm{C}$ is the final product.

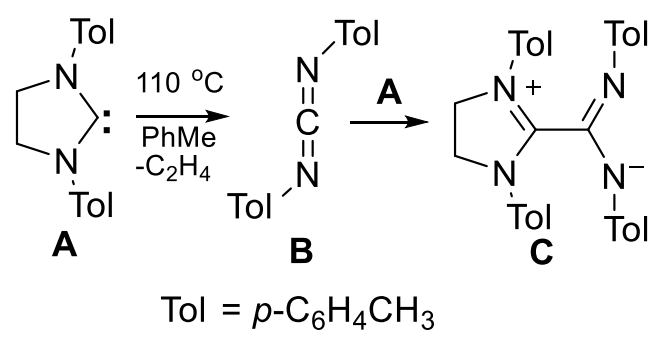

Scheme 66. Tandem autotransformation of 1,3-ditolyl-4,5-dihydroimidazol-2-ylidene. 
4.1.3. Ring expansions of heterocyclic carbenes. The reactions of mono- and di-substituted silanes with aliphatically substituted imidazol-2-ylidenes 67A resulted in ring expansion to give the six-membered carbene sila-containing diazines $67 \mathrm{C}$ (Scheme 67). ${ }^{302}$ In the course of the reaction, the carbene was inserted into the $\mathrm{Si}-\mathrm{H}$ bond of the silane (intermediate 67B). This was followed by reduction of the heterocyclic carbene by the silyl moiety at the 2-position, thus moving the hydride anion from silicon to the carbon atom. The outcome was confirmed by deuteration of the carbon atoms with $\mathrm{R}^{\prime} \mathrm{R}^{\prime \prime} \mathrm{SiD}_{2}$ and also by calculation. ${ }^{303}$

The ring expansion of imidazol-2-ylidenes is also effected by other Lewis acids, particularly boranes ${ }^{304}$ and aminoboranes. ${ }^{305,306}$ These result in the formation of borazines of types 67D,E, along with boroxoles 68B (Scheme 68). ${ }^{307}$ A beryllium analogue ${ }^{308}$ of the silazines 67C, compound 67F (Scheme 67), is also known. Compounds of this type (and their precursor borane carbene complexes) are promising reduction catalysts of the FLP-type.
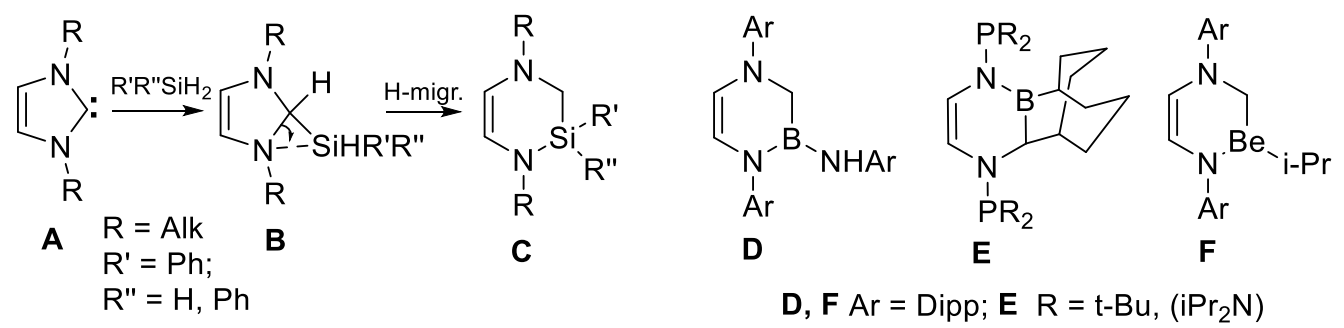

Scheme 67. Ring expansion of imidazol-2-ylidenes with silanes.

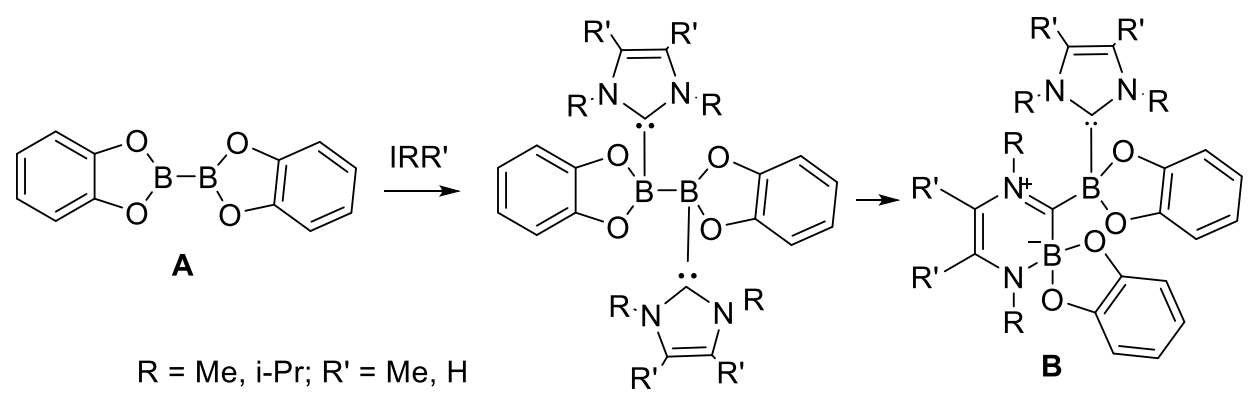

Scheme 68. Transformation of carbene-boroxole complexes.

The benzimidazol-2-ylidene related derivatives of the indazol-3-ylidene 69A, and their mesoionic pyrazol3 -ylidenes, have not yet been isolated in a pure state. However, if the process is carried out in situ by refluxing in a variety of solvents, they can be converted by ring expansion into the 9-amino derivatives of acridine 69D (Scheme 69). ${ }^{309,310}$ 


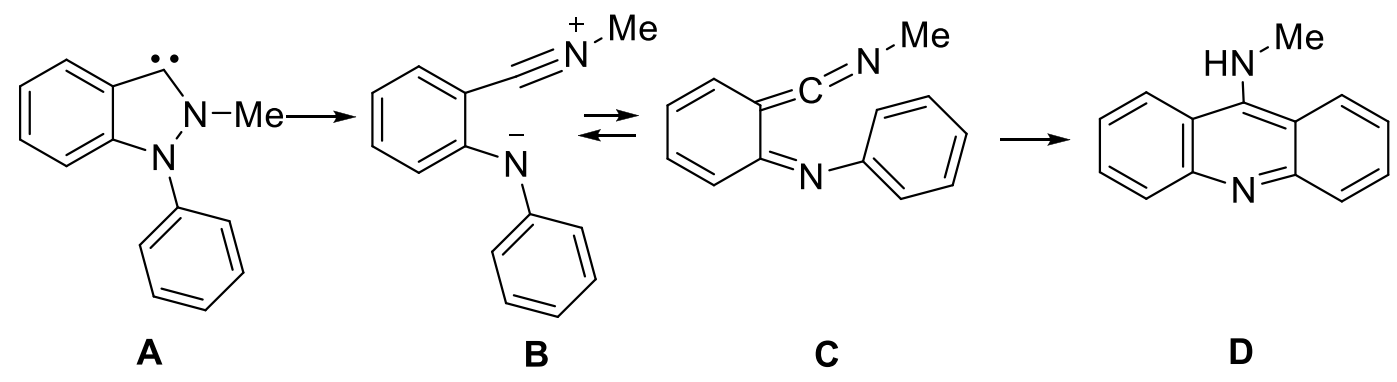

Scheme 69. Rearrangement of indazol-3-ylidenes into 10-aminoacridines.

In carbene chemistry, the reconstruction processes for heterocyclic or aliphatic moieties (proton migrations, rearrangements, cleavages, and ring expansions) play a particularly important role. The most stable species are the imidazol-2-ylidenes, for which decomposition does not occur even at elevated temperatures (for the 1,3-diadamantyl derivative the temperature is $240{ }^{\circ} \mathrm{C}$ ). In the case of fused rings (24D, at $300{ }^{\circ} \mathrm{C}$ ) and the conjugated biscarbenes chemical behavior upon heating is similar (the melting points for 1,1'-diadamantyl- and 1,1'-di-tert-butyl-substituted bistriazolylidenes 43A1,2 are 208-210 and 196-197 ${ }^{\circ} \mathrm{C}$, respectively, without the autotransformation inherent to tert-butyl-substituted mononuclear systems).

4.1.4. Dimerization reactions and cross-couplings. On the basis of thermodynamic and kinetic data, the dimerization (coupling) of many types of carbenes without sterically shielding groups was found to be preferred under normal conditions. Theoretical data have received extensive experimental confirmation, starting with Wanzlick's work. ${ }^{7,311}$ Nevertheless, it has long been debated whether dimerization is a catalyzed process (e.g., with acids) or if it occurs spontaneously without a catalyst. Lemal's data ${ }^{312-314}$ provides evidence in favor of a catalytic reaction. According to this theory, impurities of protic substances (e.g. azolium salts in the case of Hahn's dimerization of 1,3-diisobutylbenzimidazol-2-ylidene, ${ }^{107}$ Arduengo's 3-substituted thiazol-2ylidenes, ${ }^{315}$ Alder's diaminocarbenes, ${ }^{316,317}$ and others) may well be present in the reaction mixtures when carbene dimerizations occur. According to Lemal the pure dimers do not dissociate. However, Denk's experiments $^{318}$ give reason to acknowledge the possibility of a cross-dissociation occurring in the dimer forming reaction. On the other hand, Taton and Chen have shown ${ }^{319}$ that dimerization is observed for the cyclic bisimidazole-2-ylidenes with two linkers of three methylene units, while for the analogue with four methylene links only the biscarbene was detected.

Recently Bertrand et al. have developed a new method to accomplish certain carbene couplings. These authors successfully conducted cross-coupling reactions between the aromatic 1,2-bis(diisopropylamino)cyclopropenylidene and a number of non-aromatic carbenes (pyrrolidin-2-ylidenes, 3,5-dioxo-4H-pyrimidin-2ylidenes, and 1,5-dioxo-2,4-benzodiazepin-3-ylidenes) (Scheme 70). In the first two cases, the initial coupling products of type $70 \mathrm{~B}$ rearranged, via a ring expansion, into the azetidinylallenes $70 \mathrm{D}, \mathrm{E}^{320}$ while in the last case the olefin 70F was formed.

The results of these experiments have established that a prerequisite for dimerization is an adequate difference in the HOMO and LUMO energies of the reactive carbenes. Thus far, comparable experiments with heteroaromatic carbenes of the azole series have not yet been carried out. 


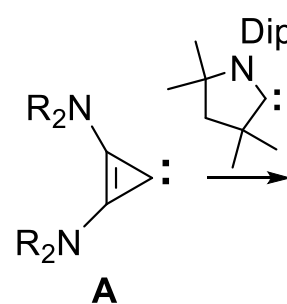

A $\mathrm{R}=\mathrm{i}-\mathrm{Pr}$

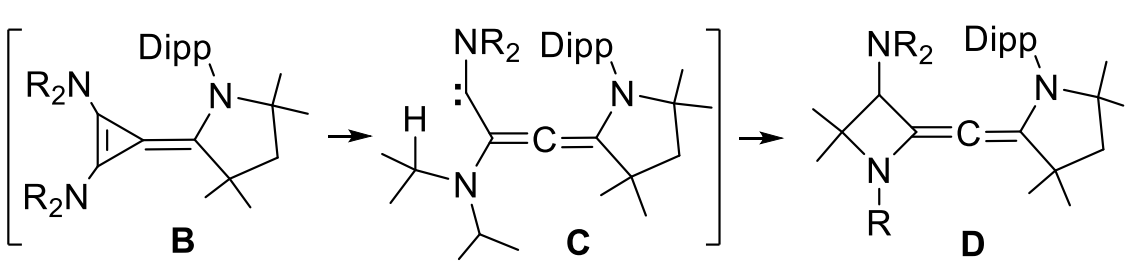

B

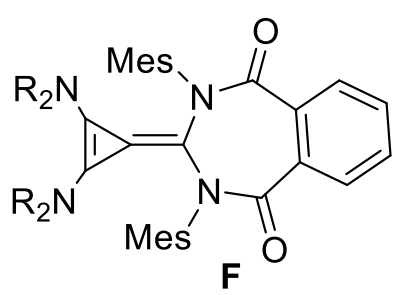

Scheme 70. Couplings of different stable carbenes and their accompanying reactions.

Bielawski et al. used the dimerization process of benzimidazole-type carbenes for the preparation of polymeric biscarbenes 71A (Scheme 71). ${ }^{321}$ The biscarbene polymers were combined with dimers, thereby forming shorter mixed polymers $\mathbf{7 1 B}$ that confirmed the possibility of the dissociation of Denk's dimers. ${ }^{318}$ Taking into account the potential use of conjugated polymers as photosensitive materials in solar cells, the utilization of benzimidazol-2-ylidene dimers, as structural fragments of polymers with both electron donating and electron withdrawing substituents, was studied to try to control their properties. ${ }^{322}$ By varying the substituents on the 5- and 6-positions of the nucleus, the absorption bands were found to undergo a shift to the visible region (up to $444 \mathrm{~nm}$ ), thereby signaling a change in their redox potentials. The structure of the dimer is characterized by the presence of almost planar rings. However, with the addition of halogen and methoxy substituents both rings become twisted by $16-17^{\circ}$.<smiles>[R]N1C(C)=C(C)N([R])c2cc3c(cc21)N([R])C(=C(C)C)N3[R]</smiles>

$\mathrm{R}=\mathrm{Me}, \mathrm{Et}, \mathrm{Bu}, \mathrm{Hx}$

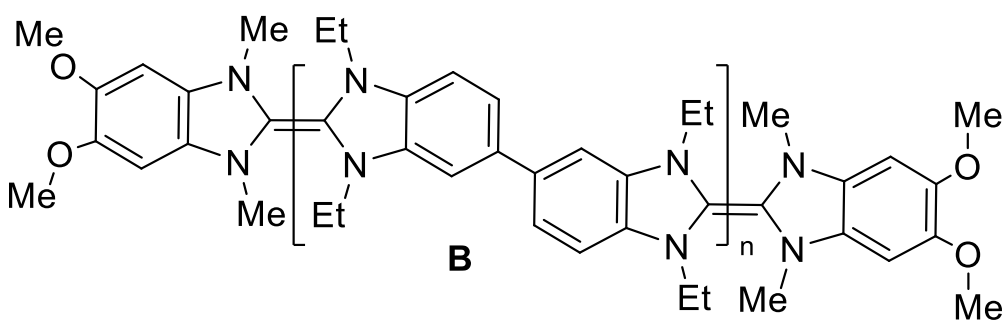

Scheme 71. Polymers based on biscarbenes.

\section{2. $\mathrm{X}-\mathrm{H}$ insertion reactions}

4.2.1. Insertions into polar $\mathrm{X}-\mathrm{H}$ bonds. One of the characteristic properties of the heterocyclic carbenes relates to their reactions with substances that contain mobile protons, $\mathrm{XH}$. ${ }^{7,9,168,198}$ As such, these reagents can act as alcohols, thiols or amines. However, such insertion products are generally labile and upon heating transform back into the original carbenes. For this reason the generation of carbenes in liquid ammonia by Herrmann et al. allowed isolation of the carbenes but not of the insertion products, aminoazolines. ${ }^{90}$ The stabilities of the insertion products can vary depending on the type of $\mathrm{X}-\mathrm{H}$ bond, on the heterocycle, and on the steric conditions around the carbenoid center. As an example, 5-methoxy-1,3,4-triphenyl-5H-1,2,4triazoline 36B is relatively stable, and decomposes to a carbene and methanol only when heated at $80{ }^{\circ} \mathrm{C}$ for 24 hours (Scheme 36$).{ }^{168}$ On the other hand, 1,3-dimethyl-2-( $N$-morpholinyl)-2H-benzimidazoline sublimes 
when heated, which may be due to its reversible cleavage into the carbene and the amine. ${ }^{198}$ The reactions with alcohols have been used to protect carbenic centers and to produce high quality carbenes. ${ }^{103,104,195-199}$

The role of product insertion in the hydrolysis of carbenes is described in the following references. ${ }^{33,198}$ However, it has been noted that imidazol-2-ylidenes and diaminocarbenes fail to react with such nucleophiles (in this case $\mathrm{NH}_{3}$ ). This is in contrast to pyrrolidin-2-ylidenes, aminoalkylcarbenes and 3,5-dioxo-4H-pyrimidin2-ylidenes, all of which react even at low temperature $\left(-78{ }^{\circ} \mathrm{C}\right) .{ }^{323}$ The possibility of a reaction occurring between aromatic carbenes and ammonia was confirmed by calculating the enthalpies of the reactions, which were confirmed to be negative. The calculated activation energies, even for diaminocarbenes, were significantly reduced compared to those for pyrrolidin-2-ylidenes and aminoalkylcarbenes (from approximately 33 to $21 \mathrm{Kcal} / \mathrm{mol})$. However, as for the $\mathrm{C}-\mathrm{H}$ bond insertion reactions, the energetically unfavorable proton loss from the amine molecule must be compensated for by the formation of new bonds via a concerted reaction mechanism. The final result of the reaction in ammonia (return of the heteroaromatic carbene upon heating or even at room temperature when dry) is due to the equilibrium nature of the reaction and an insufficient $\mathrm{C}-\mathrm{N}$ bond strength.

4.2.2. Hydrogen bonds of carbenes. In the presence of steric hindrances, or if the proton donor is highly acidic, the insertion reaction becomes unprofitable and the $\mathrm{H}$-carbene complexes that are formed can be of the azolium or carbene type. For example, with 2,6-di-tert-butyl-4-cresol,324 1,3-dimesitylimidazol-2-ylidene forms the azolium phenoxide structure $\mathbf{7 2 A}$, and with less acidic alcohols and diphenylamine the carbene complexes 72B, $72 \mathrm{C}$ are formed (Scheme 72 ). ${ }^{325}$ According to $\mathrm{X}$-ray diffraction studies the $\mathrm{C} \cdots \mathrm{H}$ distances are 2.801(4) and 2.832(2) $\AA$, in 72A and 72B, respectively. They are considerably shorter than those of known systems with $\mathrm{C}-\mathrm{H} . \ldots \mathrm{O}$ bonds, including the related $\mathrm{H}$-complexes of some $\mathrm{C}-\mathrm{H}$ acids with dioxane $(2.94-3.02$ $\AA$ ). ${ }^{325}$ The length of the $C . . . H$ bond in structure $72 C$ is $2.30(1) \AA$, while the N...C distance is $3.196(2) \AA$.
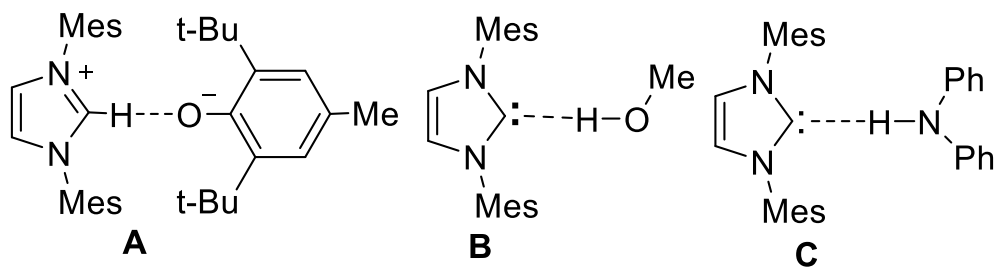

Scheme 72. Hydrogen bonds of 1,3-dimesitylimidazol-2-ylidene.

Confirmation of the carbenic nature of the complexes with methanol and diphenylamine (72B and $\mathbf{7 2 C}$ ) is provided by the presence of $\delta_{\mathrm{c}}{ }^{13} \mathrm{C}$ NMR signals at 210 and $215 \mathrm{ppm}$, respectively, which are close to those of the pure carbene $\left(\delta_{\mathrm{c}} 220 \mathrm{ppm}\right)$.

Depending on the substituents at the nitrogen atoms of the carbene, a shift of the hydrogen bound proton has been observed. Thus, TEMPO-H is bound to 1,3-dimesitylimidazol-2-ylidene by a hydrogen bond (73A), and the corresponding Dipp-substituted analogue transfers the proton of TEMPO-H to form a complex of an imidazolium salt with the respective $N$-oxide (73B) (Scheme 73). ${ }^{326}$

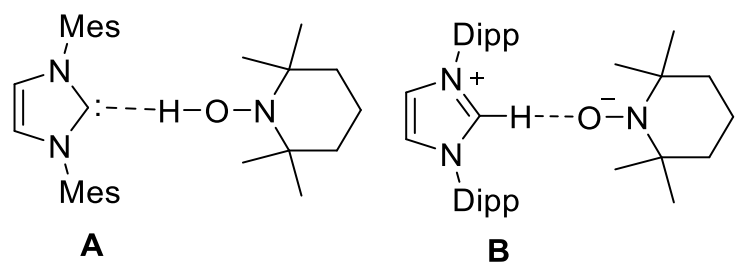


Scheme 73. Hydrogen bonds of imidazol-2-ylidenes with TEMPO-H.

4.2.3. Insertions into $\mathbf{C}-\mathbf{H}$ bonds. Reference was made earlier ${ }^{8}$ to the absence of reactions between stable carbenes and $\mathrm{C}-\mathrm{H}$ bonds. Enders et al. assumed that the formation of such products falls outside the temperature limits of carbene stability $\left(>150{ }^{\circ} \mathrm{C}\right) .{ }^{327}$ Nevertheless, it should be noted that carbene insertions have been carried out with the $\mathrm{C}-\mathrm{H}$ bonds of malononitrile and other $\mathrm{CH}$-acids from carbene dimers. ${ }^{7}$ Obviously, these reactions take place via carbenoid mechanisms and can therefore differ significantly from the reactions of individual free carbenes.

It was later found ${ }^{104,195,279,328}$ that benzimidazol-2-ylidene 20E, 1,3,4,5-tetraphenyl substituted imidazol-2ylidene, and the soluble 1,2,4-triazol-5-ylidenes 42D are all easily inserted (at room temperature) into a $\mathrm{C}-\mathrm{H}$ bond of acetonitrile thereby producing the corresponding azolines 74A-C (Scheme 74). Dibenzyl- and dimethyl-substituted benzimidazol-2-ylidenes react in situ in a similar fashion. The reactions of the sparingly soluble 1,2,4-triazol-5-ylidenes proceed slowly (but more easily when heated to $100{ }^{\circ} \mathrm{C}$ ). The formation of sparingly soluble analogues of the 1,2,4-triazol-5-ylidenes 42D and the bis-1,2,4-triazol-5-ylidenes 43A,B became the basis for the preparation of highly pure samples of these carbenes when solutions of the

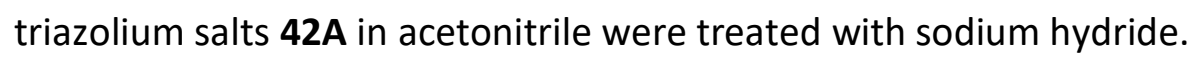

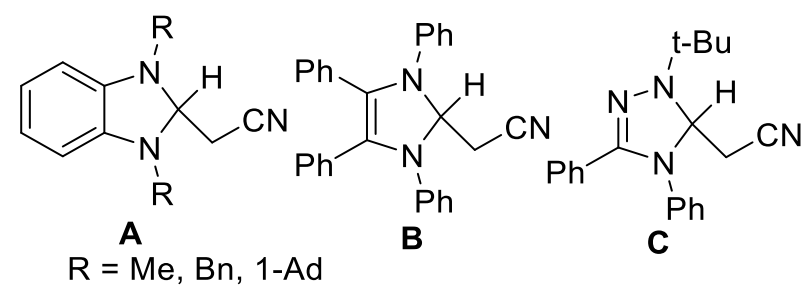

Scheme 74. Insertion products of azolylidenes into the $\mathrm{C}-\mathrm{H}$ bond of acetonitrile.

On the other hand, 1,3-di(1-adamantyl)imidazol-2-ylidene failed to give an insertion product and only a weakly bound carbene-acetonitrile solvated complex was isolated. ${ }^{329}$ The reverse decomposition reaction of 1,3-di(1-adamantyl)-2-benzimidazoline 20D was used for the preparation of the first representative carbenes of the benzimidazole series $20 \mathrm{E}$ (Scheme 20). ${ }^{103,104}$

Subsequently, the insertion reactions of 4,5-dihydroimidazol-2-ylidenes into the $\mathrm{C}-\mathrm{H}$ bonds of acetylene, dimethyl sulfone, acetonitrile, and chloroform were studied. ${ }^{329}$ In the case of acetylene two types of products were isolated, namely the heteryl- and diheteryl- substituted azolines 75A,B. The reactions of dimethylsulfone and acetonitrile resulted in the formation of the compounds 75C,D (Scheme 75).

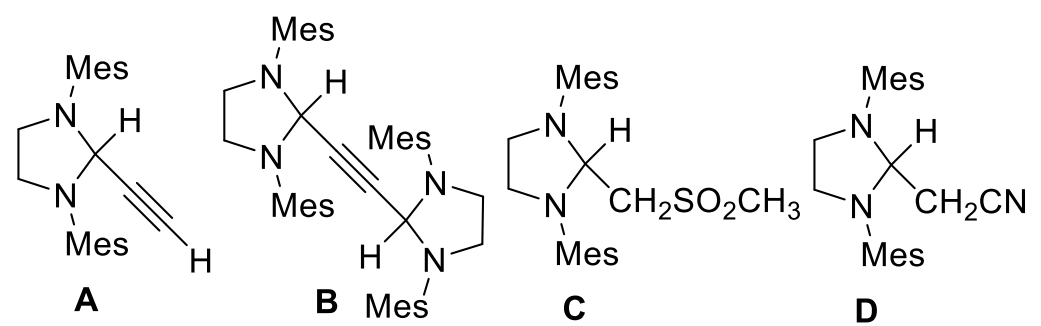

Scheme 75. Insertion products of 1,3-dimesityl-4,5-dihydroimidazol-2-ylidene into C-H bonds. 
Thus, the reactions of compounds with a mobile proton $\mathrm{CH}$ are very characteristic for carbenes, and take place with compounds that have slightly acidic $\mathrm{C}-\mathrm{H}$ bonds. For comparison, the reaction of the 1,3-dimethyl1,3-diadamantylamidinium salt 76A (related to azolium compounds) with sodium hydride in acetonitrile formally gives the insertion product of the carbene into a $\mathrm{C}-\mathrm{H}$ bond of acetonitrile 76B (Scheme 76). ${ }^{330}$

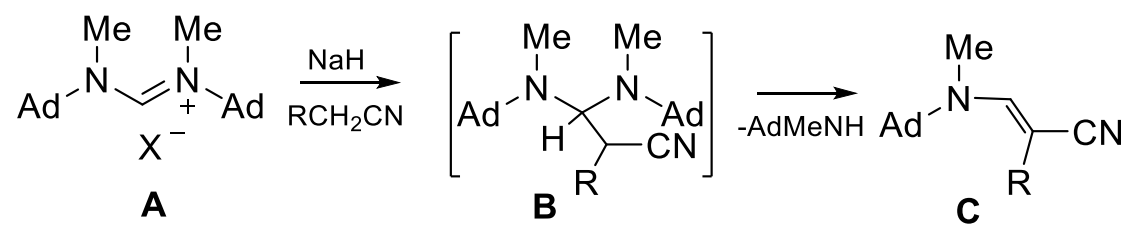

Scheme 76. Carbenoid Hofmann cleavage in amidinium systems.

The absence of any meso-substitution of the protons (to deuterium) in the reaction of the salts 76A with deuteroacetonitrile has shown that compounds 76B are generated via deprotonation of acetonitrile and addition of the ${ }^{-} \mathrm{CH}_{2} \mathrm{CN}$ anion to the amidinium cation. The resulting adducts $76 \mathrm{~B}$ undergo an unusual (carbenoid) Hofmann cleavage in non-aqueous media to form the $\beta$-aminoacrylonitriles 76C.

The insertion of carbenes into the $\mathrm{C}-\mathrm{H}$ bonds of aldehyde groups occurs with both aliphatic and aromatic aldehydes, e.g., propionaldehyde and benzaldehyde (Scheme 77). ${ }^{331}$ The reaction proceeds in THF solution at room temperature if left for 60 hours and results in the formation of the racemic products 77B,C. Attempts to obtain the enol form by silylation of the product with $\mathrm{N}, \mathrm{O}$-bistrimethylsilylacetamide (BSA) was only successful with the propionaldehyde adduct. Furthermore, this approach afforded the Z-enol isomer after participation of the alkyl group. In the case of the product from the benzaldehyde reaction, the keto-form was favoured over the enol form by 11.7 and $13.1 \mathrm{Kcal} / \mathrm{mol}$ ( $E$ - and Z-forms, respectively).

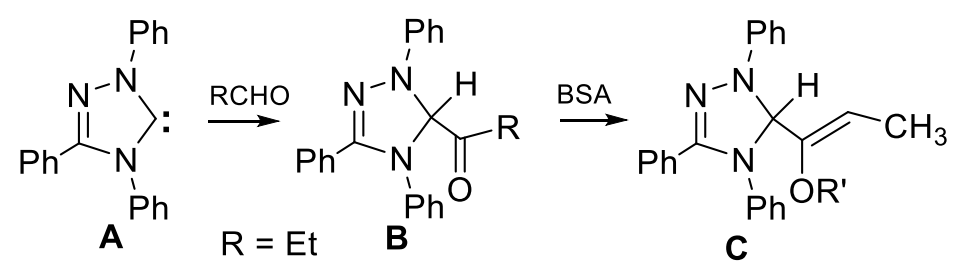

Scheme 77. Insertion of 1,3,4-triphenyl-1,2,4-triazol-5-ylidene into the C-H bonds of aldehydes.

4.2.4. Carbenoid properties of carbene insertion products. By increasing the degree of ionization of the $C-C$ bond in the insertion product its carbenoid properties are increased due to the interaction of the anion with the meso-proton. An example of such a reaction is the interaction of azolium carboxylates with sulfur at room temperature, $^{332}$ in which the formation of a complex acetic acid-acetate anion is postulated (the authors explain this by the existence of an equilibrium between the acetate salts and the free carbenes in ionic liquids). According to the authors of this review, this behavior is observed during the reaction of acetates in common organic solvents and is connected with the carbenoid reaction.

Another example of carbenoid promotion is provided by the carbene reduction that occurs upon heating azolium formates. ${ }^{32,333}$ Similarly to the hydroxyazolines, ${ }^{33}$ azolium formates $78 \mathrm{~A}$ are capable of reducing the salts $78 \mathrm{~A}$ to form the $2 \mathrm{H}$-azolines $\mathbf{7 8 C}$ (Scheme 78 ). The sensitivity of the reaction to moisture, which reduces the yields of the azolines $\mathbf{7 8 C}$, confirms the mechanism of the carbene reaction. 


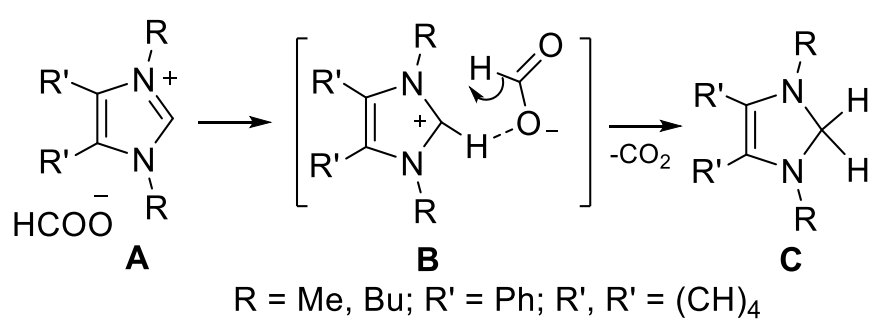

Scheme 78. Carbenoid decomposition of azolium formats.

The $\mathrm{C}-\mathrm{C}$ bond of the covalent products of carbene $\mathrm{C}-\mathrm{H}$-insertions is weaker than those found in alkanes, albeit to a lesser degree than those in the ionic compounds. The $\mathrm{C}-\mathrm{C}$ bond is, however, stronger than the $\mathrm{C}-\mathrm{O}$ and $\mathrm{C}-\mathrm{N}$-bonds of the $\mathrm{OH}$ - and $\mathrm{NH}$-insertion products (Scheme 79). The consequence of these weakened bonds is evident not only in the above-mentioned decomposition of cyanomethylazolines to carbenes but also in the carbenoid properties of the cyanomethylazoline 79A, the reactions of which were carried out under the influence of metal salts to give the carbene complexes 79B,C (Scheme 79). ${ }^{216,334,335}$

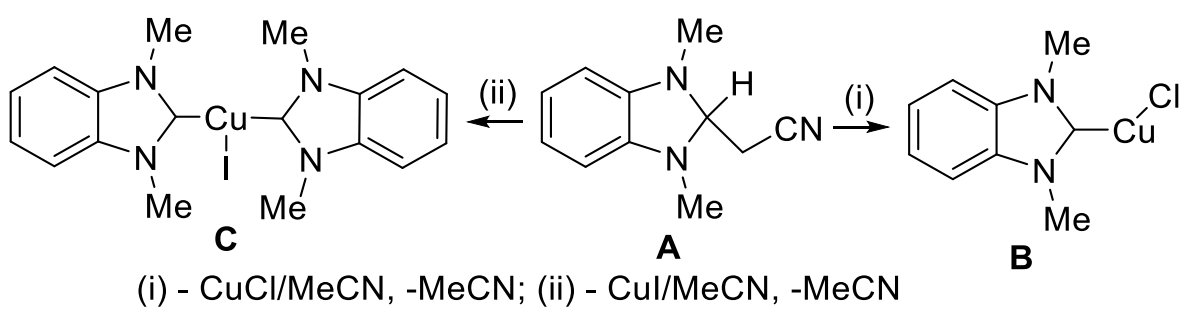

Scheme 79. Carbenoid reactions of 2-cyanomethyl-2H-benzimidazoline with copper(I) salts.

\subsection{Alkylation and arylation of carbenes}

The methylation of a stable carbene was first reported by Enders et al. It involved the reaction of 1,3,4triphenyl-1,2,4-triazol-5-ylidene with trimethyloxonium tetrafluoroborate and gave the anticipated salt. ${ }^{327} \mathrm{An}$ analogous reaction was used subsequently by Arduengo; 1,3-dimesityl-4,5-dihydroimidazol-2-ylidene and methyl iodide were combined, followed by deprotonation of the intermediate salt to form methyleneimidazolidine. ${ }^{57}$ In this study it was also shown that 1,3-dimesityl-4,5-dichloroimidazol-2-ylidene 80A, which results from the combination of the unchlorinated analogue and $\mathrm{CCl}_{4}$, reacts further with $\mathrm{CCl}_{4}$ by removal of two chlorine atoms thus forming the salt 80B. The generated dichlorocarbene adds to the heterocyclic compound to afford 2-(dichloromethylen)imidazoline 80C (Scheme 80). Aryl- and arylmethoxy-substituted methylenimidazolines, analogous to $80 \mathrm{C}\left(\mathrm{R}=\mathrm{Ar}, \mathrm{R}^{\prime}=\mathrm{H}, \mathrm{OMe}\right)$, were obtained via the reaction of the carbene with benzyl halides and methoxybenzyl chloride, respectively. ${ }^{336-338}$

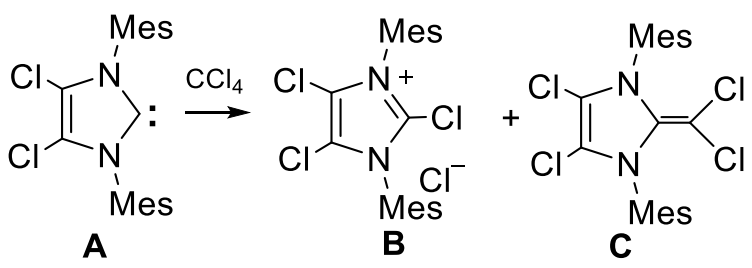

Scheme 80. Carbene-carbene coupling upon chlorination of imidazol-2-ylidenes with $\mathrm{CCl}_{4}$. 
Aromatic carbenes have been aralkylated using diphenylmethyl salts, stabilized in the $p$-positions with dimethylamino groups, or arylated by quinoids 81B (deprotonation products of similar salts) thus forming the desired azolium salts $\mathbf{8 1 C}$, E (Scheme 81 ). ${ }^{337}$ According to kinetic data collected, the reactivity of carbene $\mathbf{8 1 A}$ is slightly inferior to that of its 4,5-dihydro analogue, but significantly higher than that of triazolylidene 81D. The reactivity of the latter is even smaller than that of DBU, but significantly higher than that of triphenylphosphine. Note also, that if this was not the case, it would suggest that deprotonation of the alkylating reagent by the carbene had taken place.

An unusual feature was found when the reactivities of the 1,3-diarylimidazol-2-ylidene 81A and its 4,5dihydro analogue, in the arylation reactions by quinoids and diarylmethyl salts, were compared with the azolium methylide arylation at the terminal atom of the olefinic bond. ${ }^{336}$ Although the reactivity of carbene $\mathbf{8 1 A}$ is inferior to that of its 4,5-dihydro analogue by about 2.5 times, the aromatic azolium methylide is three orders of magnitude more reactive than its 4,5-dihydro analogue.

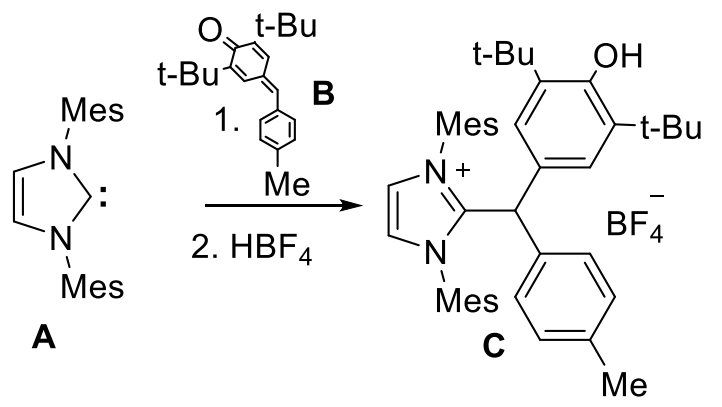

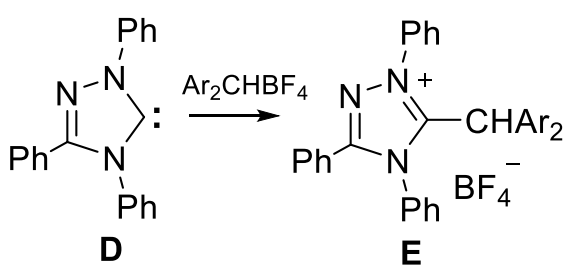

$\mathrm{Ar}=\mathrm{Me}_{2} \mathrm{NC}_{6} \mathrm{H}_{4}$

Scheme 81. Alkylation of carbenes with quinoids and carbenium salts.

In the case of the 4-nitro-substituted azolium phenylmethylide, the difference in reactivity was maintained (by approximately two orders of magnitude); moreover, the reactivity of the 1,3,4-triphenyl-1,2,4-triazolium phenylmethylide is almost an order of magnitude higher than that for the 4,5-dihydroimidazolium phenylmethylide. In our opinion, this effect can be explained by the stronger stabilization of the ylide state in the aromatic structures than that in their non-aromatic analogues.

The alkylation of carbenes $\mathbf{8 2 A}$ has been carried out using activated unsaturated ketones, e.g., tetrakis(trifluoromethyl)cyclopentanone (Scheme 82). Two types of products were obtained, after bond formation at either a carbon atom (82B) or the oxygen atom of the ketone $(\mathbf{8 2 C})$, thereby forming zwitterionic complexes. ${ }^{339}$ In the case of the dimesityl and Dipp derivatives 82A1 and 82A2 only products with the carbon product 82B1,2 were observed. For the more sterically shielded carbene 82A3, the trifluoromethyl group partly migrated to the 4-position of the cyclopentadiene ring thus forming the stable derivative 82D3 along with the O-connected zwitterionic compound $\mathbf{8 2 C 3}$. 


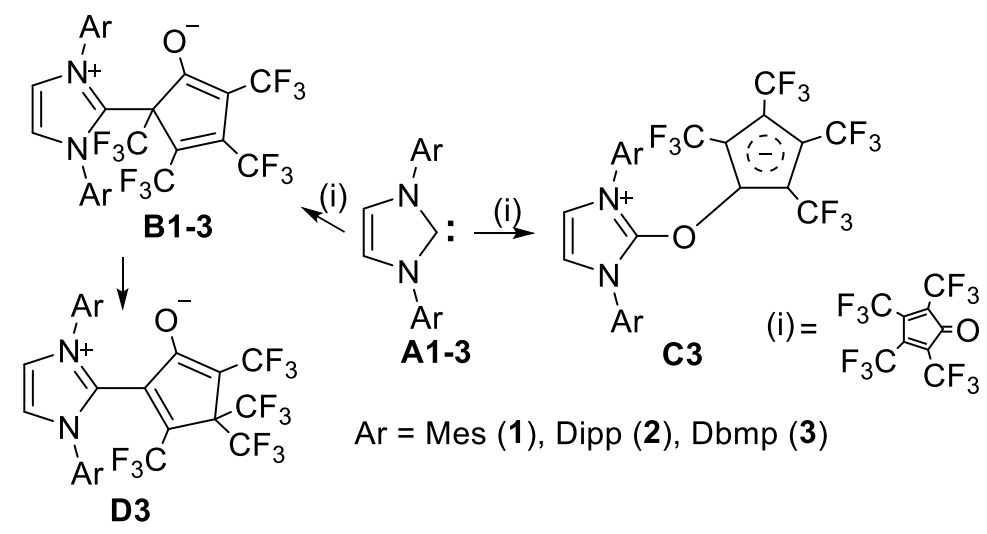

Scheme 82. Additions of tetrakis(trifluoromethyl)cyclopentanone to imidazol-2-ylidenes.

The first example of the arylation of an imidazol-2-ylidene was reported by Kuhn et al. ${ }^{340}$ These authors carried out the reaction with pentafluoropyridine and obtained the salt product after substitution at the 4position of the pyridine nucleus. The arylations of carbenes with less active aryl halides were easily carried out using palladium(0) complexes as catalysts (Scheme 83). ${ }^{341}$ The resulting 2-aryl substituted salts 83B have been used to prepare sterically shielded complexes of mesoionic carbenes $\mathbf{8 3 C}$.

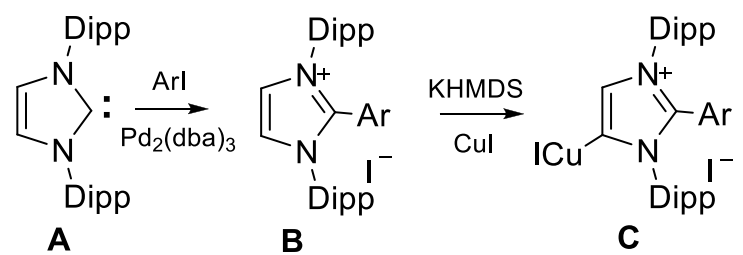

Scheme 83. Catalytic arylation of imidazol-2-ylidenes.

\subsection{Reactions with activated multiple bonds}

4.4.1. Reactions with olefins. Nucleophilic heteroaromatic carbenes of the azole series, thanks to their electron donating nature, do not react with non-activated olefins such as cyclohexene (effective traps of electrophilic carbenes). However, it has been reported that the benzothiazol-2-ylidenes do form adducts with substrates containing electron deficient multiple bonds 84A (Scheme 84). ${ }^{342}$

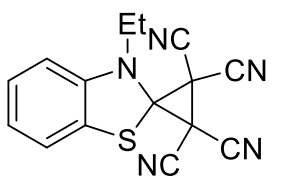

A<smiles>[R]C1=C([R])N([2H])CN1[R]</smiles>

B

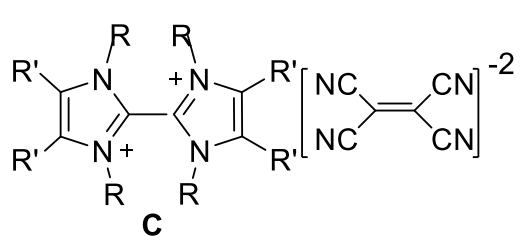

$R=$ Mes, $R^{\prime}=H ; R=i-P r, R^{\prime}=M e$

Scheme 84. Carbene adduct $\mathbf{A}$ and reaction of imidazol-2-ylidenes with tetracyanoethylene.

Recently, transformations of this type have been studied for the imidazol-2-ylidenes 84B $\left(R=i \operatorname{Pr}\right.$, Mes) ${ }^{343}$ In this case the transfer of two electrons (one electron from each of the carbene molecules) to an electron acceptor were carried out thereby forming the bis-salts $\mathbf{8 4 C}$. Although the authors (JACC) invoked a possible 
radical cation intermediate, recent results clearly show that this cation is not involved, ${ }^{344}$ The reactions of NHCs with TCNE gave a variety of cyclized products that were isolated and characterized, including X-ray crystal structures. Formation of $\mathbf{8 4 C}$ was probably due to hydrolysis although this needs to be reinvestigated.

Carbene adducts with multiple bonds are only obtained if the electrophile is sufficiently strong, contains electron withdrawing substituents and competitive with carbene, otherwise carbene can form the selfcondensation products.

In early work, W.M. Jones et al. observed the in situ transformation of cyclopropenylidene 85B (Scheme 85) with fumaric esters, thereby forming the corresponding cyclopropenylidene succinic esters 85D. ${ }^{345}$

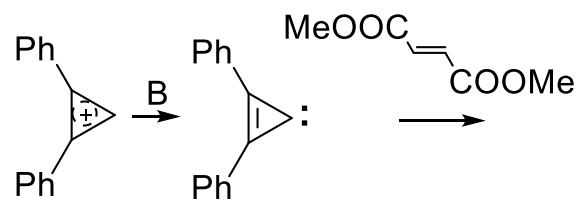

A

B

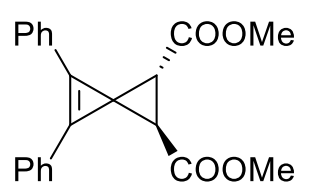

C

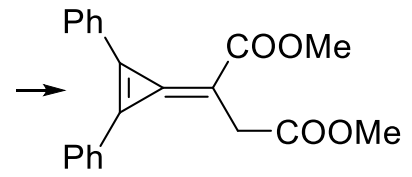

D

Scheme 85. In situ reaction of 2,3-diphenylcyclopropenylidene B with fumaric esters.

Enders et al. obtained several transformation products of 1,2,4-triazol-5-ylidenes 86A with maleic and fumaric esters, acrylonitrile, nitrostyrene and maleimides ( $\mathrm{N}-\mathrm{Me}, \mathrm{Bu}, \mathrm{Ph}$ ) (Scheme 86$){ }^{327}$ According to the authors, the first step in the reaction involves a hypothetical spirocyclic compound 86B that is formed and subsequently converted into the carbanion $\mathbf{8 6 C}$. Finally, a 1,2-H shift of the proton generates the respective azolinylidene substituted alkanes 86D.

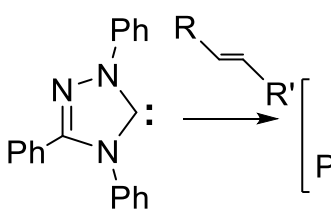

A

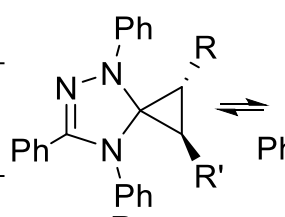

B

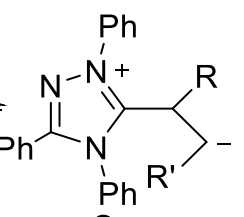

C

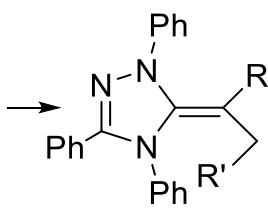

D1-6

$\mathrm{R}, \mathrm{R}^{\prime}=\mathrm{COOMe}(\mathbf{1}), \mathrm{R}, \mathrm{R}^{\prime}=\mathrm{CONR} \mathrm{COO}^{\prime \prime} \mathrm{R}^{\prime \prime}=\mathrm{Me}(\mathbf{2}), \mathrm{R}^{\prime \prime}=\mathrm{Bu}(\mathbf{3}), \mathrm{R}^{\prime \prime}=\mathrm{Ph}(\mathbf{4})$;

$\mathrm{R}=\mathrm{H}, \mathrm{R}^{\prime}=\mathrm{C}_{6} \mathrm{H}_{4} \mathrm{NO}_{2}-p(5) ; \mathrm{R}=\mathrm{H}, \mathrm{R}^{\prime}=$ COOMe (6).

Scheme 86. Reaction of 1,3,4-triphenyl-1,2,4-triazol-5-ylidene with activated olefins.

The results of the reactions of $\mathrm{N}$-phenylmaleimide with two carbenes, namely 1,3-di-(1-adamantyl) benzimidazol-2-ylidene 20E and 1-adamantyl-3,4-di(4-bromophenyl)-1,2,4-triazol-5-ylidene 42D3 have been compared. ${ }^{346}$ The first compound reacts to give predominantly the oligomeric structure, while the second one undergoes addition and a proton shift to give a product of the type 86D. The cause of such a change in the latter case may be the larger contribution of the cyclopropane structure 86B in the equilibrium $86 \mathrm{~B} \rightleftarrows 86 \mathrm{C}$. This, in turn, is likely to be connected with the larger electron deficiency of the triazole ring compared to that of benzimidazole. Decreasing the carbanion $\mathbf{8 6 C}$ content in the mixture tends to reduce the possibility of the chain growth by the addition of new maleimide molecules and, consequently, causes the transformation of the anion $86 \mathrm{C}$ to the olefin $86 \mathrm{D}$. 
It is noteworthy that, in contrast to the three-membered heterocyclic adducts which cannot be isolated, the phosphanylsilylcarbenes form stable derivatives of cyclopropanes. ${ }^{347}$ This is apparently due to the more pronounced electrophilic nature of the carbene.

Carbanion formation in a chain reaction is also confirmed by dimer formation, which in turn is a consequence of the nucleophilic attack of the carbanion on a second olefin molecule. Thus, carbene initiated growth of the alkane chain is possible in the reaction products. This was confirmed by Matsuoka et al., ${ }^{348,349}$ who studied a reaction which underwent an unusual catalytic dimerization (tail-to-tail) upon heating methyl methacrylate 87A (Scheme 87). Related olefins were also activated by electron withdrawing groups in the presence of carbenes, e.g., 86A (10 mol\%).

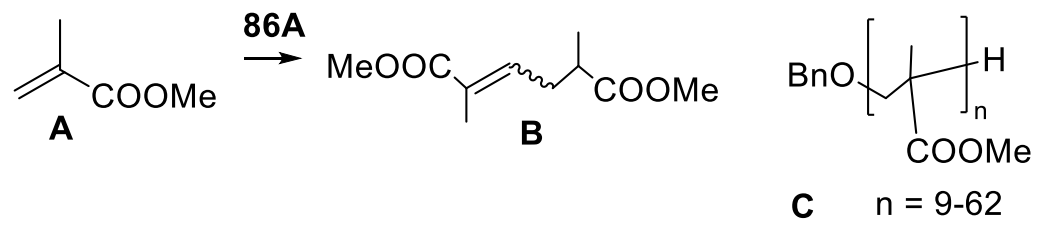

Scheme 87. Unusual carbene catalyzed dimerization (tail-to-tail) of methyl methacrylate.

The direction of the reaction differs from that of the known Rauhut-Courier reaction (head to tail) which is attributable to the nucleophilic properties of the olefinic carbon atom adjacent to the R-intermediate of type 86C. Further attack on a second olefin molecule forms the dimeric olefin 87B.

In the presence of carbenes $(10 \mathrm{~mol} \%)$ and alcohols in dimethylformamide, acrylates are capable of polymerizing under mild conditions (at room temperature) to form $\mathbf{8 7 C}$. ${ }^{350}$ Previously, it had been shown that alcohols could add to activated olefins without polymerization. ${ }^{351}$ When the ratio of carbene to methyl methacrylate is $1: 2$, two molecules of the substrate join and the cyclization to the zwitterion $88 \mathrm{~F}$ occurs via the intermediates 88B-E (Scheme 88). ${ }^{352}$

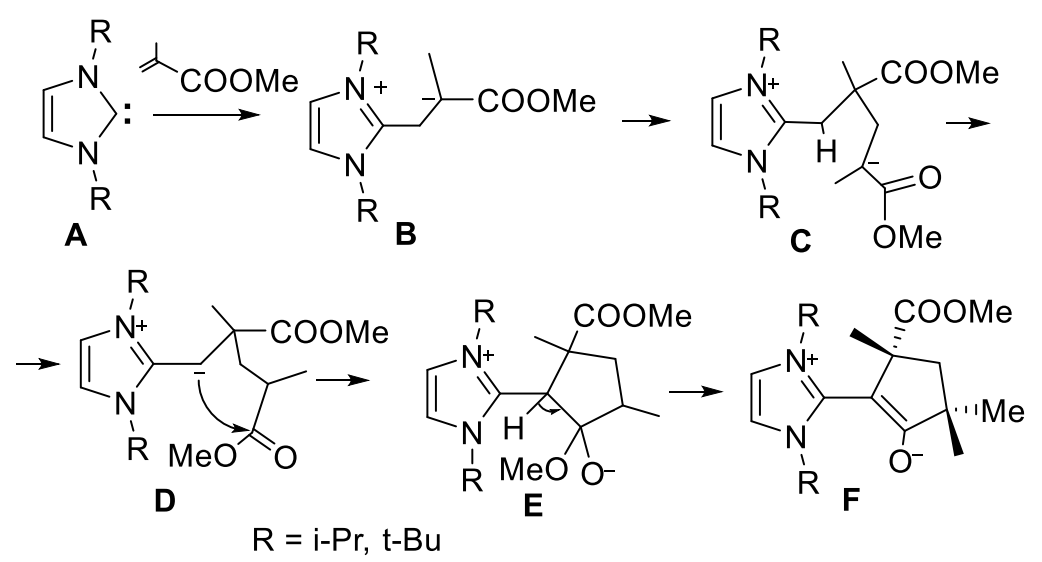

Scheme 88. Cycloaddition of methyl methacrylate with imidazol-2-ylidenes.

4.4.2. Reactions with acetylenes. The transformations of heteroaromatic carbenes with acetylene derivatives also require activation of the triple bond by electron withdrawing substituents. The usual cycloaddition to the ethyne bond is observed, via a characteristic transcarbenation reaction with terminal transfer of the carbene center in the intermediate. Subsequent stabilization occurs by intramolecular cyclization or secondary addition of the respective electrophilic reagent in the reaction mixture (e.g., 89B, see also refs 7,32) (Scheme 89). 


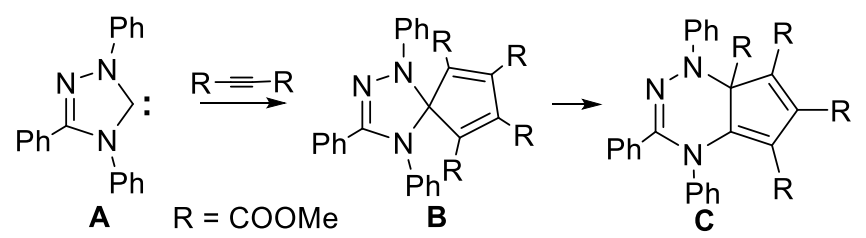

Scheme 89. Cycloaddition of 1,3,4-triphenyl-1,2,4-triazol-5-ylidenes with an activated acetylene.

The reactions of stable 1,2,4-triazol-5-ylidenes $89 \mathrm{~A}$ with acetylenedicarboxylate esters ${ }^{327}$ also begin by cycloaddition of the reagent and formation of the spiro-adducts $89 \mathrm{~B}$ followed by their rearrangement upon heating to form the fused 1,2,4-triazine derivatives $\mathbf{8 9 C}$.

Carbenes with different levels of steric shielding revealed unusual behavior with respect to their reactions with dimesitylboryl acetylene 90A (Scheme 90). ${ }^{353}$ If 1,3-dimethylimidazol-2-ylidene (IMe) forms the complexed borane, the zwitterionic product $90 \mathrm{~B}$ as a result of the reaction at the boron centre. The dimesityl substituted carbene reacts at the terminal carbon atom of the acetylene to form a new bora-allene zwitterion 90C. However, in the case of the Dipp-substituted imidazol-2-ylidenes (IPr), cyclization is observed along with insertion of a central nucleophilic carbon of the bora-allene into the $\mathrm{C}-\mathrm{H}$ bond of one of the borane mesityl groups thereby forming the boracyclic derivative 90D.

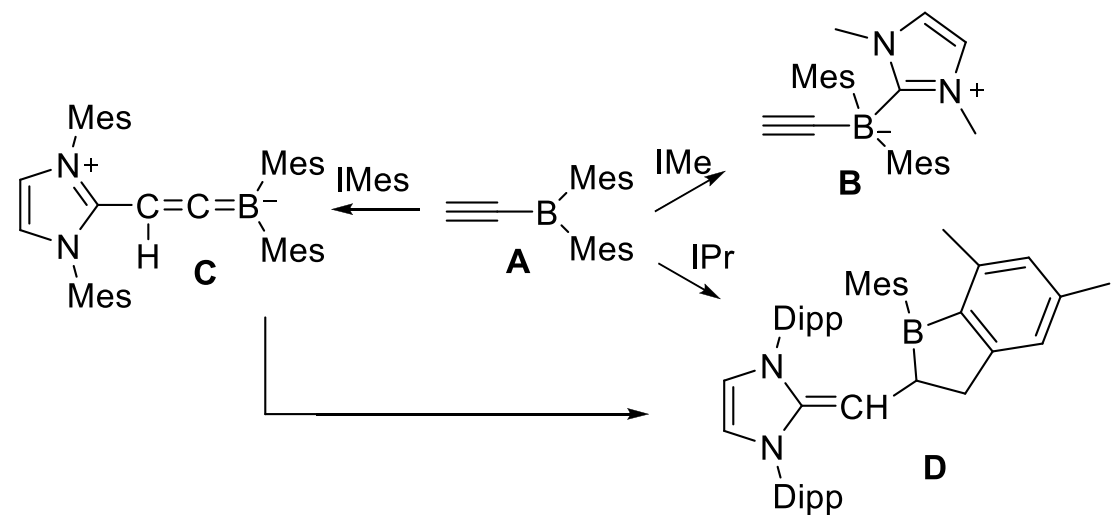

Scheme 90. Addition of dimesitylborylacetylene to imidazol-2-ylidenes.

4.4.3. Reactions with allenes and fullerenes. The highly electrophilic allene $91 \mathrm{~A}$ reacts readily with the carbene 91B at $-78{ }^{\circ} \mathrm{C}$ to form the adduct 91C (Scheme 91). ${ }^{354}$ Due to the conjugation in the fluorene fragment, the electron transfer is carried out from the carbene to the aromatic ring, and the resulting polar system is blue in color. However, with the Dipp-substituted carbene this reaction is not observed due to the extremely high steric hindrances that are encountered on approach to the reaction center.

In the presence of diphenyl disulfide, the reaction does proceed with the participation of the disulfide to form the more complicated salt system 92A. Unlike the allene $\mathbf{9 2 A}$, fullerene $\mathrm{C}_{60}$ reacts with the Dippsubstituted carbene IPr in 0 -dichlorobenzene at room temperature thereby forming an adduct with a C-C single bond (1.502 $\AA$ ) (Scheme 92). ${ }^{355}$ Furthermore, a charge transfer takes place in the molecule, from the carbene to the fullerene, and hence the structure of the molecule is zwitterionic. Rapid rotation of the fullerene fragment occurs around the imidazolium stator (around the C-C bond) even in the solid state. ${ }^{356}$ 
Compounds of the type 91C, 92B are typically FLP-adducts and are promising catalysts for reduction processes. $^{357}$

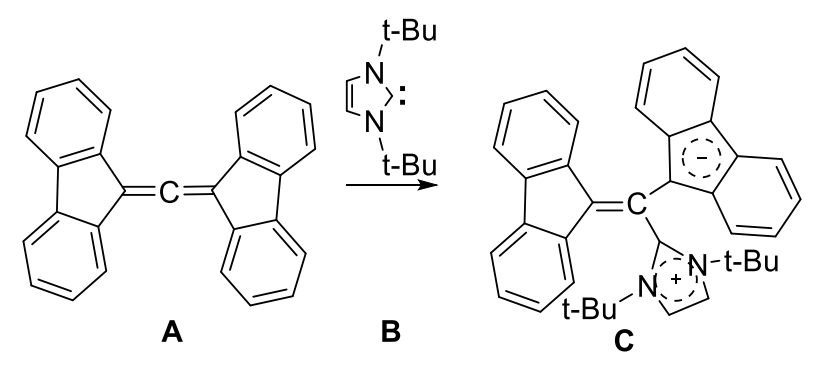

Scheme 91. Addition of 1,3-di-tert-butylimidazol-2-ylidene to an allene.

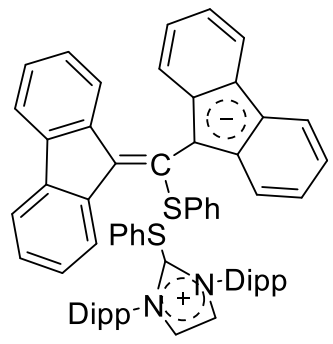

A

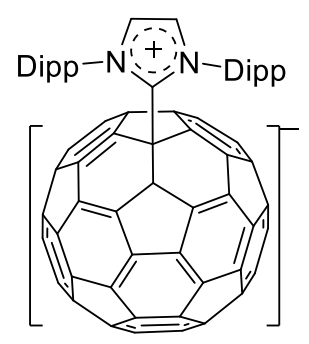

B

Scheme 92. Adducts of Dipp-substituted imidazol-2-ylidene with allenes (in the presence of diphenyl disulfide) and fullerene.

4.4.4. Reactions with $\mathbf{C X}_{\mathbf{2}}(\mathbf{X}=\mathbf{O}, \mathbf{S})$. It has long been known that carbenes add $\mathrm{CS}_{2}{ }^{7}$ as was first shown for an individual compound by Enders. ${ }^{168}$ The reaction of carbene $93 \mathrm{~A}$ with $\mathrm{CO}_{2}$ was carried out by Kuhn et al., forming the adduct 93B (Scheme 93). ${ }^{358}$ In both cases, zwitterionic compounds were obtained. Subsequently, $\mathrm{CO}_{2}$ complexation by carbenes has been the subject of several studies. ${ }^{359-361}$ The in situ methylation of 1methylimidazole with dimethyl carbonate (DMC) leads directly to the imidazolium-2-carboxylate 93B ( $R=$ Me). ${ }^{362}$ The imidazole is first $N$-alkylated by DMC. The acidic hydrogen of the resulting cation is abstracted by the methyl carbonate anion, leading to the heterocarbene and $\mathrm{HOC}(\mathrm{O}) \mathrm{OMe}$ which is unstable and breaks down to $\mathrm{MeOH}$ and $\mathrm{CO}_{2}$. Nucleophilic attack on $\mathrm{CO}_{2}$ by the carbene gives the observed product. Given the reversibility of the addition, the reaction deserves attention as a way of separating $\mathrm{CO}_{2}$ from the air (for imidazol-2-ylidenes this proceeds efficiently even in the solid state). ${ }^{363}$

Subsequently, it has been shown that instead of using the carbene, its 4-lithium derivative $93 \mathrm{C}$ can be selectively directed to undergo carboxylation at the 4-position of the nucleus to give the carbene salt 93D. ${ }^{364}$ As expected, reaction at both centers is not observed due to passivation of the nucleus by the carboxyl group. Treatment of the lithium salts 93D with water afforded the zwitterions 93E.

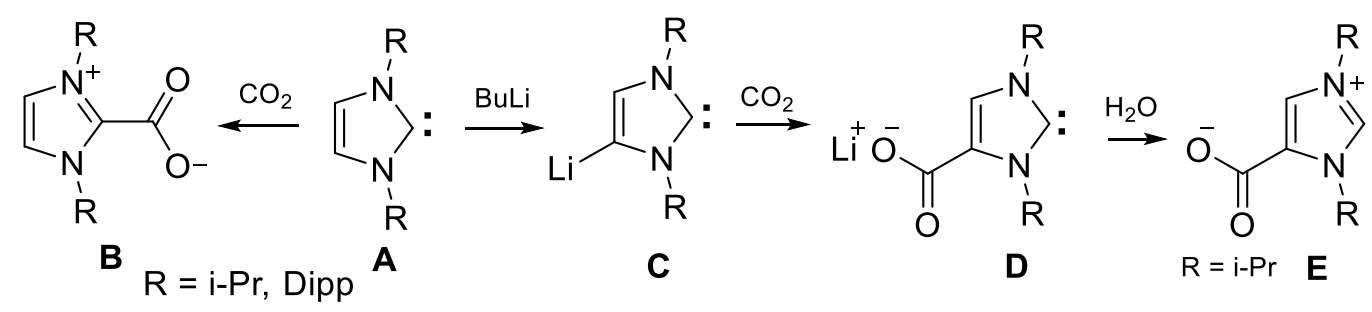

Scheme 93. Carboxylation of imidazol-2-ylidenes with $\mathrm{CO}_{2}$. 
4.4.5. Reactions with azides. Organic azides, as well as diazo compounds, as stabilized forms of nitrenes exhibit predominantly electrophilic properties. Their reactions with stable nucleophilic carbenes have predictably led to addition products; the imidazol-2-ylidenes 94A react with azides to give the corresponding triazenes 94B in high yields (Scheme 94). ${ }^{365}$

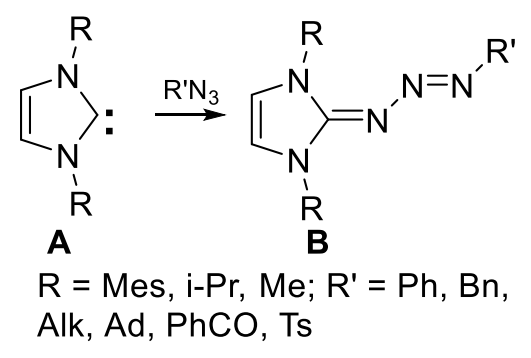

Scheme 94. Addition of imidazol-2-ylidenes with alkyl azides.

Similar conjugated compounds have been prepared from a series of benzimidazoles. These compounds contain donating substituents on the azole nucleus and accepting substituents on the aromatic nucleus of the azide 95A1-13 (Scheme 95). ${ }^{366}$ Thus, electron transfer is carried out in the resulting triazenes, from a donor to an acceptor moiety along the conjugated chain in the products 95B1-13. The yields are close to quantitative.<smiles>[R]c1ccc(N=NN=c2n([R])c3cc([R])c([R])cc3n2[R])cc1</smiles>

A1-13 $\mathrm{Ar}=\mathrm{C}_{6} \mathrm{H}_{4} \mathrm{R}^{\prime \prime}-\mathrm{p} \quad \mathrm{B} 1-13$

A, B: $1-9 \mathrm{R}=\mathrm{t}-\mathrm{Bu} ; 1 \mathrm{R}^{\prime}=\mathrm{H}, \mathrm{R}^{\prime \prime}=\mathrm{H} ; 2 \mathrm{R}^{\prime}=\mathrm{H}, \mathrm{R}^{\prime \prime}=\mathrm{OMe} ; 3 \mathrm{R}^{\prime}=\mathrm{H}, \mathrm{R}^{\prime \prime}=\mathrm{NO}_{2}$;

$4 \mathrm{R}^{\prime}=\mathrm{OMe}, \mathrm{R}^{\prime \prime}=\mathrm{H} ; 5 \mathrm{R}^{\prime}=\mathrm{OMe}, \mathrm{R}^{\prime \prime}=\mathrm{OMe} ; 6 \mathrm{R}^{\prime}=\mathrm{OMe}, \mathrm{R}^{\prime \prime}=\mathrm{NO}_{2}$;

$7 \mathrm{R}^{\prime}=\mathrm{F}, \mathrm{R}^{\prime \prime}=\mathrm{H} ; 8 \mathrm{R}^{\prime}=\mathrm{F}, \mathrm{R}^{\prime \prime}=\mathrm{OMe} ; 9 \mathrm{R}^{\prime}=\mathrm{F}, \mathrm{R}^{\prime \prime}=\mathrm{NO}_{2} ; 10-13 \mathrm{R}=\mathrm{Me}$;

$10 R^{\prime}=H, R^{\prime \prime}=H ; 11 R^{\prime}=H, R^{\prime \prime}=\mathrm{NO}_{2} ; 12 R^{\prime}=O M e, R^{\prime \prime}=H$;

$13 \mathrm{R}^{\prime}=\mathrm{OMe}, \mathrm{R}^{\prime \prime}=\mathrm{NO}_{2}$.

Scheme 95. Addition of benzimidazol-2-ylidenes with aryl azides.

When heated in DMSO or toluene, the triazenes 96A undergo decomposition into nitrogen and the corresponding imines 96B (Scheme 96). These can be considered as adducts of carbenes and the appropriate nitrenes.<smiles>[R]c1c([R])n(S(C)(=O)=O)c(=NN=NBr)n1C</smiles>

A

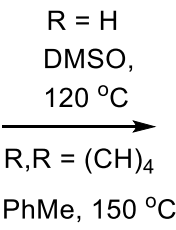

$-\mathrm{N}_{2}$<smiles>[R]c1c([R])n(S(C)(=O)=O)c(=NCc2ccccc2)n1C</smiles>

B

Scheme 96. Decomposition of carbene-azide adducts. 
4.4.6. Reactions with diazoalkanes. It has been found that the reaction of 1,3-dimesitylimidazol-2-ylidene with 9-diazofluorene leads to the conjugated azine 97A. ${ }^{367}$ Analogues with donor and acceptor moieties on the molecule have also been obtained. ${ }^{369}$ The azine fragment, depending on its substituents, can act as a conductor or breaker of the conjugation. ${ }^{369}$ Diphenylmethylenetriazolylidenazine 97C was prepared from the triazolylidene 97B and diphenyldiazomethane (Scheme 97). ${ }^{196}$

A similar reaction was carried out for the related biscarbenes and produced a similar result (97D). ${ }^{216}$ Note that decomposition of the diazo-compound, followed by addition of the intermediate diphenylcarbene to the heteroaromatic carbene, does not take place. This is due to the high stability of the diazo compound under the reaction conditions and the high reactivity of the carbene.

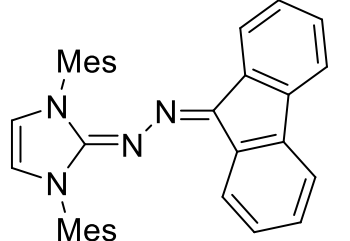

A

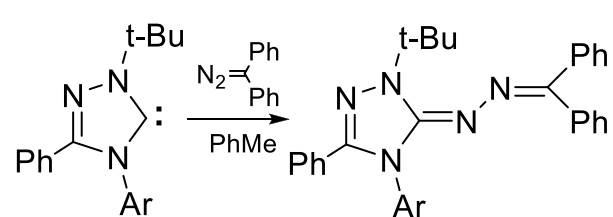

B
C

$$
\text { B,C Ar }=\mathrm{C}_{6} \mathrm{H}_{4} \mathrm{Br}-p ; \text { D Ar }=\mathrm{Ph}
$$

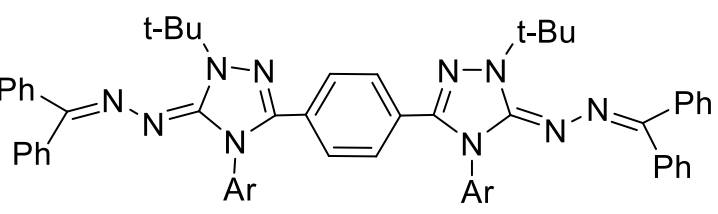

D

Scheme 97. Addition of azolylidenes with diazo compounds.

4.4.7. Reactions with $\mathrm{N}_{2} \mathrm{O}$ and NO. Nitrous oxide $\mathrm{N}_{2} \mathrm{O}$ is a polar compound and a mild oxidant. It can be viewed as a stable form of a nitrenium zwitterion. Being a strong electrophile it reacts readily with the carbenes 98A to form the zwitterionic compounds 98B (Scheme 98). ${ }^{370}$

Upon heating in toluene the adduct 98B (Mes) decomposes to form the corresponding imidazolone 98C and nitrogen, as a result, the oxidizing action of the reagent $\left(\mathrm{N}_{2} \mathrm{O}\right)$ is carried out. The activation of $\mathrm{N}_{2} \mathrm{O}$ by a carbene leads to a substantial change in its properties. For example, with electrophiles, the adduct 98B reacts at the oxygen atom, and insertion of a nickel compound into the N-N bond has also been observed. ${ }^{371-373}$
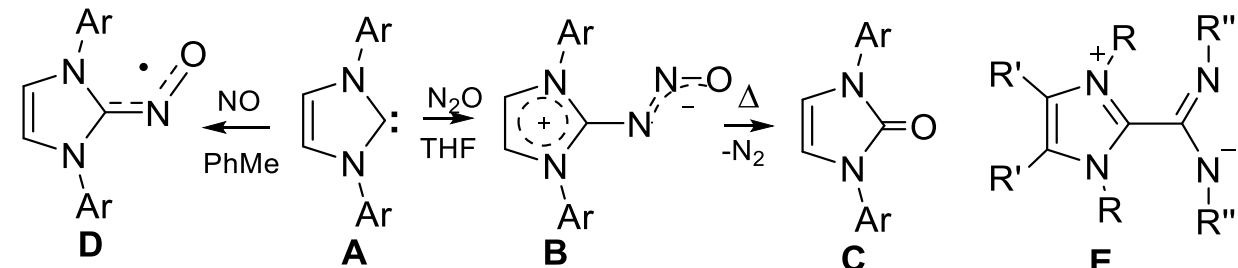

A, B, C Ar = Mes; D R = Mes, Dipp; E R = R' = Me, R" = i-Pr (1);

$\mathrm{R}=$ Mes, $\mathrm{R}^{\prime}=\mathrm{H}, \mathrm{R}^{\prime \prime}=$ Tol (2), R = Dipp, $\mathrm{R}^{\prime}=\mathrm{H}, \mathrm{R}^{\prime \prime}=$ Tol (3)

Scheme 98. Reactions of imidazol-2-ylidenes with $\mathrm{N}_{2} \mathrm{O}$ and NO.

In contrast, the reaction of imidazol-2-ylidenes with NO gives the stable radical 98D. ${ }^{374}$ Thermal decomposition of the radical leads to imidazolones of the type $\mathbf{9 8 C}$ and the initial carbene $\mathbf{9 8 A}$.

4.4.8. Reactions with carbodiimides. The zwitterionic adduct 98D1 was obtained from the reaction of 1,3diisopropylimidazol-2-ylidene with diisopropylcarbodiimide. ${ }^{375}$ The analogous zwitterions 98D2,3 were synthesized from ditolylcarbodiimide at room temperature. ${ }^{301}$ This reaction is one step in the more complicated decomposition process involving 1,3-ditolyl-4,5-dihydroimidazol-2-ylidene, which proceeds upon heating at $110^{\circ} \mathrm{C}$ (Scheme 66). 
Carbenes of the 1,2,4-triazole series also react with a variety of carbodiimides, and the nature of the carbodiimide significantly influences the reaction pathway. ${ }^{196}$ As was shown above, in the tandem autotransformation of carbenes, interaction with alkylarylcarbodiimides forms amidinotriazoles. This reaction occurs not only in the tandem transformation of stable 1,2,4-triazol-5-ylidenes (the in situ reaction), but also with previously isolated tert-butylarylcarbodiimides. The reaction results in the formation of amidinotriazoles 63C1,2 in $47-50 \%$ yields.

In the reaction with diphenylcarbodiimide 99B, the formation of the spiro-compound 99D was observed (Scheme 99). The process likely proceeds via the zwitterionic intermediate 99C, an intermediate similar to that observed in the tandem transformation of 63C. In the next step, a second molecule of carbodiimide 99B reacts rapidly at the nitrogen atom of compound 99C, thereby forming the triazolo-spiro-imidazolidine 99D. This type of transformation is a well known interaction of carbenes with isocyanates and isothiocyanates. ${ }^{7,169,327}$ However, in the case of carbodiimides similar transformations had not been observed earlier.

The reactions with aliphatic carbodiimides are slower than those with alkylarylcarbodiimides. For example, the reaction of carbene 99A with dicyclohexylcarbodiimide (DCC) was not observed at temperatures below $100{ }^{\circ} \mathrm{C}$. However, the more nucleophilic imidazol-2-ylidenes do react with the related diisopropylcarbodiimide, which results in the formation of the stable zwitterionic compounds 98D. ${ }^{358}$

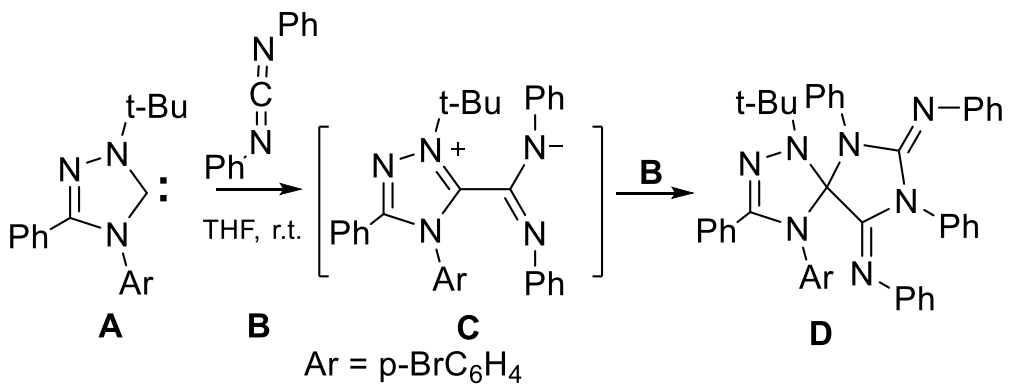

Scheme 99. Cycloaddition of 1-alkyl-3,4-diaryl-1,2,4-triazol-5-ylidenes to diphenylcarbodiimide.

The reactivities of carbenes with carbodiimides can be explained by the electronic influence of the substituents of the carbodiimide molecule on its central carbon atom. According to DFT calculations (B3LYP5/3-21G/RHF), the positive charge on the central carbon atom in the series diphenylcarbodiimide 100A, tert-butylphenylcarbodiimide 100B, and dicyclohexylcarbodiimide 100C decreases in the order: $0.846,0.805$ and 0.783 (Scheme 100). A similar comment can be made about the chemical hardnesses of these molecules: ( $\eta=6.45,6.12,5.73 \mathrm{eV}$, respectively).

In the case of diphenylcarbodiimide, the electron withdrawing phenyl substituents significantly enhance the electrophilicity of the molecule. This makes it possible not only to react quickly with the carbene molecule, but also to interact with the zwitterionic compound (99C) eventually forming the spiro-adduct 99D.

tert-Butylphenylcarbodiimide is less electrophilic, hence only one molecule of the carbodiimide reacts with the carbene. The electrophilicity of dicyclohexylcarbodiimide is the smallest calculated and reaction with the carbene is not observed even under forcing conditions $\left(100{ }^{\circ} \mathrm{C}\right)$.

The adducts of carbenes and azolides, such as phosphabenzimidazolide 100D, which serve as active carbenoids, ${ }^{376}$ participate in a similar reaction with di-tert-butylcarbodiimide. 


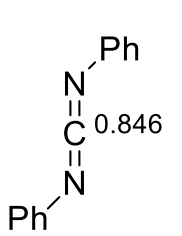

$\eta 6.45 \mathrm{eV}$

A

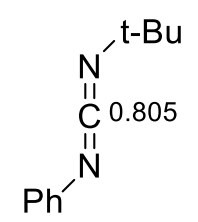

$\eta 6.12 \mathrm{eV}$

B

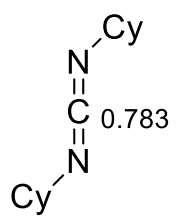

$\eta 5.83 \mathrm{eV}$

C

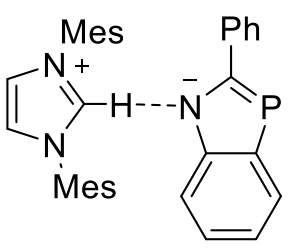

D

Scheme 100. Calculated carbon charges and chemical hardnesses for carbodiimides and a carbenephosphazole adduct.

\subsection{Carbenes in the synthesis of zwitterionic and ionic compounds}

Since they have both basic and nucleophilic properties, azolylidenes are capable of forming polarized products (zwitterionic or ionic compounds) with electrophiles, due to a shift of the electron density (electron transfer) from the carbene to the electrophilic part of the molecule or the breakaway of an acidic proton(s) by the carbene.

4.5.1. Reactions with esters. Interaction with a malonic ester (a carbene version of the Claisen reaction). Given the presence of $\alpha$-protons in the ester molecule, insertion reactions into the $\mathrm{C}-\mathrm{H}$ bond of the substrate might be expected. However, it was found that the stable carbenes 101A reacted instead with an ester function of the malonic substrate thereby forming the heterocyclic zwitterionic compounds 101C (Scheme 101). ${ }^{197}$ Removal of the alcohol, formed during the reaction, by means of a nitrogen gas flow, promoted product formation.

Initially the carbene nucleophilically attacks the ester carbonyl group to form the zwitterionic intermediate 101B. This is stabilized by removal of the alcohol molecule and subsequently forms the anionconjugated zwitterionic product 101C. The observed reaction is a carbene version of the Claisen reaction (leading to the condensation of two carbon compounds with the participation of an ester group). As in the traditional Claisen reaction, the carbene can be regarded as being analogous to an anionic methylene group that has been formed by deprotonation of the appropriate azolium salt.

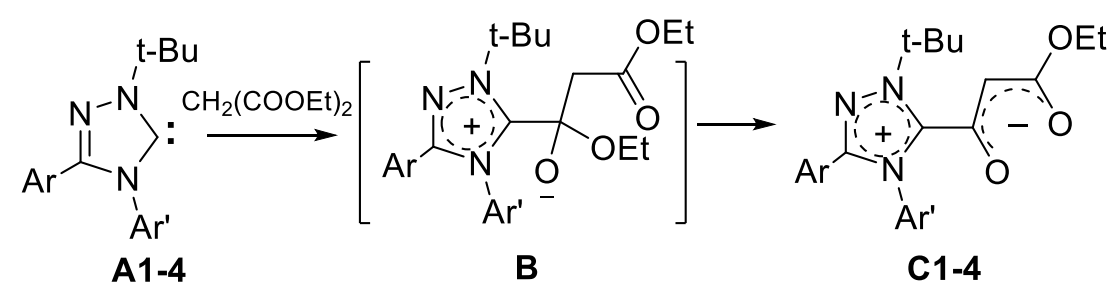

$\mathrm{A}, \mathrm{C} \mathrm{Ar}=\mathrm{Ph}, \mathrm{Ar}^{\prime}=p-\mathrm{BrC}_{6} \mathrm{H}_{4}(\mathbf{1}) ; \mathrm{Ar}=\mathrm{Ar}^{\prime}=\mathrm{Ph}(2) ;$

$\mathrm{Ar}=\mathrm{Ph}, \mathrm{Ar}^{\prime}=p-\mathrm{FC}_{6} \mathrm{H}_{4}(3) ; \mathrm{Ar}=0-\mathrm{ClC}_{6} \mathrm{H}_{4}, \mathrm{Ar}^{\prime}=p-\mathrm{FC}_{6} \mathrm{H}_{4}(4)$

Scheme 101. Carbene version of the Claisen reaction with a malonic ester.

Deesterification reactions. In the absence of $\alpha$-protons, esters react in a different fashion. Thus, when carbene 102A is heated with methyl benzoate in toluene solution, deprotonation of the methyl ester group occurs to form the triazolium benzoate $102 \mathrm{C}$ (deesterification). This is accompanied by the elimination of ethylene (Scheme 102). ${ }^{218}$ In contrast to the ester saponification reaction, this transformation takes place in 
non-aqueous media. The reaction with diethyl oxalate also proceeds extremely quickly (within a few minutes at room temperature) to form the salt 102D.

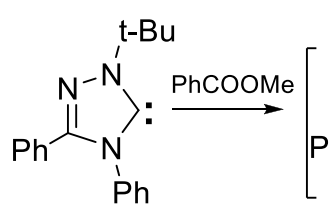

A

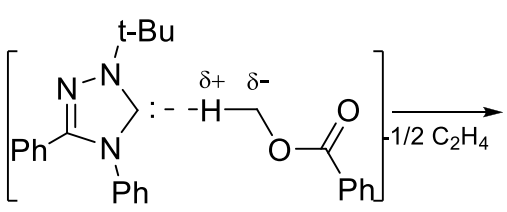

B

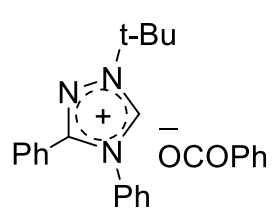

C

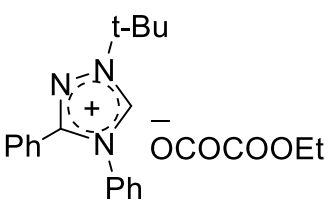

D

Scheme 102. Deesterification reaction by 1-tert-butyl-3,4-diphenyl-1,2,4-triazol-5-ylidene.

The anions of azolium perchlorates can also be replaced using a similar method. Heteroaromatic salts that would otherwise be difficult to prepare can easily be isolated. ${ }^{32}$

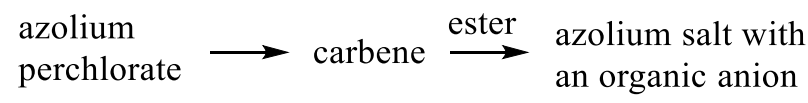

Reactions with acetoacetic ester, 1,3-dimethylbarbituric acid and malononitrile. Reaction of the carbene 103A with the acetoacetic ester (pKa 11), 1,3-dimethylbarbituric acid (pKa 4.68) and malononitrile (pKa 11-12) produces the organic salts 103A1-3 as a result of deprotonation of the substrates by the carbene (Scheme 103). The salt $103 \mathrm{~A} 1$ was isolated as a toluene solvate. ${ }^{197}$

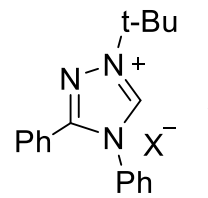

A

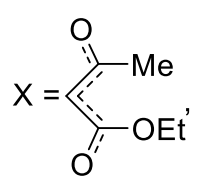

A1

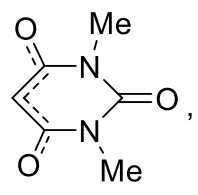

A2<smiles>N=C=C=N</smiles>

A3

Scheme 103. Products of deprotonation of C-H acids by 1-tert-butyl-3,4-diphenyl-1,2,4-triazol-5-ylidene.

This is in contrast to the results of the interaction of dithiolenylidene dimers with malononitrile. ${ }^{377}$ Singlet nucleophilic carbenes of the type $102 \mathrm{~A}$ are capable of deprotonating the above substrates to form the salts $103 \mathrm{~A}$.

Some preliminary conclusions can be drawn on the basis of the observed transformation routes. These are helpful in predicting the outcomes of the reactions of carbenes with $\mathrm{C}-\mathrm{H}$ acids. For example, 1,2,4-triazol-5ylidenes give the corresponding salts when reacted with $\mathrm{C}-\mathrm{H}$ acids having a $\mathrm{p} K_{\mathrm{a}}$ less than 12 (e.g., 1,3dimethylbarbituric acid ( $\left.\mathrm{pK}_{\mathrm{a}} 4.68\right)$, malononitrile $\left(\mathrm{p} K_{\mathrm{a}} 9\right)$ and the acetoacetic ester $\left.\left(\mathrm{pK_{a }} 11\right)\right)$. The malonic ester $\left(\mathrm{pK}_{\mathrm{a}} 12-13\right)$ also generated the corresponding salts when reacted with carbenes. Upon heating these undergo rearrangements involving the ester groups to afford zwitterionic compounds. ${ }^{218}$ Insertion of the carbene into a $\mathrm{C}-\mathrm{H}$ bond of the substrate proceeds with the less acidic acetonitrile $\left(\mathrm{p} K_{\mathrm{a}} 25\right)$.

It should be emphasized that the nature of the transformation products greatly depends on the type and properties of the particular carbene used. For example, 1,3-di(1-adamantyl)imidazol-2-ylidene, some aromatic derivatives of the 1,2,4-triazol-5-ylidenes and conjugated biscarbenes of the type 9A do not react with acetonitrile, at least under mild conditions. On the other hand, 1,3-dimesityl-4,5-dihydroimidazol-2-ylidene is easily inserted into the $\mathrm{C}-\mathrm{H}$ bonds of some of the compounds. Generally speaking, the more basic carbenes undergo deprotonation more easily than do their less basic analogues. 


\subsubsection{Formation of zwitterionic compounds in reactions with other multiple bonds and cyclic sulfoesters.} To obtain new types of zwitterionic heterocyclic compounds, it is worth focussing on the reactions of carbenes with some activated multiple bonds and cyclic ester groups. The zwitterionic compound 104B was isolated from the reaction of the carbene 104A1 with benzylidenemalononitrile (Scheme 104). The reaction of the carbenes 104A1,2 with propanesultone proceeds, with ring opening of the latter, thereby forming the zwitterionic compounds $104 C 1,2 .^{218}$

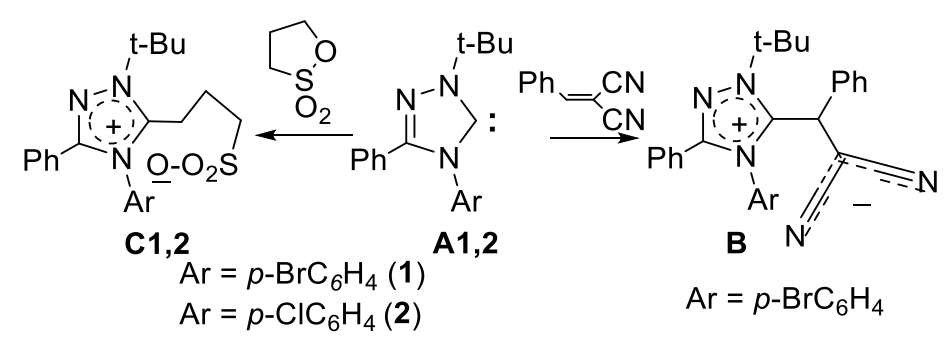

Scheme 104. Synthesis of zwitterionic compounds from 1,2,4-triazol-5-ylidenes and electrophiles.

Treatment of the $o$-dicarbethoxyvinyl substituted $N$-phenylimidazolium salt 105A with silver oxide or carbonate resulted in a similar in situ reaction. Proton migration is followed by oxidation and formation of the fused ring compound 105B (Scheme 105). ${ }^{378}$
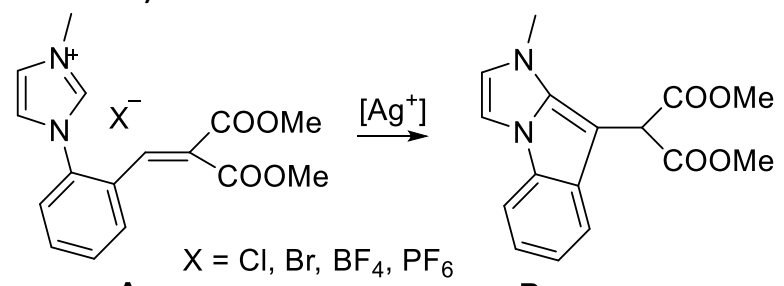

A

B

Scheme 105. Carbenoid cycloaddition in an olefinic derivative of imidazolium salts.

The reaction of stable carbenes with methylphenylketene resulted in the generation of new zwitterionic compounds, namely the azolium enolates 106B as a mixture of two isomers (Scheme 106). ${ }^{379}$ The latter compounds are ambident in terms of their reactivities. For example, they react with carbocations to form both azoliumketones 106C and azoliumalkenes 106D.

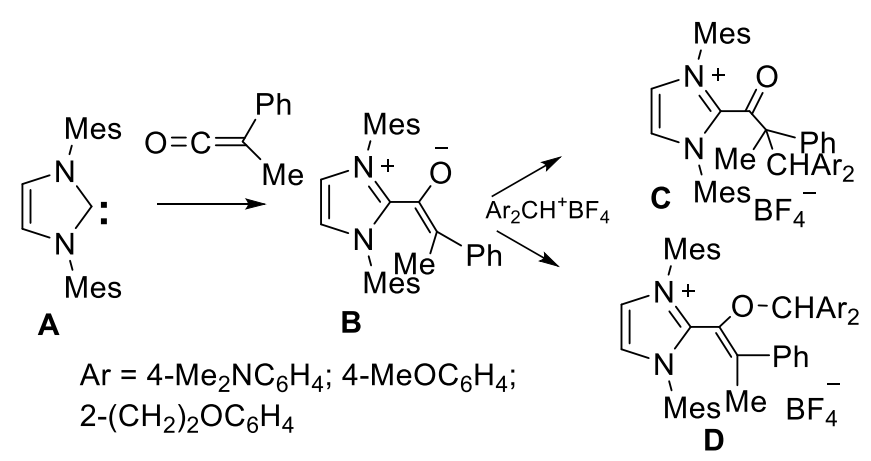

Scheme 106. Addition of methylphenylketene to imidazol-2-ylidenes. 
Carbene reactions with isocyanates and isothiocyanates have been well studied for in situ processes and result in spirocyclic products of the type 107E (with isocyanates) or zwitterionic compounds 107B (with isothiocyanates) ${ }^{7}$ (Scheme 107). For isolated carbenes the same reactivity was confirmed in the case of 1,3,4triphenyl-1,2,4-triazol-5-ylidene. ${ }^{327}$ Later it was found that, due to the reversible nature of the reaction of 1,3dimesityl- or 1,3-bis-Dipp-substituted imidazol-2-ylidenes with phenylisocyanate, catalytic trimerization of the latter forms 1,3,5-triphenylisocyanuric acid 107D. ${ }^{380,381}$

The reversibility of the reaction was confirmed by the transformation of zwitterion 107B with sulfur, which resulted in the formation of the imidazole-2-thione 107C. Similarly, carbenes are known to cause polymerization of lactides and other related electrophiles. ${ }^{21,381}$

Recently, the possibility of carrying out three-component reactions involving carbenes, methyl methacrylate and isocyanates or isothiocyanates has been explored. ${ }^{382}$ However, these reactions often take place with ambiguous mechanisms.

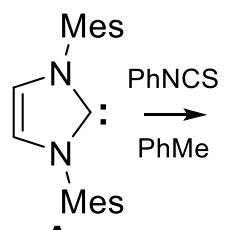

A
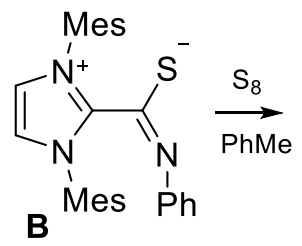
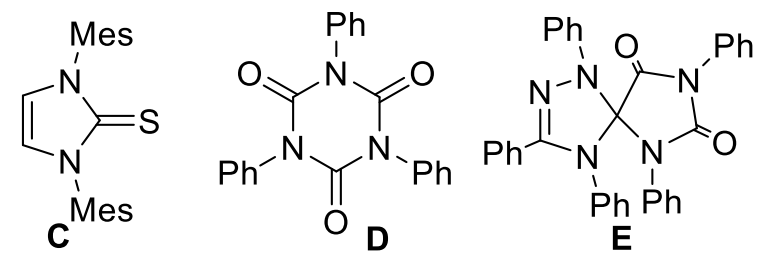

Scheme 107. Addition of isocyanates and isothiocyanates to 1,3-dimesitylimidazol-2-ylidene.

In this section, some of the major types of heteroaromatic carbene transformations have been discussed. These include autotransformations, from a simple proton to group migrations and more complicated reconstructions of the molecule. Induced tandem autotransformations of 1,2,4-triazol-5-ylidenes with a labile alkyl group at the 1-position result in the formation of amidinotriazoles. The reactions with compounds that contain mobile protons often result in the insertion of a carbene into an $\mathrm{X}-\mathrm{H}$ or $\mathrm{C}-\mathrm{H}$ bond of the substrate molecule. In some cases, $\mathrm{H}$-bonded complexes are formed, and in the case of compounds that contain multiple bonds (acetylenes, azides, carbodiimides) new heterocyclic compounds have been obtained. From the standpoint of the preparation of zwitterionic and ionic compounds, the utility of carbenes is evident from the examples of ester reactions. Among these, there is a carbene version of the Claisen reaction (the interaction of carbenes with malonic esters), and the various reactions with cyclic esters and arylidenemalononitrile.

\subsection{Reactions with non-metals and some nucleophiles}

The interactions of carbenes with active non-metals (halogens, oxygen, sulfur) have been well studied by in situ processes ${ }^{7}$ and subsequently used for transformations of individual carbenes. ${ }^{9}$

Reactions with halogens form either halogenazolium salts or carbene complexes with halogens. ${ }^{383,384}$ The structure of a reaction product with iodine proved to be a carbene complex with an extended I-I bond. ${ }^{383}$ Chlorination of imidazol-2-ylidenes was carried out using dichloroethane, and the resulting products were identified $\mathrm{L} \mathrm{Cl}_{2}$ although the exact structures were not determined. ${ }^{384}$ However, the complexes did exhibit chlorinating action, indicative of their containing a reactive $\mathrm{Cl}-\mathrm{Cl}$ bond. Similar chlorinated complexes from the reaction of 4,5-dichloroimidazol-2-ylidenes and $\mathrm{CCl}_{4}$ were determined to be the 2,4,5-trichloroimidazolium salts. $^{57}$

The reactions of carbenes with chalcogens have resulted in the formation of azolchalcogenones (for a recent report of fused carbenes, see, e.g., reference 385). The oxidation of even relatively stable carbenes 
with triplet oxygen occurs rapidly. For example, passing anhydrous oxygen through a THF solution of 1-tertbutyl-3-phenyl-4-( $p$-bromophenyl)-1,2,4-triazol-5-ylidene 42D6 causes the oxidation to proceed over an $8 \mathrm{~h}$ period ( $24 \mathrm{~h}$ in the case of toluene) at room temperature; the corresponding triazolone is formed. In the case of some carbene complexes of copper(I), the oxidation process is even faster due to the catalytic action of the metal. ${ }^{386}$ Even dimethylformamide transfers its oxygen atom to the carbene ligand of the complex under mild conditions.

Singlet oxygen ${ }^{1} \mathrm{O}_{2}$ can be generated by UV irradiation of triplet ${ }^{3} \mathrm{O}_{2}$ in the presence of meso-tetraphenylporphyrin. The interaction of imidazol-2-ylidenes with ${ }^{1} \mathrm{O}_{2}$ in deuterobenzene results in the formation of two products, namely the diimine $108 \mathrm{C}$ and the imidazolium carboxylate 108D. ${ }^{387}$ Both result from the decomposition of the intermediate peroxide 108B (Scheme 108).

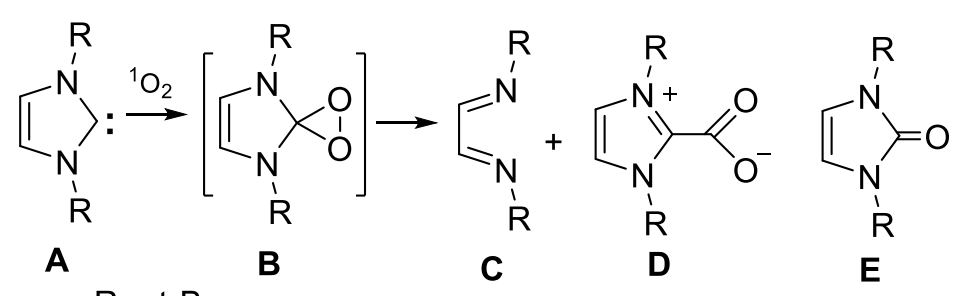

Scheme 108. Oxidation of imidazol-2-ylidenes with singlet oxygen.

The oxidation of the above-mentioned carbene with ${ }^{1} \mathrm{O}_{2}$ also proceeds easily in the presence of diphenyl sulfoxide. However, diimine formation is significantly suppressed, such that the imidazolone 108E and diphenyl sulfone become the major products of the reaction.

The interaction of carbene compounds with sulfur, selenium or tellurium normally proceeds readily at room temperature, even in the case of the dimesityl substituted carbenes. ${ }^{57}$ The reaction of 1,3-diadamantylbenzimidazol-2-ylidene with sulfur ${ }^{104}$ also results in the formation of an azolethione in high yield. Additionally, a quite labile, deeply colored reaction product was isolated (probably a hypervalent compound of sulfur). The latter was easily oxidized and hydrolyzed thus forming the expected azolethione. In contrast, selenium does not react with the carbene under these conditions; steric hinderence blocks the approach of molecular selenium to the reaction center. These observations may shed light on why the thione yields are sometimes decreased in these reactions; it may be due to an unusual reaction pathway involving hypervalent sulfur compounds.

The reactions of carbenes with chalcogens are sometimes used in organic synthesis. For example, the in situ reactions of $N$-substituted imidazoles and benzimidazoles 109A1-3 with epichlorohydrin and sulfur take place via cyclization of the intermediate cations $\mathbf{1 0 9 C , H}$ thus forming the thiirane derivatives of azolones $109 \mathrm{I}$ in high yields (Scheme 109)..$^{388}$ Isolation of the stable $N$-glycidylazolium salts $109 \mathrm{C}$ and the related $N$ glycidylazinium (pyridinium and quinolinium) salts is an argument in favor of the reaction route (a) that involves the salts $109 \mathrm{C}$ and carbenes 109D (Scheme 109). ${ }^{388,389}$ There is a second possible route (b) which proceeds via the intermediate chlorohydrin derivatives 109B,G. 


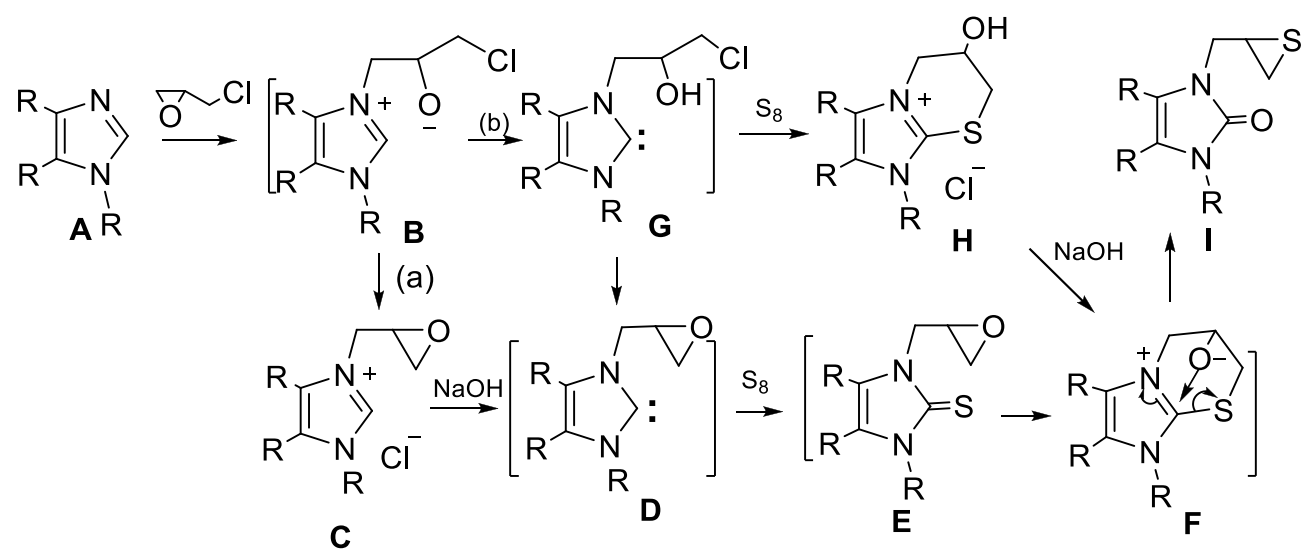

$A, C, H, I: R=H(1) ; P h(2) ; R, R=(C H)_{4}(3) ; R^{\prime}=M e$

Scheme 109. Carbenic transformation of imidazoles with epichlorohydrine and sulfur.

In contrast to the transformations of halogens and chalcogens, the reactions of nonmetals such as hydrogen and phosphorus have only recently attracted attention. Highly active, non-aromatic carbenes (for example, the pyrrolidin-2-ylidenes reported by Bertrand et al.) serve as activators of hydrogen, thus allowing the reduction reaction to run more easily. However, imidazol-2-ylidenes and 1,2,4-triazol-5-ylidenes do not react with hydrogen.

Reactions with white phosphorus proceed more easily. As in the case of the non-aromatic carbenes (the pyrrolidinylidenes of Bertrand et al., or the 4,5-dihydroimidazol-2-ylidenes), the aromatic imidazol-2-ylidenes react with phosphorus to form stabilized phosphorous units, ranging in size from 2 to 12 phosphorus atoms (see, e.g., 110A ${ }^{323,390}$ ). The first products are formed by reaction of the carbene with the simple molecule, $\mathrm{P}_{4}$ 110B. Heating produces more complicated compounds such as 110C (Scheme 110).

An adduct of a carbene and $\mathrm{PCl}_{3}$ has been reduced using potassium graphite $\mathrm{KC}_{8}$ to give a compound with two phosphorus atoms. ${ }^{323}$

Phosphorus atoms are liable to oxidation with triplet oxygen. Thus, a product with two phosphorus atoms such as $\mathrm{RI}=\mathrm{P}-\mathrm{P}=\mathrm{IR}$ (where IR represents the 1,3- $\mathrm{R}_{2}$-imidazol-2-ylidenes) can be oxidized to the tetraoxide $\mathrm{RI}=\mathrm{P}\left(\mathrm{O}_{2}\right)-\mathrm{P}\left(\mathrm{O}_{2}\right)=\mathrm{IR}$ either with cooling or at room temperature. ${ }^{391,392}$
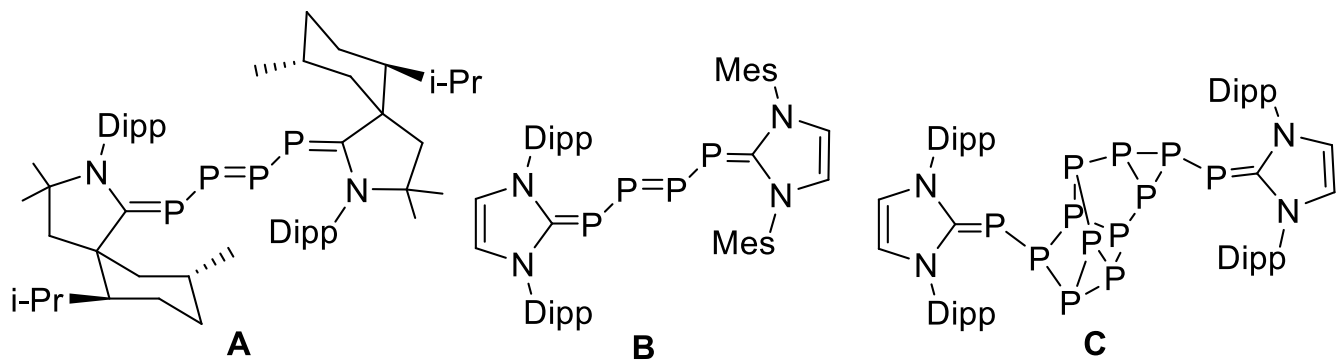

Scheme 110. Adducts of carbenes and phosphorus.

Nucleophiles, such as carbon(II) monoxide and isonitriles, do not react with aromatic nucleophilic carbenes. However, they do react readily with more electrophilic non-aromatic carbenes, even at ambient temperature and pressure. ${ }^{323,393}$

Generally speaking, the outcomes of these reactions are dependent upon thermodynamic factors. For example, if the reaction enthalpies for aromatic carbenes are close to zero or positive, then for the more 
electrophilic carbenes, these values are significantly negative. However, the absence of products for the reactions of carbon(II) monoxide with diaminocarbenes (which react readily with isonitriles) cannot be explained by this reasoning. The authors believe that the ketene formed initially undergoes further reaction with the diaminocarbene. However, it has proven impossible to isolate any reaction products.

\section{Catalytic Properties of Carbenes and their Complexes with Transition Metals}

The favourable catalytic properties of transition metal carbene complexes were reported in the literature long before the first syntheses of stable carbenes. ${ }^{21,394-396}$ Catalysis by carbenes had long been known and exploited. However, they were usually generated in situ which generally did not produce pure, isolable carbenes. ${ }^{24}$ In the case of the thiazol-2-ylidenes and the benzothiazol-2-ylidenes, the formation of carbene dimers resulted in the catalytic effect, and had been utilized, e.g., for benzoin condensation. As a result of the syntheses of individual carbenes (Bertrand, Arduengo et al.) new catalysts became available. ${ }^{21,23,24,26,28-30}$ It became possible to use the pure carbenes as catalysts and to prepare pure complex compounds for catalysis using individual carbenes.

The present section will focus briefly on some of the well-known catalytic transformations, for which new and unusual properties have been revealed. Their effectiveness as catalysts for possible use in industry will be discussed. The use of pure individual carbenes is of particular importance, since their level of efficiency exceeds those of their in situ generated analogues. To evaluate the effectiveness of catalysis, the indices TON (turnover number) and TOF (turnover frequency) have been used in many studies. ${ }^{21}$ TON represents the number of cycles of catalytic transformation and is equal to the ratio of the number of moles of the product to the number of moles of the catalyst. Overall, it is a measure of catalyst activity. TOF corresponds to the value of TON for a certain period of time, usually 1 hour (measured in $\mathrm{h}^{-1}$ ) and is a measure of catalyst performance. It is often convenient to compare the relative efficiency values, RTON (relative TON), taking the lowest value per unit.

\subsection{Catalysis by carbenes}

The present section focuses on only two types of reactions: 1) the transesterification reaction and 2) the benzoin condensation reaction, for which high catalytic efficiencies were achieved.

5.1.1. The transesterification reaction. The transesterification reaction is an important method of fine organic synthesis, which finds multiple uses in industry. In addition to the synthesis of drugs, this reaction can be utilized for the industrial synthesis of biodiesel fuels. Transesterification reactions can be catalyzed by both acids and bases. However, it is best to use basic catalysis, since this limits the corrosion of equipment in industrial applications.

$$
\mathrm{RCOOR}^{\prime}+\mathrm{R} " \mathrm{OH} \stackrel{\text { cat }}{\longrightarrow} \mathrm{RCOOR"} \mathrm{+} \mathrm{R'OH}
$$

Stable carbenes are highly basic catalysts and have been used to catalyze the reaction of methyl benzoate in an excess of ethanol to form ethyl benzoate. ${ }^{397,398}$ The carbene was combined with stoichiometric amounts of the required reagents in the presence of molecular sieves. ${ }^{399-401}$ In the first case, catalysis with imidazol-2ylidenes in the presence of primary alcohols, resulted values for TON and TOF of 17-19 and $1 \mathrm{~h}^{-1}$. In a subsequent set of reactions, the values obtained were 20-60 and 30-220 $\mathrm{h}^{-1}$, respectively. Very efficient 
transesterification takes place with vinyl ethers (TON to 200 and TOF to $2300 \mathrm{~h}^{-1}$ ) but proceeds irreversibly due to the release of acetaldehyde.

Important results were obtained recently for the transesterification of ethyl benzoate in methanol using carbene catalysis. ${ }^{402,403}$ The carbenes were added either in a pure individual form (111A,I) (Scheme 111) or generated in situ via the reaction of potassium alkoxides with organic perchlorate salts (methanol -substrate ratio of 1:9). The catalyst loading in most cases was 0.04 mol\%. The study showed that the catalytic efficiency depended greatly on the type of carbene that was used. In the case of the triazolylidenes $\mathbf{1 1 1 A}, \mathbf{B}$, the lowest values were obtained (TON 175-255, TOF 44-64 $\mathrm{h}^{-1}$, RTON 1.0-1.5). For benzyl- and methyl-substituted imidazol-2-ylidenes and benzimidazol-2-ylidenes 111C-E, the TON was almost an order of magnitude higher (TON 1625-1800, TOF 406-450 $\mathrm{h}^{-1}$, RTON 9.3-10.3). The efficiencies of the diaminocarbenes 111F,G and cycloheptadienylidene 111H (TON 2100-2250, 525-553 TOF $\mathrm{h}^{-1}$, RTON 12.0-12.9) were even higher, particularly, in the case of the adamantyl derivatives of benzimidazol-2-ylidene and the imidazol-2-ylidenes 111I-K (TON 2338-2350, TOF 584-588 $\mathrm{h}^{-1}$, RTON 13.3-13.4).

Biscarbenes of the 1,2,4-triazole series 112A were also less efficient (per nucleus), being similar to their monocarbene analogues. However, they were 1,8 times more effective (Scheme 112) than the monocarbene 111A. A significant increase in the catalytic efficiency was observed in the case of the bisimidazol-2-ylidenes 112B,C. Moreover, the system with a xylylene bridge $112 \mathrm{C}$ is almost twice as effective (TON 2175, TOF 544 $\mathrm{h}^{-1}$, RTON 6,2), than that with an aliphatic bridge 112B (TON 1300, TOF $325 \mathrm{~h}^{-1}$, RTON 3.7). The efficiencies of the polycarbenes with a xylylene bridge 112D,E (TON 2100-2350, 525-588 TOF ${ }^{-1}$, RTON 6.0-6.7) were close to that of the biscarbene $112 \mathrm{C}$, which also contains the same structural moiety. Overall, however, the simplest polymer with a xylylene bridge $\mathbf{1 1 2 F}$ turned out to be the most effective (TON 2350, TOF $588 \mathrm{~h}^{-1}$, RTON 13.4).

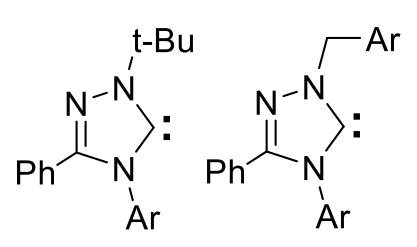

A

RTON 1.0 TON 175 TOF 44<smiles>[C]1N(Cc2ccccc2)C=CN1Cc1ccccc1</smiles>

C

RTON 9.3 TON 1625 TOF 406<smiles>CN1CN(C)c2ccccc21</smiles>

E RTON 10.3 TON 1800 TOF 450

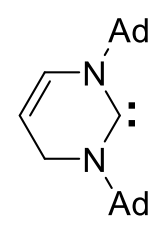

F

RTON 12.0

TON 2100 TOF 525

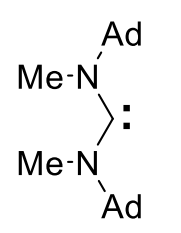

G

RTON 12.6 RTON 12.9

TON 2213 TON 2250

TOF 553 TOF 563<smiles>[AlH2]N1[CH]N([AlH2])c2ccccc21</smiles>

\begin{tabular}{lll}
\multicolumn{1}{l}{$\mathbf{I}$} & \multicolumn{1}{c}{$\mathbf{J}$} & $\mathbf{K}$ \\
RTON 13.3 & RTON 13.3 & RTON 13.4 \\
TON 2338 (2600) & TON 2338 (3500) & TON 2350 (4300) \\
TOF 584 (650) & TOF 584 (875) & TOF 588 (1075)
\end{tabular}

Scheme 111. Catalytic efficiencies of monocarbenes in the transesterification reaction of ethyl benzoate in methanol. 


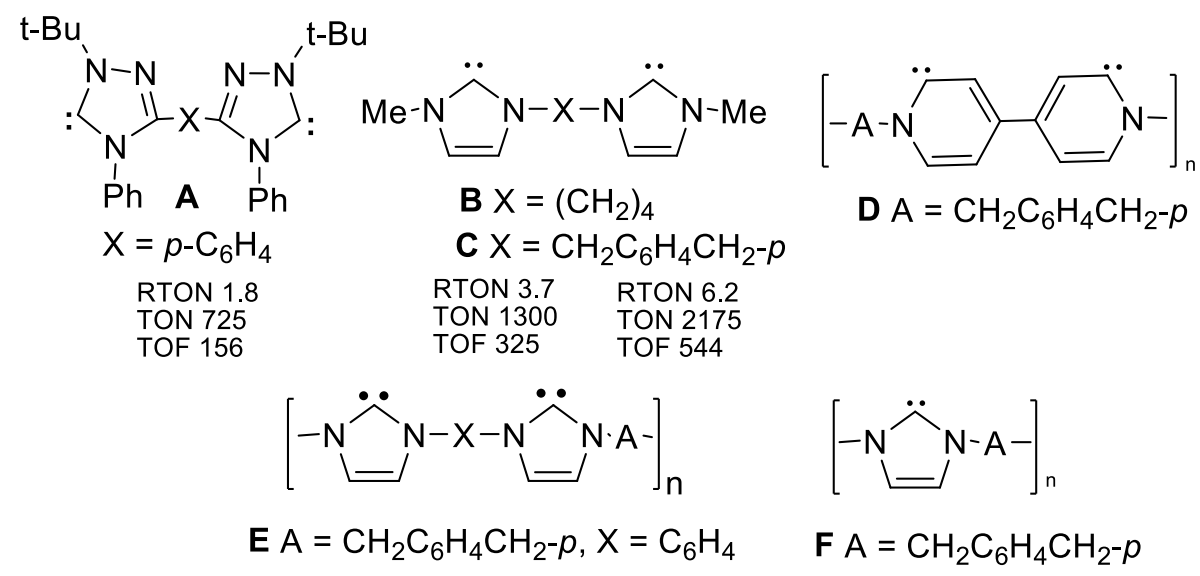

Scheme 112. Catalytic efficiencies of bis- and poly-carbenes in the transesterification reaction of ethyl benzoate in methanol.

The reverse reaction of methyl benzoate in excess ethanol in the presence of the catalyst 112F, was less favourable thermodynamically (the molar ratio of substrate-ethanol was 1:9, the catalyst loading was 0.04 mol\%). The TON reached 168 cycles, which is almost an order of magnitude higher than that for a similar reaction that was studied in the following works. ${ }^{397,398}$

A dilution experiment was carried out with a ratio of substrate to methanol of 1:18 and a catalyst loading of $0.01 \mathrm{~mol} \%$. The best catalysts, as shown by the highest efficiencies, were the carbenes $111 \mathrm{~K}$ and $112 \mathrm{~F}$ (TON 4000-4300). Using the same conditions, the carbenes 1111,J were significantly inferior (TON 2600 and 3500, respectively). However, the use of the pure carbene $\mathbf{1 1 1 l}$ (instead of the in situ generated product) resulted in an enhanced effect (TON 6150).

Thus, the following conclusions can be drawn:

1) The most efficient catalysts for the transesterification reaction have adamantyl and aromatic groups (even non-connected with a nucleus as in the case of the xylylenes) (111F, $\mathbf{G}, \mathbf{I}, \mathbf{J}, \mathbf{K}$, and $\mathbf{1 1 2 F})$.

2) Individual carbenes are substantially more effective than those generated in situ (for carbene 111 l by 2.6 times). The efficiency of catalysis is also dependent on the method used for generation of the carbene.

The efficiency was observed to increase for carbenes generated from the action of alkoxides on organic perchlorate salts. This occurs because the perchlorate anions are almost completely removed from the solution in the form of a poorly soluble potassium perchlorate.

5.1.2. Benzoin condensation. The asymmetric carbene catalysis of this reaction results in high yields and (in some cases) enhanced enantioselectivity of the benzoin derivatives. ${ }^{21,24}$ However, the efficiencies of the currently available catalysts are insufficient. Typically, high loadings of the catalyst are used (up to $10 \mathrm{~mol} \%$ ) for this reaction. However, this approach is not appropriate for the synthesis of expensive chiral catalysts and their reaction products.

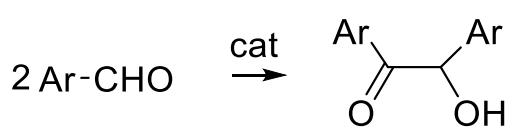

The pure carbene 1,3,4-triphenyl-1,2,4-triazole-5-ylidene 113A reported by Enders et al. has been used as a catalyst in the condensation of 5-(3-trifluoromethylphenyl)furfural in tetrahydrofuran solution. Its carbenoid methoxyazoline form 113B, and the in situ generated 3-benzyl-4-methyl-5-(2-hydroxyethyl)-thiazol-2-ylidene 
113C (all at 5 mol\%) were also tested. TON indices of 19.2, 17.8 and 17.2, respectively, were obtained (Scheme 113). ${ }^{404}$ The reaction of furfural without a solvent was carried out with smaller loadings of Enders' carbene (1 mol\%). This reaction resulted in a TON of 78 and a TOF of $156 \mathrm{~h}^{-1}$.

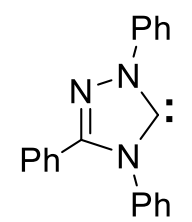

A

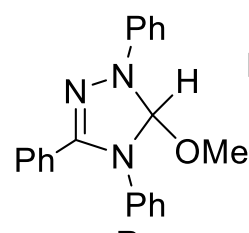

B<smiles>CC1=C(CCO)SC=CN1Cc1ccccc1</smiles>

C

Scheme 113. Efficient catalysts of the benzoin condensation reaction.

The efficiencies of the catalysts $\mathbf{1 1 1}, \mathbf{K}$ generated in situ (two of the best for the transesterification reaction) were very moderate for the reaction of furfural (TON 10.8 and $15.4 \mathrm{~h}^{-1}$ when loaded at 5 mol\%). However, in the case of the individual carbene 111 l the value was significantly higher (TON 62 at a loading of 1 mol\%). Using a load of 0.5 mol\% of catalyst the achieved TON is maximal for this reaction (120).

A possible reason for the poor catalytic efficiency of carbenes in the benzoin condensation reaction is the hypersensitivity of the carbene catalyst (or their intermediates in the catalytic cycle) to the presence of small amounts of oxygen and moisture. Their presence prevents the regeneration of the catalyst. In the transesterification reaction, the entry of the carbene into the catalytic cycle is carried out in an alcohol protected form (hydrogen carbene complexes with alcohols or alkoxyazolines are less sensitive to these agents) and hence the results are significantly better.

\subsection{Catalysis by carbene complexes of transition metals}

Complex carbene catalysts were used for the first time in the 1970s. Today, this type of catalysis is now widely utilized (see e.g., the following reviews $21,26,30,395,405,406$ ). The reaction center in the complex is an electrophilic metal atom. At the same time, the carbene has a significant impact on the state of the former by its strong electron donating effect, and its steric influence. This results in a strengthening of the metal-ligand bond compared to those in, for example, phosphine complexes. The result is a change in the characteristics of the catalyst, such as the strength of its binding to other ligands. A study of the impact of the foregoing factors, including steric influence of the carbene ligand on catalyst efficiency, is in progress. Although many of the mechanisms of the catalytic processes are well known, complete control over the efficiency of such catalysts has not yet been discovered.

Given the preceding information, it is important to consider some empirical observations from two types of reactions: 1) reduction of multiple bonds by alcohols and 2) reductive dehalogenation (hydrodehalogenation) of haloarenes. The influence of the catalyst on these transformations has been studied using the classes of carbene complexes described herein.

5.2.1. Reduction of multiple bonds with alcohols (hydrogen transfer). This reaction involves the reversible interaction of an alcohol with a multiple bond, such as is found in carbonyl compounds, imines and olefins, in order to produce the desired reduction product (alcohol, amine or alkane). ${ }^{21,405}$ Generally the reaction takes place in the presence of a base and under catalytic promotion by a metal complex. In this process the base reacts reversibly with the alcohol to form an alkoxide. The alkoxide is the source of a hydride ion that undergoes transfer, thus transforming itself into another carbonyl compound (e.g., to acetone from isopropanol). 
$\prod_{\mathrm{O}}^{\mathrm{R}}+{\underset{\mathrm{OH}}{\mathrm{R}}}_{\mathrm{B}}^{\mathrm{Me}} \underset{\mathrm{OH}}{\mathrm{cat}} \mathrm{Y}^{\mathrm{R}}+\prod_{\mathrm{O}}^{\mathrm{Me}} \prod^{\mathrm{Me}}$

This reaction can be used for fine organic synthesis and, like many catalytic processes, potentially could be a solution for "green chemistry" problems. The reaction is also extremely important for the pharmaceutical industry. However, its utilization in asymmetric reactions has not very effective thus far. ${ }^{405}$

Many carbene complex catalysts have been suggested in the literature. However, the most effective of those studied so far are complexes of rhodium, iridium and ruthenium. The reaction of acetophenone with isopropanol and aldehydes in the presence of $\mathrm{KOH}$ proceeds more readily than the same reaction with aromatic ketones. The TON and TOF values achieved with the catalyst 114A ( $R=i$-Pr) were 890-1000 and 220$3000 \mathrm{~h}^{-1}$, respectively (Scheme 114). ${ }^{407}$ The reaction of cyclohexanone with the catalyst 114B can produce TOF values as high as $6000 \mathrm{~h}^{-1}$, 408 while for the same reaction with $p$-chloroacetophenone the values can be as high as $11400 \mathrm{~h}^{-1} .{ }^{409}$ In the reaction of benzophenone with the same catalyst the index is substantially lower (1800 $\left.\mathrm{h}^{-1}\right)$.

Complex 114C catalyzes the reaction of benzophenone very effectively and achieves the greatest TON value (10580). However, the TOF is reduced to $441 \mathrm{~h}^{-1} .410$ Moreover, the reaction time is quite long (24 hours at a catalyst loading of $0.006 \mathrm{~mol} \%)$, and a quantitative yield of the reduction product was not obtained.

Complexes 114A (TON 4000, TOF to $\left.24000 \mathrm{~h}^{-1}\right)^{411}$ and 114D (TON to 3330, TOF to $50000 \mathrm{~h}^{-1}$ ) 412 gave the best results for TOF values. Note, however, that the structure of 114D is ionic.

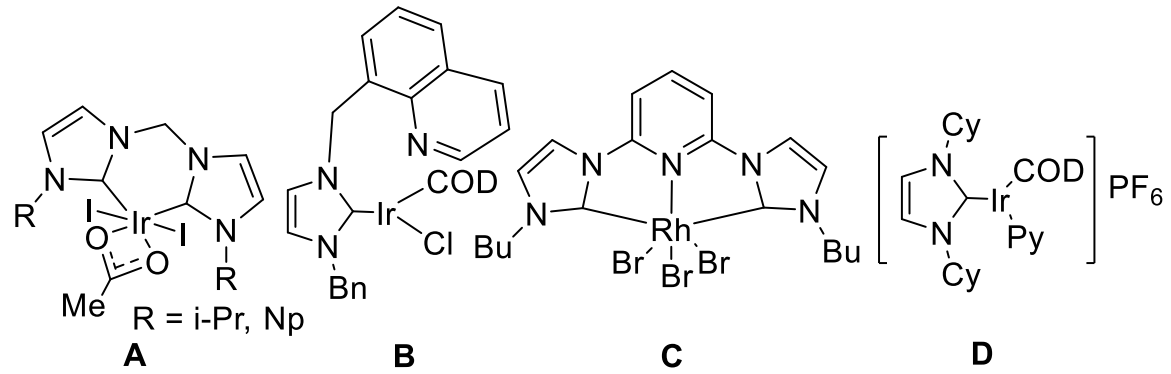

Scheme 114. Carbene complex catalysts for reduction of multiple bonds by alcohols in alkaline medium.

Three new types of transition metal carbene complexes 115A-E have been reported, all of which display high catalytic effects for the reduction of 4-phenylbenzophenone and benzophenone (Scheme 115). ${ }^{334}$ The chelated carbene complex of nickel 115A1 ( $R=1-\mathrm{Ad}, \mathrm{M}=\mathrm{Ni}$ ) has shown high catalytic efficiency (TON 4500, TOF to $1500 \mathrm{~h}^{-1}$ ). However, the value for its palladium analogue $115 \mathrm{~A} 2$ is significantly higher (TON 7000, TOF of $3500 \mathrm{~h}^{-1}$ ). A particularly high efficiency was shown by the copper biscarbene complex 115B (TON to 5000055000, TOF to 20000-22000 $\mathrm{h}^{-1}$ ).

The polymeric crown-carbene complex of copper $115 \mathrm{C}\left(\mathrm{M} 43800, \mathrm{n}_{\text {aver }}=77\right.$; TON to 80000-85000, TOF to 28330-32000 $\mathrm{h}^{-1}$ ), was found to have particularly high TON values. Neither of these systems was sterically shielded. Furthermore, the polymeric complex $115 \mathrm{C}$ has an unusually narrow molecular-weight distribution $\mathrm{K}_{\mathrm{n}}$ $\left(\mathrm{M}_{\mathrm{w}} / \mathrm{M}_{\mathrm{n}}\right)=1.03$. The cyclic complexes 115D1 (TON to 45000, TOF to $15000 \mathrm{~h}^{-1}$ ) and 115D2 (TON to 47000, TOF to $15667 \mathrm{~h}^{-1}$ ) also exhibit efficiency indices that are close to those of 115B. Note that the monocarbene copper(I) complex 115E is significantly less efficient (TON 5300, TOF $883 \mathrm{~h}^{-1}$ ) than the complexes 115B,C. 
The high catalytic effect for the carbene complexes of copper(I) 115B,C could be due, at least in part, to a high degree of $\mathrm{Cu}-\mathrm{I}$ ionization, which in turn could facilitate the exchange of halogen with the isopropoxide ion providing a reducing effect. 395

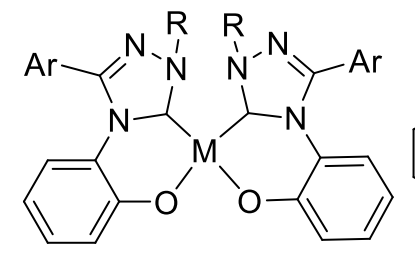

$\mathrm{A} 1,2$<smiles>CC(C)C1N(C)c2ccccc2N1C</smiles>

B

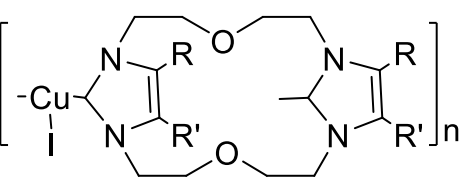

$\mathrm{R}, \mathrm{R}^{\prime}=(\mathrm{CH})_{4} \quad \mathrm{C}$

A1 $R=1-\mathrm{Ad}, \mathrm{Ar}=\mathrm{Ph}, \mathrm{M}=\mathrm{Ni}$
A2 $\mathrm{R}=\mathrm{t}-\mathrm{Bu}, \mathrm{Ar}=\mathrm{Ph}, \mathrm{M}=\mathrm{Pd}$

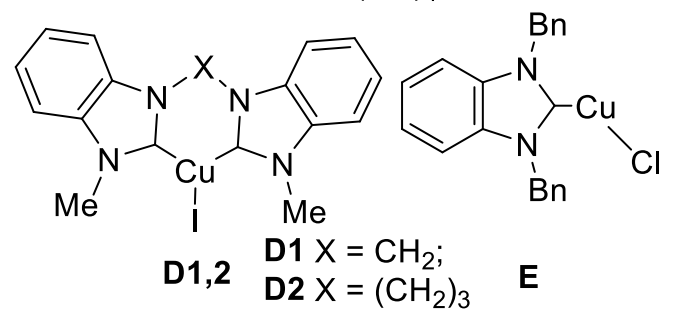

Scheme 115. New carbene complex catalysts for reduction of multiple bonds by alcohols in alkaline medium.

5.2.2. Hydrodehalogenation reactions of haloarenes. The application of this reaction is a potential solution for the environmental problems that are associated with the neutralization of haloaromatic production waste, including obsolete pesticides and used pharmaceuticals. Some of chemicals are now banned from production and use by the Stockholm convention of 22 May 2001, due to their very high toxicities (the so-called "persistent organic pollutants" - POPs). Well-known POPs of this type include such pesticides as DDT and hexachlorobenzene, dioxins (impurities to pesticides and industrial wastes), polychlorinated dibenzofurans and polychlorinated biphenyls, all of which are included on the list of the 12 most dangerous POPs.

The hydrodehalogenation reaction can be used for the effective neutralization of haloarene POPs. The reaction with metal alkoxides in alcohols in the presence of a catalyst forms metal halides and arenes. Usually a halogen atom of the haloarene interacts very strongly with the aromatic nucleus, such that replacement by other atoms or functional groups without the use of a catalyst is difficult. There are however many catalysts for the reaction. There are a number of palladium carbene complexes that are capable of achieving high yields of the desired products under relatively mild conditions $\left(60-100^{\circ} \mathrm{C}\right)$.

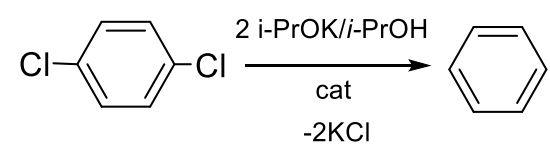

The known in situ methods of generating new catalysts are not particularly efficient (TON to 50, TOF to 50 $\left.\mathrm{h}^{-1}\right) .{ }^{413}$ However, individual complexes such as $116 \mathrm{~A}$ are able to achieve up to 200 cycles per hour at room temperature using monochlorobenzene (TON 100, TOF to $200 \mathrm{~h}^{-1}$ ). ${ }^{414}$ The complexes 116B1,2 undergo reaction with $p$-dichlorobenzene thus achieving similar results at $60{ }^{\circ} \mathrm{C}$ (TON of up to 200, TOF up to $110 \mathrm{~h}^{-1}$ ) 415 (Scheme 116). The effectiveness of the catalyst 116B2 increases significantly when $p$-dichlorobenzene is exposed to microwave irradiation at $120{ }^{\circ} \mathrm{C}$ (TON 3800, TOF to $114000 \mathrm{~h}^{-1}$ ). In fact, a quantitative yield of benzene was obtained in 2 minutes.

The carbene complexes of nickel $116 \mathrm{C}$, as well as nickel(0) complexes of the types $L \mathrm{Ni}$ and $L_{2} \mathrm{Ni}(L=I M e s)$, are not as effective as the palladium complexes. The first complex demonstrates low efficiency (TON and TOF values are 15-22, 4-44 $\mathrm{h}^{-1}$, respectively) for the debromination of $p$-bromofluorobenzene and for the 
dechlorination of $p$-chlorofluorobenzene. ${ }^{416}$ The second type of complex exhibits only moderate indices of efficiency (TON 18-31, TOF 6-10 $\mathrm{h}^{-1}$ ) for the defluorination reaction of 1-fluoronaphthalene. ${ }^{417}$

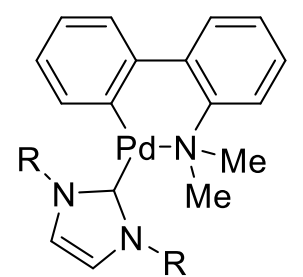

A

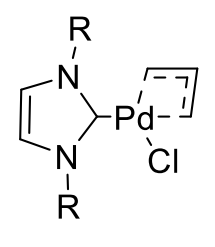

B1,2

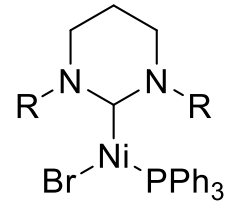

C

A, B1, C R = Dipp; B2 R = Mes

Scheme 116. Metal carbene complexes as catalysts of haloarene hydrodehalogenation.

Significantly higher TON and TOF values were obtained by using the catalyst (IPrPdCl$)_{2} 117 A 2$ for the hydrodehalogenation reaction of $3,3^{\prime}, 4,4^{\prime}$-tetrachlorobiphenyl at $80{ }^{\circ} \mathrm{C}$ in isopropanol in the presence of sodium hydroxide (10000 and $400 \mathrm{~h}^{-1}$, respectively) ${ }^{418}$ (Scheme 117). An even better result was obtained for the hydrodehalogenation of $o$-dichlorobenzene carried out under the same conditions, but with potassium tert-butoxide replacing the $\mathrm{NaOH}$ (TON 25000, TOF $1040 \mathrm{~h}^{-1}$ ). For the reaction of 1,2,4,5-tetrachlorobenzene with potassium tert-butoxide it was necessary to use the high efficiency catalysts 116B1,2, 117A1,2, the most effective of which proved to be the 117A1. For the reaction of potassium tert-butoxide and 1,2,4,5tetrachlorobenzene with 0.02 mol\% palladium, the indicated catalysts are listed on the basis of their efficiencies per one atom of chlorine (TON, TOF, $\left.h^{-1}\right)$ : $117 A 1(19700,821)>116 B 2(17250,719)>117 B 1$ $(16700,696)>116 B 1(16550,690)>117 A 2(14750,615)>117 B 2(12100,504)$.

It is noteworthy that the Dipp-substituted catalysts 117A1, 117B1 (that have more steric protection) are more efficient than the mesityl-substituted compounds $117 \mathbf{A 2}$ and 117B2, and the imidazolylidene catalysts 117A1,2 are more efficient than the 4,5-dihydroimidazolylidene analogues 117B1,2.

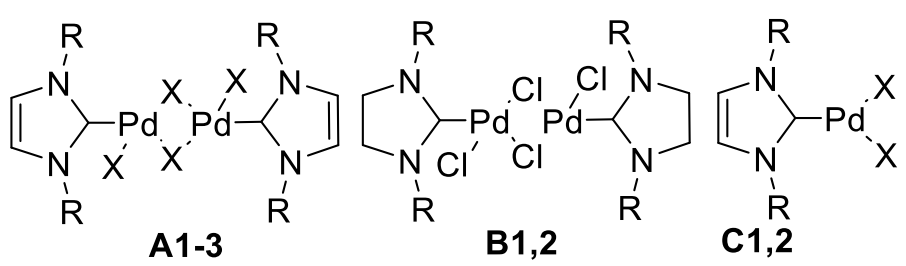

R, X: Dipp, Cl (A1, B1), Mes, Cl (A2, B2); Dipp, I (A3);

Dbep, Cl (C1), Dbep, I (C2); Dbep - 2,6-dibenzhydryl-4-ethylphenyl.

Scheme 117. Palladium carbene complexes for efficient catalysis of haloarene hydrodehalogenation.

The effectiveness of the 2-imidazol-2-ylidenes as catalysts was compared with that of the corresponding 1,2,4-triazol-5-ylidenes for the reaction of $p$-dichlorobenzene with potassium or sodium isopropoxides. These were generated in isopropanol by the addition of a variety of bases $(\mathrm{NaOH}, t$-BuOK, $t$-BuONa, MeONa). ${ }^{51,52,419,420}$ The most effective base was found to be potassium tert-butoxide.

Using potassium tert-butoxide as a reagent the following series of efficiencies was measured for the listed complexes (TON, TOF, $\mathrm{h}^{-1}$ ) (Schemes 117, 118): 118E $(160,20)<118 \mathrm{A2}(220,28)<118 \mathrm{D}(320,40) \approx 118 \mathrm{A3}$ $(320,40)$ < 118A1 $(500,62)<118 A 5(760,96)<118 B 2(1160,146)<118 B 1(1320,166)<118 A 4(1400,176)<$ 118B4 $(1440,180)<117 A 1(17600,734)<118 B 3(20000,840)<117 A 3(44000,1830)$. 
It has been shown that, in general, the efficiencies of imidazol-2-ylidene catalysts with highly electron donating aromatic substituents exceed the effectiveness of the 1-alkyl-3,4-diaryl-1,2,4-triazol-5-ylidenes. Furthermore, the iodide Dipp-substituted imidazolylidene complex 117A3 is more effective than its chloride analogue 117A1. Moreover, the iodide triazolylidene complexes 118B1, 118B3 are superior to their chloride analogues 118B2 and 118B4. However, it should also be noted that in the triazolylidene series, the monocarbene adamantyl substituted iodide complex 118B3 (TON 20000, TOF $840 \mathrm{~h}^{-1}$ ) is the most effective. In turn, 118B3 is superior in terms of efficiency to its less sterically shielded analogue 118B2 and even to that of the imidazol-2-ylidene chloride complex 117A1. The sterically open bistriazolylidene complexes 118A1-3, and even their more hindered forms 118A4,5, appear to be less effective. However, in the presence of 1 mol\% of lithium tert-butoxide, the efficiencies of these complexes increase (118B4 TON from 1140 to 8000, 117A3 TON from 44000 to 60000).
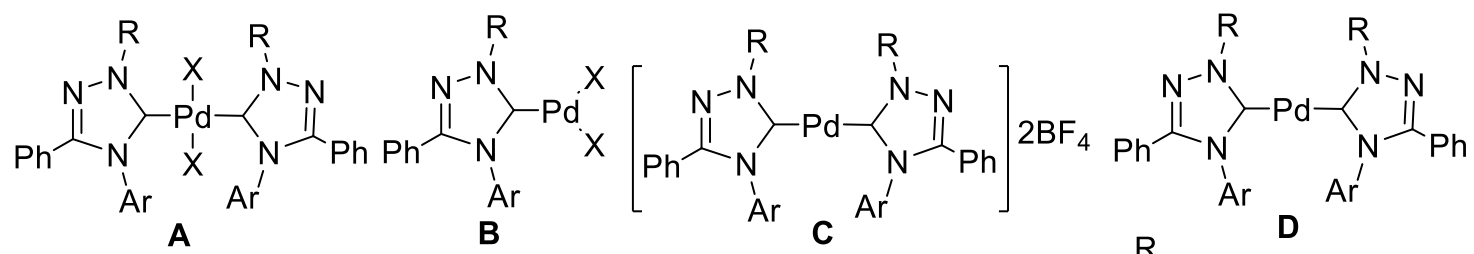

$\mathrm{R}, \mathrm{Ar}, \mathrm{X}: \mathrm{t}-\mathrm{Bu}, 4-\mathrm{BrC}_{6} \mathrm{H}_{4}, \mathrm{Cl}(\mathbf{A} 1) ; \mathrm{t}-\mathrm{Bu}, 4-\mathrm{BrC}_{6} \mathrm{H}_{4}, \mathrm{I}$ (A2); t-Bu, 4- $\mathrm{MeC}_{6} \mathrm{H}_{4}$, I (A3); Ad, Mes, I (A4) t-Bu, Dipp, I (A5); t-Bu, Dipp, I (B1); t-Bu, Dipp, Cl (B2); 1-Ad, Dipp, I (B3); 1-Ad, Dipp, Cl (B4); R, Ar: t-Bu, 4-BrC ${ }_{6} \mathrm{H}_{4}$ (D); t-Bu, $\mathrm{Ph}(\mathrm{E})$

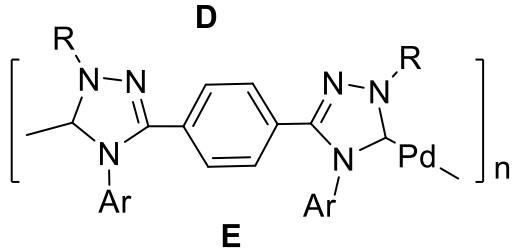

Scheme 118. Palladium 1,2,4-triazol-5-ylidene complexes for catalysis of haloarene hydrodehalogenations.

Overall, empirical observations suggest that the best catalysts in these series should be the iodide monoimidazol-2-ylidene complexes with higher steric shielding. The introduction of high volume substituents (Dbep) to the imidazol-2-ylidene complexes 117C1,2 resulted in an improvement in the efficiency of the catalysts. The reaction of $p$-dichlorobenzene, under the conditions described at $80{ }^{\circ} \mathrm{C}$, results in high indices even for the chloride complex 117C1 (TON 140000, TOF $5833 \mathrm{~h}^{-1}$ ), and those for its iodide analogue 117C2 are even higher (TON 180000, TOF $\left.7500 \mathrm{~h}^{-1}\right)^{51,52,421}$. The efficiencies of these catalysts were shown to be unusually high for the reaction of hexachlorobenzene under similar conditions. In the case of the chloride 117C1 the indices were TON $=210000$ and TOF $=8750 \mathrm{~h}^{-1}$, while for the iodide $117 \mathrm{C} 2$ they were 318000 and $13350 \mathrm{~h}^{-1}$, respectively.

Thus, the complexes $\mathbf{1 1 7 C 1 , 2}$ are the best catalysts available today for the hydrodehalogenation reaction and offer, in principle, a viable low temperature method for the industrial neutralization of persistent organic pollutants.

\section{Biological Activity of Carbene Derivatives}

Carbenes themselves are likely to be toxic, taking into account those properties of their nearest analogues (carbon(II) oxide, carbon(II) thioxide and isocyanides). However, nucleophilic carbenes are readily hydrolyzable in water. Thus, it can be assumed that the actual toxicity of stable carbenes (more precisely, their hydrolysis products) may be low, except for those compounds that have increased stability in aqueous solutions. It is known that such examples are few and far between (excluding, of course, the aforementioned carbon(II) compounds). 
In contrast to the individual carbenes, their metal complexes have been studied as biologically active substances for more than a decade; strong antimicrobial and antitumor properties have been found (see, e.g., the following reviews ${ }^{422-424}$ ). In the present section, some of the little-known antimicrobial properties of transition metal carbene complexes are described.

The diameter of growth delay (DGD) caused by the complexes 119A,C,D for the bacteria Staphylococcus aureus is $23.6-27.5 \mathrm{~mm}$ at a concentration of $0.1 \%$. For oxacillinum and vancomycin at a concentration of $0.01 \%$ the measured DGDs were 21 and $18 \mathrm{~mm}$, respectively (Scheme 119).

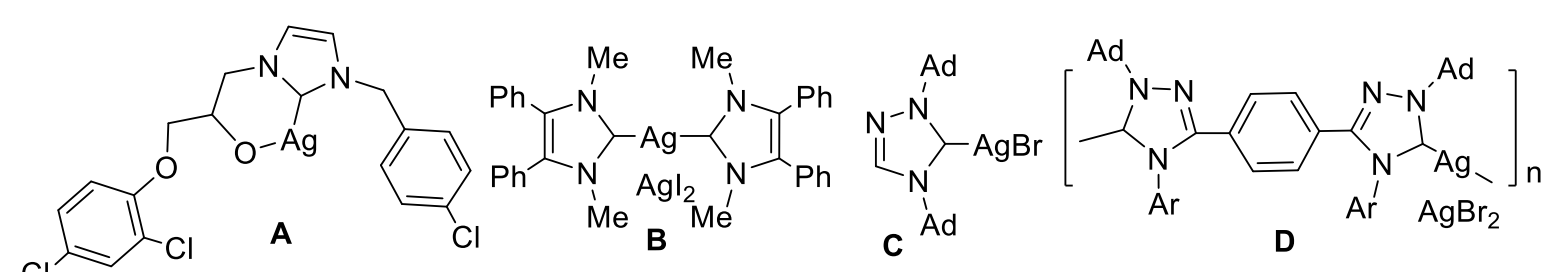

$24.0,27.5,27.6$ 19.026 .017 .0

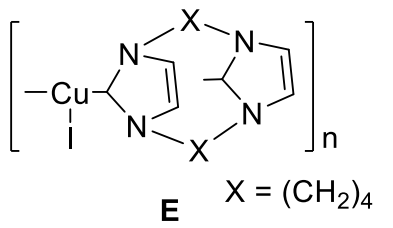

$11.6,10.6,16.6$ $11.0,8.6,16.6$

$20.0,26.3,20.3$

$18.624 .0,13.0$

$17.6,23.6,19.6$

16.316 .011 .6

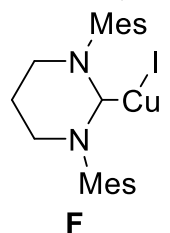

Dipp Dipp

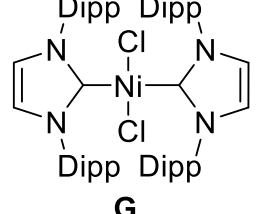

Dipp Dipp

$500,15.6,32.5,15.6,62.5$

$-, 62.5,15.6,7.8,125--, 62.5,7.8,15.6,125-, 62.5,7.8,1.9,250$

$-31.2-31.2500$

- $12531.2,31.2$,

- 125 15.6, 31.2, -

$12515.6,3.9$, -

Scheme 119. Antimicrobial activity of carbene complexes of transition metals.

For compounds 119A-D, the DGD is shown in the numerator of the scheme caption for cultures of Escherichia coli, S. aureus and Micrococcus luteus, respectively, at concentrations of $0.5 \%$. The DGDs shown in the denominator are for concentrations of $0.1 \%$. For the compounds $119 \mathrm{E}-\mathrm{H}$ the lowest inhibitory concentration (IC) is shown in the caption numerator, while the denominator lists the minimum biocidal concentration (BC) for cultures of $E$ coli, S. aureus, M. luteus, Candida tenuis and Aspergillus niger, respectively. Both $\mathrm{IC}$ and $\mathrm{BC}$ are in $\mathrm{mg} / \mathrm{mL}$ and (-) means that the minimum concentration was not attained.

For the cultures of $M$. luteus, the measured DGD values are $16.6-27.6 \mathrm{~mm}$ at a concentration of $0.5 \%$. In all cases, compound 119A is the most active (24.0, 27.5 and $27.6 \mathrm{~mm}$, respectively, for the indicated cultures), although it is close in activity to $119 \mathrm{C}(20.0,26.3$ and $20.3 \mathrm{~mm})$. It was also shown that the silver carbene complexes 119A-C exhibit a strong antibacterial effect on cultures of S. aureus and M. luteus, with 119A being particularly effective. ${ }^{425}$ The complex 119B had the lowest observed activity. The DGDs for cultures of $E$. coli at a concentration of $0.5 \%$ for the compounds $119 \mathrm{~A}-\mathrm{C}$ are $11.6-24.0 \mathrm{~mm}$. The compounds do not show pronounced antifungal properties.

Typically, carbene complexes of copper show less activity towards antimicrobial compounds than do their silver analogues. However, the complex 119E appeared to be active against cultures of S. aureus, M. Iuteum and $C$. tenuis (at inhibitory concentrations (IC) of 15.6, 32.5, $15.6 \mathrm{mg} / \mathrm{mL}$ ). The respective biocidal concentrations $(B C)$ were $31.2,-, 31.2 \mathrm{mg} / \mathrm{mL} .{ }^{426}$ The levels of biocidal activity for carbene complexes of copper iodide $119 \mathrm{~F}^{427}$ and nickel chloride $119 \mathrm{G}$ were similar. For the $C$. tenuis cultures, the carbene complex of cobalt $119 \mathrm{H}$ appeared to be the most active (IC $1.9 \mathrm{mg} / \mathrm{mL}$; BC $3.9 \mathrm{mg} / \mathrm{mL}$ ). However, it exhibited activities close to those for the related compounds $119 \mathrm{E}-\mathrm{G}$ on other cultures. ${ }^{428}$

The obtained results suggest that more significant biological effects may be achieved for carbene complexes, by varying the metal, the structure of ligand(s), and the type of complex. 


\section{Conclusions}

The heteroaromatic carbenes of the imidazole, the 1,2,4- and the 1,2,3-triazole series and their fused analogues are the most diverse divalent carbon compounds yet known in chemical research. They can be considered to be the most accessible, since their syntheses have been well developed. However, improvement of the methods used for obtaining these compounds is continuing to provide broader practical applications for individual carbenes. The newest in this series are the mesoionic carbenes (mesoions) of which two types have been prepared, namely the imidazolium-4-ides and the 1,2,3-triazolium-5-ides. Novel syntheses of individual carbenes involve the preparation of hyperbasic and hypernucleophilic systems that exhibit high electron donating behavior. Another important development is the preparation of structures with high buried volumes $\left(\% \mathrm{~V}_{\text {bur }}>50\right)$. This leads to a fundamental change in the properties of the carbene, namely they become more passive in reactions with electrophiles, in comparison to conventional carbenes. In some cases their complexes with transition metals can exhibit unusually high catalytic activity.

The need for practical applications of pure carbenes (instead of using reaction mixtures) is becoming more urgent. From the standpoint of organic synthesis, the in situ processes do not always give the same products as reactions carried out with pure compounds. In some cases, the very utilization of in situ processes may be problematic. For example, catalysis experiments involving the in situ generation of carbenes often do not give results that correspond to the maximum capabilities of these compounds. This is particularly evident in organic reactions, where it has been shown that many transformations proceed effectively only when pure carbenes are used as catalysts. Generating the required carbenes from mixtures of precarbenes has been found to be less effective in certain reactions, as in, for example, transesterification reactions and benzoin condensations. The same can be said of the carbene complexes of transition metals, in the sense that a pure compound is often more catalytically efficient than the generating mixtures (e.g., in haloarene hydrodehalogenations). Further development of the synthesis of individual carbenes should be encouraged to provide new directions for their application.

\section{Acknowledgements}

We thank the Ukrainian Academy of Sciences for financial support (theme no. III-02-2015), and the generous financial support provided by the Robert A. Welch Foundation (grant F-0003) (A.H.C.). J.A.C.C. thanks Saint Mary's University and the Natural Sciences and Engineering Research Council of Canada (through the Discovery Grants Program) for financial support of this research. J.A.C.C. also acknowledges support from the Canada Research Chairs Program, the Canadian Foundation for Innovation and the Nova Scotia Research and Innovation Trust Fund.

\section{References}

1. Igau, A.; Grutzmacher, H.; Baceiredo, A.; Bertrand, G. J. Amer. Chem. Soc. 1988, 110, 6463-6466. http://dx.doi.org/10.1021/ja00227a028

2. Igau, A.; Baceiredo, A.; Trinquier, G.; Bertrand, G. Angew. Chem. Int. Ed. 1989, 28, 621-622. http://dx.doi.org/10.1002/anie.198906211

3. Gillette, G.R.; Baceiredo, A.; Bertrand, G. Angew. Chem. 1990, 102, 1486-1488. 
http://dx.doi.org/10.1002/ange.19901021233

4. Arduengo, A.J.; Harlow, R.L.; Kline, M. J. Amer. Chem. Soc. 1991, 113, 361-363.

http://dx.doi.org/10.1021/ja00001a054

5. Arduengo, A.J.; Dias, H.V.R.; Harlow, R.L.; Kline, M. J. Amer. Chem. Soc. 1992, 114, 5530-5534.

http://dx.doi.org/10.1021/ja00040a007

6. Nefedov, O. M.; loffe, A. I.; Menchikov, L. G. Chemistry of carbenes; Moscow; Chemistry: 1990; p 303p.

7. Shvaika, O.P.; Korotkikh, N.I.; Aslanov, A.F. Chem. Heter. Compd. (Latvia) 1992, 9, 1155-1170.

8. Herrmann, W.A.; Kocher, K. Angew. Chem. Int. Ed. 1997, 36, 2162-2187.

http://dx.doi.org/10.1002/anie.199721621

9. Bourissou, D.; Guerret, O.; Gabbai, F. P.; Bertrand, G. Chem. Rev. 2000, 100, 39-92.

http://dx.doi.org/10.1021/cr940472u

10. Vignolle, J.; Cattoen, X.; Bourissou, D. Chem. Rev. 2009, 109, 3333-3384.

http://dx.doi.org/10.1021/cr800549j

11. Melaimi, M.; Soleilhavoup, M.; Bertrand, G. Angew. Chem. Int. Ed. 2010, 49, 8810-8849.

http://dx.doi.org/10.1002/anie.201000165

12. Martin, D.; Melaimi, M.; Soleilhavoup, M.; Bertrand, G. Organometallics 2011, 30, 5304-5313.

http://dx.doi.org/10.1021/om200650x

13. Jahnke, M. C.; Hahn, F. E. RSC Catalysis, Ser. 6: N-Heterocyclic carbenes: from laboratory curiosities to efficient synthetic tools, Diez-Gonzalez, S. Ed.; RSC: 2011; Chapter 1, p. 1-41.

http://dx.doi.org/10.1039/9781782626817

14. Carbene chemistry. From fleeting intermediates to powerful reagent, Bertrand G. Ed.; Fontis Media, 2002; 303 p.

15. Kirmse W. Angew. Chem., Int. Ed. 2010, 49, 8798-8801.

http://dx.doi.org/10.1002/anie.201001658

16. Hopkinson, M. N.; Richter, C.; Schedler, M.; Glorius, F. Nature 2014, 510, 485-496.

http://dx.doi.org/10.1038/nature13384

17. Hahn, F. E. Angew. Chem., Int. Ed. 2006, 45, 1348-1352.

http://dx.doi.org/10.1002/anie.200503858

18. Crabtree, R. H. J. Organomet. Chem. 2005, 690, 5451-5457.

http://dx.doi.org/10.1016/j.jorganchem.2005.07.099

19. Canal, J. P.; Ramnial, T.; Dickie, D. A.; Clyburne, J. A. C. Chem. Commun. 2006, 1809-1818. http://dx.doi.org/10.1039/B512462J

20. Land M. A., Clyburne J. A. C. Synlett 2016, 27, A-I.

http://dx.doi.org/10.1055/s-0035-1562622 Art ID: st-2016-a0623-a

21. Korotkikh, N. I.; Shvaika, O. P. Carbene and carbene complex catalysis of organic reactions; Donetsk: Ukraine, DonNU: 2013; 372 p. (Ukr.).

22. Korotkikh, N. I.; Shvaika, O. P. Organic reactions catalysis by carbenes and metal carbene complexes; LAP Lambert Academic Publishing: 2015, 385 p. (eng.).

23. Cheng, Y.; Meth-Cohn, O. Chem. Rev. 2004, 104, 2507-2530.

http://dx.doi.org/10.1021/cr030604w

24. Enders, D.; Niemeier, O.; Henseler, A. Chem. Rev., 2007, 107, 5606-5655.

http://dx.doi.org/10.1021/cr068372z

25. Flanigan, D. M.; Romanov-Michailidis, F.; White, N. A.; Rovis, T. Chem. Rev 2015, 115, 9307-9387.

http://dx.doi.org/10.1021/acs.chemrev.5b00060 
26. N-Heterocyclic Carbenes in Synthesis; Nolan S. P. Ed.; Weinheim, Wiley VCH Verlag GmbH \& Co KgaA: 2006; 304 p.

http://dx.doi.org/10.1002/9783527609451.ch12

27. N-Heterocyclic Carbenes. Effective Tools for Organometallic Synthesis, Nolan S. P. ed.; Weinheim, Wiley VCH Verlag GmbH \& Co KgaA: 2015; 543 p.

28. Izquierdo, J.; Hutson, G. E.; Cohen, D. T.; Scheidt, K. A. Angew. Chem., Int. Ed. 2012, 51, 11686. http://dx.doi.org/10.1002/anie.201203704

29. Fuchter, M. J. Chem. - Eur. J., 2010, 16, 12286-12294.

http://dx.doi.org/10.1002/chem.201001120

30. Chiang, P.-C.; Bode, J. Y. W. RSC Catalysis Ser. 6: N-Heterocyclic carbenes: from laboratory curiosities to efficient synthetic tools, Diez-Gonzalez ed., S.; RSC: 2013; Chapter 14; p. 399.

http://dx.doi.org/10.1039/9781849732161

31. Liu, B.; Ma, X.; Wu, F.; Chen, W. Dalton Trans. 2015, 44, 1836-1844.

http://dx.doi.org/10.1039/C4DT02986K

32. Shvaika, O.P.; Korotkikh, N.I. J. Org. Pharm. Chem. 2013, 11, 4(44), 3-14 (Ukr.). http://nuph.edu.ua/wp-content/uploads/2015/04/ZhOFH 42013 03-14.pdf

33. Korotkikh, N. I.; Glinyanaya, N. V.; Rayenko, G. F.; Shvaika, O. P. Stable azole carbenes in organic synthesis: chemistry and biological activity of azoles (selected reviews); Brovarets, V.; Zyabrev, V. Eds.; LAP Lambert Academic Publishing: 2014, p. 423.

34. Wang, Y.; Robinson, G. H. Inorg. Chem. 2011, 50, 12326-12337. http://dx.doi.org/10.1021/ic200675u

35. Schaper, L.-A.; Tosh, E.; Herrmann, W. A. RSC Catalysis Ser. 6: N-Heterocyclic carbenes: from laboratory curiosities to efficient synthetic tools; Diez-Gonzalez, S. Ed; RSC: 2011; Chapter. 6; p. 166-195.

http://dx.doi.org/10.1039/9781849732161

36. Kruger, A.; Albrecht, M. RSC Catalysis Ser. 6: N-Heterocyclic carbenes: from laboratory curiosities to efficient synthetic tools; Diez-Gonzalez, S. Ed; RSC: 2011; Chapter. 5; p. 134. http://dx.doi.org/10.1039/9781849732161

37. Crabtree, R. H. Coord. Chem. Rev. 2013, 257, 755-766.

http://dx.doi.org/10.1016/j.ccr.2012.09.006

38. Arduengo, A.J. III; Bock, H.; Chen, H.; Denk, M.; Dixon, D.A.; Green, J.C.; Herrmann, W.A.; Jones, N.L.; Wagner, M.; West, R. J. Am. Chem. Soc. 1994, 116, 6641-6649.

http://dx.doi.org/10.1021/ja00094a020

39. Arduengo, A.J. III; Dias, H.V.R.; Dixon, D.A.; Harlow, R.L.; Klooster, W.T.; Koetztle, T.F. J. Am. Chem. Soc. 1994, 116, 6812-6822.

http://dx.doi.org/10.1021/ja00094a040

40. Arduengo, A. J. III; Goerlich, J. R.; Krafczyk, R.; Marshall, W. J. Angew. Chem., Int. Ed. Engl. 1998, 37, 1963-1965.

http://dx.doi.org/10.1002/(SICI)1521-37731998080337:13/14<1963::AID-ANIE1963>3.0.CO;2-M

41. Arduengo, A. J.; Goerlich, J. R.; Marshall, W. J. J. Amer. Chem. Soc. 1995, 117, 11027-11028. http://dx.doi.org/10.1021/ja00149a034

42. Alder, R.W.; Allen, P.R.; Williams, S.J. J. Chem. Soc. Chem. Commun. 1995, 1267-1268. http://dx.doi.org/10.1039/C39950001267

43. Arduengo, A.J. US Pat. 5,077,414, 1992. 
https://worldwide.espacenet.com/publicationDetails/originalDocument?CC=US\&NR=5077414A\&KC=A\& $\mathrm{FT}=\mathrm{D} \& N D=3 \&$ date $=19911231 \& \mathrm{DB}=\mathrm{EPODOC}$ \&locale $=$ en $E P$

44. Arduengo A.J. US Pat. 5,182,405. 1993.

https://worldwide.espacenet.com/publicationDetails/originalDocument?CC=US\&NR=5182405A\&KC=A\& $\mathrm{FT}=\mathrm{D} \& N D=3 \&$ date $=19930126 \& D B=E P O D O C \& l o c a l e=e n \quad E P$

45. Knishevitsky A.V. Cand. Chem. Sci. Thesis, Donetsk (Ukraine), IPOCC, 2009.

46. Arduengo, A. J., III; Krafczyk, R.; Schmutzler, R.; Craig, H. A.; Goerlich, J. R.; Marshall, W. J.; Unverzagt, M. Tetrahedron 1999, 55, 14523-14534.

http://dx.doi.org/10.1016/S0040-4020(99)00927-8

47. Berthon-Gelloz, G.; Siegler, M. A.; Spek, A. L.; Tinant, B.; Reek, J. N. H.; Marko, I. E. Dalton Trans. 2010, 39, 1444-1446.

http://dx.doi.org/10.1039/B921894G

48. Balogh, J.; Slawin, A. M. Z.; Nolan, S. P. Organometallics 2012, 31, 3259-3263.

http://dx.doi.org/10.1021/om300104j

49. Meiries, S.; Speck, K.; Cordes, D. B.; Slawin, A. M. Z.; Nolan, S. P. Organometallics 2013, 32, 330-339. http://dx.doi.org/10.1021/om3011867

50. Weber, S. G.; Loos, C.; Rominger, F.; Straub, B. F. Arkivoc 2012, (iii), 226-242. http://www.arkat-usa.org/get-file/42743/

51. Glinyanaya, N. V.; Saberov, V. Sh.; Korotkikh, N. I.; Cowley, A. H.; Butorac, R. R.; Evans, D. A.; Pekhtereva, T. M.; Popov, A. F.; Shvaika, O. P. Dalton Trans. 2014, 43, 16227-16237.

http://dx.doi.org/10.1039/C4DT01353K

52. Saberov, V. Sh.; Evans, D. A.; Korotkikh, N. I.; Cowley, A. H.; Pekhtereva, T. M.; Popov, A. F.; Shvaika, O. P. Dalton Trans. 2014, 43, 18117-18122.

http://dx.doi.org/10.1039/C4DT02908A

53. Lesieur, M.; Slawin, A. M. Z.; Cazin, C. S. J. Org. Biomol. Chem. 2014, 12, 5586-5589.

http://dx.doi.org/10.1039/C4OB01269K

54. Kuhn, N.; Kratz, T. Synthesis 1993, № 12, 561-562.

http://dx.doi.org/10.1055/s-1993-25902

55. Liu, P.; Wesolek, M.; Danopoulos, A. A.; Braunstein, P. Organometallics 2013, 32, 6286-6297. http://dx.doi.org/10.1021/om400599v

56. Danopoulos, A.A.; Winston, S.; Gelbrich, T.; Hursthouse, M.B.; Tooze, R.P. Chem. Comm. 2002, $482-483$. http://dx.doi.org/10.1039/B111659B

57. Arduengo, A.J.; Davidson, F.; Dias, H.V.R.; Goerlich, J.R.; Khasnis, D.; Marshall, W.J.; Prakasha, T.K. J. Amer. Chem. Soc. 1997, 119, 12742-12749.

http://dx.doi.org/10.1021/ja9732410

58. Furfari, S. K.; Gyton, M. R.; Twycross, D.; Cole, M. L. Chem. Commun. 2015, 51, 74-76. http://dx.doi.org/10.1039/C4CC06809B

59. Bates, J. I.; Kennepohl, P.; Gates, D. P. Angew. Chem. Int. Ed. 2009, 48, 9844-9846. http://dx.doi.org/10.1002/anie.200905401

60. Mendoza-Espinosa, D.; Donnadieu, B.; Bertrand, G. J. Am. Chem. Soc. 2010, 132, 7264-7265. http://dx.doi.org/10.1021/ja102639a

61. Mendoza-Espinosa, D.; Donnadieu, B.; Bertrand, G. Chem. Asian. J. 2011, 6, 1099-1103. http://dx.doi.org/10.1002/asia.201000856

62. Ghadwal, R. S.; Roesky, H. W.; Granitzka, M.; Stalke, D. J. Amer. Chem. Soc. 2010, 132, $10018-10020$. 
http://dx.doi.org/10.1021/ja104386g

63. Ruiz, J.; Mesa, A. F. Chem. Eur. J. 2012, 18, 4485-4488.

http://dx.doi.org/10.1002/chem.201200031

64. Majhi, P. K.; Serin, S. C.; Schnakenburg, G.; Gates, D. P.; Streubel, R. Eur. J. Inorg. Chem. 2014, 49754983.

http://dx.doi.org/10.1002/ejic.201402440

65. Marchenko, A. P.; Koidan, H. N.; Pervak, I. I.; Huryeva, A. N.; Zarudnitskii, E. V.; Tolmachev, A. A.; Kostyuk, A. N. Tetrahedron Lett. 2012, 53, 494-496.

http://dx.doi.org/10.1016/j.tetlet.2011.11.054

66. Gaillard, S.; Renaud; J.-L. Dalton Trans. 2013, 42, 7255-7270.

http://dx.doi.org/10.1039/C2DT32789A

67. Ghadwal, R. S.; Reichmann, S. O.; Carl, E.; Herbst-Irme, R. Dalton Trans. 2014, 43, 13704-13710. http://dx.doi.org/10.1039/C4DT01681E

68. Winkler, A.; Freytag, M.; Jones, P. G.; Tamm, M. J. Organomet. Chem. 2015, 775, 164-168. http://dx.doi.org/10.1016/j.jorganchem.2014.04.037

69. Huber, S. M.; Heinemann, F. W.; Audebert, P.; Weiss, R. Chem. Eur. J. 2011, 17, 13078-13086. http://dx.doi.org/10.1002/chem.201101999

70. Baier, H.; Metzner, P.; Korzdorfer, T.; Kelling, A.; Holdt, H.-J. Eur. J. Inorg. Chem. 2014, 2952-2960. http://dx.doi.org/10.1002/ejic.201402040

71. Baier, H.; Metzner, P.; Korzdorfer, T.; Kelling, A.; Holdt, H.-J. Eur. J. Inorg. Chem. 2015, 1950-1957. http://dx.doi.org/10.1002/ejic.201500010

72. Xiong, Y.; Yao, S.; Driess, M. Chem. Asian J. 2010, 5, 322-327. http://dx.doi.org/10.1002/asia.200900434

73. Tan, G.; Enthaler, S.; Inoue, S.; Blom, B.; Driess, M. Angew. Chem. Int. Ed. 2015, 54, 2214-2218. http://dx.doi.org/10.1002/anie.201409739

74. Henderson, A. S.; Bower, J. F.; Galan, M. C. Org. Biomol. Chem. 2014, 12, 9180-9183. http://dx.doi.org/10.1039/C4OB02056A

75. El-Hellani, A.; Lavallo, V. Angew. Chem. Int. Ed. 2014, 53, 4489-4493. http://dx.doi.org/10.1002/anie.201402445

76. Glorius, F.; Altenhoff, G.; Goddard, R.; Lehman, C. Chem.Commun. 2002, 2704-2705. http://dx.doi.org/10.1039/B208045A

77. Altenhoff, G.; Goddard, R.; Lehman, C. W.; Glorius, F. Angew. Chem., Int. Ed. 2003, 42, 3690-3693. http://dx.doi.org/10.1002/anie.200351325

78. Altenhoff, G.; Goddard, R.; Lehmann, C. W.; Glorius, F. J. Am. Chem. Soc. 2004, 126, 15195-15201. http://dx.doi.org/10.1021/ja045349r

79. Wurtz S., Glorius F. Acc. Chem. Res. 2008, 41, 1523-1533. http://dx.doi.org/10.1021/ar8000876

80. Bildstein, B.; Malaun, M.; Kopacka, H.; Wurst, K.; Mitterböck,M.; Ongania, K.-H.; Opromolla, G.; Zanello, P. Organometallics 1999, 18, 4325-4336.

http://dx.doi.org/10.1021/om990377h

81. Seo, H.; Kim, B. Y.; Lee, J. H.; Park, H.-J.; Son, S. U.; Chung,Y. K. Organometallics 2003, 22, 4783-4791. http://dx.doi.org/10.1021/om0303193

82. Gischig, S.; Togni, A. Organometallics 2004, 23, 2479-2487.

http://dx.doi.org/10.1021/om049893k 
83. Labande, A.; Daran, J.-C.; Manoury, E.; Poli, R. Eur. J. Inorg.Chem. 2007, 1205-1209. http://dx.doi.org/10.1002/ejic.200601193

84. Seo, H.; Park, H.; Kim, B. Y.; Lee, J. H.; Son, S. U.; Chung, Y. K. Organometallics 2003, 22, 618-620. http://dx.doi.org/10.1021/om020878u

85. Broggini, D.; Togni, A. Helv. Chim. Acta 2002, 85, 2518-2522.

http://dx.doi.org/10.1002/1522-2675(200208)85:8<2518::AID-HLCA2518>3.0.CO;2-N

86. Bertogg, A.; Camponovo, F.; Togni, A. Eur. J. Inorg. Chem. 2005, 347-356.

http://dx.doi.org/10.1002/ejic.200400691

87. Loxq, P.; Daran, J.-C.; Manoury, E.; Poli, R.; Labande, A. Eur. J. Inorg. Chem. 2015, 609-616. http://dx.doi.org/10.1002/ejic.201403001

88. Gorodetsky, B.; Ramnial, T.; Branda, N. R.; Clyburne, J. A. C. Chem . Commun. 2004, 1972-1973. http://dx.doi.org/10.1039/B407386J

89. Enders, D.; Breuer, K.; Raabe, G.; Simonet, J.; Ghanimi, A.; Stegmann, H. B.; Teles, J. H. Tetrahedron Lett. 1997, 38, 2833-2836.

http://dx.doi.org/10.1016/S0040-4039(97)00493-0

90. Herrmann, W.A.; Elison, M.; Fischer, J.; Kocher, C.; Artus, G.R.J. Chem. Eur. J. 1996, 2, 772-780. http://dx.doi.org/10.1002/chem.19960020708

91. Huffer, A.; Jeffery, B.; Waller, B. J.; Danopoulos, A. A. C. R. Chimie 2013, 16, 557-565. http://dx.doi.org/10.1016/i.crci.2013.01.016

92. Dias H. V. R.; Jin, W. Tetrahedron Lett. 1994, 35, 1365-1366. http://dx.doi.org/10.1016/S0040-4039(00)76219-8

93. Danopoulos, A. A.; Winstona, S.; Motherwell, W. B. Chem. Commun. 2002, 1376-1377. http://dx.doi.org/10.1039/B202814J

94. Meyer, K.; Hu, X.; Castro-Rodriguez, I. Organometallics 2003, 22, 3016-3018. http://dx.doi.org/10.1021/om0304006

95. Fränkel, R.; Kniczek, J.; Ponikwar, W.; Nöth, H.; Polborn, K.; Fehlhammer, W. P. Inorg. Chim. Acta 2001, 312, 23-39.

http://dx.doi.org/10.1016/S0020-1693(00)00323-6

96. Nieto, I.; Bontchev, R. P.; Smith, J. M. Eur. J. Inorg. Chem. 2008, 2476-2480. http://dx.doi.org/10.1002/ejic.200800034

97. Arrowsmith, M.; Hill, M. S.; Kociok-Köhn, G. Organometallics 2009, 28, 1730-1738. http://dx.doi.org/10.1021/om8010933

98. Shishkov, I. V.; Rominger, F.; Hofmann, P. Organometallics 2009, 28, 3532. http://dx.doi.org/10.1021/om801097f

99. Xiong, Y.; Szilvási, T.; Yao, S.; Tan, G.; Driess, M. J. Am. Chem. Soc. 2014, 136, 11300-11303. http://dx.doi.org/10.1021/ja506824s

100. Xiong, Y.; Yao, S.; Szilvasi, T.; Driess, M. Eur. J. Inorg. Chem. 2015, 2377-2380. http://dx.doi.org/10.1002/ejic.201500154

101. Schneider, H.; Schmidt, D.; Radius, U. Chem. Eur. J. 2015, 21, 2793-2797. http://dx.doi.org/10.1002/chem.201406264

102. Rayenko, G.F.; Korotkikh, N.I.; Pekhtereva, T.M.; Shvaika, O.P. Rus. J. Org. Chem. 2001, 37, $1153-1157$. http://dx.doi.org/10.1023/A:1013148532518

103. Korotkikh, N.I.; Rayenko, G.F.; Shvaika, O.P. Rep. Ukr. Acad. Sci. 2000, № 2, 135-140 (ukr.). 
104. Korotkikh, N. I.; Raenko, G. F.; Pekhtereva, T. M.; Shvaika, O. P.; Cowley, A. H.; Jones, J. N. Rus. J. Org. Chem. 2006, 42, 1822-1833.

http://dx.doi.org/10.1134/S1070428006120116

105. Hadei, N.; Kantchev, E. A. B.; O’Brien, C. J.; Organ, M. G. Org. Lett. 2005, 7, 1991-1994. http://dx.doi.org/10.1021/ol050471w

106. Hahn, F.E.; Wittenbecher, L.; Boese, R.; Blaser, D. Chem. Eur. J. 1999, 82, 1931-1935. http://dx.doi.org/10.1002/(SICI)1521-3765199906045:6<1931::AID-CHEM1931>3.0.CO;2-M

107. Hahn, F. E.; Wittenbecher, L.; Le Van, D.; Frohlich, R. Angew. Chem. Int. Ed. 2000, 39, 541-544. http://dx.doi.org/10.1002/(SICI)1521-37732000020439:3<541::AID-ANIE541>3.0.CO;2-B

108. Borguet, Y.; Zaragoza, G.; Demonceau, A.; Delaude, L. Dalton Trans. 2013, 42, 7287-7296. http://dx.doi.org/10.1039/C2DT31520C

109. Wang, H.; Xia, Y.; Lv, S.; Xu, J.; Sun, Z. Tetrahedron Lett. 2013, 54, 2124-2127.

http://dx.doi.org/10.1016/j.tetlet.2013.02.006

110. Marchenko, A. P.; Koidan, H. N.; Hurieva, A. N.; Pervak, I. I.; Shishkina, S. V.; Shishkin, O. V.; Kostyuk, A. N. Eur. J. Org. Chem. 2012, 4018-4033. http://dx.doi.org/10.1002/ejoc.201200282

111. Bildstein, B.; Malaun, M.; Kopacka, H.; Ongania, K.-H.; Wurst, K. J. Organomet. Chem. 1999, 572, 177187.

http://dx.doi.org/10.1016/j.jorganchem.2014.04.037

112. Varnado, C. D., Jr.; Lynch, V. M.; Bielawski, C. W. Dalton Trans. 2009, 7253-7261. http://dx.doi.org/10.1039/B908696J

113. Ullah, F.; Bajor, G.; Veszpremi, T.; Jones, P.G.; Heinicke, J.W. Angew. Chem. Int. Ed. 2007, 46, 26972700.

http://dx.doi.org/10.1002/anie.200604516

114. Saravanakumar, S.; Oprea, A.I.; Kindermann, M.K.; Jones, P.G.; Heinicke, J. Chem. Eur. J. 2006, 12, 31433154.

http://dx.doi.org/10.1002/chem.200501183

115. Saravanakumar, S.; Kindermann, M.K.; Heinicke, J.; Ko“ckerling, M. Chem. Commun. 2006, 640-642. http://dx.doi.org/10.1039/B512884F

116. Vasudevan, K. V.; Butorac, R. R.; Abernethy, C. D.; Cowley, A. H. Dalton Trans. 2010, 39, 7401-7408. http://dx.doi.org/10.1039/CODT00278J

117. Ciancaleoni, G.; Biasiolo, L.; Bistoni, G.; Macchioni, A.; Tarantelli, F.; Zuccaccia, D.; Belpassi, L. Organometallics 2013, 32, 4444-4447.

http://dx.doi.org/10.1021/om4005912

118. Liu, Z.; Dong, N.; Xu, M.; Sun, Z.; Tu, T. J. Org. Chem. 2013, 78, 7436-7444. http://dx.doi.org/10.1021/jo400803s

119. Crawford, K. A.; Cowley, A. H.; Humphrey, S. M. Catal. Sci. Technol. 2014, 4, 1456-1464. http://dx.doi.org/10.1039/C4CY00192C

120. Tapu, D.; Owens, C.; VanDerveer, D.; Gwaltney, K. Organometallics 2009, 28, 270-276. http://dx.doi.org/10.1021/om800822m

121. Mormul, J.; Steimann, M.; Maichle-Mossmer, C.; Nagel, U. Eur. J. Inorg. Chem. 2013, 19, 3421-3428. http://dx.doi.org/10.1002/ejic.201300061

122. Ullah, F.; Kindermann, M. K.; Jones, P. G.; Heinicke J. Organometallics 2009, 28, 2441-2449. http://dx.doi.org/10.1021/om9000132 
123. Mormul, J.; Steimann, M.; Nagel, U. Eur. J. Inorg. Chem. 2014, 1389-1393. http://dx.doi.org/10.1002/ejic.201301499

124. Valdés, H.; Poyatos, M.; Peris, E. Organometallics 2014, 33, 394-401. http://dx.doi.org/10.1021/om401134w

125. Gonell, S.; Poyatos, M.; Peris, E. Chem. Eur. J. 2014, 20, 9716-9724.

http://dx.doi.org/10.1002/chem.201304952

126. Prades, A.; Peris, E.; Alcarazo, M. Organometallics 2012, 31, 4623-4626.

http://dx.doi.org/10.1021/om3003834

127. Guisado-Barrios, G.; Hiller, J.; Peris, E. Chem. Eur. J. 2013, 19, 10405-10411.

http://dx.doi.org/10.1002/chem.201300486

128. Gonell, S.; Poyatos, M.; Peris, E. Chem. Eur. J. 2014, 20, 5746-5751.

http://dx.doi.org/10.1002/chem.201400371

129. Lefebvre, J.-F.; Lo, M.; Leclercq, D.; Richeter, S. Chem. Commun. 2011, 47, 2976-2978. http://dx.doi.org/10.1039/C0CC05052K

130. Lefebvre, J.-F.; Leclercq, D.; Gisselbrecht, J.-P.; Richeter, S. Eur. J. Org. Chem. 2010, 1912-1920. http://dx.doi.org/10.1002/ejoc.200901310

131. Kriechbaum, M.; List, M.; Berger, R. J. F.; Patzschke, M.; Monkowius, U. Chem. Eur. J. 2012, 18, 55065509.

http://dx.doi.org/10.1002/chem.201200465

132. Alcarazo, M.; Roseblade, S.J.; Cowley, A.R.; Fernandez, R.; Brown, J.M.; Lassaletta, J.M. J. Am. Chem. Soc. 2005, 127, 3290-3291.

http://dx.doi.org/10.1021/ja0423769

133. Nonnenmacher, M.; Kunz, D.; Rominger, F.; Oeser, T. Chem. Commun. 2006, 1378-1380. http://dx.doi.org/10.1039/B517816A

134. Burstein, C., Lehmann, C.W., Glorius F. Tetrahedron 2005, 61, 6207-6217. http://dx.doi.org/10.1016/i.tet.2005.03.115

135. Kriechbaum M., Winterleitner G., Gerisch A., List M., Monkowius U. Eur. J. Inorg. Chem. 2013, 55675575.

http://dx.doi.org/10.1002/ejic.201300575

136. Roseblade, S. J.; Ros, A.; Monge, D.; Alcarazo, M.; Ivarez, E. A.; Lassaletta, J. M. Organometallics 2007, 26, 2570-2578.

http://dx.doi.org/10.1021/om070063r

137. Focken, T.; Rudolph, J.; Bolm, C. Synthesis 2005, 429-436.

http://dx.doi.org/10.1055/s-2005-861800

138. Furstner A., Alcarazo M., Krause H., Lehman C.W. J. Am. Chem.Soc. 2007, 129, 12676-12677. http://dx.doi.org/10.1021/ja076028t

139. Weiss R., Reichel S., Handtke M., Hampel F. Angew. Chem. Int. Ed. 1998, 37, 344-347. http://dx.doi.org/10.1002/(SICI)1521-37731998021637:3<344::AID-ANIE344>3.0.CO;2-H

140. Nonnenmacher, M.; Kunz, D.; Rominger, F.; Oeser, T. J. Organomet. Chem. 2005, 690, 5647-5653. http://dx.doi.org/10.1016/j.jorganchem.2005.07.033

141. Nonnenmacher, M.; Kunz, D.; Rominger, F. Organometallics 2008, 27, 1561-1568. http://dx.doi.org/10.1021/om701196c

142. Fuku-en, S.; Yamamoto, J.; Minoura, M.; Kojima, S.; Yamamoto, Y. Inorg. Chem. 2013, 52, $11700-11702$. http://dx.doi.org/10.1021/ic402301u 
143. Arduengo III, A. J.; Bannenberg, T. P.; Tapu, D.; Marshall, W. J. Tetrahedron Lett. 2005, 46, 6847-6850. http://dx.doi.org/10.1016/j.tetlet.2005.08.018

144. Arduengo III, A. J.; Bannenberg, T. P.; Tapu, D.; Marshall, W. J. Chem. Lett. 2005, 34, 1010-1011. http://dx.doi.org/10.1246/cl.2005.1010

145. Arduengo, III, A. J.; Tapu, D.; Marshall, W. J. Angew. Chem., Int. Ed. 2005, 44, 7240-7244. http://dx.doi.org/10.1002/anie.200502814

146. Arduengo, III, A. J.; Tapu, D.; Marshall, W. J. J. Am. Chem. Soc. 2005, 127, 16400-16401. http://dx.doi.org/10.1021/ja055565f

147. Metallinos, C.; Barrett, F. B.; Chaytor, J. L.; Heska, M. E. A. Org. Lett. 2004, 6, 3641-3644. http://dx.doi.org/10.1021/ol048393k

148. Metallinos, C.; Barrett, F.; Wang, Y.; Xu, S.; Taylor, N. Tetrahedron 2006, 62, 11145-11157. http://dx.doi.org/10.1016/i.tet.2006.09.023

149. Metallinos, C.; Du, X. Organometallics 2009, 28, 1233-1242. http://dx.doi.org/10.1021/om801063w

150. Li, J.; Stewart, I. C.; Grubbs, R. H. Organometallics 2010, 29, 3765-3768. http://dx.doi.org/10.1021/om100262x

151. Huynh, H. V.; Ong, H. L; Bernhammer, J. C.; Frison, G. Eur. J. Inorg. Chem. 2013, 4654-4661. http://dx.doi.org/10.1002/ejic.201300334

152. Khramov, D. M.; Boydston, A. J.; Bielawski, C. W. Org. Lett. 2006, 8, 1831-1834. http://dx.doi.org/10.1021/ol060349c

153. Khramov, D. M.; Boydston ,A. J.; Bielawski, C. W. Angew.Chem. Int. Ed. 2006, 45, 6186-6189. http://dx.doi.org/10.1002/anie.200601583

154. Rosen, E. L.; Varnado, C. D., Jr.; Tennyson, A. G.; Khramov, D. M.; Kamplain, J. W.; Sung, D. H.; Cresswell, P. T.; Lynch, V. M.; Bielawski, C.W. Organometallics 2009, 28, 6695-6706. http://dx.doi.org/10.1021/om900698x

155. Su, J.-H.; Lee, G.-H.; Peng, S.-M.; Chiu, C.-W. Dalton Trans. 2014, 43, 3059-3062. http://dx.doi.org/10.1039/C3DT52131A

156. Chen, Y.-H.; Peng, K.-E.; Lee, G.-H.; Peng, S.-M.; Chiu, C.-W. RSC Adv. 2014, 4, 62789-62792. http://dx.doi.org/10.1039/C4RA12597E

157. Bielawski, C. W.; Williams, K. A. Chem. Commun. 2010, 46, 5166-5168. http://dx.doi.org/10.1039/C0CC01070G

158. Gonell, S.; Poyatos, M.; Peris, E. Angew. Chem. Int. Ed. 2013, 52, 7009-7013. http://dx.doi.org/10.1002/anie.201302686

159. Gonell, S.; Alabau, R. G.; Poyatos, M.; Peris, E. Chem. Commun. 2013, 49, 7126-7128. http://dx.doi.org/10.1039/C3CC44109A

160. Wang, Y.-T.; Chang, M.-T.; Lee, G.-H.; Peng, S.-M.; Chiu, C.-W. Chem. Commun. 2013, 49, 7258-7260. http://dx.doi.org/10.1039/C3CC43278E

161. Fantuzzi, F.; Nascimento, M. A. C. Chem. Eur. J. 2015, 21, 7814-7819. http://dx.doi.org/10.1002/chem.201500241

162. Braunschweig, H.; Dewhurst, R. D.; Hammond, K.; Mies, J.; Radacki, K.; Vargas, A. Science 2012, 336, 1420-1422.

http://dx.doi.org/10.1126/science.1221138

163. Korotkikh N.I., Marichev K.A., Kiselev A.V., Shvaika O.P. Ukr. bioorganica acta 2008, 6, № 2, 22-27 (Ukr.). 
164. Marichev K.A. Cand. Chem. Sci. Thesis, IPOCC, Donetsk (Ukraine), 2012.

165. Marichev K.A., Korotkikh N.I., Kiselev A.V., Papayanina E.S., Dudarenko G.V., Shvaika O.P. Proceed. DonNTU. Ser.: Chem. \& chem. technol. 2012, № 18, 100-107 (ukr.).

166. Arduengo, III, A. J.; Iconaru, L. I. Dalton Trans. 2009, 6903-6914. http://dx.doi.org/10.1039/B907211J

167. Hill, N. J.; Vargas-Baca, I.; Cowley, A. H. Dalton Trans. 2009, 240-253. http://dx.doi.org/10.1039/B815079F

168. Enders, D.; Breuer, K.; Raabe, G.; Runsink, J.; Teles, J. H.; Melder, J. P.; Ebel, K.; Brode, S. Angew. Chem. Int. Ed. 1995, 34, 1021-1023.

http://dx.doi.org/10.1002/anie.199510211

169. Enders, D.; Breuer, K.; Kallfass, U.; Bahlensiefer, T. Synthesis 2003, 1292-1295. http://dx.doi.org/10.1055/s-2003-39409

170. Glinyanaya, N.V.; Korotkikh, N.I.; Knishevitsky, A.V.; Rayenko, G.F.; Shvaika, O. P. Proceedings of the VI Ukr. confer. “Dombrovsky chem. readings-2015”, Chernivtsi (Ukraine), 2015 Sep. 22-25, C-73.

171. Teles, J.H.; Breuer, K.; Enders, D.; Gielen, H. Synth. Commun. 1999, 29, 1-9. http://dx.doi.org/10.1080/00397919908085727

172. Teles, J. H.; Melder, J.-P.; Ebel, K.; Schneider, R.; Gehrer, E.; Harder, W.; Brode, S.; Enders, D.; Breuer, K.; Raabe, G. Helv. Chim. Acta 1996, 79, 61-83.

http://dx.doi.org/10.1002/hlca.19960790108

173. Knight, R. L.; Leeper, F. J. J. Chem. Soc., Perkin Trans. 1, 1998, 1891-1894.

http://dx.doi.org/10.1039/A803635G

174. Kerr, M. S.; Read de Alaniz, J.; Rovis T. J. Am. Chem. Soc. 2002, 124, 10298-10299. http://dx.doi.org/10.1021/ja027411v

175. Enders, D.; Kallfass, U. Angew. Chem., Int. Ed. 2002, 41, 1743-1745. http://dx.doi.org/10.1002/1521-3773(20020517)41:10<1743::AID-ANIE1743>3.0.CO;2-Q

176. Enders, D.; Han, J. Tetrahedron Asymmetry 2008, 19, 1367-1371.

http://dx.doi.org/10.1016/j.tetasy.2008.05.017

177. Jousseaume, T.; Wurz, N. E.; Glorius, F. Angew. Chem. Int. Ed. 2011, 50, 1410-1414. http://dx.doi.org/10.1002/anie.201006548

178. Rovis, T. Chem. Lett. 2008, 37, 1, 2-7. http://dx.doi.org/10.1246/cl.2008.2

179. Enders, D.; Niemeier, O.; Balensiefer, T. Angew. Chem. Int. Ed. 2006, 45, 1463-1467. http://dx.doi.org/10.1002/anie.200503885

180. Enders, D.; Breuer, K.; Runsink, J. Helv. Chim. Acta 1996, 79, 1899-1902. http://dx.doi.org/10.1002/hlca.19960790712

181. Rovis, T.; Dirocco, D.; Guiles, J. WO Pat. 2012009372, 2012. https://worldwide.espacenet.com/publicationDetails/originalDocument?CC=WO\&NR=2012009372A2\& $\underline{K C}=\mathrm{A} 2 \& \mathrm{FT}=\mathrm{D} \& N D=3 \&$ date $=20120119 \& \mathrm{DB}=\mathrm{EPODOC} \&$ locale $=$ en $E P$

182. Reynolds, N. T.; Read A., J.; Rovis, T. J. Am. Chem. Soc. 2004, 126, 9518-9519. http://dx.doi.org/10.1021/ja0469910

183. Moore, J. L.; Kerr, M. S.; Rovis T. Tetrahedron 2006, 62, 11477. http://dx.doi.org/10.1002/9780470638859.conrr600

184. Maki, B. E.; Chan, A.; Phillips, E. M.; Scheidt, K. A. Org. Lett. 2007, 9, 371-374. http://dx.doi.org/10.1021/ol062940f 
185. Orellana, A.; Rovis, T. Chem. Commun. 2008, 730-732.

http://dx.doi.org/10.1039/B716445A

186. Read de Alaniz, J.; Kerr, M. S.; Moore, J. L.; Rovis, T. J. Org. Chem. 2008, 73, 2033-2039. http://dx.doi.org/10.1021/jo302072p

187. Wong F. T., Patra P. K., Seayad J., Zhang Y., Ying J. Y. Org. Lett. 2008, 10, 2333-2336. http://dx.doi.org/10.1021/ol8004276

188. Cullen, S. C.; Rovis, T. Org. Lett. 2008, 10, 3141-3144.

http://dx.doi.org/10.1021/ol801047k

189. Liu Q., Perreault S., Rovis T.T. J. Am. Chem. Soc. 2008, 130, 14066-14067.

http://dx.doi.org/10.1021/ja805680z

190. DiRocco, D. A.; Oberg, K. M.; Dalton, D. M.; Rovis, T. J. Am. Chem. Soc. 2009, 131, 10872-10874. http://dx.doi.org/10.1021/ja904375q

191. Hirano, K.; Biju, A. T.; Piel, I.; Glorius, F. J. Am. Chem. Soc. 2009, 131, 14190-14191. http://dx.doi.org/10.1021/ja906361g

192. Campbell, C. D.; Concellon, C.; Smith, A.D. Tetrahedron Asymmetry 2011, 22, 797-811. http://dx.doi.org/10.1016/i.tetasy.2011.04.001

193. Campbell, C. D.; Collett, C. J.; Thomson, J. E.; Slawin, A. M. Z.; Smith, A. D. Org. Biomol. Chem. 2011, 9, 4205-4218.

http://dx.doi.org/10.1039/C10B05160A

194. DiRocco, D. A.; Noey, E. L.; Houk, K. N.; Rovis, T. Angew. Chem. Int. Ed. 2012, 51, 2391-2394. http://dx.doi.org/10.1002/anie.201107597

195. Korotkikh, N. I.; Rayenko, G. F.; Shvaika, O. P.; Pekhtereva, T. M.; Cowley, A. H.; Jones, J. N.; Macdonald, C. L. B. J. Org. Chem. 2003, 68, 5762-5765.

http://dx.doi.org/10.1021/jo034234n

196. Korotkikh, N. I.; Glinyanaya, N. V.; Cowley, A. H.; Moore, J. A.; Knishevitsky, A. V.; Pekhtereva, T. M.; Shvaika, O. P. Arkivoc 2007, (XVI), 156-172.

http://www.arkat-usa.org/get-file/23279/

197. Korotkikh, N. I.; Cowley, A. H.; Moore, J. A.; Glinyanaya, N. V.; Panov, I. S.; Rayenko, G. F.; Pekhtereva, T. M.; Shvaika, O. P. Org. Biomol. Chem. 2008, 6, 195-199.

http://dx.doi.org/10.1039/B712885A

198. Korotkikh, N. I.; Shvaika, O. P.; Rayenko, G. F.; Kiselyov, A. V.; Knishevitsky, A. V.; Cowley, A. H.; Jones, J. N.; Macdonald, C. L. B. Arkivoc 2005, (VIII), 10-43.

http://www.arkat-usa.org/get-file/20208/

199. Korotkikh, N. I.; Kiselyov, A. V.; Knishevitsky, A. V.; Rayenko, G. F.; Pekhtereva, T. M.; Shvaika, O. P. Chem. Heter. Compd. 2005, 7, 866-871.

200. Marchenko, A. P.; Koidan, H. N.; Zarudnitskii, E. V.; Hurieva, A. N.; Kirilchuk, A. A.; Yurchenko, A. A.; Biffis, A.; Kostyuk, A. N. Organometallics 2012, 31, 8257-8264.

http://dx.doi.org/10.1021/om300872g

201. Kirilchuk,A. A.; Marchenko, A. P.; Koidan, H. G.; Zarudnitskii, E. V.; Huryeva, A. N.; Yurchenko, A. A.; Kostyuk, A. N. Phosphorus, Sulfur, and Silicon 2013, 188, 254-255.

http://dx.doi.org/10.1080/10426507.2012.741162

202. Korotkikh, N.I.; Kiselyov, A.V.; Rayenko, G.F.; Oliynik, M.M.; Shvaika, O.P. Rep. Ukr. Acad. Sci. 2003, № 6, 142-146 (Ukr.). 
203. Kiselyov, A.V.; Korotkikh, N.I.; Cowley, A.H.; Moore, J.A.; Pekhtereva, T.M.; Shvaika, O.P. Arkivoc 2008, (XV), 329-342.

http://www.arkat-usa.org/get-file/26761/

204. Knishevitsky A. V., Korotkikh N. I., Cowley A. H., Moore J. A., Pekhtereva T. M., Shvaika O. P., Reeske G. J. Organomet. Chem. 2008, 693, 1405-1411.

http://dx.doi.org/10.1016/j.jorganchem.2007.07.056

205. Turek, J.; Panov, I.; Horaček, M.; Černošek, Z.; Padělkova, Z.; Růžička, A. Organometallics 2013, 32, 7234-7240.

http://dx.doi.org/10.1021/om400912s

206. Turek, J.; Panov, I.; Semler, M.; Štěpnička, P.; De Proft, F.; Padělková, Z.; Růžička, A. Organometallics 2014, 33, 3108-3118.

http://dx.doi.org/10.1021/om500342z

207. Poyatos, M.; McNamara, W.; Incarvito, C.; Peris, E.; Crabtree R. H. Chem. Commun. 2007, 26, 22672269.

http://dx.doi.org/10.1039/B705246D

208. Poyatos, M.; McNamara, W.; Incarvito, C.; Clot, E.; Peris, E.; Crabtree, R.H. Organometallics 2008, 27, 2128-2136.

http://dx.doi.org/10.1021/om800021c

209. Korotkikh, N.I.; Knishevitsky, A. V.; Rayenko, G.F.; Pekhtereva, T.M.; Shvaika, O.P. Rep. Ukr. Acad. Sci. 2003, № 1, 139-145.

210. Sato, T.; Hirose, Y.; Yoshioka, D.; Shimojo, T.; Oi, S. Chem. Eur. J. 2013, 19, 15710-15718. http://dx.doi.org/10.1002/chem.201302567

211. Ma, Y.; Wei, S.; Lan, J.; Wang, J.; Xie, R.; You, J. J. Org. Chem. 2008, 73, 8256-8264.

http://dx.doi.org/10.1021/jo801349d

212. Korotkikh N.I., Saberov V.Sh., Rayenko G.F., Glinyana N.V., Shvaika O.P. Ternopil NPU sci. notes, 2016, 23, 3-11.

213. Larsen, A.O.; Leu, W.; Oberhuber, N.C.; Campbell, J. E.; Hoveida, A.H. J. Am. Chem. Soc. 2004, 126, 11130-1131.

http://dx.doi.org/10.1021/ja046245j

214. Waltman, A.W.; Grubbs, R.H. Organometallics 2004, 23, 3105-3107.

http://dx.doi.org/10.1021/om049727c

215. Korotkikh, N.I.; Pekhtereva, T.M.; Shvaika, O.P.; Cowley, A.H.; Jones, J.N. Rep. Ukr. Acad. Sci. 2005, № 6, 150-155 (Ukr).

216. Kiselyov, A. V. Cand. Chem. Sci. Thesis, Donetsk (Ukraine), 2008.

217. Boydston, A. J.; Rice, J. D.; Sanderson, M. D.; Dykhno, O. L.; Bielawski, C. W. Organometallics 2006, 25, 6087-6098.

http://dx.doi.org/10.1021/om060494u

218. Glinyanaya, N. V. Cand. Chem. Sci. Thesis; IPOCC, Donetsk (Ukraine), 2011.

219. Glinyanaya, N.V.; Korotkikh, N.I.; Knishevitsky, A.V.; Pekhtereva, T.M.; Shvaika, O.P. Proceedings of the XII Ukr. Conf. Org. Chem., Uzhgorod, Sep. 20-25, 2010, 88 (Carbenoid transformations of 1,4-diphenyl1,2,4-triazolium-3-phenylimide).

220. Farber, C.; Leibold, M.; Bruhn, C.; Maurer, M.; Siemeling, U. Chem. Commun. 2012, 48, $227-229$. http://dx.doi.org/10.1039/C1CC16460K

221. Hitzel, S.; Färber, C.; Bruhn, C.; Siemeling, U. Organometallics 2014, 33, 425-428. 
http://dx.doi.org/10.1021/om401058e

222. Zhang, J.; Pidlypnyi, N.; Nieger, M.; Namyslo, J. C.; Schmidt A. Org. Biomol. Chem. 2014, 12, $2737-2744$. http://dx.doi.org/10.1039/C3OB42462F

223. Pidlypnyi, N.; Wolf, S.; Liu, M.; Rissanen, K.; Nieger, M.; Schmidt, A. Tetrahedron 2014, 70, 8672-8680. http://dx.doi.org/10.1016/i.tet.2014.09.035

224. Pidlypnyi, N.; Uhrner, F.; Nieger, M.; Drafz, M. H. H.; Hubner, E. G.; Namyslo, J. C.; Schmidt, A. Eur. J. Org. Chem. 2013, 7739-7748.

http://dx.doi.org/10.1002/ejoc.201300728

225. Benhamou, L.; Bastin, S.; Lugan, N.; Lavigne, G.; César, V. Dalton Trans. 2014, 43, 4474-4482. http://dx.doi.org/10.1039/C3DT53089B

226. Danopoulos, A. A.; Braunstein, P. Chem. Commun. 2014, 50, 3055-3057. http://dx.doi.org/10.1039/C3CC49517E

227. Arnold, P. L.; Liddle, S. T. Organometallics 2006, 25, 1485-1491. http://dx.doi.org/10.1021/om050895u

228. Wang, Y.; Xie, Y.; Abraham, M. Y.; Wei, P.; Schaefer, H. F., III; Schleyer, P. R.; Robinson, G. H. J. Am. Chem. Soc. 2010, 132, 14370-14372.

http://dx.doi.org/10.1021/ja106631r

229. Waters, J. B.; Goicoechea, J. M. Dalton Trans. 2014, 43, 14239-14248. http://dx.doi.org/10.1039/C4DT00954A

230. Majhi, P. K.; Schnakenburg, G.; Kelemen, Z.; Nyulaszi, L.; Gates, D. P.; Streubel, R. Angew. Chem. Int. Ed. 2013, 52, 10080-10083.

http://dx.doi.org/10.1002/anie.201304431

231. Arduengo, A. J.; Dolphin, J. S.; Gurau, G.; Marshall, W. J.; Nelson, J. C.; Petrov, V. A.; Runyon, J. W. Angew. Chem. Int. Ed. 2013, 52, 5110-5114.

http://dx.doi.org/10.1002/anie.201301503

232. Aldeco-Perez, E.; Rosenthal, A. J.; Donnadieu, B.; Parameswaran, P.; Frenking, G.; Bertrand, G. Science 2009, 326, 556-559.

http://dx.doi.org/10.1126/science.1178206

233. Ung, G.; Bertrand, G. Chem. Eur. J. 2011, 17, 8269-8272.

http://dx.doi.org/10.1002/chem.201101130

234. Lavallo, V.; Dyker, C. A.; Donnadieu, B.; Bertrand, G. Angew. Chem. Int. Ed. 2008, 47, 5411-5414. http://dx.doi.org/10.1002/anie.200801176

235. Bouffard, J.; Keitz, B. K.; Tonner, R.; Guisado-Barrios, G.; Frenking, G.; Grubbs, R. H.; Bertrand, G. Organometallics 2011, 30, 2617-2627.

http://dx.doi.org/10.1021/om200272m

236. Mathew, P.; Neels, A.; Albrecht, M. J. Am. Chem. Soc. 2008, 130, 13534-13535.

http://dx.doi.org/10.1021/ja805781s

237. Donnelly, K. F.; Petronilho A.; Albrecht, M. Chem. Commun., 2013, 49, 1145-1159. http://dx.doi.org/10.1039/c2cc37881g

238. Arnold, P. L.; Pearson, S. Coord. Chem. Rev. 2007, 251, 596-609.

http://dx.doi.org/10.1016/j.ccr.2006.08.006

239. Albrecht, M. Chem. Commun. 2008, 3601-3610.

http://dx.doi.org/10.1039/b806924g

240. Schuster, O.; Yang, L.; Raubenheimer, H. G.; Albrecht, M. Chem. Rev. 2009, 109, 3445-3478. 
http://dx.doi.org/10.1021/cr8005087

241. Albrecht, M. Chimia 2009, 63, 105-110.

http://dx.doi.org/10.2533/chimia.2009.105

242. Aizpurua, J. M.; Fratila, R. M.; Monasterio, Z.; Pérez-Esnaola, N.; Andreieff, E.; Irastorza, A.; SagartzazuAizpurua, M. New J. Chem. 2014, 38, 474-480.

http://dx.doi.org/10.1039/C3NJ00667K

243. Guisado-Barrios, G.; Bouffard, J.; Donnadieu, B.; Bertrand, G. Angew. Chem. Int. Ed. 2010, 49, 47594762.

http://dx.doi.org/10.1002/anie.201001864

244. Bezuidenhout, D. I.; Kleinhans, G.; Guisado-Barrios, G.; Liles, D. C.; Ung, G.; Bertrand, G. Chem. Commun. 2014, 50, 2431-2433.

http://dx.doi.org/10.1039/c3cc49385g

245. Tapu, D.; Dixon, D. A.; Roe, C. Chem. Rev. 2009, 109, 3385-3407.

http://dx.doi.org/10.1021/cr800521g

246. Dewar, M. J. S. The molecular orbital theory of organic chemistry, McGraw Book Co., N.-Y.: 1969; p. 216.

247. Alder, R.W.; Allen, P.P.; Murray, M.; Orpen, A.G. Angew. Chem. Int. Ed. 1996, 35, 1121-1123.

http://dx.doi.org/10.1002/anie.199611211

248. Kim, Y.-J.; Streitwieser, A. J. Am. Chem. Soc. 2002, 124, 5757-5761.

http://dx.doi.org/10.1021/ja025628j

249. Chu, Y.; Deng, H.; Cheng, J.-P. J. Org. Chem. 2007, 72, 7790-7793.

http://dx.doi.org/10.1021/jo070973i

250. Higgins E. M.; Sherwood J. A.; Lindsay A. G.; Armstrong J.; Massey R. S.; Alder R. W.; O’Donoghue A. C. Chem. Commun. 2011, 47, 1559-1561.

http://dx.doi.org/10.1039/c0cc03367g

251. Amyes, T. L.; Diver, S. T.; Richard, J. P.; Rivas, F. M.; Toth, K. J. Am. Chem. Soc. 2004, 126, $4366-4374$.

http://dx.doi.org/10.1021/ja039890j

252. Massey, R. S.; Collett, C. J.; Lindsay, A. G.; Smith, A. D.; O’Donoghue, A. C. J. Am. Chem. Soc. 2012, 134, 20421-20432.

http://dx.doi.org/10.1021/ja308420c

253. Magill, A. M.; Cavell, K. J.; Yates, B. F. J. Am. Chem. Soc. 2004, 126, 8717-8724.

http://dx.doi.org/10.1021/ja038973x

254. Nelson, D. J.; Nolan, S. P. 2013, 42, 6723-6753.

http://dx.doi.org/10.1039/c3cs60146c

255. Tolman, C. A., Chem. Rev. 1977, 77, 313-348.

http://dx.doi.org/10.1021/cr60307a002

256. Iglesias, M.; Beetstra, D. J.; Stasch, A.; Horton, P. N.; Hursthouse, M. B.; Coles, S. J.; Cavell, K. J.; Dervisi, A.; Fallis, A. Organometallics 2007, 26, 4800-4809.

http://dx.doi.org/10.1021/om7004904

257. Phukan, A. K.; Guha, A. K.; Sarmah, S.; Dewhurst, R. D. J. Org. Chem. 2013, 78, $11032-11039$. http://dx.doi.org/10.1021/jo402057g

258. Phukan, A. K.; Guha, A. K.; Sarmah, S. Organometallics 2013, 32, 3238-3248.

http://dx.doi.org/10.1021/om400162a

259. Decken, A.; Carmalt, C. J.; Clyburne, J. A. C.; Cowley, A. H. Inorg. Chem. 1997, 36, 3741-3744.

http://dx.doi.org/10.1021/ic970281k 
260. Back, O.; Henry-Ellinger, M.; Martin, C. D.; Martin, D.; Bertrand, G. Angew. Chem. Int. Ed. 2013, 52, 2939-2943.

http://dx.doi.org/10.1002/anie.201209109

261. Rodrigues, R. R.; Dorsey, C. L.; Arceneaux, C. A.; Hudnall, T. W. Chem. Commun. 2014, 50, $162-164$. http://dx.doi.org/10.1039/c3cc45134h

262. Verlinden, K.; Buhl, H.; Frank, W.; Ganter, C. Eur. J. Inorg. Chem. 2015, 2416-2425. http://dx.doi.org/10.1002/ejic.201500174

263. Liske, A.; Verlinden, K.; Buhl, H.; Schaper, K.; Ganter, C. Organometallics 2013, 32, 5269-5272. http://dx.doi.org/10.1021/om400858y

264. Nelson, D. J.; Collado, A.; Manzini, S.; Meiries, S.; Slawin, A. M. Z.; Cordes, D. B.; Nolan, S. P. Organometallics 2014, 33, 2048-2058.

http://dx.doi.org/10.1021/om5001919

265. Nelson, D. J.; Nahra, F.; Patrick, S. R.; Cordes, D. B.; Slawin, A. M. Z.; Nolan, S. P. Organometallics 2014, 33, 3640-3645.

http://dx.doi.org/10.1021/om500610w

266. Vummaleti, S. V. C.; Nelson, D. J.; Poater, A.; Gomez-Suarez, A.; Cordes, D. B.; Slawin, A. M. Z.; Nolan, S. P.; Cavallo, L. Chem. Sci. 2015, 6, 1895-1904.

http://dx.doi.org/10.1039/C4SC03264K

267. Clavier, H.; Nolan, S. P. Chem. Commun., 2010, 46, 841-861.

http://dx.doi.org/10.1039/b922984a

268. Le Duc, G.; Meiries, S.; Nolan, S. P. Organometallics, 2013, 32, 7547-7551.

http://dx.doi.org/10.1021/om4010143

269. Meiries, S.; Le Duc, G.; Chartoire, A.; Collado, A.; Speck, K.; Athukorla Arachchige, K. S.; Slawin, A. M. Z.; Nolan, S. P. Chem. Eur. J. 2013, 19, 17358-17368.

http://dx.doi.org/10.1002/chem.201302471

270. Izquierdo, F.; Manzini, S.; Nolan, S. P. Chem. Commun., 2014, 50, 14926-14937. http://dx.doi.org/10.1039/c4cc05289g

271. Guest, D.; Chen, M.-T.; Tizzard, G. J.; Coles, S. J.; Turner, M. L.; Navarro, O. Eur. J. Inorg. Chem. 2014, 2200-2203.

http://dx.doi.org/10.1002/ejic.201400072

272. Martin, A. R.; Makida, Y.; Meiries, S.; Slawin, A. M. Z.; Nolan, S. P. Organometallics 2013, 32, 6265-6270. http://dx.doi.org/10.1021/om4004863

273. Bastug, G.; Nolan, S. P. J. Org. Chem. 2013, 78, 9303-9308.

http://dx.doi.org/10.1021/jo401492n

274. Collado, A.; Balogh, J.; Meiries, S.; Slawin, A. M. Z.; Falivene, L.; Cavallo, L.; Nolan, S. P. Organometallics 2013, 32, 3249-3252.

http://dx.doi.org/10.1021/om400168b

275. Dierick, S.; Dewez, D. F.; Markó, I. E. Organometallics 2014, 33, 677-683.

http://dx.doi.org/10.1021/om4008955

276. Regitz, M. Angew. Chem. Int. Ed. 1991, 30, 674-676.

http://dx.doi.org/10.1002/anie.199106741

277. Regitz, M. Angew. Chem. Int. Ed. 1996, 35, 725-728.

http://dx.doi.org/10.1002/anie.199607251

278. Liu, M. T. H. Acc. Chem. Res. 1994, 27, 287-294. 
http://dx.doi.org/10.1021/ar00046a001

279. Korotkikh, N. I.; Rayenko, G. F.; Shvaika, O. P. Proceedings of the 17-th International Congress of Heterocyclic Chemistry, Aug. 1-6 1999, Vienna; PO-383.

280. Nickon, A. Acc. Chem. Res. 1993, 26, 84-89. http://dx.doi.org/10.1021/ar00027a002

281. Hoffmann, R.; Zeiss, J. D.; Van Dine, G. W. J. Am. Chem. Soc. 1968, 90, 1475-1485. http://dx.doi.org/10.1021/ja01008a016

282. Storer, J. W.; Houk, K. N. J. Am. Chem. Soc. 1993, 115, 10426-10427. http://dx.doi.org/10.1021/ja00075a095

283. Sander W., Bucher G.; Wierlacher S. Chem. Rev. 1993, 93, 1583-1621. http://dx.doi.org/10.1021/cr00020a009

284. Jackson, J. E.; Platz, M.S. Advances in Carbene Chemistry, Brinker U. Ed.; JAI: Greenwich, CT: 1994; Vol. 1; p. 145.

285. Bonneau, R.; Liu, M. T. H.; Kim, K. C.; Goodman, J. L. J. Am. Chem. Soc. 1996, 118, 3829-3837. http://dx.doi.org/10.1021/ja952700n

286. Keating, A. E.; Garcia-Garibay, M. A.; Houk, K. N. J. Am. Chem. Soc. 1997, 119, 10805-10809. http://dx.doi.org/10.1021/ja970642v

287. Heinemann, C.; Thiel, W. Chem. Phys. Lett. 1994, 217, 11-16. http://dx.doi.org/10.1016/0009-2614(93)E1360-S

288. McGibbon, G. A.; Heinemann, C.; Lavorato, D. J.; Schwarz, H. Angew. Chem. Int. Ed. 1997, 36, 14781481.

http://dx.doi.org/10.1002/anie.199714781

289. Maier, G.; Endres, J.; Reisenauer, H. P. Angew. Chem. Int. Ed. 1997, 36, 1709-1712. http://dx.doi.org/10.1002/anie.199717091

290. Karmakar, S.; Datta, A. Angew. Chem. Int. Ed. 2014, 53, 9587-9591. http://dx.doi.org/10.1002/anie.201404368

291. Sole S., Gornitzka H., Guerret O., Bertrand G. J. Am. Chem. Soc. 1998, 120, 35, 9100-9101. http://dx.doi.org/10.1021/ja980797i

292. Denk, M. K.; Rodezno, J. M. J. Organomet. Chem. 2000, 608, 122-125. http://dx.doi.org/10.1016/S0022-328X(00)00390-9

293. Denk, M. K., Rodezno, J. M. J. Organomet. Chem. 2001, 617/618, 737-740. http://dx.doi.org/10.1016/S0022-328X(00)00765-8

294. Oda, R.; Mieno, M.; Hayashi, Y. Tetrahedron Lett. 1967, 8, 2363-2365. http://dx.doi.org/10.1016/S0040-4039(00)71607-8

295. Holm, R. H.; Donahue, J. P. Polyhedron 1993, 12, 571-589. http://dx.doi.org/10.1016/S0277-5387(00)84972-4

296. Boëhler, C.; Stein, D.; Donati, N.; Gruëtzmacher, H. New J. Chem. 2002, 262, 1291-1295. http://dx.doi.org/10.1039/B203670C

297. Belenkii, L. I.; Chuvylkin, N.D. Chem. Heter. Compd. 1996, (11/12), 1535-1563.

298. General organic chemistry, Barton D., Ollis V.D. Eds. Moscow, Chemistry: 1985; 460 p.

299. Korotkikh, N.I.; Kiselyov, A.V.; Rayenko, G. F.; Opeida, I.A.; Shvaika, O. P. Proceed. Shevchenko. Sci. Commun., Ser. Chem. 2008, 21, 7-63 (Ukr.). http://dspace.nbuv.gov.ua/handle/123456789/74094 
300. Schaper, L.-A.; Wei, X.; Altmann, P. J.; Öfele, K.; Pöthig, A.; Drees, M.; Mink, J.; Herdtweck, E.; Bechlars, B.; Herrmann, W. A.; Kühn, F. E. Inorg. Chem. 2013, 52, 7031-7044.

http://dx.doi.org/10.1021/ic4005449

301. Zhukhovitskiy, A. V.; Geng, J.; Johnson, J. A. Chem. Eur. J. 2015, 21, 5685-5688.

http://dx.doi.org/10.1002/chem.201500052

302. Schmidt, D.; Berthel, J. H. J.; Pietsch, S.; Radius, U. Angew. Chem. Int. Ed. 2012, 51, 8881-8885. http://dx.doi.org/10.1002/anie.201204333

303. Iversen, K. J.; Wilson, D. J. D.; Dutton, J. L. Dalton Trans. 2013, 42, 11035-11038. http://dx.doi.org/10.1039/c3dt51503f

304. Wang, T.; Stephan, D. W. Chem. Eur. J. 2014, 20, 3036-3039.

http://dx.doi.org/10.1002/chem.201304870

305. Franz, D.; Inoue, S. Chem. Asian J. 2014, 9, 2083-2087.

http://dx.doi.org/10.1002/asia.201402233

306. Al-Rafia, S. M. I.; McDonald, R.; Ferguson, M. J.; Rivard, E. Chem. Eur. J. 2012, 18, 13810-13820.

http://dx.doi.org/10.1002/chem.201202195

307. Pietsch, S.; Paul, U.; Cade, I. A.; Ingleson, M. J.; Radius, U.; Marder, T. B. Chem. Eur. J. 2015, 21, 90189021.

http://dx.doi.org/10.1002/chem.201501498

308. Arrowsmith, M.; Hill, M. S.; Kociok-Kohn, G.; MacDougall, D. J.; Mahon, M. F. Angew. Chem. Int. Ed. 2012, 51, 2098-2100.

http://dx.doi.org/10.1002/anie.201107836

309. Guan, Z.; Wiechmann, S.; Drafz, M.; Hubner, E.; Schmidt, A. Org. Biomol. Chem. 2013, 11, 3558-3567. http://dx.doi.org/10.1039/c3ob40379c

310. Guan, Z.; Hillrichs, K.; Unlu, C.; Rissanen, K.; Nieger, M.; Schmidt A. Tetrahedron 2015, 71, $276-282$. http://dx.doi.org/10.1016/j.tet.2014.11.054

311. Alder, R.W.; Blake, M. E.; Chaker, L.; Harvey, J. N.; Paolini, F.; Schutz, J. Angew. Chem. Int. Ed. 2004, 43, 5896-5911.

http://dx.doi.org/10.1002/anie.200400654

312. Lemal, D. M.; Lovald, R. A.; Kawano K. I. J. Am. Chem. Soc. 1964, 86, 2518-2519. http://dx.doi.org/10.1021/ja01066a044

313. Liu, Y.; Lindner, P. E.; Lemal, D. M. J. Am. Chem. Soc. 1999, 121, 10626-10627. http://dx.doi.org/10.1021/ja9922678

314. Liu, Y.; Lemal, D. M. Tetrahedron Lett. 2000, 41, 599-602.

http://dx.doi.org/10.1016/S0040-4039(99)02161-9

315. Arduengo III, A. J.; Goerlich J. R.; Marshall, W. J. Liebigs Ann. 1997, 365-374. http://dx.doi.org/10.1002/jlac.199719970213

316. Alder, R.W.; Blake, M. E. Chem. Commun. 1997, 1513-1514.

http://dx.doi.org/10.1039/A703610H

317. Alder, R.W.; Chaker, L.; Paolini, F. P. V.; Chem. Commun. 2004, 2172-2173. http://dx.doi.org/10.1039/B409112D

318. Denk, M.K.; Hatano, K.; Ma, M. Tetrahedron Lett. 1999, 40, 2057-2060. http://dx.doi.org/10.1016/S0040-4039(99)00164-1

319. Taton, T.A.; Chen, P. Angew. Chem. Int. Ed. 1996, 35, 1011-1013. http://dx.doi.org/10.1002/anie.199610111 
320. Weinstein, C. M.; Martin, C. D.; Liu, L.; Bertrand, G. Angew. Chem. Int. Ed. 2014, 53, 6550-6553. http://dx.doi.org/10.1002/anie.201404199

321. Kamplane, J.W.; Bielawski, C. Chem. Commun. 2006, 1727-1729. http://dx.doi.org/10.1039/b518246h

322. Kamplane, J.W.; Lynch V.M.; Bielawski, C. Org. Lett. 2007, 9, 5401-5404. http://dx.doi.org/10.1021/ol702230r

323. Martin, D.; Soleilhavoup, M.; Bertrand, G. Chem. Sci. 2011, 2, 389-399. http://dx.doi.org/10.1039/COSC00388C

324. Cowan, J. A.; Clyburne, J. A. C.; Davidson, M. G.; Luke, R.; Harris, W.; Howard, J. A. K.; Kopper, P.; Leech, M. A.; Richards, S. P. Angew. Chem. Int. Ed. 2002, 41, 1432-1434. http://dx.doi.org/10.1002/1521-3773(20020415)41:8<1432::AID-ANIE1432>3.0.CO;2-M

325. Movassaghi, M.; Schmidt, M. A. Org. Lett. 2005, 7, 2453-2456. http://dx.doi.org/10.1021/ol050773y

326. Giffin, N. A.; Makramalla, M.; Hendsbee, A. D.; Robertson, K. N.; Sherren, C.; Pye, C. C.; Masuda, J. D.; Clyburne, J. A. C. Org. Biomol. Chem. 2011, 9, 3672-3680. http://dx.doi.org/10.1039/c0ob00999g

327. Enders, D.; Breuer, K.; Runsink, J.; Teles, J. H. Liebigs Ann. Chem. 1996, 2019-2028. http://dx.doi.org/10.1002/ilac.199619961212

328. Korotkikh, N. I.; Raenko, G. F.; Pekhtereva, T. M.; Shvaika, O. P. Rep. Ukr. Acad. Sci. 1998, № 6, $149-152$.

329. Arduengo, A. J. III; Calabrese, J. C.; Davidson, F.; Dias, H. V. R.; Goerlich, J. R.; Krafczyk. R; Marshall, W. J.; Tamm M.; Schmutzler, R. Helv. Chim. Acta. 1999, 82, 2348-2364.

http://dx.doi.org/10.1002/(SICI)1522-26751999121582:12<2348::AID-HLCA2348>3.0.CO;2-M

330. Knishevitsky, A. V.; Korotkikh, N. I.; Cowley, A. H.; Moore, J. A.; Vasudevan, K. V.; Pekhtereva, T. M.; Shvaika, O. P. Arkivoc 2012, (ii), 60-73.

http://www.arkat-usa.org/get-file/43795/

331. Berkessel, A.; Elfert, S.; Etzenbach-Effers, K.; Teles, J. H. Angew. Chem. Int. Ed. 2010, 49, 7120-7124. http://dx.doi.org/10.1002/anie.200907275

332. Rodriguez, H.; Gurau, G.; Holbrey, J. D.; Rogers, R. D. Chem. Commun. 2011, 47, 3222-3224. http://dx.doi.org/10.1039/c0cc05223j

333. Korotkikh, N. I.; Raenko, G. F.; Shvaika, O. P. Rep. Ukr. Acad. Sci. 2001, № 11, 130-133.

334. Korotkikh, N. I.; Saberov, V. Sh.; Kiselev, A. V.; Glinyanaya, N. V.; Marichev, K. A.; Pekhtereva, T. M.; Dudarenko, G. V.; Bumagin, N. A.; Shvaika, O. P. Chem. Heter. Compd. 2012, 47, 1551-1560. http://dx.doi.org/10.1007/s10593-012-0947-9

335. Korotkikh, N. I.; Saberov V. Sh., Kiselyov, A. V.; Marichev, K. A.; Glinyanaya, N.V.; Shvaika, O. P. Ukraine Pat. 62,301 A, 2011; Bul. № 16. http://base.uipv.org/searchINV/search.php?action=viewdetails\&IdClaim=162908\&chapter=description

336. Knappke, C. E. I.; Neudorf, J. M.; von Wangelin, A. J. Org. Biomol. Chem. 2010, 8, 1695-1705. http://dx.doi.org/10.1039/B921655C

337. Maji, B.; Horn, M.; Mayr, H. Angew. Chem. Int. Ed. 2012, 51, 6231-6235. http://dx.doi.org/10.1002/anie.201202327

338. Maji, B., Mayr, H. Angew. Chem. Int. Ed. 2012, 51, 10408-10412. http://dx.doi.org/10.1002/anie.201204524

339. Holle, S.; Escudero, D.; Ines, B.; Rust, J.; Thiel, W.; Alcarazo M. Chem. Eur. J. 2015, 21, 2744-2749. http://dx.doi.org/10.1002/chem.201405418 
340. Kuhn, N.; Fahl, J.; Boese, R.; Henkel, G. Z. Naturforsch. 1998, 53B, 881-886.

341. Ghadwal, R. S.; Reichmann, S. O.; Herbst-Irmer, R. Chem. Eur. J. 2015, 21, 4247-4251. http://dx.doi.org/10.1002/chem.201405923

342. Balli, H.; Gruner, H.; Maul, R.; Schepp, H. Helv. Chim. Acta. 1981, 64, 648-656. http://dx.doi.org/10.1002/hlca.19810640306

343. Ramnial, T.; McKenzie, I.; Gorodetsky, B.; Tsang, E.M.W.; Clyburne, J.A.C. Chem. Commun. 2004, 10541055.

http://dx.doi.org/10.1039/b314110a

344. Arduengo, A. J., III; Calabrese, J. C.; Marshall, W. J.; Runyon, J. W.; Schiel, C.; Schinnen, C.; Tamm, M.; Uchiyama, Y. Z. Anorg. Allgem. Chem. 2015, 641, 2190-2198.

http://dx.doi.org/10.1002/zaac.201500578

345. Jones, W. M.; Stowe, M. E.; Well, S. E. E.; Lester, E. W. J. Am. Chem. Soc. 1968, 90, 1849-1859.

http://dx.doi.org/10.1021/ja01009a030

346. Rayenko, G.F. Diss. Cand. Chem. Sci., Donetsk, 2000 (Ukraine).

347. Goumri-Magnet, S.; Kato, T.; Gornitzka, H.; Baceiredo, A.; Bertrand, G. J. Am. Chem. Soc. 2000, 122, 4464-4470.

http://dx.doi.org/10.1021/ja994408b

348. Matsuoka, S.-I.; Ota, Y.; Washio, A.; Katada, A.; Ichioka, K.; Takagi, K.; Suzuki, M. Org. Lett. 2011, 13, 3722-3725.

http://dx.doi.org/10.1021/ol201380m

349. Kato, T.; Ota, Y.; Matsuoka, S.-I.; Takagi, K.; Suzuki, M. J. Org. Chem. 2013, 78, 8739-8747. http://dx.doi.org/10.1021/jo401477b

350. Ottou, N. W.; Bourichon, D.; Vignolle, J.; Wirotius, A.-L.; Robert, F.; Landais, Y.; Sotiropoulos, J.-M.; Miqueu, K.; Taton, D. Chem. Eur. J. 2015, 21, 9447-9453.

http://dx.doi.org/10.1002/chem.201500594

351. Phillips, E. M.; Riedrich, M.; Scheidt, K. A. J. Am. Chem. Soc. 2010, 132, 13179-13181. http://dx.doi.org/10.1021/ja1061196

352. Ottou, W. N.; Bourichon, D.; Vignolle, J.; Wirotius, A.-L.; Robert, F.; Landais, Y.; Sotiropoulos, J.-M.; Miqueu, K.; Taton D. Chem. Eur. J. 2014, 20, 3989-3997.

http://dx.doi.org/10.1002/chem.201304492

353. Bertermann, R.; Braunschweig, H.; Brown, C. K. L.; Damme, A.; Dewhurst, R. D.; Hörl, C.; Kramer, T.; Krummenacher, I.; Pfaffinger, B.; Radacki, K. Chem. Commun. 2014, 50, 97-99.

http://dx.doi.org/10.1039/c3cc46947f

354. Ines, B.; Holle, S.; Goddard, R.; Alcarazo, M. Angew.Chem.Int.Ed. 2010, 49, 8389-8391. http://dx.doi.org/10.1002/anie.201004149

355. Li, H.; Risko, C.; Seo, J. H.; Campbell, C.; Wu, G.; Bredas, J.-L.; Bazan, G. C. J. Am. Chem. Soc. 2011, 133, 12410-12413.

http://dx.doi.org/10.1021/ja204974m

356. Lorbach, A.; Maverick, E.; Carreras, A.; Alemany, P.; Wu, G.; Garcia-Garibay, M. A.; Bazan, G. C. Phys. Chem. Chem. Phys. 2014, 16, 12980-12986.

http://dx.doi.org/10.1039/c4cp01036a

357. Iglesias-Sigenza, J.; Alcarazo, M. Angew. Chem. Int. Ed. 2012, 51, 1523-1524.

http://dx.doi.org/10.1002/anie.201107399

358. Kuhn, N.; Niquet, E.; Steimann, M.; Walker, I. Z. Naturforsch. 1999, 54b, 427-434. 
359. Duong, H. A.; Tekavec, T. N.; Aarif, A. M.; Louie, J. Chem. Commun. 2004, 112-113. http://dx.doi.org/10.1039/b311350g

360. Van Ausdall, B. R.; Glass, J. L.; Wiggins, K. M.; Aarif, A. M.; Louie, J. J. Org. Chem. 2009, 74, 7935-7942. http://dx.doi.org/10.1021/jo901791k

361. Tudose, A.; Demonceau, A.; Delaude, L. J. Organomet. Chem. 2006, 691, 5356-5365. http://dx.doi.org/10.1016/j.jorganchem.2006.07.035

362. Holbrey, J. D.; Reichert, W. M.; Tkatchenko, I.; Bouajila, E.; Walter, O.; Tommasi, I.; Rogers, R. Chem. Commun. 2003, 28-29.

http://dx.doi.org/10.1039/B211519K

363. Vogt, M.; Bennett, J. E.; Huang, Y.; Wu, C.; Schneider, W. F.; Brennecke, J. F.; Ashfeld, B. L. Chem. Eur. J. 2013, 19, 11134-11138.

http://dx.doi.org/10.1002/chem.201302013

364. Vogt, M.; Wu, C.; Oliver, A. G.; Meyer, C. J.; Schneider, W. F.; Ashfeld, B. L. Chem. Commun. 2013, 49, 11527-11529.

http://dx.doi.org/10.1039/c3cc46555a

365. Khramov, D. M.; Bielawski, C. W. Chem. Commun. 2005, 4958-4960. http://dx.doi.org/10.1039/b508679e

366. Khramov, D. M.; Bielawski, C. W. J. Org. Chem. 2007, 72, 9407-9417. http://dx.doi.org/10.1021/jo070789x

367. Hopkins, J. M.; Bowdridge, M.; Robertson, K. N.; Cameron, T. S.; Jenkins, H. A.; Clyburne, J. A. C. J. Org. Chem. 2001, 66, 5713-5716.

http://dx.doi.org/10.1021/jo001515b

368. Choytun, D. D.; Langlois, L. D.; Johansson, T. P.; Macdonald, C. L. B.; Leach, G. W.; Weinber, N.; Clyburne, J. A. C. Chem . Commun. 2004, 1842-1843.

http://dx.doi.org/10.1039/B404129A

369. McLoughlin, C.; Clyburne, J. A. C.; Weinberg, N. J. Mater. Chem. 2007, 17, 4304-4308. http://dx.doi.org/10.1039/B706964B

370. Tskhovrebov, A.G.; Solari, E.; Wodrich, M. D.; Scopelliti, R.; Severin, K. Angew. Chem. Int. Ed. 2012, 51, 232-234.

http://dx.doi.org/10.1002/anie.201106589

371. Tskhovrebov, A. G.; Vuichoud, B.; Solari, E.; Scopelliti, R.; Severin, K. J. Am. Chem. Soc. 2013, 135, 94869492.

http://dx.doi.org/10.1021/ja4030287

372. Tskhovrebov, A. G.; Solari, E.; Scopelliti, R.; Severin, K. Inorg. Chem. 2013, 52, 11688-11690. http://dx.doi.org/10.1021/ic401524w

373. Theuergarten, E.; Bannenberg, T.; Walter, M.D.; Holschumacher, D.; Freytag, M.; Daniliuc, C. G.; Jones, P. G.; Tamm, M. Dalton Trans. 2014, 43, 1651-1662.

http://dx.doi.org/10.1039/c3dt52742e

374. Park, J.; Song, H.; Kim, Y.; Eun, B.; Kim, Y.; Bae, D. Y.; Park, S.; Rhee, Y. M.; Kim, W. J.; Kim, K.; Lee E. J. Am. Chem. Soc. 2015, 137, 4642-4645.

http://dx.doi.org/10.1021/jacs.5b01976

375. Kuhn, N.; Steimann, M.; Weyers, G.; Henkel, G. Z. Naturforsch. B. 1999, 54, 434-440.

376. Pi, C.; Yu, X.; Zheng, W. Eur. J. Inorg. Chem. 2015, 1804-1810.

http://dx.doi.org/10.1002/ejic.201500058 
377. Pazdro, M., Polaczkowa, W. Rocz. Chem. 1971, 54, 1487-1494.

378. Shang, X.; Chen, C.; Qiu, H.; Chen, W. Tetrahedron 2014, 70, 3073-3077. http://dx.doi.org/10.1016/j.tet.2014.02.031

379. Maji, B.; Mayr, H. Angew. Chem. Int. Ed. 2013, 52, 11163-11167. http://dx.doi.org/10.1002/anie.201303524

380. Duong, H. A.; Cross, M. J.; Louie, J. Org. Lett. 2004, 6, 4679-4681. http://dx.doi.org/10.1021/ol048211m

381. Norris, B.C.; Sheppard, D. G.; Henkelman, G.; Bielawski, C. W. J. Org. Chem. 2011, 76, 301-304. http://dx.doi.org/10.1021/jo101850g

382. Matsuoka, Sh.; Tochigi, Y.; Takagi, K.; Suzuki, M. Tetrahedron 2012, 68, 9836-9841. http://dx.doi.org/10.1016/j.tet.2012.08.076

383. Kuhn, N.; Kratz, T.; Henkel, G. J. Chem. Soc., Chem.Commun. 1993, 1778-1779. http://dx.doi.org/10.1039/C39930001778

384. Kuhn, N.; Fahl, J.; Fawzi, R.; Maichle-Mossmer, C.; Steimann, M. Z. Naturforsch. 1998, 53b, $720-727$.

385. Gierz, V.; Seyboldt, A.; Maichle-Mossmer, C.; Frohlich, R.; Rominger, F.; Kunz, D. Eur. J. Inorg. Chem. 2012, 1423-1429.

http://dx.doi.org/10.1002/ejic.201100905

386. Zeng, W.; Wang, E.; Qiu, R.; Sohail, M.; Wu, S.; Chen, F.-X. J. Organomet. Chem. 2013, 743, 44-48. http://dx.doi.org/10.1016/j.jorganchem.2013.06.017

387. Ishiguro, K.; Hirabayashi, K.; Nojima, T.; Sawaki, Y. Chem. Lett. 2002, 796-797. http://dx.doi.org/10.1246/cl.2002.796

388. Shvaika, O. P.; Korotkikh, N. I.; Aslanov, A.F. Rep. Ukr. Acad. Sci. B. 1990, № 5, 46-49.

389. Aslanov, A.F.; Korotkikh N. I., Shvaika O. P. Rep. Ukr. Acad. Sci. B. 1992, № 4, 92-95.

390. Nick, A.; Giffin, J.; Masuda D. Coord. Chem. Rev. 2011, 255, 1342-1359. http://dx.doi.org/10.1016/i.ccr.2010.12.016

391. Wang, Y.; Xie, Y.; Wei, P.; Schaefer, H. F. III; Schleyer, P. von R.; Robinson G. H. J. Am. Chem. Soc. 2013, 135, 19139-19142.

http://dx.doi.org/10.1021/ja411667f

392. Gudat, D. Angew. Chem. Int. Ed. 2014, 53, 4753-4754.

http://dx.doi.org/10.1002/anie.201400762

393. Martin, D.; Canac, Y.; Lavallo, V.; Bertrand, G. J. Am. Chem. Soc. 2014, 136, 5023-5030. http://dx.doi.org/10.1021/ja412981x

394. Herrmann, W. A.; Cornils, B. Angew. Chem., Int. Ed. 1997, 36, 1048-1067. http://dx.doi.org/10.1002/anie.199710481

395. Herrmann, W. A. Angew. Chem., Int. Ed. 2002, 41, 1290-1309. http://dx.doi.org/10.1002/1521-3773(20020415)41:8<1290::AID-ANIE1290>3.0.CO;2-Y

396. Korotkikh, N. I.; Saberov, V. Sh.; Glinyanaya, N. V.; Marichev, K. A.; Kiselyov, A. V.; Knishevitsky, A. V.; Rayenko, G. F.; Shvaika, O. P. Chem. Heter. Compd. 2013, 49, 19-38.

http://dx.doi.org/10.1007/s10593-013-1230-4

397. Nyce, G. W.; Lamboy, J. A.; Connor, E. F.; Waymouth, R. M.; Hedrick, J. L. Org. Lett. 2002, 4, 3587-3590. http://dx.doi.org/10.1021/ol0267228

398. Connor, E. F.; Nyce, G. W.; Myers, M.; Mock, A.; Hedrick, J. L. J. Am. Chem. Soc. 2002, 124, $914-915$. http://dx.doi.org/10.1021/ja0173324

399. Grasa, G. A.; Kissling, R. M.; Nolan, S. P. Org. Lett. 2002, 4, 3583-3586. 
http://dx.doi.org/10.1021/ol0264760

400. Grasa, G. A.; Gveli, T.; Singh, R.; Nolan, S. P. J. Org. Chem. 2003, 68, 2812-2819. http://dx.doi.org/10.1021/jo0267551

401. Singh, R.; Kissling, R. M.; Letellier, M.-A., Nolan, S. P. J. Org. Chem. 2004, 69, 209-212. http://dx.doi.org/10.1021/jo035431p

402. Marichev, K. A.; Korotkikh, N. I.; Kiselyov, A. V.; Pekhtereva, T. M.; Bumagin, N. A.; Rayenko, G. F.; Shvaika, O. P. Rep. Ukr. Acad. Sci. 2011, № 7, 133-137.

403. Korotkikh, N. I.; Marichev, K. A.; Kiselyov, A. V.; Knishevitsky, A.V.; Glinyanaya, N.V.; Popov, A.F.; Shvaika, O. P. Ukraine Pat. 68,789 A, 2012; Bul. № 7.

http://base.uipv.org/searchINV/search.php?action=viewdetails\&/dClaim=171727\&chapter=description

404. Hashmi, A. S. K.; Wolfle, M.; Teles, J. H.; Frey, W. Synlett 2007, 1747-1752. http://dx.doi.org/10.1055/s-2007-982569

405. Cetinkaya, B. RSC Catalysis, Ser. No. 6. N-Heterocyclic carbenes: from laboratory curiosities to efficient synthetic tools; Diez-Gonzalez, S. ed.; RSC: 2011; p. 366.

406. Poyatos, M., Guisado-Barrios, G., Peris, E. N-Heterocyclic carbenes; Nolan S. P. Ed.; Wiley VCH Verlag, Gmbh: 2014; 542 p.

407. Miecznikowski, J. R.; Crabtree, R. H. Organometallics 2004, 23, 629-631.

http://dx.doi.org/10.1021/om034393x

408. Hahn, F. E.; Holtgrewe, C.; Pape, T.; Martin, M.; Sola, E.; Oro, L. A. Organometallics 2005, 24, 22032209.

http://dx.doi.org/10.1021/om0500873

409. Sun, J.-F., Chen, F., Dougan, B. A., Xu, H.-J., Cheng, Y., Li, Y.-Z., Chen, X.-T., Xue, Z.-L. J. Organomet. Chem. 2009, 694, 2096-2105.

http://dx.doi.org/10.1016/j.jorganchem.2009.02.007

410. Poyatos, M.; Mas-Marza, E.; Mata, J. A.; Sanau, M.; Peris, E. Eur. J. Inorg. Chem. 2003, 1215-1221. http://dx.doi.org/10.1002/ejic.200390157

411. Albrecht, M.; Miecznikowski, J. R.; Samuel, A.; Faller, J. W.; Crabtree, R. H. Organometallics 2002, 21, 3596-3604.

http://dx.doi.org/10.1021/om020338x

412. Hillier, A. C.; Lee, H. M.; Stevens, E. D.; Nolan, S. P. Organometallics. 2001, 20, 4246-4252.

http://dx.doi.org/10.1021/om0103456

413. Viciu, M. S.; Grasa, G. A.; Nolan, S. P. Organometallics 2001, 20, 3607-3612.

http://dx.doi.org/10.1021/om010332s

414. Navarro, O.; Marion, N.; Oonishi, Y.; Kelly, R. A.; Nolan, S. P. J. Org. Chem. 2006, 71, 685-692. http://dx.doi.org/10.1021/jo0521201

415. Navarro, O.; Kaur, H.; Mahjoor, P.; Nolan, S. P. J. Org. Chem. 2004, 69, 3173-3180. http://dx.doi.org/10.1021/jo035834p

416. Davies, C. J. E.; Page, M. J.; Ellul, C. E.; Mahon, M. F.; Whittlesey, M. K., Chem. Commun. 2010, 51515153.

http://dx.doi.org/10.1039/COCC01335H

417. Kuhl, S.; Schneider, R.; Fort, Y. Adv. Synth. Catal. 2003, 345, 341-344.

http://dx.doi.org/10.1002/adsc.200390036

418. Akzinnay, S.; Bisaro, F.; Cazin, C. S. J. Chem. Commun. 2009, 5752-5753.

http://dx.doi.org/10.1039/B910415A 
419. Saberov, V. Sh.; Korotkikh, N. I.; Glinyanaya, N. V.; Kiselyov, A. V.; Pekhtereva, T.M.; Rayenko, G. F.; Popov, A.F.; Shvaika, O. P. Rep. Ukr. Acad Sci. 2013, № 2, 112-119.

420. Korotkikh, N. I.; Saberov, V. Sh.; Glinyanaya, N.V.; Kiselyov, A. V.; Popov, A.F.; Shvaika, O. P. Ukraine Pat. 77,420 A, 2013; Bul. № 3.

http://base.uipv.org/searchINV/search.php?action=viewdetails\&/dClaim=183228\&chapter=description

421. Korotkikh, N. I.; Saberov, V. Sh.; Popov, A.F.; Shvaika, O. P. Ukraine Pat. 112,395, 2016; Bul. № 16. http://base.uipv.org/searchINV/search.php?action=viewdetails\&IdClaim=183228\&chapter=description

422. John, A.; Ghosh, P. Dalton Trans. 2010, 39, 7183-7206.

http://dx.doi.org/10.1039/c002475a

423. Liu, W.; Gust, R. Chem. Soc. Rev. 2013, 42, 755-773.

http://dx.doi.org/10.1039/c2cs35314h

424. Oehninger, L.; Rubbiani, R.; Ott, I. Dalton Trans. 2013, 42, 3269-3284.

http://dx.doi.org/10.1039/c2dt32617e

425. Korotkikh, N. I., Shvaika, O. P.; Kiselyov, A. V.; Knishevitsky, A. V.; Glinyanaya, N. V.; Marichev, K. A.; Novikov, V. P.; Lubenets, V. I.; Iskiv, O.P.; Moskalenko, N.I.; Komarovska-Porokhnyavets O.P. J. Univ. Lviv Polytechnika, 2008, 622, 3-12.

426. Marichev, K. A.; Glinyanaya, N.V.; Korotkikh, N. I.; Shvaika, O. P.; Kiselyov, A. V.; Knishevitsky, A. V., Pekhtereva, T.M.; Dudarenko, G.V.; Komarovska-Porokhnyavets, O.P.; Novikov, V. P., Lubenets, V. I. J. Org. Pharm. Chem. 2011, 9, № 3(35), 72-78.

http://nuph.edu.ua/wp-content/uploads/2015/04/ZHOFH_2011335 72-79.pdf

427. Saberov, V. Sh.; Marichev, K. A.; Korotkikh, N. I.; Shvaika, O. P.; Rodik, R.V.; Drapaylo, A.B.; Pekhtereva, T.M.; Komarovska-Porokhnyavets, O.P.; Lubenets, V. I.; Novikov, V. P. J. Org. Pharm. Chem. 2014, 12, № 2 (46), 36-43.

http://nuph.edu.ua/wp-content/uploads/2015/04/ZhOFH2-14-36-43.pdf

428. Glinyanaya, N. V.; Saberov, V. Sh.; Knishevitsky, A. V.; Korotkikh, N. I.; Shvaika, O. P.; Kiselyov, A. V.; Papayanina, E.S.; Komarovska-Porokhnyavets, O.P.; Lubenets, V. I.; Novikov, V. P. J. Org. Pharm. Chem. 2014, 12, № 2 (46), 44-52.

http://nuph.edu.ua/wp-content/uploads/2015/04/ZhOFH2-14-44-52.pdf

\section{Authors' Biographies}

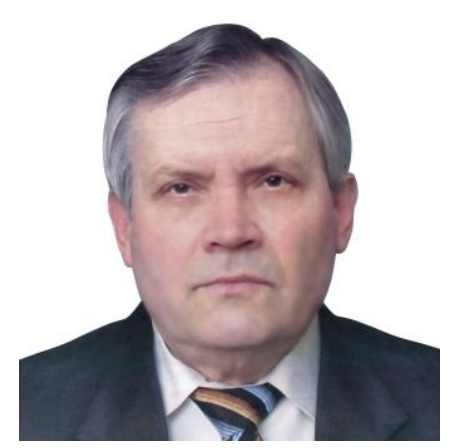

Prof. Nikolai Korotkikh was born in Donetsk, Ukraine, in 1951. He was educated at the Donetsk State University, Ukraine (1968-1973), obtained his Candidate of Chemistry (Ph.D.) degree in the Institute of Physical Organic \& Coal Chemistry in 1982, and Doctor of Sciences degree in 1998. After defending a Doctor of Sciences thesis in 1997 he was elected to the position of Head of Department in 2000 and that he held up to 2014. In 2014 he moved to Kiev 
where was elected to the position of Head of Laboratory for Chemistry of Stable Carbenes in the Institute of Organic Chemistry. Current research is connected with the synthesis, structures, reactivities, and catalytical properties of heteroaromatic carbenes, carbenoids and their analogues. Earlier works were devoted to the synthesis of heterocyclic derivatives of small rings, ring transformations of heterocycles, materials relevant to the pharmaceutical and polymer industries.

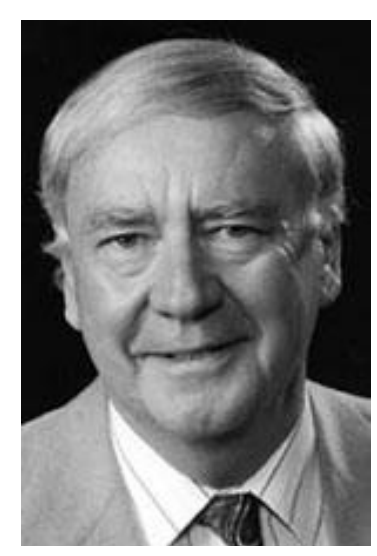

Prof. Alan H. Cowley was born in Manchester, U.K. He attended the University of Manchester from 1952 until 1958, where he received B.Sc., M.Sc. and Ph.D. degrees. After a postdoctoral sojourn at the University of Florida, he returned to the U.K. in 1960 where he was employed as a research chemist by Imperial Chemical Industries until 1962. Most of his academic career has been spent at the University of Texas at Austin where he holds the Robert A. Welch Chair in Chemistry. He has close to 500 publications, most of which are concerned with synthetic, structural, and theoretical main group chemistry. He was elected a Fellow of the Royal Society in 1988 and received an Honorary Doctorate from the University of Bordeaux I in 2003. He has served on the Board of Trustees of the Gordon Research Conferences and on several Editorial Boards, including the Journal of the American Chemical Society, Inorganic Chemistry, and Organometallics.

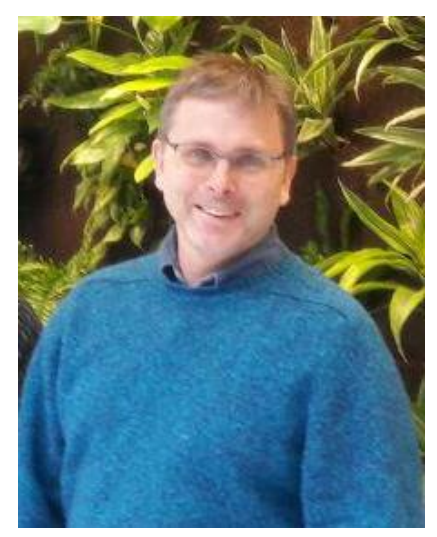

Dr. Jason Clyburne holds a joint appointment in Environmental Science and Chemistry at Saint Mary's University in Halifax, Nova Scotia, Canada. He obtained a BSc (Honours) from Acadia University and a PhD under the supervision of Professor Neil Burford at Dalhousie University. After a short post-doctoral project with Prof. Melbourne Schriver, he joined the research group of Prof. Alan Cowley (FRS) at the University of Texas at Austin, where he examined the coordination chemistry of main group elements. Dr. Clyburne is also an adjunct professor at Simon Fraser University. His research deals mostly with inorganic and organic materials as they apply to green chemistry, including catalysis and acid gas capture. The chemistry of $\mathrm{N}$ heterocyclic carbenes and ionic liquids play key roles in his research. 


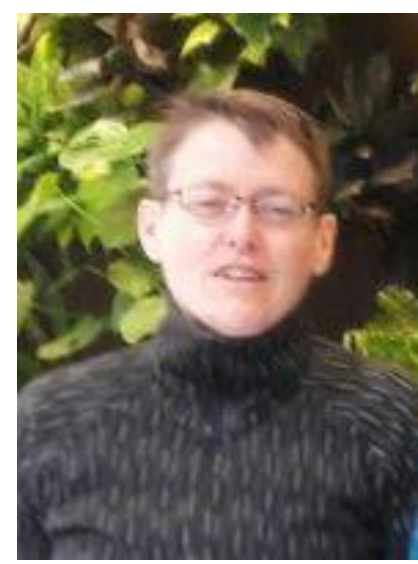

Dr. Katherine Robertson obtained her PhD from Dalhousie University in 2001, working in the fields of X-ray crystallography and experimental charge density analysis under the supervision of Professors O. Knop and T. S. Cameron. Since that time she has held a variety of positions, including her current association with Dr. J. A. C. Clyburne at Saint Mary's University in Halifax, Nova Scotia.

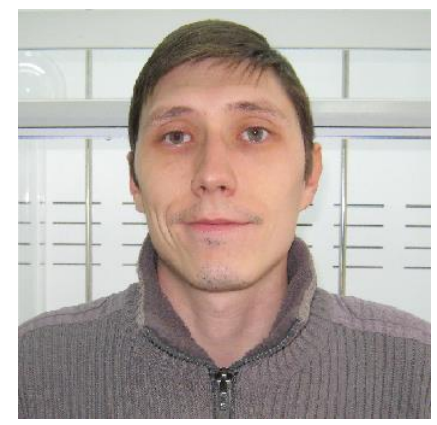

Dr. Vagiz Saberov was born in Makeevka, Ukraine, in 1990. He studied at the Donetsk National University in Donetsk (2007 - 2012), were he received Master's Degree in organic chemistry. From 2009 he joined to the research group of Prof. N. I. Korotkih in the L.M.Litvinenko Institute of Physical Organic and Coal Chemistry (Donetsk, Ukraine). Under his supervision in 2016 he obtained his Ph.D. degree in the Institute of Organic Chemistry (Kiev, Ukraine). He is presently working on new types of carbenes, their complexes with transition metals and organocatalysis by these compounds. Also, he is an associate chemist in lab of molecular diversity at Enamine Ltd. (Kiev, Ukraine).

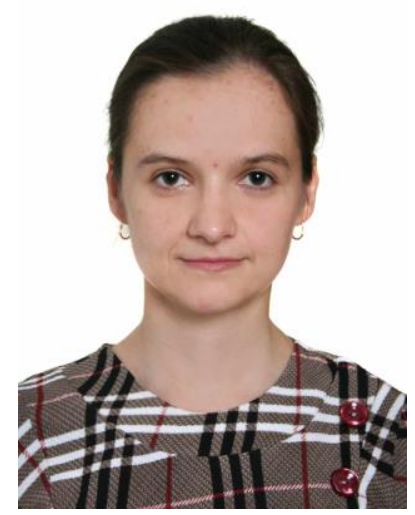

Dr. Nataliya V. Glinyanaya was born in Kramatorsk, Ukraine, in 1983. She was educated at the Donetsk National University, Ukraine (2001-2006) and obtained her B.Sc. and M.Sc. degrees in 2006. She obtained her Candidate of Chemistry (Ph.D.) degree in the L.M.Litvinenko Institute of Physical Organic \& Coal Chemistry in 
2011 under the guidance of Professor Nikolai Korotkikh. Her current research is connected with the synthesis, structures, and reactivities of heteroaromatic carbenes and their metal complexes. She has 18 publications.

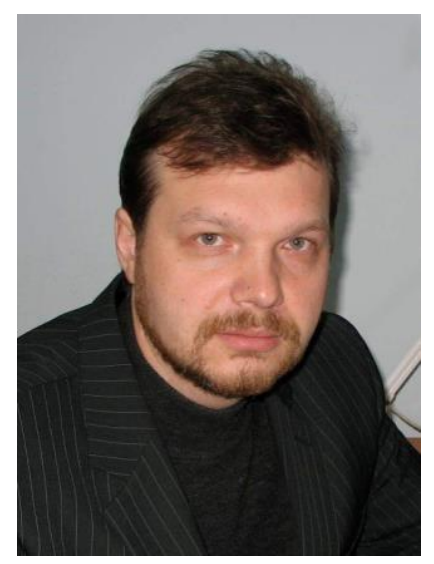

Dr. Gennady Rayenko was born in Donetsk, Ukraine, in 1970. He was educated at the Donetsk State University, Ukraine (1987-1992), obtained his Candidate of Chemistry (Ph.D.) degree in the L.M.Litvinenko Institute of Physical Organic \& Coal Chemistry in 2000. In 2001 he was appointed to the position of Scientific Secretary and in 2015 to the position of vice-director of the Institute that he holds up to now. Current research is concerned with the synthesis, structures, and reactivities of heteroaromatic carbenes and their analogues, chemistry of azolines.

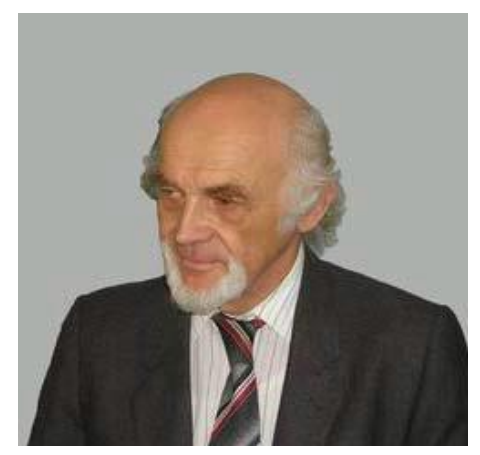

Prof. Oles Shvaika was born in Ukraine in 1932. He completed the Lviv Polythechnical Institute, Ukraine, in 1953, obtained his Candidate of Chemistry (Ph.D.) degree at the Kharkiv State University in 1963, and Doctor of Sciences degree in 1977 at Kiev State University, became Professor in 1988. He had been Head of the Department of Azole Chemistry in the L.M.Litvinenko Institute of Physical Organic and Coal Chemistry in Donetsk for 22 years. His Doctor of Sciences thesis and major scientific works were devoted to the ring transformations of heterocyclic compounds especially azoles, azolidines and azolium salts, later to the synthesis of heterocyclic derivatives of small rings. In the $90 \mathrm{~s}$ his interest was directed to the chemistry of heteroaromatic carbenes, electrochemical research of heteroaromatic salt association in solution, and applied chemistry concerning pharmaceutical, polymer and optical techniques. 